Universidade de São Paulo

Instituto de Física

Instituto de Química

Instituto de Biociências

Faculdade de Educação

\title{
Identificação dos perfis das pesquisas em argumentação no ensino de Ciências no período de 1988 a 2008
}

Marcel Valentino Bozzo 
Universidade de São Paulo

Instituto de Física

Instituto de Química

Instituto de Biociências

Faculdade de Educação

\title{
Identificação dos perfis das pesquisas em argumentação no ensino de Ciências no período de 1988 a 2008
}

\author{
Marcel Valentino Bozzo
}

Orientador: Prof. Dr. Marcelo Tadeu Motokane

Dissertação de mestrado apresentada ao Instituto de Física, ao Instituto de Química, ao Instituto de Biociências e à Faculdade de Educação da Universidade de São Paulo, para a obtenção do título de Mestre em Ensino de Ciências

São Paulo

2011 
AUTORIZO A REPRODUÇÃO PARCIAL DESTE TRABALHO, PARA FINS DE ESTUDO E PESQUISA, DESDE QUE CITADA A FONTE. A REPRODUÇÃO COMERCIAL, EM TODO OU EM PARTE, POR QUALQUER MEIO, SOMENTE É PERMITIDA COM EXPRESSA AUTORIZAÇÃO ESCRITA DO AUTOR.

\section{FICHA CATALOGRÁFICA}

Preparada pelo Serviço de Biblioteca e Informação do Instituto de Física da Universidade de São Paulo

Bozzo, Marcel Valentino

Identificação dos perfis das pesquisas em argumentação no ensino de Ciências no período de 1988 a 2008 - São Paulo, 2011.

Dissertação (Mestrado) - Universidade de São Paulo. Faculdade de Educação, Instituto de Física, Instituto de Química e Instituto de Biociências

Orientador: Prof. Dr. Marcelo Tadeu Motokane Área de Concentração: Ensino de Biologia

Unitermos:1. Argumentação; 2. Ensino; 3. Classificação; 4. Pesquisa Científica 


\section{AGRADECIMENTOS}

À banca de defesa pelo trabalho de leitura e escrita.

Ao Prof. Marcelo Tadeu Motokane, pela dedicada orientação ao longo dos mais de quatro anos que trabalhamos juntos. Desde a graduação, aceitando-me no grupo de pesquisa que lidera, até a leitura atenta da dissertação, na "subida final" para a finalização da dissertação, escutei, discuti, refleti, posicionei-me, moderei, avancei, enfim, aprendi bastante sob sua supervisão. Dedico grande parte do mérito acadêmico deste trabalho ao olhar clínico do professor ao me propor a pergunta de pesquisa que norteou a investigação.

A todos do Grupo de Pesquisa em Linguagem e Ensino de Ciências (LINCE), especialmente, à Mariana Guelero do Valle com quem tive a oportunidade de ter tido aula durante a graduação, quando ela esteve à frente de uma disciplina do curso de licenciatura em Ciências Biológicas, na Faculdade de Ciências Agrárias e Veterinárias de Jaboticabal (UNESP). Sempre que possível essa colega me incentivou e apoiou às atividades de ensino e pesquisa.

À Profa. Maria Elice Brzezinski Prestes, que me supervisionou durante a monitoria no Laboratório de Licenciatura do Instituto de Biociências, por compreender algumas ausências e desvios do trabalho no laboratório, devido à demanda acadêmica do mestrado. Mas, principalmente a agradeço, pelo imenso aprendizado sobre o cotidiano universitário que tive, tendo o privilégio de ser supervisionado por uma docente e pesquisadora de tamanha envergadura profissional. Para além da pesquisa, meus aprendizados durante este mestrado tiveram grande parcela de contribuição sua.

À colega de trabalho da EMEF Prof. Roberto Mange, Tathiane Graziela Cipullo, cuja ajuda foi essencial, imprescindível, nos últimos momentos de finalização deste trabalho. Seu companheirismo, alento e, por que não, sua cobrança diária e motivadora, não só auxiliou, mas, antes, possibilitou a conclusão desta dissertação. Deixo aqui registrado meu profundo agradecimento por estar ao meu lado nessa decisiva etapa de vida. Compartilho muitos dos louros desta vitória a essa dedicada educadora, com quem tenho o prazer de atuar, até o presente momento, no ensino básico da rede pública. 
À Sarah Milani de Moraes Leandrini, colega de grupo de estudo e de programa de Pós-Graduação, que não se negou a me escutar e a compartilhar angústias, em momentos de profunda incerteza acadêmica. Seus ouvidos e suas palavras foram fundamentais para que eu pudesse dar continuidade no projeto de pesquisa e no curso de mestrado.

À Renata de Paula Orofino da Silva, também colega de curso pós-graduação que, junto com a Sarah, indicaram-me valiosas literaturas, as quais compuseram o referencial teórico do presente trabalho, enriquecendo as discussões e análises.

À minha irmã, que realizou a revisão ortográfica e de formatação durante todo o fim de semana que antecedeu à impressão do material. Meus sinceros agradecimentos acadêmicos e fraternais.

À minha prima, Luciana Bozzo Alves, pelas conversas acadêmicas, e outras não tão acadêmicas, que tive com ela tanto em momentos difíceis, quanto em momentos de furor produtivo. Sua companhia em São Paulo foi primordial para o meu assentamento nesta cidade desde 2009 até o presente momento e, dessa forma, fundamental na criação de condições para cursar o mestrado.

Aos meus familiares, especialmente aos meus pais, Felipe Valentino Bozzo ("seu Bozzo") e Nilza Barreto Bozzo ("Dona Nilza"), que sempre me apoiaram nos estudos e que de forma direta têm enorme parcela de contribuição nesta conquista. Vibraram comigo no começo, acompanharam com interesse e orgulho paternal e maternal durante, e rezaram comigo no final. Meu abraço de eterna gratidão a esses dois seres que se responsabilizaram por mim durante tanto tempo e que, eu sei, não se negariam até o último suspiro de vida a me auxiliar em tudo e qualquer coisa que me fosse necessária. Tenho a graça de dizer que tenho verdadeiros pais. Parafraseando alguns dos termos e definições da nomenclatura biológica, sem nenhum compromisso com sua correção conceitual, são espécimes-tipo dos eugenitores, espécie em extinção na sociedade atual.

A todos que não foram lembrados nominalmente neste agradecimento, mas que interagiram, incentivaram, dificultaram, motivaram, desmotivaram, contribuíram, puseram obstáculos para a conclusão dessa etapa formativa, pois todos, sem exceção, fazem parte da minha história como ser eternamente aprendente e em progresso. 


\section{RESUMO}

BOZZO, Marcel Valentino. Identificação dos perfis das pesquisas em argumentação no ensino de Ciências no período de 1988 a 2008. 2011. 159 f. Dissertação (Mestrado em Ensino de Ciências - Ensino de Biologia) - Instituto de Biologia, Faculdade de Educação, Universidade de São Paulo, São Paulo, 2011.

Este estudo teve como objetivo identificar as tendências de pesquisa em argumentação no ensino de Ciências (AEC) no período de 1988 a 2008 (21 anos). A argumentação é uma prática discursiva central na Ciência e, por isso, defendemos ser também central no ensino de Ciências (EC). Apesar da AEC vir ganhando importância na pesquisa em EC, são raros estudos que avaliam o histórico e as tendências dessa produção científica. Nosso estudo trata-se de uma pesquisa descritiva documental, em que se analisaram 51 artigos científicos, publicados em revistas especializadas. Estes artigos foram classificados segundo (a) o tipo (empírico, de revisão ou de posição), (b) sujeito foco de análise (aluno ou professor), (c) seus perfis e supraperfis (categorias criadas a partir de dados coletados do foco, da pergunta e do objetivo de pesquisa) e (d) o tipo de uso da obra de Toulmin (1958) como referencial teórico. Os resultados mostraram que, na pesquisa em AEC: (a) apesar do predomínio de estudos empíricos, os de revisão tiveram papel de destaque no desenvolvimento da área; (b) a maioria dos estudos enfatiza o estudante como sujeito foco de análise e recentemente tem aumentado o número de artigos com foco no professor; (c) a maior parte das publicações referem-se a estudos com foco na estrutura do argumento e/ou na construção da argumentação, no entanto estudos com foco no ensinoaprendizagem vêm aumentando gradual e crescentemente nos últimos anos; e (d) o padrão de argumento de Toulmin (1958) foi, e ainda dá mostras que será, amplamente utilizado na pesquisa para a análise de argumentos, ressalvando, entretanto, que suas limitações como ferramenta metodológica têm motivado pesquisadores da área a criar novos instrumentos de análise, mais condizentes com os atuais focos de pesquisa.

Palavras-chave: argumentação, ensino de Ciências, pesquisa, tendências. 


\begin{abstract}
BOZZO, Marcel Valentino. Identification of the research profiles in argumentation in Science teaching in the period of 1988 to 2008. 2011. 159 f. Dissertation (Master in Science Education - Biology Education) - Biosciences Institute, School of Education, University of São Paulo, São Paulo, 2011.
\end{abstract}

This study aimed to identify research trends in argumentation in Science teaching (AST) in the period of 1988 to 2008 (21 years). Argumentation is a discursive practice central to Science and therefore we defend it to be central to Science teaching (ST) as well. Even though research in ST is gaining importance, only a few studies have assessed the history and trends of scientific production in the area. Our study is a documental descriptive research, in which 51 scientific papers, published in specialized journals, were analyzed. These papers were classified according to (a) type (empirical research article, review or position paper), (b) subject focused in analysis (student or teacher), (c) its profiles and supraprofiles (categories created from data gathered from research focus, question and objective) and, (d) type of use of Toulmin's (1958) work in the theoretical framework. Results showed that, in AST research: (a) despite predominance of empirical studies, review studies had a major role in the development of the area; (b) most studies emphasize the student as the subject focused on analysis and have recently increased the number of articles focusing on teachers, (c) most of the reports refer to studies focusing on argument structure of and/or construction of the argumentation; however, studies focusing on teaching and learning have been increasing gradually in recent years, and; (d) Toulmin's Argument Pattern (1958) was and shows signs that will continue to be widely used in argument analysis, stressing, however, that its limitations as a methodological tool have motivated researchers of the area to create new analytical tools, more consistent with the current research focus.

Keywords: argumentation, Science teaching, research, trends 


\section{SUMÁRIO}

APRESENTAÇÃO ................................................................................................................... 9

1. PROBLEMA DE PESQUISA ....................................................................................... 15

2. O PAPEL DA ARGUMENTAÇÃO NA CIÊNCIA E SUAS IMPLICAÇÕES PARA

O ENSINO DE CIÊNCIAS................................................................................................................. 16

2.1. Papel central da argumentação na Ciência.................................................................... 16

2.2. Papel central da argumentação no ensino de Ciências ....................................................... 19

\section{AS PESQUISAS EM LINGUAGEM E ENSINO DE CIÊNCIAS E SUA RELAÇÃO} COM OS ESTUDOS SOBRE ARGUMENTAÇÃO ……………………………………………... 26

3.1. A pesquisa em linguagem e ensino de Ciências ............................................................ 26

3.2. A pesquisa em argumentação no ensino de Ciências.................................................... 31

4. METODOLOGIA DA PESQUISA ................................................................................. 39

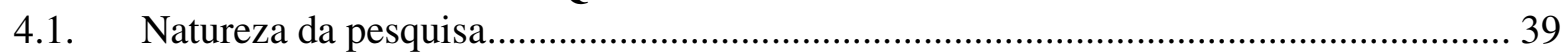

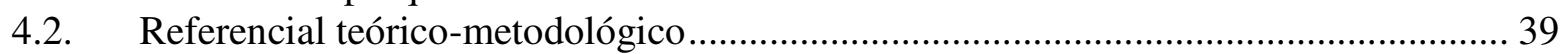

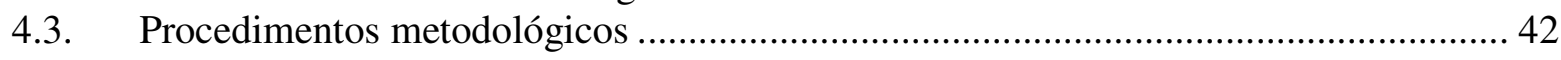

5. RESULTADOS E DISCUSSÃO …………………......................................................... 54

$5.1 \quad$ Descrição das categorias de análise ………………………………………………... 54

5.2 Análise dos perfis e supraperfis de pesquisa............................................................... 60

5.3 Análise do uso da obra de Toulmin (1958) como referencial teórico............................. 93

5.3. Triangulação de dados: relação entre o foco de análise 'perfis e supraperfis de pesquisa' e o foco 'uso da obra de Toulmin (1958) como referencial teórico' ........... 108

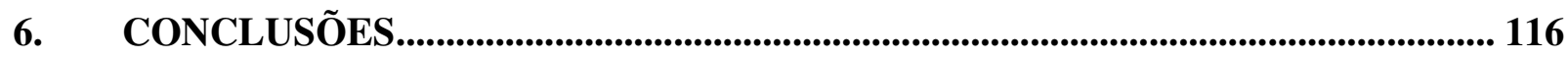

REFERÊNCIAS BIBLIOGRÁFICAS .............................................................................. 122

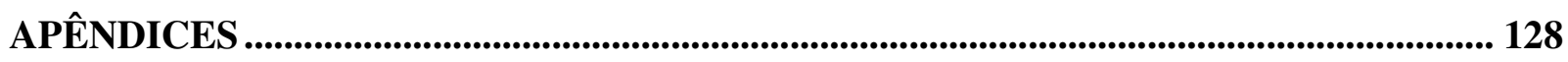

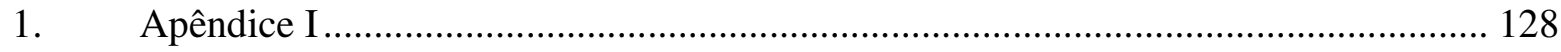

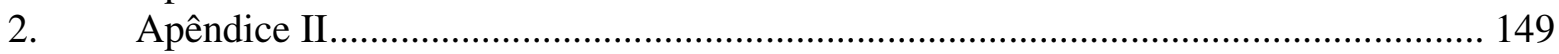

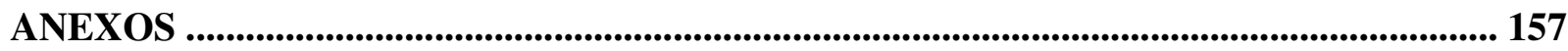




\section{APRESENTAÇÃO}

Percurso do autor para produção da dissertação

Meu interesse pela área de ensino remete a um momento anterior ao ingresso no ensino superior. Esse interesse, somado àquele que aflorava nos momentos de fruição estética da natureza, motivou-me a escolher o curso de Ciências Biológicas na modalidade licenciatura. Na busca de atividades que atendessem à expectativa formativa nessa área, vivenciei quantidade significativa de experiências em estágios, monitorias e atividades extracurriculares durante o período de graduação. Esse ímpeto resultou na realização de contatos com grupos de pesquisa da Universidade de São Paulo (USP), câmpus Ribeirão Preto, onde tive a oportunidade de conhecer duas linhas de investigação, uma em educação ambiental e outra em linguagem e ensino de Ciências (EC). Tive maior afinidade com o grupo de linguagem devido tanto a motivações internas, representadas pelo interesse em questões lingüísticas nutridas desde o Ensino Médio; quanto a motivações externas, dada a proposta do grupo de realizar reuniões sistemáticas, nas quais haveria a possibilidade de imersão no assunto.

Assim, a minha aproximação com o Grupo de Pesquisa em Linguagem e Ensino de Ciências (LINCE) ocorreu gradativamente, com a participação nas leituras e discussões realizadas ao longo do mesmo ano em que decorria meu último ano da graduação.

Dentre as propostas de pesquisa levantadas nesse grupo de pesquisa, uma delas mereceu atenção e, então, começou a ser discutida com o orientador, para desenvolvermos juntos a idéia. Mais tarde, essa proposta resultaria na elaboração do anteprojeto de pesquisa, a ser realizado em um curso de mestrado acadêmico.

Foram duas as principais motivações que conduziram minha procura por um curso de mestrado acadêmico: possibilidade de formação teórica, tendo em vista a necessidade de caráter continuado na formação individual; e a realização de pesquisa na área de ensino, dada a importância do processo investigativo como estratégia de formação. Nesse sentido, acreditei que $\mathrm{o}$ ato de pesquisar promoveria o aprimoramento da capacidade de agir crítica e reflexivamente sobre os fenômenos estudados. 
Apesar das motivações para a realização do mestrado na área, o início da pós-graduação propiciou um processo de reflexão sobre minhas limitações pessoais. Dentre elas, ressalta-se a decorrente da imaturidade, tanto referente à metodologia científica, quanto à abordagem qualitativa de pesquisa. De um modo geral, atribuo como causa dessa imaturidade a leitura e discussão deficientes sobre assuntos da metodologia de pesquisa em ensino de Ciências durante boa parte do curso graduação.

Com o início do mestrado, iniciei a participação em disciplinas da Faculdade de Educação (FE), do Instituto de Biociências (IB) e do Instituto de Física (IF). Na disciplina cursada nesta última unidade, Introdução à pesquisa no Ensino de Ciências, ressalta-se a importância das leituras propostas e das discussões, as quais puderam trazer aspectos essenciais da abordagem qualitativa de pesquisa. Também digna de nota, foi a disciplina Características de pesquisas em ensino de Ciências: discussão de dissertações e teses da área, cursada na FE. Cursá-la permitiume visualizar melhor a área de pesquisa. As outras disciplinas cursadas ora na FE, ora no IB, possibilitaram uma ampliação de visão sobre os fenômenos educacionais e biológicos.

Além da participação nas disciplinas, tive a oportunidade de ministrar aulas no ensino superior no início do mestrado. Essas aulas foram ministradas durante um semestre na própria universidade onde me formei, Faculdade de Ciências Agrárias e Veterinárias de Jaboticabal (UNESP). No caráter de professor-bolsista, ministrei as disciplinas Instrumentação para o ensino de Ciências e Projeto temático I, que cobriam, respectivamente, conteúdos de metodologia para o ensino de Ciências e conteúdo sobre avaliação de material didático para o ensino de Ciências e Biologia. Sinto que este período foi, ao mesmo tempo, rico e angustiante. Rico, pois estar à frente de duas disciplinas de ensino superior incentivou-me à leitura na área de ensino de Ciências, aumentando meu arcabouço teórico sobre a área. Angustiante, pois, passadas as primeiras semanas - e esse sentimento perdurou ao longo dos quatro meses que ministrei as disciplinas -, notei graves lacunas de formação. Mais à frente, no decurso do mestrado, porém, essa angústia transformou-se em motor da busca de aprofundamento teórico substancial na área. A oportunidade das aulas em Jaboticabal, apesar de não retratarem a condição real de docência no ensino superior, ajudou a vivenciar um pouco da rotina e das práticas docentes relacionadas à formação inicial de professores.

A participação em eventos acadêmico-científicos ao longo do curso de mestrado também foi de grande importância. Neles, foi possível trocar experiências e discutir os problemas de 
pesquisa com pares ou com pesquisadores mais experientes na área. Essas oportunidades levaram à revisão constante deste trabalho, além de terem sido fundamentais para sua elaboração na forma como está aqui apresentado. Destaque para a apresentação oral feita no Encontro Nacional de Pesquisa em Ensino de Ciências, em que o trabalho passou pela avaliação de pesquisadores de renome na área de argumentação no ensino de ciências. Além da oportunidade de receber críticas sobre as comunicações apresentadas, durante esses eventos também foi possível conhecer algumas obras que presentemente foram utilizadas para revisão bibliográfica.

Além da partipação em disciplinas e em eventos na área, as discussões no grupo de pesquisa contribuíram para a constante reformulação desta pesquisa.

O objetivo inicial do trabalho era investigar o estado da arte da produção científica sobre a argumentação no ensino de Ciências e Biologia. Desde então, seguiram vários testes a fim de orientar a escolha, tanto de descritores para a coleta de dados, quanto de uma base - ou bases - de dados que atendessem aos propósitos da investigação. Após o primeiro ano do curso de mestrado, foram escolhidos os descritores e somente uma base de dados para realizar a prévia da pesquisa. A adoção de apenas uma base de dados, nesse contexto, teve caráter parcial, dado que não foi possível à época a escolha de mais bases de dados que atendessem às expectativas para a realização de um estado da arte na área investigada. Contudo, sua adoção foi de essencial importância para vislumbrar outras possibilidades durante o processo de pesquisa. Após a qualificação, atendendendo a sugestões da banca examinandora, a amostra foi aumentada. Para tanto, adotaram-se novas bases de dados, tornando mais consistentes os dados coletados.

No segundo ano do mestrado, os dados coletados a partir dos descritores e das bases de dados escolhidas, renderam resultados que foram explorados em dois resumos e um artigo completo, publicados em anais de congresso da área e em revista internacional especializada, respectivamente.

Ressalto aqui, novamente, a importância de ter participado de eventos acadêmicocientíficos, em especial o ocorrido em Barcelona, em setembro de 2009. Este evento possibilitoume entrar em contato com pesquisadores seniores, reconhecidos internacionalmente como referências na pesquisa em ensino de Ciências. Essa oportunidade concretizou-se em uma conversa que tive com um desses pesquisadores presentes. Após eu ter apresentado minha pergunta de pesquisa, a pesquisadora com quem eu conversava se dispôs a enviar alguns artigos que, segundo seu julgamento, poderiam ser utilizados como fonte de dados para minha pesquisa. 
Entre outros episódios que justificam a importância da participação neste evento, apresentei esse último para ilustrar um pouco dos intercâmbios que realizei.

Ao final deste período o trabalho sofreu mudanças significativas, trazendo como novo objetivo identificar as tendências da pesquisa em argumentação no ensino de Ciências a partir de artigos científicos publicados entre os anos de 1988 e 2008.

\section{A estrutura da dissertação}

O presente trabalho foi organizado em seis capítulos. No primeiro é apresentado o problema de pesquisa. Para tanto, são anunciadas as perguntas que conduziram a investigação e, depois, o objetivo da pesquisa.

O segundo capítulo, dividido em duas partes, trata da relação entre a argumentação e a Ciência, e sua implicação para o ensino de Ciências. A linha mestra do texto baseia-se na concepção de Ciência como construção social. Nesse quadro, aponta-se para a necessidade de revisão da noção de Ciência; de uma que enfatiza o empirismo, para outra que ressalta, entre outras coisas, a importância de saber avaliar e julgar as evidências que fundamentam as alegações produzidas nesse meio. Dessa forma, o conceito de argumento e argumentação e aspectos da natureza da Ciência são discutidos, a fim de justificar a centralidade da argumentação na produção do conhecimento científico. Dando continuidade, examina-se a natureza da Ciência, apresentando e desenvolvendo as contribuições de estudos sobre Ciência, com destaque para a argumentação. O papel do debate na Ciência, estudos sobre períodos de controvérsia e sobre o dia-a-dia nos laboratórios foram temas desenvolvidos no intuito de justificar a importância da argumentação na produção do conhecimento científico.

Na segunda parte do segundo capítulo são examinadas as implicações da centralidade da argumentação na Ciência dentro do ensino de Ciências. $O$ texto traz pesquisas na área que defendem a centralidade da argumentação no ensino de Ciências, devido à igual centralidade dessa prática discursiva na Ciência. Primeiramente, são apresentadas algumas das contribuições da argumentação para o ensino, de forma geral, para, depois, serem expostas e desenvolvidas as contribuições para o ensino de Ciências. Em seguida, a AEC é analisada sob um olhar mais sistemático, descrevendo os tipos e as condições em que ocorrem os argumentos durante as aulas 
de Ciências. No final, é sintetizada a linha condutora do texto, retomando a ideia apresentada inicialmente.

O terceiro capítulo, também dividido em duas partes, trata da pesquisa em linguagem e ensino de Ciências e sua relação com os estudos sobre argumentação. Na primeira parte, assumem-se quais são os referenciais utilizados que justificam o foco na linguagem e ensino de Ciências no presente trabalho. Nesse sentido, destacam-se as correntes sócio-culturais e os estudos de Vygotsky, nos quais o autor salienta o papel da linguagem no desenvolvimento daquilo que chama de processos superiores do pensamento. Dessa forma, seus estudos ganham destaque na área de ensino, uma vez que podem contribuir para o entendimento de aspectos ligados à relação linguagem e ensino. Em seguida, justifica-se a importância de estudos que investigam essa relação, por meio da apresentação de alguns pesquisadores na área. Finalmente, após retratar brevemente o cenário da pesquisa em EC nos últimos 10 anos, o foco da primeira parte deste capítulo é desenvolvido: a pesquisa em linguagem e ensino de Ciência. Isso é feito por meio de um trabalho de estado da arte, que resgata caminhos e tendências da área entre 1978 e 2003.

A segunda parte do terceiro capítulo trata do tema que foi foco do presente trabalho: a pesquisa em argumentação no ensino de Ciências. Inicialmente são mostrados os temas sobre os quais a pesquisa brasileira tem se debruçado, para, então, apresentar um quadro internacional da pesquisa na área. Para tanto, são trazidas duas obras que ajudam a entender o panorama da pesquisa em AEC, as quais foram utilizadas como principais referenciais teóricos deste trabalho. Em seguida, ressalta-se a escassez de trabalhos que façam um levantamento das tendências de pesquisa nessa área. Nesse sentido, são retomadas as perguntas e o intuito do presente trabalho de identificar perfis de pesquisa em AEC.

O quarto capítulo se ocupa da apresentação da metodologia de pesquisa utilizada no presente trabalho, organizada em três partes: natureza da pesquisa, referenciais teóricometodológicos e procedimentos metodológicos. Descritas brevemente, essas partes referem-se, respectivamente, a: a natureza da pesquisa descritiva documental do trabalho; a apresentação das partes que compõem um relatório científico e quais delas foram analisadas na presente pesquisa; e, por último, as etapas para a seleção da amostra e como foi feita a coleta de dados.

No quinto capítulo, são apresentados e discutidos os resultados da pesquisa. O capítulo inicia-se com a descrição das categorias de análise. Em seguida, é feita a análise dos perfis e 
supraperfis considerados. Categoria a categoria, discute-se a natureza dos artigos que as compõem e o padrão de distribuição ao longo do período estudado. Discutidos os perfis e os supraperfis, o foco passa para o exame minucioso dos tipos de uso da obra de Toulmin (1958) como referencial teórico. Novamente, são discutidos a natureza e o padrão de distribuição ao longo do tempo dos artigos. Por fim, é realizada uma triangulação dos dados, visando não só ampliar as considerações até então expostas, mas também desvelar outras, só possíveis de serem visualizadas mediante esse cruzamento de dados.

O sexto, e último capítulo, trata das conclusões do trabalho. As conclusões sobre as tendências da pesquisa em AEC foram feitas abordando três tópicos: 1. a natureza da pesquisa empírica, de revisão e de posição; 2. as tendências gerais da pesquisa em AEC; e 3. considerações metodológicas. 


\section{PROBLEMA DE PESQUISA}

O presente trabalho buscou responder às seguintes perguntas: é possível identificar perfis nas pesquisas em argumentação no ensino de Ciências publicadas em periódicos especializados? esse agrupamento auxilia na identificação de tendências de pesquisa em argumentação no ensino de Ciências ao longo das últimas duas décadas? qual a influência da obra de Toulmin (1958) para a pesquisa na área, nesse período?

Visando responder a essas perguntas de pesquisa, o objetivo geral do presente trabalho foi identificar as tendências da pesquisa em argumentação no ensino de Ciências a partir de artigos científicos publicados em revistas especializadas, entre os anos de 1988 e 2008 .

Para tanto, nesta pesquisa buscou-se:

1. Identificar bases de dados consistentes para o levantamento bibliográfico de artigos relevantes na pesquisa em argumentação no ensino de Ciências;

2. Realizar levantamento bibliográfico da produção de pesquisa na área, no período de 1988 a 2008;

3. Propor agrupamentos dos artigos da pesquisa em argumentação no ensino de Ciências, a partir da análise de elementos pré-textuais e textuais desses artigos;

4. Verificar como o Padrão de Argumento de Toulmin (1958) é utilizado nas pesquisas sobre argumentação no ensino de Ciências. 


\section{O PAPEL DA ARGUMENTAÇÃo NA CIÊNCIA E SUAS IMPLICAÇÕES PARA O ENSINO DE CIÊNCIAS}

\subsection{Papel central da argumentação na Ciência}

Pesquisas na área de ensino de Ciências evidenciam que, durante muito tempo, as aulas de Ciências deixaram para trás aspectos de ensino relevantes para a área. Um dos exemplos refere-se à ausência de discussão a respeito das controvérsias ligadas ao fazer científico (DRIVER et. al., 2000). Isso dificulta conceber a produção de conhecimento científico como algo em constante desenvolvimento e, consequentemente, conduz a uma visão de Ciência como conhecimento irrevogável, absoluto. Ainda os mesmos pesquisadores remetem-se a essa concepção de Ciências como um ranço "positivista”, já que limitam os alcances do ensino na área.

No entanto, pesquisas recentes, muitas delas sobre epistemologia da Ciência, permitem enxergá-la de outra forma, enfatizando seus aspectos comunicativos. Latour e Woolgar (1986), por exemplo, afirmam que práticas como a avaliação de evidências, a interpretação textos e a avaliação do potencial científico das alegações produzidas nesse meio, são vistas como componentes essenciais na construção de argumentos científicos.

Dessa forma, ao procurar um ensino de Ciências mais próximo das práticas que ocorrem no bojo da Ciência deve-se considerar a argumentação como parte essencial do aprendizado na área. Driver et. al. (2000) alegam que se o objetivo da educação científica é ajudar os jovens a se envolver com o processo de produção dessse conhecimento, deve-se dar acesso a práticas discursivas inerentes à Ciência, promovendo atividades em sala de aula adequadas a esse fim. Essas práticas são os meios de aproximar os jovens das normas do argumento científico.

Assim sendo, é essencial expor o conceito de argumento e argumentação assumido no presente estudo, assim como expor as contribuições dos estudos sobre Ciência, justificando, dessa forma, a centralidade da argumentação na Ciência.

Sobre a conceituação de argumento, o artigo de Driver et. al. (2000), contribui significativamente, na medida em que apresenta um conceito de argumento que se aproxima do conceito utilizado no presente estudo. Os autores afirmam que há duas formas de entender o argumento. De um lado, ele é estudado do ponto de vista da lógica formal. Segundo esses 
autores, o estudo da lógica leva em conta regras que, mesmo sem muita coerência conceitual, produzem conclusões corretas a partir de determinadas premissas. Por outro lado, o argumento é estudado sob um ponto de vista das reais práticas discursivas, ocorridas em diversos meios sociais. Sob esta óptica, analisa-se como as pessoas em situações específicas, de fato, raciocinam quando percorrem o caminho entre as premissas e as conclusões.

Segundo Driver et. al. (2000), enquanto a lógica é vista como uma disciplina acadêmica que apresenta regras um tanto descontextualizadas para relacionar premissas a conclusões, argumentar é uma prática humana e, portanto, está presente nas práticas discursivas de diversos grupos sociais. A partir dessa perspectiva, o argumento pode ser visto como processo individual, por meio do pensamento e da escrita, ou como uma atividade social dentro de um grupo - uma ação social negociada, dentro de uma comunidade específica.

Os autores prosseguem destacando duas definições de argumento. A primeira refere-se à encontrada no dicionário. O Oxford English Dictionary (apud DRIVER et. al., 2000, p. 291) define argumento como o "desenvolvimento de uma justificativa a favor ou contra um ponto sustentado ou curso de ação" (tradução nossa). Essa interpretação de argumento é descrita em Boulter e Gilbert (1995) como didático sendo o argumento visto como a linha de raciocínio utilizada pelo professor quando o objetivo é fazer uma explicação. Nesta situação, o professor é o sujeito de referência sobre determinado assunto por dois motivos: ora sua fala é legitimada por sua autoridade intelectual, ora pela posição social que ele possui perante seus alunos. Em ambos os casos, não é força do argumento que "pesa" mais na aceitação ou não de determinado argumento pelos estudantes, e sim o lugar social de onde o professor fala. Essa relação possui sérias limitações, considerando uma concepção de ensino de Ciências para além do foco quase exclusivo no "método cietífico". A esse respeito, Norris (1997 apud Driver et. al., 2000) pontua

\footnotetext{
Pedir a outros seres humanos que aceitam e memorizem o que o professor de Ciências diz, sem qualquer preocupação com o significado e a justificativa do que é dito, além de tratar esses seres humanos com desrespeito, é também demonstrar cuidado insuficiente com o seu bem estar. [...] Isso mostra cuidado insuficiente com o bem-estar dos alunos, pois possuir crenças que não podem ser justificadas vale muito pouco quando, na verdade, esse aluno precisa de crenças que podem guiar sua ação de forma confiável. (p. 252, tradução nossa)
}

Driver et. al. (2000) seguem trazendo à baila a segunda definição apresentada; o argumento como dialógico. Novamente a interpretação de Boulter e Gilbert (1995) auxilia na compreensão do termo. Esses autores levantaram alguns cenários em sala de aula e quais tipos de 
argumento estão associados a esses cenários. No caso do argumento dialógico, o cenário a ele associado refere-se ao ambiente de aprendizagem onde a atividade predominante é resolver problemas colaborativos. Nesses casos, o professor passa a ter um papel de mediação ao invés de fonte de conhecimento, propiciando uma troca de ideias menos centralizada.

A esse respeito, Driver et. al., op. cit., p. 18, declaram que o argumento dialógico está envolvido quando diferentes pontos de vista estão sendo analisados e o objetivo é chegar a um acordo sobre aceitabilidade das declarações em análise. Esses argumentos continuam os autores, podem acontecer individualmente ou dentro de um grupo social. A construção de um argumento implica considerar posições alternativas. Mesmo os argumentos construídos por um indivíduo são organizados pensando em casos em que os argumentos seriam contestados. É claro que, dentro de um grupo, a natureza multivocal (tradução literal do termo multivoiced, in Driver et. al., 2000, p. 291) da construção do argumento é muito mais evidente na medida em que o indivíduo está exposto a posições divergentes sobre determinado assunto.

Zeidler (1997 apud Driver et. al., 2000) comenta sobre esse processo. O autor argumenta que a mudança na forma como as pessoas pensam não acontece em passos lineares. Ao contrário, diversos fatores continuamente se reestruturam, alteram-se, ou se ajustam aos propósitos, procedimentos e conhecimento pessoal dos alunos.

Dessa forma, assim como declaram Driver e colabores no artigo que fundamenta este estudo, o presente trabalho considera a prática da argumentação um importante mecanismo que auxilia a construção individual de argumentos pelos alunos.

Ainda ressaltando a importância da argumentação na produção do conhecimento científico, seguem algumas ideias sobre a questão da argumentação, vista sobre a óptica dos estudos sobre Ciência. Essas ideias, no entanto, não se esgotam no presente trabalho, porém auxiliam a compreender o lugar da argumentação na Ciência.

Estudos que investigam o papel do debate na Ciência apontam para a importância dos debates; e a importância do contexto em que os argumentos são produzidos. A ponte entre persuasão e conhecimento científico, afirma Pera (1994 apud BRICKER e BELL, 2008), é construída por meio de debates científicos. O mesmo autor defende que, a fim de verificar a lógica correta para um argumento, uma análise de sua estrutura não é suficiente. Somente o contexto pode fornecer as informações necessárias. Esses apontamentos contribuem para o 
entendimento do papel da argumentação na Ciência, na medida em que destaca a importância dessa prática discursiva nas negociações ocorridas no interior da comunidade científica.

Estudos de controvérsias científicas também fornecem um caminho fecundo para o estudo da argumentação científica, pois "mostram como as pessoas dão sentido à informação e como elas, por vezes, convencem os membros de uma comunidade a concordar com esse significado" (SISMONDO 2004 apud BRICKER e BELL, 2008, p. 482). É também no período de controvérsias científicas que aquelas informações que normalmente não estão disponíveis quando o conhecimento já é extensamente aceito pela comunidade científica, estão desnudadas. Isso torna possível tomar conhecimento quais tipos de expedientes estão sendo utilizados para defender essa ou aquela interpretação científica e, portanto, conhecer quais são os argumentos que estão sendo produzidos para tanto.

Estudos sociológicos sobre o trabalho realizado nos laboratórios científicos constituem outra arena rica para o estudo da argumentação científica. Latour e Woolgar (1986) afirmam que os cientistas no laboratório são declaradamente cientes de como suas próprias afirmações estão sendo utilizadas por outros (rejeitada, citada). Em vez de serem meros cientistas, os autores argumentam que os cientistas são escritores e leitores no 'negócio' de ser convencido e convencer os outros.

É por meio dessa prática discursiva, racional, que os cientistas apresentam as evidências, associam-nas com um corpo teórico existente e concluem, propondo modelos explicativos mais ou menos convincentes aos pares.

Em síntese, a relação entre os estudos sobre Ciência e a argumentação brevemente apresentada, auxilia a entender a importância e a centralidade de aspectos que influenciam diretamente a produção do conhecimento científico. Por reconhecermos a relevância desses aspectos, tais como o contexto sócio-histórico, o papel do debate e da controvérsia associados à produção desse tipo de conhecimento, defendemos a centralidade da argumentação na construção de conhecimento científico.

\subsection{Papel central da argumentação no ensino de Ciências}


Assim como na pesquisa sobre Ciência, a compreensão da Ciência como uma atividade humana tem sido tema amplamente discutido nas pesquisas em educação científica. Tais estudos reconhecem a relevância de compreendê-la como um corpo de conhecimentos historicamente construído, imerso no contexto cultural de cada época e de cada povo. Conhecer não apenas os conteúdos da Ciência, mas também seus pressupostos, limites de validade e influência contextual, permitem criticar o dogmatismo geralmente presente no ensino de Ciências (EC), além de promover o pensamento reflexivo e crítico.

A discussão de Ciência como produção de conhecimento socialmente construído é o passo inicial para compreender o papel da AEC. A análise das práticas discursivas desenvolvidas na comunidade científica avança essa discussão. Driver et. al. (2000) sustentam que essas práticas têm papel central no estabelecimento de afirmações científicas. O fato da construção de conhecimento científico ser realizado por meio de debates e da tentativa de convencimento entre os pares, auxilia a entender essa relação. O conhecimento científico não é uma leitura direta da natureza, em que a verdade está posta e resta ao ser humano desvendá-la por meio dos sentidos. Ela é, antes, construída. Ideias são discutidas perante uma comunidade de especialistas, para, então, ser legitimada dentro dessas condições. Sobre o assunto, Driver, op. cit., p. 18 posicionamse da seguinte forma.

\footnotetext{
Observação e experiência não são os alicerces sobre os quais a ciência é construída, são, antes, condições necessárias para a atividade racional de elaboração de argumentos, nos quais as afirmações científicas são apoiadas. Mas é a partir da força dos argumentos (e seus dados de apoio) que os cientistas avaliam afirmações científicas concorrentes e trabalham as aceitando ou rejeitando. (DRIVER et. al., 2000, p. 297, tradução nossa, ênfase nossa)
}

Nesse contexto, a argumentação surge como prática discursiva que, por exercer papel central na construção do conhecimento científico, deve também ter papel de destaque no EC. Por meio da oportunidade de ensaiar o uso de uma nova linguagem, que carrega consigo características da cultura científica, o estudante pode ir adquirir desenvoltura dentro da mesma, bem como experimentar e ponderar as vantagens de sua utilização em contextos adequados (DRIVER et. al., 2000). 
Partindo dessa ideia, que fundamenta o restante do texto, abaixo são apresentadas e desenvolvidas as contribuições da argumentação no ensino em geral e, em seguida, no ensino de Ciências.

De Chiaro e Leitão (2005) afirmam que o espaço para a fala dos aprendizes e, mais especificamente, para a argumentação em sala de aula seja fundamental partindo de uma concepção de aprendizagem autônoma. Para Leitão (2000), a contribuição da argumentação para o ensino se dá na medida em que o confronto entre a posição defendida pelo proponente de um argumento; e os pontos de vista alternativos levantados por um oponente, mpelem o primeiro ao exame de suas posições à luz das perspectivas contrárias trazidas pelo segundo. Embora o engajamento de um indivíduo no processo de revisão de pontos de vista, por si só, não garanta mudanças de ponto de vista, este processo é visto como pré-requisito fundamental para que essas mudanças possam ocorrer. Essas características do discurso argumentativo apresentam singular potencial para gerar condições de ensino-aprendizagem durante as aulas de Ciências devido à aproximação da forma de produção de conhecimento da Ciência e, consequentemente, do discurso científico. A questão sobre discurso será mais bem discutida no próximo capítulo.

Jiménez-Aleixandre e Erduran (2007) traçam um panorama do tema na obra Argumentation in Science Education: Perspectives from Classroom-Based Research. Os autores trazem cinco potenciais contribuições da argumentação para o EC, quais sejam: tornar públicos os processos cognitivos dos estudantes; desenvolver competências comunicativas e o pensamento crítico; alcançar letramento científico ${ }^{1}$; promover enculturação na cultura científica; e desenvolver o raciocínio científico e critérios racionais.

Tornar públicos os processos cognitivos, tanto de estudantes, como de professores, permite às duas partes terem acesso ao racicíonio do outro. Baseados na noção de Vygostky (1989) de gênese social da compreensão individual, e na estrutura do argumento de Toulmin (1958), Brown e Palincsar (1989 apud JIMÉNEZ-ALEIXANDRE e ERDURAN, 2007) afirmam que o papel da colaboração na sala de aula está em fornecer modelos de processos cognitivos, para o que, depois, terá que ser feito individualmente. A argumentação no contexto de sala de aula pode apoiar o desenvolvimento de processos cognitivos de ordem superior, uma vez que o

\footnotetext{
1 Neste trabalho, foi adotado o termo letramento, e não alfabetização, como tradução do termo literacy. Porém, a adoção daquele termo em detrimento deste não indica um posicionamento deste autor quanto aos referencias teóricos de que cada termo é oriundo. Essa discussão não é feita, pois não faz parte do foco desta pesquisa.
} 
raciocínio se torna público. Dessa forma, espera-se que os estudantes não só revisem suas afirmações a partir de evidências, mas que também avaliem opções alternativas ou explicações.

A fim de esclarecer a segunda contribuição da argumentação no EC, Jiménez-Aleixandre e Erduran, op. cit., p. 22, citam a teoria crítica e as correntes socioculturais. Aquela defende que o alcance de níveis superiores de pensamento não deve passar por cima de valores democráticos. Nesse contexto, as competências comunicativas são essenciais para o sujeito se posicionar, instrumentalizando-o para a promoção de mudanças sociais. "A linguagem e as competências comunicativas exercem papel central na ação comunicativa: as pessoas refletem sobre elas mesmas e sobre o mundo, e compartilham essas explicações com os outros" (p. 6, tradução nossa). Educadores que envolvem seus alunos em situações em que devem se posicionar sobre questões sóciocientíficas, por exemplo, auxiliam seus estudantes a desenvolver seus pensamentos críticos.

Visando superar concepções de ensino de Ciências em que há uma superênfase à experimentação e às fórmulas matemáticas, a concepção de letramento científico procura fomentar outras habilidades, entre elas, as comunicativas. Nesse sentido, falar e escrever Ciência (LEMKE, 1990) aparece com importância redobrada para a área de ensino correlata. Além das contribuições do 'falar' Ciências citadas anteriormente, a argumentação tem lugar de destaque na escrita científica, na medida em que se concebe a produção do texto científico não só como relatório, mas também como defesa fundamentada de um ponto de vista. O presente autor reconhece a diversidade de significados do termo letramento, ou alfabetização, científica existente na literatura. No entanto, a abordagem e o grau de aprofundamento que JiménezAleixandre e Erduran dão ao tema, e cujos conceitos e definições foram adotados neste estudo, atende aos propósitos da presente pesquisa.

Outra contribuição da argumentação no ensino de Ciências refere-se à enculturação científica. Jiménez-Aleixandre e Erduran, op. cit., p. 22, definem este termo como sendo a apropriação das práticas da comunidade científica pelos estudantes. Dentre essas práticas, está a utilização de critérios epistêmicos. Kelly (2005 apud JIMÉNEZ-ALEIXANDRE e ERDURAN, 2007) define práticas epistêmicas como sendo as formas específicas que os membros de uma comunidade propõem, justificam, avaliam e legitimam suas declarações dentro de determinado referencial disciplinar. Com foco nas aulas de Ciências, Sandoval e Reiser (2004 apud JIMÉNEZ-ALEIXANDRE e ERDURAN, 2007) definem práticas epistêmicas como práticas 
cognitivas e discursivas envolvidas na construção e avaliação de conhecimento, práticas essas relacionadas ao desenvolvimento da compreensão epistemológica do estudante. Sob um ponto de vista complementar ao exposto acima, a inserção dessas práticas no currículo do ensino de Ciências fomentam a formação do pensamento crítico, na medida em que instrumentaliza o estudante para tratar das questões sociocientítifcas que o cercam.

Por último, Jiménez-Aleixandre e Erduran apresentam as contribuições da argumentação no que diz respeito ao desenvolvimento do raciocínio científico e da utilização de critérios racionais. Os próprios autores reconhecem que pode parecer uma sobreposição falar de racionalidade logo após tratar de critérios epistêmicos. Lembram em seguida que, de fato, existe um debate acalorado sobre o tema na literatura, que diz respeito às pressões internas e externas que influenciam no fazer científico. No entanto, os autores assumem sua filiação ao conceito de racionalidade, defendendo que a ênfase à avaliação de evidências, nesse caso, não exclui a possibilidade de pensamento crítico. Essa ideia, ainda segundo Jiménez-Aleixandre e Erduran, vai ao encontro do que propõe Habermmas (1997, 1981 apud JIMÉNEZ-ALEIXANDRE e ERDURAN, 2007) quando atribui à falta de vigor do Ilumismo ao seu alcance parcial, e não à própria ideia central dessa corrente de pensamento.

De forma geral, para Jiménez-Aleixandre e Erduran, op. cit., p. 22, uma síntese das contribuições da argumentação para o EC seria permitir o desenvolvimento de processos cognitivos de alto nível, a enculturação nas práticas científicas e a compreensão epistemológica da Ciência.

Pelo até aqui exposto, e no que se refere às questões de ensino, ressaltou-se a noção do argumento como prática social, ao invés da noção de argumento como sequência individual e lógica entre premissas e conclusões. As passagens de Leitão (2000), e na sequência, de Brown e Palincsar (1989 apud Jimenez-Aleixandre e Erduran, 2007), auxiliam a resgatar esse significado, reiterado ao longo do texto:

a contribuição da argumentação para o ensino se dá na medida em que o confronto entre a posição defendida pelo proponente de um argumento; e pontos de vista alternativos levantados por um oponente impelem o primeiro ao exame de suas posições à luz das perspectivas contrárias trazidas pelo segundo (LEITÃO, 2000). 
A argumentação no contexto de sala de aula pode apoiar o desenvolvimento de processos cognitivos de ordem superior, uma vez que o raciocínio torna-se público. Dessa forma, espera-se que os estudantes não só revisem suas afirmações a partir de evidências, mas que também avaliem opções alternativas ou explicações. (BROWN e PALINCSAR 1989 apud JIMÉNEZ-ALEIXANDRE E ERDURAN, 2007).

Mas de qual argumento exatamente estamos falando quando elencamos suas contribuições para o EC? E em que situações surgem durante aulas de Ciências? Os autores Boulter e Gilbert (1995) ajudam nessa classificação, quando apresentam as condições em que os argumentos ocorrem nas aulas de Ciências.

A argumentação é analisada de duas formas: segundo as tensões existentes no EC; e segundo os possíveis cenários de sala de aula. Sob o primeiro ponto de vista, uma das tensões trazida à discussão relaciona-se às diferentes concepções de conhecimento, ou muito elitista ou muito popular, concretizadas nas propostas de currículo para as Ciências Naturais. Outras tensões evolvem utilitarismo (necessidades da sociedade) versus necessidades individuais; conteúdo comunicado versus descobertas experimentais; e, concepção realista do conhecimento versus concepção construtivista do conhecimento.

No segundo contexto de análise da argumentação, de acordo com as situações de ensino em sala de aula, os autores apresentam três cenários e três tipos de argumento a eles associados, a saber: argumento didático (quando a atividade predominante no cenário é informar); argumento socrático (quando a atividade predominante no cenário é questionar); e argumento dialógico (quando a atividade predominante no cenário é resolver problemas colaborativos). As situações em que são produzidos os dois primeiros tipos de argumento carregam uma semelhança. Nesses, o professor aparece no cenário em sala de aula como principal agente detentor do conhecimento, situação diferente da ocorrida em um cenário de produção de argumentos dialógicos, o terceiro tipo. Nestes casos, o professor passa a ter um papel de mediação ao invés de fonte de conhecimento, propiciando uma troca de ideias menos centralizada. Os mesmos autores ressaltam, porém, que a importância da flexibilidade do professor em identificar a melhor estratégia de ensino, reconhecendo a hora apropriada para o uso de determinado tipo de argumento, é uma característica importante do educador.

As implicações desses cenários e tipos de argumentos apresentados são desenvolvidas na mesma obra (BOULTER e GILBERT, op. cit., p. 18) à luz de três questões: assimetria de poder 
em sala de aula; privilégio de um gênero em detrimento de outro no acesso ao conhecimento científico devido ao tipo de linguagem; e, mudança conceitual.

Sobre esta última questão, os autores defendem que mudança conceitual não é um processo solitário, e sim social, fazendo ressaltar o papel da argumentação dialógica no EC. Jiménez-Aleixandre e Erduran (2007) aproximam-se dessa perspectiva quando defendem, como uma das contribuições da argumentação para o EC, o tornar públicos os processos cognitivos dos estudantes. Collins et. al. (1989 apud JIMÉNEZ-ALEIXANDRE e ERDURAN, 2007), afirmam que as atuais práticas pedagógicas deixam invisíveis aspectos chave de expertise, dando pouca ou nenhuma atenção para os processos pelos quais peritos adquirem ou usam conhecimento quando realizam tarefas complexas e reais. Jiménez-Aleixandre e Erduran prosseguem, dizendo que

\footnotetext{
Aplicar a noção de aprendizado para habilidades requer a internalização de processos externos. No entanto, no contexto educacional atual, nem o professor nem os estudantes têm acesso aos processos cognitivos um do outro, assim criando um quadro que resulta na impossibilidade da observação desses processos. (JIMÉNEZ-ALEIXANDRES e ERDURAN, 2007, p. 6, tradução nossa)
}

Portanto, em um contexto de sala de aula no qual estudantes são participantes de uma comunidade de aprendizes (MASON, 1996), a argumentação pode apoiar o desenvolvimento de processos cognitivos de alto nível, dado que o raciocínio interno de cada estudante é externalizado e é esperado que eles declarem suas afirmações com evidências e que avaliem alternativas de explicação.

Pesquisadores do ensino de Ciências (BROWN e PALINCSAR, 1989; DRIVER et. al., 2000; JIMÉNEZ-ALEIXANDRE e ERDURAN, 2007; KELLY, 2005; SANDOVAL e REISER, 2004) apresentam, cada qual à sua linha de construção teórica, as contribuições e o lugar da argumentação no EC. Como linha-mestra do texto, é possível ainda identificar que o reconhecimento da centralidade da AEC justifica-se pelo fato dessa prática ocupar papel central na Ciência.

Nessa perspectiva, e entendendo o desenvolvimento da argumentação nas aulas de Ciências como uma das medidas promotoras da melhoria do EC, o assunto figura como profícuo tema de investigação científica. 


\section{AS PESQUISAS EM LINGUAGEM E ENSINO DE CIÊNCIAS E SUA RELAÇÃO COM OS ESTUDOS SOBRE ARGUMENTAÇÃO}

\subsection{A pesquisa em linguagem e ensino de Ciências}

Nos últimos anos, um número crescente de estudos vêm focalizando a análise do discurso argumentativo em contextos de aprendizagem de Ciências (ver Driver et al, 2000; JiménezAleixandre et. al., 2000; Zohar e Nemet, 2002). Segundo Jiménez-Aleixandre e Erduran (2007), entre os diversos referenciais teóricos utilizados para fundamentar a pesquisa em ensino de Ciências, sobressaem dois. Um deles refere-se ao destaque dado pelos estudos sobre Ciência à importância do discurso na construção do conhecimento científico (Latour e Woolgar, 1986) e suas consequências para a educação (BOULTER e GILBERT, 1995; ERDURAN et al, 2004). O outro, no qual nos deteremos a seguir, refere-se à perspectiva sociocultural (VYGOTSKY, 1989; WERTSCH, 1991). Esse referecial aponta para o papel da interação social nos processos de aprendizagem e de pensamento, e propõe que processos superiores de pensamento se originam de atividades socialmente mediadas, por meio da linguagem. Em especial, as contribuições de L.S. Vygosky auxiliam a desenvolver o tema central tratado a seguir: a relação entre a linguagem e o ensino.

Parte significativa da obra de Vygotsky refere-se à compreensão da consciência humana, com especial destaque para o desenvolvimento do pensamento e o papel da linguagem nesse processo. No entanto, esse autor também dedicou esforços em questões de aprendizagem. Sobre o assunto, Vygotsky concorda que esta deve se dar de forma coerente com o nível de desenvolvimento do aluno. Entretanto, distanciando-se de correntes maturacionistas (MEIRA, 1998) que consideram que determinados sujeitos apresentam dificuldades de aprendizagem porque não atingiram o nível de desenvolvimento psico-intelectual necessário, Vygotsky classificou os níveis de desenvolvimento humano em dois: Nível de Desenvolvimento Atual e Zona de Desenvolvimento Proximal. O primeiro refere-se àquilo que sujeito pode aprender 
sozinho, e o segundo, àquilo que ele precisa da ajuda de um par mais experiente para aprender. Em suas palavras:

A investigação mostra sem lugar a dúvidas que o que se acha na zona de desenvolvimento próximo num determinado estágio se realiza e passa no estágio seguinte ao nível de desenvolvimento atual. Com outras palavras, o que a criança é capaz de fazer hoje em colaboração será capaz de fazê-lo por si mesma amanhã. Por isso, parece verossímil que a instrução e o desenvolvimento na escola guardem a mesma relação que a zona de desenvolvimento próximo e o nível de desenvolvimento atual. Na idade infantil, somente é boa a instrução que vá avante do desenvolvimento e arrasta a este último. Porém à criança unicamente se pode ensinar o que é capaz de aprender. (...) O ensino deve orientar-se não ao ontem, mas sim ao amanhã do desenvolvimento infantil. Somente então poderá a instrução provocar os processos de desenvolvimento que se acham na zona de desenvolvimento próximo (VYGOTSKY, 1993, p. 241-242, ênfase nossa).

Embora esteja claro que esse autor debruçou-se de alguma forma a questões do ensino escolar, interessa-nos discutir mais detidamente sua colaboração para o entendimento da evolução do pensamento dos indivíduos e o papel da linguagem.

Desse modo, consideramos importante apresentar brevemente algumas questões teóricofilosóficas centrais que se encontram na base de suas formulações. Os estudos de Vygotsky têm como pressupostos filosóficos, epistemológicos e metodológicos, os princípios do materialismo histórico, com ênfase no contexto sociocultural no processo de trabalho, no uso de instrumentos e na interação dialética entre seres humanos e ambiente.

Um dos focos centrais de sua teoria refere-se às funções psicológicas superiores, originadas da realidade sociocultural (VYGOTSKY, 1998). As funções psicológicas superiores diferem dos processos psicológicos elementares, visto que estes estão presentes nas crianças pequenas e nos animais, e correspondem às reações automáticas, ações reflexas e associações simples, que são de origem biológica. Já as funções psicológicas superiores consistem na capacidade dos seres humanos de planejamento, memória voluntária e imaginação referem-se a mecanismos intencionais, ações conscientemente controladas e processos voluntários, possibilitando ao ser humano independência frente às características do momento e espaço presentes. Estes processos não são inatos, e ocorrem a partir das relações entre as pessoas, 
desenvolvendo-se ao longo do processo de internalização de formas culturais de comportamento. (VYGOTSKY, 1998).

Vygotsky (1987) considera que os processos psicológicos superiores humanos constituem-se em atividades mediadas pela linguagem, estruturadas em sistemas funcionais, dinâmicos e historicamente mutáveis. Diz ele:

\begin{abstract}
O pensamento e a linguagem, que refletem a realidade de uma forma diferente daquela da percepção, são a chave para a compreensão da natureza da consciência humana. As palavras desempenham um papel central não só no desenvolvimento do pensamento, mas também na evolução histórica da consciência como um todo. (VYGOTSKY, 1987, p. 132).
\end{abstract}

Disso decorre que processos como comunicação, linguagem e raciocínio são adquiridos em um contexto social, para depois serem internalizados. Na internalização, o produto do uso de determinado comportamento cognitivo em um contexto social, um processo interpessoal, transforma-se em intrapessoal, por meio da referida mediação. De acordo com Vygotsky (1987), a linguagem aparece, assim, como um sistema integrado de signos elaborados culturalmente, consistindo num fator determinante da evolução do pensamento. À medida que é internalizada, passa a converter-se em estrutura básica do pensamento.

As ideias desse autor ajudam na compreensão da relação entre linguagem e pensamento, na medida em que explicitam o desenvolvimento de funções cognitivas superiores por meio da mediação. A partir de seus estudos, entendemos que a linguagem é, ao mesmo tempo, meio e resultado das relações entre sujeitos e possui forte componente histórico e social. Sendo assim, consideramos que as habilidades cognitivas superiores desenvolvem-se por meio do outro e por meio da linguagem.

Declarada a relação entre linguagem e desenvolvimento de habilidades cognitivas superiores, estudos sobre o papel da linguagem ganham relevo para a pesquisa na área de ensinoaprendizagem. Dessa forma, no rastro de estudos da Psicologia ${ }^{2}$, outras áreas do saber vão se

\footnotetext{
${ }^{2}$ Reconhecemos que os estudos de Psicologia, como é caso dos acima citados de autoria de Vygotsky, não são os únicos que contribuem para a pesquisa em EC. Outras disciplinas, como a Linguística, Filosofia da linguagem e Sociologia, colaboram substancialmente para o avanço do conhecimento na área. No entanto, a assunção de que existem processos superiores de pensamento possíveis de serem desenvolvidos por meio da linguagem é de especial interesse para as discussões realizadas no presente estudo e, portanto, o são para a delimitação do tema.
} 
apropriando desses conhecimentos para investigar a relação entre linguagem e ensino. É o caso da área de ensino de Ciências, que vê a importância da linguagem no processo de aprendizagem da disciplina, porém guarda suas singularidades. Dentro dessa área, é possível notar recentemente o gradativo aumento de destaque da linha de pesquisa em linguagem e ensino de Ciências (LEC), ao lado de linhas já consagradas como Formação de professores de Ciências e Aprendizagem de conceitos científicos ${ }^{3}$.

Seguem algumas das contribuições de pesquisas sobre linguagem e sua relação com o ensino de Ciências. Vemos que estudos dentro dessa área de pesquisa vêm mostrando escassez de trabalhos que bebem de fontes da epistemologia (YORE, 2003), a existência de diferenças entre a linguagem científica e a do dia-a-dia (MORTIMER, 1998), a importância da utilização da linguagem para que o estudante possa, na aprendizagem da linguagem científica, apropriar-se dela (ETKINA, 2000; KEYS, 1994; MUÑOZ-CHÁPULI, 1995), o papel fundamental da produção escrita da linguagem na aprendizagem dos conceitos da Ciência, especialmente na sistematização das ideias (RIVARD, 1994), e a importância das habilidades de comunicação no ensino de Ciências, ao lado de outras já consagradas nesta área de ensino (SANMARTÍ, 1997). Todos os estudos baseiam-se na justificativa da importância do aprendizado da linguagem da Ciência no ensino de Ciências.

As contribuições acima referidas ajudam a entender as razões que dão relevo para o aprendizado de linguagem nas aulas de Ciências, porém, ainda não auxiliam na visualização do quadro geral da pesquisa na área de forma mais consistente. Antes de apresentar esse quadro, contudo, é relevante apresentar brevemente o cenário da pesquisa em EC ao longo dos últimos anos. Essa rápida incursão permite que as tendências da pesquisa em linguagem e ensino de Ciências (LEC), tratada mais à frente, sejam lidas em um contexto mais amplo.

Nesse sentido, o recente estudo de Lee et. al. (2009) é de grande relevância. Essa pesquisa desvela tendências gerais na pesquisa em EC, na medida em que aprofunda e estende os resultados de Tsai e Wen (2005). Lee et. al. (2009) selecionaram 869 artigos publicados entre 2003-2007, dos três principais periódicos da área (Journal of Research in Science Teaching, Science Education e International Journal of Science Education), analisando-os segundo a

\footnotetext{
3 As áreas de Formação de professores de Ciências e Aprendizagem de conceitos científicos foram as que apresentaram maior número de trabalhos publicados no último Encontro Nacional de Pesquisa em Ensino de Ciências (VII ENPEC, Florianópolis, Brasil, 2009).
} 
nacionalidade dos autores, o tipo de pesquisa, o tema de pesquisa e a frequência de citações por outros pesquisadores.

Feita a coleta e análise dos dados do período de 2003-2007, Lee et. al., op. cit., p. 31, compararam-nos com os da pesquisa de Tai e Wen (2005), relativos ao período de 1998-2002. Os resultados são esclarecedores e lançam luz nos caminhos percorridos pela pesquisa em EC ao longo dos últimos anos.

As primeiras conclusões do trabalho dizem respeito à nacionalidade dos autores. Apesar dos países falantes da língua inglesa dominarem a pesquisa em EC, outros países não falantes da lingua vêm ganhando destaque no cenário de pesquisa mundial.

Em seguida, Lee et. al., op. cit., p. 31, levantam as tendências de pesquisa na área segundo o tipo de pesquisa. Os autores afirmam que, embora pesquisas empíricas tenham sido em maior número, as teóricas e de revisão foram fundamentais para o desenvolvimento da área.

As próximas considerações são sobre o tema de pesquisa. Os autores constataram mudanças no perfil de pesquisa em EC, em que gradativamente veio ganhando importância estudos sobre os contextos de aprendizagem. Ao mesmo tempo, perderam espaço pesquisas sobre mudança conceitual e concepções dos alunos, assim como as relacionadas a questões culturais, sociais e de gênero.

Quando Lee et. al. op. cit., p. 31, analisam a frequência de citações, os resultados também são bem interessantes. Entre os 10 artigos mais citados no período de 1998-2002, destacaram-se trabalhos sobre natureza da Ciência e sobre argumentação. No segundo período estudado, novamente trabalhos sobre argumentação situaram-se no topo da lista, acompanhados agora por trabalhos sobre enculturação científica.

Os resultados da pesquisa de Lee et. al., op. cit., p. 31, clarificam a situação da pesquisa em EC nos últimos 10 anos e, por isso, auxiliam a situar também outras linhas de pesquisa na área, como é o caso da pesquisa em LEC. Para ampliar a compreensão e apresentar um quadro da pesquisa nesta área, o pressente trabalho serviu-se do trabalho de Yore e colaboradores.

Yore et. al. (2003) examinaram a produção científica em EC com foco na questão da linguagem, investigando, assim, o estado da arte sobre a pesquisa em LEC. Nesse estudo os autores categorizam trabalhos publicados entre 1978 e 2003 (25 anos) no periódico International Journal of Science Education, segundo seus focos, a saber: pesquisas sobre leitura nas aulas de 
Ciências, pesquisa sobre escrita nas aulas de Ciências e pesquisa sobre o texto oral das aulas de Ciências.

De acordo com esse estudo, as pesquisas em LEC eram escassas no início das publicações do periódico, devido ao enorme desejo de promover atividades hands-on e afastar-se de livros de Ciências. Contudo, a situação mudou a partir dos anos 80. Estudos da época sugeriram que atividades hands-on, sem nenhuma forma de promoção do raciocínio lógico, não eram tão eficazes como proposto.

Dentro desse cenário de produção científica na área, o primeiro foco de investigação identificado pelos autores (YORE et. al., op. cit., p. 31) a ser aqui apresentado será o de leitura no EC. A revisão demonstra que houve uma mudança na forma que os livros textos eram lidos pelos estudantes: de uma mão de via única, para uma reinterpretação muito pessoal, em que o conhecimento prévio e a metacognição falam muito mais alto na leitura. Essa diferente forma de entender a relação dos estudantes com o livro resultou na divulgação de orientações que visavam à promoção de mudanças de comportamento dos professores em relação à utilização do livro texto. Em uma palavra, após essa mudança, a análise dos trabalhos sugere que a comunidade acadêmica passou a ver a leitura como interativa em sua natureza.

Tratando da pesquisa sobre escrita nas aulas de Ciências, o estudo revela que essa subárea da pesquisa em LEC também sofreu mudanças ao longo do tempo. De uma perspectiva centrada na produção escrita dos estudantes em um contexto de avaliação, as investigações passaram a analisar seu aspecto sócio-interacionista, embasadas no conceito de competências e habilidades de que os estudantes têm que lançar mão para aprenderem a natureza da Ciência.

Finalmente, os autores discutem a pesquisa sobre o texto oral, apontando para a ênfase dada à investigação do discurso verbal nas aulas de Ciências conforme foi aumentando a influência das orientações construtivistas sobre a pesquisa. Yore et. al., op. cit., p. 31 sugerem que a revisão sobre os estudos em LEC aponta para a necessidade de mudança da expectativa de formação de estudantes no ensino básico: de uma atual ênfase curricular excessiva, para a formação de leitores da Ciência, críticos e reflexivos.

\subsection{A pesquisa em argumentação no ensino de Ciências}


Ao longo de seu trabalho defendendo a AEC, Driver et. al. (2000) apontam para o importante papel da prática da argumentação a fim de promover uma aproximação de diversas dimensões próprias da atividade científica. Essa obra é considerada um estudo de alta relevância para a AEC, o que permitiu seu surgimento como uma subárea de pesquisa da área de LEC.

Em estudos exploratórios, os autores desta pesquisa (BOZZO e MOTOKANE, 2009a, 2009b), realizaram um levantamento bibliográfico sobre a área, procurando identificar quais eram os principais focos de interesse da pesquisa sobre o uso da AEC. Os resultados corroboraram a ideia de que a publicação do trabalho de Driver et. al. (2000) ajudou a impulsionar a pesquisa em AEC.

No trabalho de Driver et. al. (2000), a argumentação é colocada como potencial meio de desenvolvimento de compreensão conceitual, desenvolvimento de competências investigativas, de compreensão da epistemologia da Ciência, de compreensão da Ciência como prática social e de seu potencial para desenvolver a compreensão pública da Ciência.

No Brasil, estudos recentes analisam o tema sob diversos focos. Entre eles destacam-se aqueles sobre a avaliação de ferramentas de análise de argumentos, sobre a construção de conhecimento por meio da argumentação, sobre a investigação de atividades promotoras da argumentação em sala de aula, sobre a presença e qualidade da argumentação nas aulas de Ciências como indicador de enculturação científica, entre outros focos de pesquisa. A obra de Nascimento e Plantin (2009) reúne alguns dos trabalhos com os enfoques acima apresentados.

Um exemplo de trabalho que faz a avaliação de ferramenta de análise é o realizado por Nascimento e Vieira (2009). Nele, os autores utilizam-se do padrão de Toulmin (2001) na análise de uma situação de formação de professores. Apesar de deixar algumas lacunas quanto ao contexto no qual ocorre a atividade sugerida pelo professor em sala de aulaae o papel da coletividade na produção do argumento, os autores afirmam que o modelo de Toulmin (2001) pode ser utilizado com certa utilidade na pesquisa em EC. Nascimento e Vieira (op. cit., p. 34) defendem claramente o uso do padrão de Toulmin no contexto de pesquisa em EC, apresentando as desvantagens e vantagens dessa escolha metodológica. Os autores avaliam que, se, de um lado, o padrão de Toulmin por si só não permite identificar o contexto de produção dos argumentos, de outro lado, ele permite identificar com relativa clareza os elementos que compõem o argumento.

Outro trabalho que também segue tratando de instrumentos da pesquisa na área é o de Giordan e Posso (2009). Nessa pesquisa, no entanto, o enfoque sobre o instrumento é diferente, 
avaliando o papel de uma ferramenta analítica, ao invés de avaliar a eficácia da própria ferramenta. Esse trabalho analisou, a partir da ferramenta proposta por Mortimer e Scott (2003), como professores em formação inicial apropriam-se de informações de imagens e quais são as relações dessa apropriação com sua prática pedagógica. A argumentação, no trabalho mencionado, está presente em um dos aspectos de análise da ferramenta utilizada para interpretar seus dado: o aspecto da 'abordagem comunicativa'. Em comparação com os outros aspectos categorizados na ferramenta utilizada (aspecto de interação aluno-professor, e aspecto da natureza do conhecimento), a abordagem comunicativa é seu conceito principal.

Pela análise dos dois trabalhos citados, observa-se uma diferença entre os enfoques de pesquisa sobre o uso de ferramentas de análise. Nesses casos, os enfoques variaram, respectivamente, entre os propósitos de avaliar uma ferramenta de análise dos argumentos dos estudantes, e de avaliar uma ferramenta cuja categoria principal de análise envolve a dialogicidade $^{4}$ e, portanto, a argumentação.

Sobre a construção de conhecimento no EC, o trabalho de Rezende e Castells (2009) investigou a construção social de conhecimento de professores de Física em formação continuada a distância, por meio da análise do discurso em fóruns de discussão on-line. Essa pesquisa chama a atenção pela utilização de um referencial teórico utilizado com menor frequência em pesquisas do gênero; a obra de Perelman e Olbrechts-Tyteca (2005). A análise do trabalho de Rezende e Castells sugere algumas diferenças em comparação com análises baseadas no layout de argumento de Toulmin. Uma dessas diferenças refere-se ao fato de que os elementos constituintes do argumento propostos naquele referencial teórico não permitem a identificação clara e objetiva, como é possível em grande número dos casos quando analisados pelo modelo de Toulmin.

O trabalho de Teixeira (2009), por sua vez, investiga ações didáticas de professores que promovem argumentação nas séries inicias. Nesse trabalho, foi observado que a enunciação de um problema aberto não garante a instauração de uma polêmica. Para o debate ser instalado foi a necessária a mediação da professora da sala de aula investigada, fazendo os alunos posicionaremse sobre dois pontos distintos. Os resultados indicaram, dessa forma, que além da proposição de problemas abertos e de temas polêmicos nas aulas de Ciências, o professor tem papel essencial na mediação das situações de ensino para a promoção de argumentação.

\footnotetext{
${ }^{4}$ Entende-se dialogicidade no sentido apresentado por Giordan e Posso (2009), o da possibilidade de expressão de diferentes pontos de vista.
} 
A argumentação também está presente em pesquisas brasileiras sobre enculturação científica. Sasseron e Carvalho (2009) utilizam um referencial teórico ligado à alfabetização científica e entendem a argumentação como um de seus indicadores. Nesse estudo, esses indicadores são identificados por meio dos argumentos em um contexto de aula de conhecimento físico em que há a introdução de temas CTSA (Ciência, Tecnologia, Sociedade e Ambiente); os dados são oriundos de observação da sequência intitulada Navegação e meio ambiente.

Ao final da pesquisa, Sasseron e Carvalho, op. cit., p. 36, apontam para o fato de que os indicadores de alfabetização científica observados no discurso dos alunos na sequência analisada, permitiram concluir que os estudantes relacionaram os temas de Ciência com sociedade, tecnologia e meio ambiente.

Essa breve exposição dos focos da pesquisa em AEC é importante para os fins desta pesquisa na medida em que apresenta a riqueza de temas em âmbito nacional. Desde a avaliação de instrumentos analíticos, passando pela investigação da relação entre construção de conhecimento e argumentação, a promoção desta, a análise dos argumentos por meio de referenciais distintos, até a avaliação do grau de enculturação científica com indicadores de argumentação; todos são focos que, de uma forma ou de outra, também estão presentes nas pesquisas internacionais da área.

Abaixo, serão apresentadas outras pesquisas, no intuito de traçar brevemente o cenário internacional de pesquisa em AEC.

$\mathrm{Na}$ tentativa de ressaltar a mudança de focos de pesquisa em AEC, Nascimento e Vieira, op. cit., p. 34, apresentam uma interpretação para a tendência geral da pesquisa na área, desde os precursores, até os atuais focos. Apontam que, "inicialmente os estudos se concentraram na fala do professor (RUSSEL e MORROW, 1986), para irem se ampliando entre alunos e professores e a participação de aprendizes (CANDELA, 1999; DRIVER et. al., 1999; SANDOVAL \& REISER, 2004)" (p. 22).

Além de apresentar a tendência geral da pesquisa na área, Teixeira (2009) sugere alguns trabalhos que investigam contextos em sala de aulas de Ciências que promovem a produção de argumentos.

A apresentação de situações experimentais que contradizem as expectativas dos alunos (MASSA et. al., 2004; SHAKESPEARE, 2003; ANDREWS et. al., 1993; SOLOMON, 1998), a solicitação de explicações causais acerca dos fenômenos estudados (VILLANI e 
NASCIMENTO, 2003; MORTIMER e SCOTT, 2002) e debates sobre questões controversas, como, por exemplo, temas sóciocientíficos, como poluição (JIMÉNEZALEIXANDRE et. al., 2002) e clonagem (SIMONNEAUX, 2001), são alguns dos contextos das aulas de ciências que propiciam o desencadear de produção de argumentos e que têm sido amplamente utilizados pelos pesquisadores como estratégia central das atividades elaboradas para incitar a argumentação. (p. 60)

No entanto, não é possível uma visualização da situação da pesquisa na área a partir dos trabalhos citados por Teixeira (2009), pois: por um lado remetem a somente a um foco de investigação - estudo de contextos em sala de aulas de Ciências que promovem a produção de argumentos; e, por outro, não contextualizam a produção sob o aspecto cronológico.

Por isso, serão apresentadas a seguir duas revisões em que, tanto a abrangência dos focos quanto a contextualização temporal, permitem uma melhor contextualização da pesquisa em AEC.

A primeira revisão é de von Aufschnaiter et. al. (2008). Segundo estes pesquisadores, recentemente vem aumentando o número de pesquisas com foco em AEC (ver BOULTER e GILBERT, 1995; DRIVER et. al., 2000; DUSCHL e OSBORNE, 2002; KELLY e DUSCHL, 2002; Martins et. al., 2001; ZOHARe NEMET, 2002).

Aufschnaiter et. al. (2008) traçam um panorama da pesquisa na área, desde seu início até a atual situação, discorrendo primeiramente acerca de pesquisas focando o discurso em sala de aula de Ciências (ver DRIVER et. al., 2000; LEMKE, 1990; MARTINS et. al., 2001; NEWTON et. al., 1999).

\footnotetext{
Dentro dessa área de investigação, a pesquisa em argumentação não só surgiu como meio de facilitar o discurso entre aluno-aluno e entre professor-aluno, como também levou ao desenvolvimento de modelos de análise, predominantemente baseados no trabalho de Toulmin (1958) (JIMÉNEZ-ALEIXANDRE et. al., 2000; KELLY et. al., 1998; OSBORNE et. al., 2001; SCHWARZ et. al., 2003; ZOHAR e NEMET, 2002). (von AUFSCHNAITER et. al., 2008, p. 103, tradução nossa)
}

Os autores afirmam que na maioria desses trabalhos, pesquisadores focaram nos processos de argumentação nas comunidades científicas, tanto nas salas de aula como entre os próprios cientistas. 
Utilizando gravações de vídeo e áudio, os discursos foram transcritos e, então, os argumentos de professores e alunos foram investigados [...] em termos de sua qualidade e de sua quantidade (ver KELLY et. al., 1998; OSBORNE et. al., 2004; ZOHAR e NEMET, 2002) (von AUFSCHNAITER et. al., 2008, p. 103, tradução nossa).

Por último, os mesmos autores citam projetos recentes de pesquisa que focaram no entendimento da Ciência pelos estudantes.

\footnotetext{
Esses estudos usaram tanto uma análise descritiva do conteúdo que os alunos desenvolvem durante a argumentação, quanto um delineamento metodológico pré/pósteste para examinar a aquisição de conhecimento dos alunos (ver, JIMÉNEZALEIXANDRE et. al., 2000; JIMÉNEZ-ALEIXANDRE e PEREIRO-MUNHOZ, 2002; LEACH, 1999; MASON, 1996; ZOHAR e NEMET, 2002). (von AUFSCHNAITER et. al., 2008, p.103, tradução nossa).
}

A segunda revisão apresentada nesta parte do trabalho é a realizada por JiménezAleixandre e Erduran (2007). De acordo com a análise desses autores, os primeiros estudos em AEC, exploraram, desde os anos 80, a construção de conhecimento juntamente com as dimensões sociais do argumento, tais como o papel da autoridade e a liderança em grupos dinâmicos. Nessa obra, os autores apresentam dois conjuntos de pesquisa na área.

No primeiro, o referencial dos trabalhos está relacionado com os estudos em Ciências, destacando-se a importância do discurso na construção do conhecimento científico (KNORRCETINA, 1999; LATOUR e WOOLGAR, 1986) e as consequências para a educação (BOULTER e GILBERT, 1995; ERDURAN et. al., 2004; PONTECORVO, 1987). Em um segundo conjunto de trabalhos, o referencial teórico das publicações tem uma perspectiva sociocultural (VYGOTSKY, 1989, WERTSCH, 1991), que aponta para o papel das interações sociais nos processos de aprendizagem e de pensamento, e tem em vista processos de pensamento elevados originados de atividades socialmente mediadas, particularmente por meio da mediação da linguagem. (JIMÉNEZ-ALEIXANDRE e ERDURAN et. al., 2007).

Os autores traçam ainda algumas perspectivas mais recentes de pesquisa em AEC. Em uma delas, evidencia-se o papel étnico: "O papel do étnico, apesar de ser uma área pouco estudada em relação à argumentação, vem contribuindo para estudos culturais de argumentação" 
(JIMÉNEZ-ALEIXANDRE e ERDURAN, 2007, p. 21, tradução nossa). Em outra, são discutidas as questões de poder e de gênero dentro da área.

Estudos culturais e sociológicos da argumentação prometem um estimulante novo domínio de pesquisa em que tanto a questão do poder como a de gênero podem ser investigadas e conceitualizadas para a argumentação nas aulas de ciências (JIMÉNEZALEIXANDRE e ERDURAN, 2007, p. 21, tradução nossa)

Zohar e Nemet (2002) atribuem essa variação de tendências da pesquisa na área, buscando aqui um paralelo com os autores recém citados, como o reflexo das metas dos programas de investigação e das perspectivas teóricas sobre argumento no ensino e aprendizagem de Ciências que moldam os desenhos da pesquisa.

Em suma, a pesquisa em AEC passou por momentos que foram desde a identificação da importância do papel das práticas discursivas nas aulas de Ciências, embasados, em sua maioria, por estudos com bases epistemológicas (busca da compreensão do conhecimento e da natureza da Ciência), até os atuais focos de pesquisa investigando a relação argumentação-aprendizado. Em uma perspectiva ainda mais recente, focos sobre questões étnicas e de assimetria de poderes sociais prometem uma nova área de pesquisa em AEC.

As revisões sobre AEC citadas tiveram por objetivo fundamentar a presente pesquisa. A partir delas, pôde-se observar que a área, apesar de recente na pesquisa em EC se comparada a outras já consagradas, apresenta um estimulante rol de focos de investigação. Entretanto, a revisão de literatura demonstra a escassez de trabalhos que procuram levantar a situação da pesquisa na área. O tipo de estudo que atende a esse objetivo é denominado estado da arte ou estado do conhecimento.

Os estudos de estado da arte ou estado do conhecimento são definidos como de caráter bibliográfico, e trazem em comum o desafio de mapear e de discutir certa produção acadêmica em diferentes campos do conhecimento, tentando responder quais aspectos e dimensões vêm sendo destacados e privilegiados em diferentes épocas e lugares, de que formas e em que condições têm sido produzidas certas dissertações de mestrado, teses de doutorado, publicações em periódicos e comunicações em anais de congressos e de seminários. Também são reconhecidos por realizarem uma metodologia de caráter inventariante e descritiva da produção acadêmica e científica sobre o tema que busca investigar, à luz de categorias e facetas que se 
caracterizam enquanto tais em cada trabalho e no conjunto deles, sob os quais o fenômeno passa a ser analisado.

De forma geral, estudos desse tipo consistem num balanço do conhecimento, baseado na análise comparativa de vários trabalhos, sobre uma determinada temática. Podem, portanto, sugerir modificações no âmbito do tema proposto. Nesse sentido, torna-se de grande relevância acadêmica a realização de estudos que analisem de forma detalhada determinada produção científica, possibilitando o levantamento de tendências na área.

O presente tranbalho buscou realizar um levantamento da pesquisa em AEC, no entanto não se caracteriza como um estado da arte, pelo próprio alcance que se pretende; restrito, se comparado a um estudo de estado do conhecimento. Apesar disso, pretende-se com os resultados desta pesquisa permitir que outros pesquisadores da área encontrem subsídios para situar suas linhas de pesquisa, propiciando ampliação dos enfoques teóricos e metodológicos para a linha de investigação. 


\title{
4. METODOLOGIA DA PESQUISA
}

\subsection{Natureza da pesquisa}

O presente estudo trata-se de uma pesquisa descritiva, definida por:

\begin{abstract}
A pesquisa descritiva observa, registra, analisa, correlaciona fatos ou fenômenos (variáveis) sem manipulá-los. Procura descobrir, com a maior precisão possível, a frequência com que um fenômeno ocorre, sua relação e conexão com outros, sua natureza e suas características. Busca conhecer as diversas situações e relações que ocorrem na vida social, política, econômica e demais aspectos do comportamento humano, tanto do indivíduo tomado isoladamente como de grupos e comunidades mais complexas. [...] Em síntese, a pesquisa descritiva, em suas diversas formas, trabalha sobre dados ou fatos colhidos da própria realidade. (CERVO et. al., 2007, p. 61-62)
\end{abstract}

Há vários tipos de pesquisa descritiva: pesquisa de opinião, pesquisa de motivação, estudo de caso e pesquisa documental. $O$ presente estudo enquadra-se na pesquisa descritiva documental, em que, ainda segundo Cervo et. al. (2007), "são investigados documentos com o propósito de descrever e comparar usos e costumes, tendências, diferenças e outras características. As bases documentais permitem estudar tanto a realidade presente como o passado, como a pesquisa histórica." (p. 61-62).

Conforme definição da Union Française des Organismes de Documentation (apud CERVO et. al., 2007), documento "é toda base de conhecimento fixado materialmente e suscetível de ser utilizado para consulta, estudo ou prova" (p. 80).

\subsection{Referencial teórico-metodológico}

A publicação de resultados de pesquisa é essencial para a produção de conhecimento científico. Tsai e Wen (2005) afirmam que escrever para publicar (tradução nossa) é sempre uma das principais tarefas dos pesquisadores. É nesse tipo de publicação - artigos científicos publicados em revistas especializadas - que o presente estudo buscou dados para responder às 
perguntas de pesquisa. Dessa forma, torna-se fundamental conhecer a estrutura do relatório científico $^{5}$, na medida em que a descrição cuidadosa das partes que o compõem permite maior clareza na busca de informações, quando o objetivo é identificar as características de pesquisa dos artigos analisados.

O relatório científico é o documento que visa à comunicação da pesquisa. Lakatos (1986) o define como sendo

\begin{abstract}
a exposição geral da pesquisa, desde o planejamento às conclusões, incluindo os processos metodológicos empregados. Deve ter como base a lógica, a imaginação e precisão e ser expresso em linguagem simples, clara objetiva, concisa e coerente. Tem a finalidade de dar informações sobre os resultados da pesquisa, se possível, com detalhes, para que eles possam alcançar a sua relevância. São importantes a objetividade e o estilo, mantendo-se a expressão impessoal e evitando-se frases qualificativas ou valorativas, pois a informação deve descrever e explicar, mas não intentar convencer (LAKATOS, 1986, p. 163)
\end{abstract}

Segundo a atual nomenclatura proposta pela Associação Brasileira de Normas Técnicas (ABNT), na norma brasileira (NBR) $\mathrm{n}^{\circ} 14724$, de 2005, a estrutura do relatório científico é dividida da seguinte forma: elementos pré-textuais; elementos textuais; e elementos pós-textuais. Os primeiros antecedem o texto com informações que ajudam na identificação e utilização do trabalho. Os segundos referem-se à parte do trabalho em que é exposta a matéria. Deve ter três partes fundamentais: introdução, desenvolvimento e conclusão. A parte textual comporta também os elementos de apoio, constituídos por notas, citações, tabelas, quadros e ilustrações, inseridos no corpo do texto. E a última parte complementa o trabalho, sendo divididos em obrigatórios, como as referências bibliográficas, e opcionais, como os glossários, os apêndices, os anexos e os índices.

A presente pesquisa utilizou dados provenientes dos elementos pré-textuais e textuais, como será discriminado a seguir.

Dos elementos pré-textuais, foi utilizado o resumo do artigo como fonte de coleta de dados. Lakatos (1985) e Severino (2007) corroboram a ideia de que no resumo estão dispostas informações que permitem avaliar o documento e identificar o artigo como um todo.

\footnotetext{
${ }^{5}$ No caso da presente pesquisa, utilizaram-se os seguintes tipos de relatórios científicos: artigos de divulgação de resultados de pesquisa e artigos de revisão.
} 
Em análises preliminares, estes autores buscaram identificar os perfis dos artigos de pesquisa em AEC por meio da leitura de seus resumos. Suas partes foram identificadas a partir dos seguintes descritores: referencial teórico elou justificativa; foco elou objetivo; método; resultados e discussão; e conclusão. Verificou-se que as partes relacionadas aos resultados, sua discussão, e às considerações finais não continham informações relevantes para a identificação de perfis de artigos na área. Além disso, observou-se que os resultados obtidos poderiam ser complementados a partir da análise de outras partes do artigo, como, por exemplo, a parte relacionada aos aspectos metodológicos da pesquisa analisada.

A partir dos resultados obtidos nas análises preliminares, escolheu-se utilizar o descritor foco elou objetivo presente no resumo do artigo como fonte de coleta de dados. Deste ponto em diante, este descritor será denominado simplesmente objetivo do resumo.

Além da escolha do descritor referente aos dados dos elementos pré-textuais, os resultados preliminares conduziram à procura de outros descritores, os quais se referem a dados obtidos dos elementos textuais.

Dos elementos textuais, foram utilizados como descritores para a coleta dados: pergunta de pesquisa, foco, objetivo - elemento textual e trecho sobre o uso de Toulmin (1958) como referencial teórico.

Alguns autores expressam as finalidades do objetivo dentro de textos científicos. Cervo (1978) pontua que os objetivos podem definir "a natureza do trabalho, o tipo de problema a ser selecionado, o material a coletar" (p. 49). Para Lakatos (1985), “o objetivo torna explícito o problema, aumentando os conhecimentos sobre determinado assunto" (p. 148).

A coleta de dados a partir do descritor objetivo possibilitou visualizar outras informações do artigo, ainda diretamente relacionadas ao objetivo, de potencial auxílio na identificação dos focos de pesquisa. Dessa maneira, somados aos dados do objetivo do resumo e do objetivo da parte textual do artigo, foram também inclusos os descritores pergunta de pesquisa e foco.

Dada a relevância que a pergunta de pesquisa, o foco e objetivo (presente na parte prétextual ou textual) assumem no contexto da produção de conhecimento científico, e especialmente, nos relatórios científicos, o presente trabalho utilizou dados a partir desses descritores na procura dos principais focos de interesse da pesquisa sobre o uso da AEC. 
O último descritor do elemento textual, trecho sobre o uso de Toulmin (1958) como referencial teórico, foi utilizado para coletar dados sobre o tipo de uso que pesquisadores da área de ensino de Ciências vêm fazendo das ideias do autor.

Driver et. al. (2000) afirmam que Toulmin (1958), em sua obra The uses of argument, fez uma ruptura com o tradicional campo da lógica ao estudar a forma como as pessoas argumentam em ambientes naturais. Baseado em sua análise dos argumentos produzidos em uma variedade de contextos, incluindo o campo jurídico e o da Ciência, Toulmin apresentou um modelo que descreve os elementos constitutivos do argumento e a relação funcional entre eles. Suas ideias são ainda influentes e, nos últimos anos, elas têm sido exploradas por diversos pesquisadores do ensino de Ciências (e educadores de outras áreas) no intuito de fornecer um modelo para a descrição dos argumentos dos alunos.

Sua vasta aplicação nas pesquisas em AEC permite identificá-lo como importante referencial teórico para esse campo de investigação. A análise do tipo de uso que pesquisadores vêm fazendo das ideias contidas nessa obra, tem grandes chances de servir como um significativo indicador das tendências de pesquisa na área. Por isso, apesar de reconhecer a existência de outras obras de Toulmin que também versam sobre o tema, o presente estudo adotou The uses of argument, do autor Stephen Toulmin, publicado pela editora Cambridge University Press, em 1958, como padrão para as análises.

\subsection{Procedimentos metodológicos}

Esta pesquisa utilizou-se de artigos publicados em revistas especializadas. Para tanto, foram utilizadas as bases de dados ERIC (Education Resources Information Center), FRANCIS, SciELO (Scientific Electronic Library Online), e a ferramenta de pesquisa ISI Web of Knowledge.

As três bases de dados utilizadas nesta pesquisa (ERIC, FRANCIS e SciELO) fazem parte dos recursos eletrônicos que estão disponíveis para a comunidade da USP e usuários das bibliotecas de acordo com contratos de licença, firmados junto aos fornecedores.

A ISI Web of Knowledge é uma plataforma de pesquisa para a busca de informações sobre ciências, ciências sociais, artes e humanidades. 
A escolha das bases de dados e da plataforma de pesquisa acima citadas resultou de análises preliminares. Na ocasião, foram realizadas pesquisas em várias bases de dados, visando à adoção daquelas em que os resultados de busca ofereciam artigos de pesquisa que satisfaziam os critérios do presente estudo.

Utilizaram-se os seguintes critérios para seleção dos artigos, cujo detalhamento será discriminado em seguida:
a) artigos científicos;
b) publicados em revistas Qualis A e $\mathrm{B}^{6}$
c) sobre argumentação no ensino de Ciências;
d) publicados entre 1988 e 2008

a) Foram escolhidos artigos, e não dissertações e teses, pois estas são produções não circulantes e, como tal, sofrem menos o processo de regulação pela comunidade científica especializada.

b) O Qualis é uma lista de veículos utilizados para a divulgação da produção intelectual dos programas nacionais de pós-graduação stricto sensu (mestrado e doutorado), classificados quanto ao âmbito de circulação (Local, Nacional, Internacional) e à qualidade (A, B, C), por área de avaliação. A pesquisa dessa lista pode ser feita a partir da ferramenta on line WebQualis $^{7}$. Foram considerados artigos de argumentação aqueles que apresentaram, de alguma forma, foco de pesquisa envolvendo argumentação no EC, segundo a definição de argumentação discutida na introdução (p. 18-19).

c) Em estudos anteriores realizado pelo presente autor (BOZZO e MOTOKANE, 2009a, 2009b), observou-se que houve um aumento na quantidade de artigos sobre AEC a partir do final da década de 90, especialmente a partir do ano de 2000. Sugere-se que, observando-se o número de publicações desde 1988, seja possível visualizar quando de fato se iniciam os estudos da área.

Obtiveram-se as seguintes quantidades de resultados de pesquisa em cada base de dado ou plataforma de pesquisa consultada: ERIC, 85; FRANCIS, 82; SciELO, 1; e ISI Web of Knowlegde, 59; somando 227 resultados de pesquisa ao total.

\footnotetext{
${ }^{6}$ A pesquisa quanto ao conceito Qualis dos periódicos foi realizada entre o dia 01/11/08 a 15/11/08

${ }^{7}$ Para utilizar essa ferramenta, acessar o endereço http://qualis.capes.gov.br/webqualis/
} 
Como cada base de dado, ou plataforma de pesquisa, possui seu próprio sistema de busca, foram realizados procedimentos de procura distintos para atender aos critérios de seleção. Todos os procedimentos possuem bastantes similaridades, o que inclui a utilização dos termos “argumentation", "science" e "education". Porém, existem algumas peculiaridades que podem ser comparadas no quadro 1.

Quadro 1 - Procedimentos de busca nas bases de dados e na plataforma de pesquisa utilizadas na presente pesquisa!

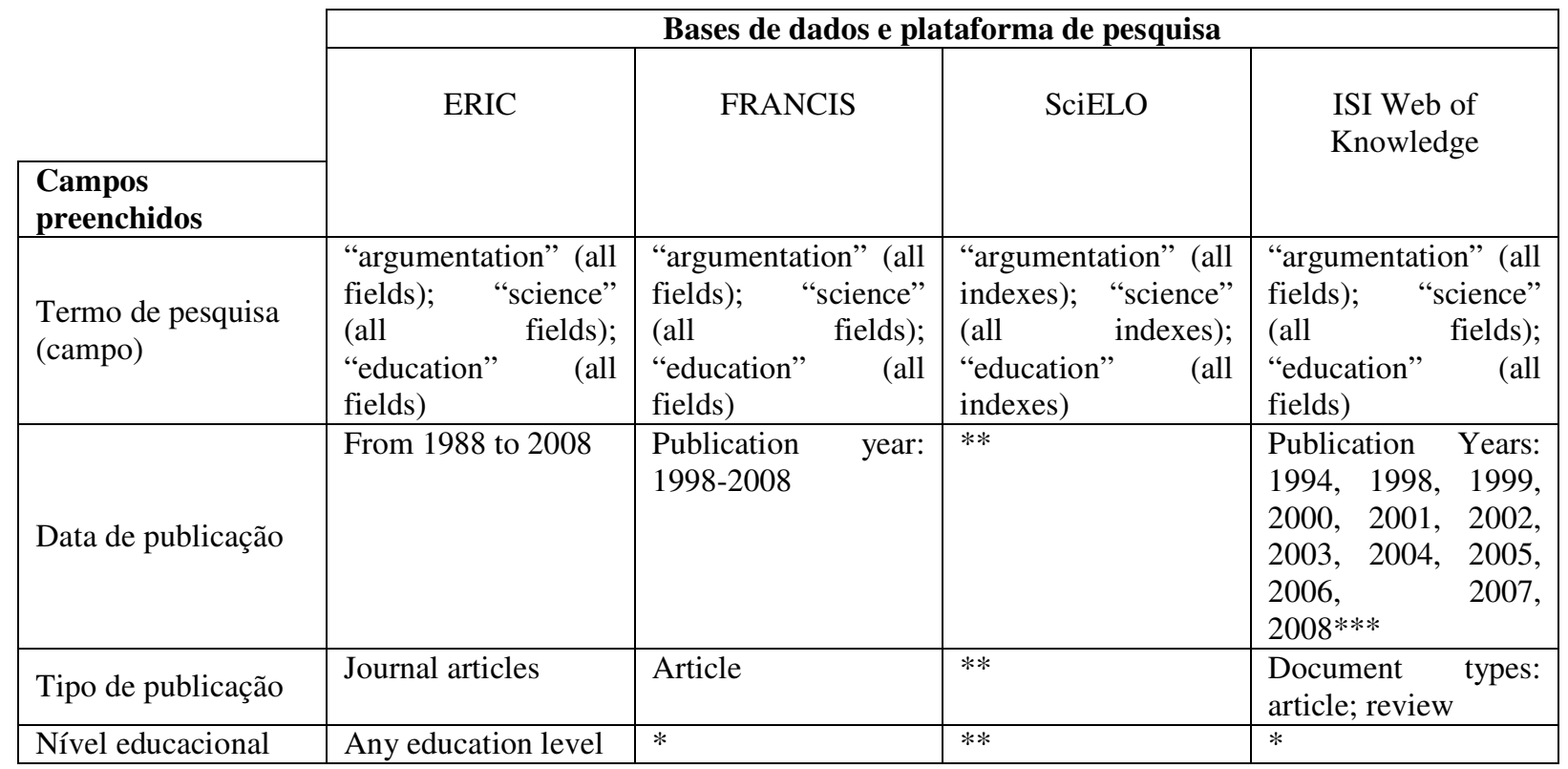

*Os campos não preenchidos no quadro não possuem correspondentes no sistema de busca da base de dados ou plataforma de pesquisa.

**Quando a base de dados não possuía opções de busca para atender aos critérios de seleção desejados, foi realizada uma pesquisa manual. Isso só foi possível devido ao reduzido número de resultados de pesquisa para a base de dados SciELO (2).

***A ferramenta de busca da plataforma de pesquisa ISI Web of Knowledge não permite a realização de buscas por período de publicação, antes que se faça uma busca simples. Feita essa busca, o usuário refina os resultados de pesquisa. Dessa forma, na opção Publication years, só é possível selecionar anos em que houve sucesso da procura. Assim, apesar das publicações dos anos 1988, 1989, 1990, 1991, 1992, 1993, 1995, 1996 e 1997 fazerem parte do recorte de tempo escolhido para a presente pesquisa, eles não estão disponíveis nessa ferramenta de busca.

Sob os 227 resultados, foram aplicados filtros de pesquisa para a seleção dos artigos utilizados no presente estudo. Os critérios de seleção "a" (artigos científicos) e "d" (publicados entre 1988 e 2008) foram atendidos no procedimento de procura das bases de dados consultadas, quando foram preenchidos os campos "Tipo de publicação" e "Data de publicação" (quadro 1). No entanto, os critérios de seleção "b" (publicados em revistas Qualis A e B) e "c" (sobre 
argumentação no ensino de Ciências) foram atendidos por meio da aplicação da triagem manual dos artigos.

Para tanto, primeiramente foi elaborada uma lista de todos os periódicos que constavam nos resultados de pesquisa, classificando-os quanto à avaliação feita no WebQualis (Qualis A1, A2, B1, B2, B3, B4, B5, C). Feita essa lista de referência, todos os artigos publicados em revistas C ou em revistas não avaliadas pelo WebQualis não foram selecionados, atendendo, assim, o critério "b".

Em segundo lugar, foram lidos os títulos, e, quando necessário, os resumos dos artigos, um a um, a fim de selecionar aqueles que atendessem o critério "c". Na ocasião, artigos da área do Direito, sobre ensino de Matemática e outras áreas do conhecimento, por exemplo, não foram contemplados.

Ao final dos dois procedimentos de triagem, realizando a busca com ajuda da ferramenta de procura da base de dados ou da plataforma de pesquisa, e realizando a seleção de forma manual, foram selecionados 51 artigos, dos 227 totais. Estes artigos encontram-se discriminados no quadro 2 a seguir.

Quadro 2. Lista de artigos que compuseram a amostra da presente pesquisa, em que IDE=Número de identificação do artigo, AUT=Autor(es), TIT=Título do artigo, REV=Revista e APU=Ano de publicação

\begin{tabular}{|c|l|l|c|c|}
\hline IDE & AUT & TIT & REV & APU \\
\hline 1 & $\begin{array}{l}\text { Nikki L. Hanegan; } \\
\text { Laura Price Jeremy } \\
\text { Peterson }\end{array}$ & $\begin{array}{l}\text { Disconnections Between Teacher Expectations and } \\
\text { Student Confidence in Bioethics }\end{array}$ & $\begin{array}{c}\text { Science \& } \\
\text { Education }\end{array}$ & 2008 \\
\hline 2 & $\begin{array}{l}\text { Claudia von } \\
\text { Aufschnaiter; Sibel } \\
\text { Erduran; Jonathan } \\
\text { Osborne; Shirley Simon }\end{array}$ & $\begin{array}{l}\text { Arguing to Learn and Learning to Argue: Case } \\
\text { Studies of How Students Argumentation Relates to } \\
\text { Their Scientific Knowledge }\end{array}$ & $\begin{array}{c}\text { Journal of } \\
\text { Research in } \\
\text { Science } \\
\text { Teaching }\end{array}$ & 2008 \\
\hline 3 & $\begin{array}{l}\text { Leah A. Bricker; Philip } \\
\text { Belll }\end{array}$ & $\begin{array}{l}\text { Conceptualizations of Argumentation from Science } \\
\text { Studies and the Learning Sciences and their } \\
\text { Implications for the Practices of Science Education }\end{array}$ & $\begin{array}{c}\text { Science } \\
\text { Education }\end{array}$ & 2008 \\
\hline 4 & $\begin{array}{l}\text { Shirley Simon; Susan } \\
\text { Johnson }\end{array}$ & $\begin{array}{l}\text { Professional Learning Portfolios for Argumentation } \\
\text { in School Science }\end{array}$ & $\begin{array}{c}\text { International } \\
\text { Journal of } \\
\text { Science } \\
\text { Education }\end{array}$ & 2008 \\
\hline 5 & $\begin{array}{l}\text { Taasoobshirazi b; Sean } \\
\text { Hendricks; Daniel T. } \\
\text { Hickey }\end{array}$ & $\begin{array}{l}\text { Argumentation: A Strategy for Improving } \\
\text { Achievement and Revealing Scientific Identities }\end{array}$ & $\begin{array}{c}\text { International } \\
\text { Journal of } \\
\text { Science } \\
\text { Education }\end{array}$ & 2008 \\
\hline
\end{tabular}




\begin{tabular}{|c|c|c|c|c|}
\hline 7 & $\begin{array}{l}\text { Victor Sampson; } \\
\text { Douglas B. Clark }\end{array}$ & \begin{tabular}{|lrrrr} 
Assessment of the Ways Students & Generate \\
Arguments in Science Education: & Current \\
Perspectives and Recommendations for & Future \\
Directions & & & & \\
\end{tabular} & $\begin{array}{l}\text { Science } \\
\text { Education }\end{array}$ & 2008 \\
\hline 8 & \begin{tabular}{|l|} 
Maria Varelas; \\
Christine C. Pappas; \\
Justine M. Kane; Amy \\
Arsenault; Jennifer \\
Hankes, Begona \\
Marnotes Cowan \\
\end{tabular} & $\begin{array}{l}\text { Urban Primary-Grade Children Think and Talk } \\
\text { Science: Curricular and Instructional Practices that } \\
\text { Nurture Participation and Argumentation }\end{array}$ & $\begin{array}{l}\text { Science } \\
\text { Education }\end{array}$ & 2008 \\
\hline 9 & $\begin{array}{l}\text { Shu-Nu Changa; Mei- } \\
\text { Hung Chiu }\end{array}$ & $\begin{array}{l}\text { Lakatos' Scientific Research Programmes as a } \\
\text { Framework for Analysing Informal Argumentation } \\
\text { about Socio-scientific Issues }\end{array}$ & $\begin{array}{l}\text { Science } \\
\text { Education }\end{array}$ & 2008 \\
\hline 10 & $\begin{array}{l}\text { Douglas B. Clark; } \\
\text { Victor Sampson }\end{array}$ & $\begin{array}{l}\text { Assessing Dialogic Argumentation in Online } \\
\text { Environments to Relate Structure, Grounds, and } \\
\text { Conceptual Quality }\end{array}$ & $\begin{array}{l}\text { Journal of } \\
\text { Research in } \\
\text { Science } \\
\text { Teaching } \\
\end{array}$ & 2007 \\
\hline 11 & $\begin{array}{l}\text { Stuart Naylor; Brenda } \\
\text { Keogh; Brigid Downing }\end{array}$ & Argumentation and Primary Science & $\begin{array}{l}\text { Research in } \\
\text { Science } \\
\text { Education }\end{array}$ & 2007 \\
\hline 12 & $\begin{array}{l}\text { Douglas B. Clark, } \\
\text { Victor D. Sampson }\end{array}$ & $\begin{array}{l}\text { Personally-Seeded Discussions to Scaffold Online } \\
\text { Argumentation }\end{array}$ & $\begin{array}{l}\text { International } \\
\text { Journal of } \\
\text { Science } \\
\text { Education }\end{array}$ & 2007 \\
\hline 13 & $\begin{array}{l}\text { Kurt D. Squire; } \\
\text { Mingfong Jan }\end{array}$ & $\begin{array}{l}\text { Mad City Mystery: Developing } \text { Scientific } \\
\text { Argumentation Skills with a Place-Based } \\
\text { Augmented Reality Game on Handheld Computers }\end{array}$ & $\begin{array}{l}\text { Journal of } \\
\text { Science } \\
\text { Education and } \\
\text { Technology }\end{array}$ & 2007 \\
\hline 14 & M. B. Ogunniyi & 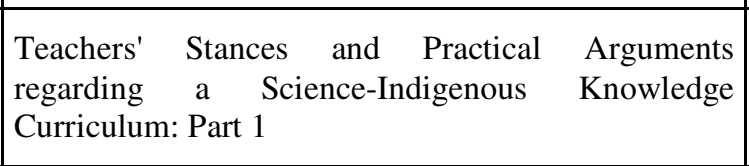 & $\begin{array}{l}\text { International } \\
\text { Journal of } \\
\text { Science } \\
\text { Education }\end{array}$ & 2007 \\
\hline 15 & M. B. Ogunniyi & $\begin{array}{l}\text { Teachers' Stances and Practical } \\
\text { regarding a Arguments } \\
\text { Curriculum: Part 2 }\end{array}$ & $\begin{array}{l}\text { International } \\
\text { Journal of } \\
\text { Science } \\
\text { Education }\end{array}$ & 2007 \\
\hline 16 & $\begin{array}{l}\text { Luciana Passos Sá; } \\
\text { Salete Linhares Queiroz }\end{array}$ & $\begin{array}{l}\text { Promovendo a argumentação no ensino superior de } \\
\text { química }\end{array}$ & Química Nova & 2006 \\
\hline 17 & $\begin{array}{l}\text { Kimberly A. Walker; } \\
\text { Dana L. Zeidler }\end{array}$ & $\begin{array}{|ll|}\begin{array}{l}\text { Promoting discourse about socioscientific issues } \\
\text { through scaffolded inquiry } \\
\text { Promoting Discourse about } \\
\text { through Scaffolded Inquiry }\end{array} \\
\end{array}$ & $\begin{array}{l}\text { International } \\
\text { Journal of } \\
\text { Science } \\
\text { Education } \\
\end{array}$ & 2006 \\
\hline 18 & $\begin{array}{l}\text { Ying-Tien Wua; Chin- } \\
\text { Chung Tsai }\end{array}$ & $\begin{array}{l}\text { High school students' informal reasoning on a socio- } \\
\text { scientific issue: Qualitative and quantitative analyses } \\
\text { / High School Students' Informal Reasoning on a } \\
\text { Socio-Scientific Issue: Qualitative and Quantitative } \\
\text { Analyses }\end{array}$ & $\begin{array}{l}\text { International } \\
\text { Journal of } \\
\text { Science } \\
\text { Education }\end{array}$ & 2006 \\
\hline 19 & $\begin{array}{l}\text { Troy D. Sadler; Lisa A. } \\
\text { Donnellyb }\end{array}$ & $\begin{array}{l}\text { Socioscientific Argumentation: The Effects of } \\
\text { Content Knowledge and Morality }\end{array}$ & $\begin{array}{l}\text { International } \\
\text { Journal of } \\
\text { Science } \\
\text { Education }\end{array}$ & 2006 \\
\hline 20 & $\begin{array}{l}\text { Shirley Simon, Sibel } \\
\text { Erduran; Jonathan } \\
\text { Osborne }\end{array}$ & $\begin{array}{l}\text { Learning to Teach Argumentation: Research and } \\
\text { Development in the Science Classroom }\end{array}$ & $\begin{array}{l}\text { International } \\
\text { Journal of } \\
\text { Science } \\
\text { Education }\end{array}$ & 2006 \\
\hline
\end{tabular}




\begin{tabular}{|c|c|c|c|c|}
\hline 21 & Stein Dankert Kolst $\varnothing$ & $\begin{array}{l}\text { Patterns in Students' Argumentation Confronted with } \\
\text { a Risk-Focused Socio-Scientific Issue }\end{array}$ & $\begin{array}{l}\text { International } \\
\text { Journal of } \\
\text { Science } \\
\text { Education } \\
\end{array}$ & 2006 \\
\hline 22 & $\begin{array}{l}\text { Jane Maloney; Shirley } \\
\text { Simon }\end{array}$ & $\begin{array}{l}\text { Mapping Children's Discussions of Evidence in } \\
\text { Science to Assess Collaboration and Argumentation }\end{array}$ & $\begin{array}{l}\text { International } \\
\text { Journal of } \\
\text { Science } \\
\text { Education }\end{array}$ & 2006 \\
\hline 23 & $\begin{array}{l}\text { Troy D. Sadler; Saman } \\
\text { R. Fowler }\end{array}$ & $\begin{array}{l}\text { A Threshold Model of Content Knowledge Transfer } \\
\text { for Socioscientific Argumentation }\end{array}$ & $\begin{array}{c}\text { Science } \\
\text { Education }\end{array}$ & 2006 \\
\hline 24 & $\begin{array}{l}\text { Heekyong Kim; } \\
\text { Jinwoong Song }\end{array}$ & $\begin{array}{l}\text { The Features of Peer Argumentation in Middle } \\
\text { School Students' Scientific Inquiry }\end{array}$ & $\begin{array}{l}\text { Research in } \\
\text { Science } \\
\text { Education }\end{array}$ & 2006 \\
\hline 25 & $\begin{array}{l}\text { Stein Dankert Kolstø; } \\
\text { Berit Bungum; Erik } \\
\text { Arnesen; Anders Isnes; } \\
\text { Terje Kristensen, Ketil } \\
\text { Mathiassen; Idar } \\
\text { Mestad; Andreas Quale; } \\
\text { Anne Sissel Vedvik } \\
\text { Tonning; Marit Ulvik }\end{array}$ & $\begin{array}{l}\text { Science students' critical examination of scientific } \\
\text { information related to socioscientific issues } \\
\text { Science Students' Critical Examination of Scientific } \\
\text { Information Related to Socioscientific Issues }\end{array}$ & $\begin{array}{l}\text { Science } \\
\text { Education }\end{array}$ & 2006 \\
\hline 26 & $\begin{array}{l}\text { Jonathan Osborne; Sibel } \\
\text { Erduran; Shirley Simon }\end{array}$ & $\begin{array}{l}\text { Enhancing the Quality of Argumentation in School } \\
\text { Science }\end{array}$ & $\begin{array}{l}\text { Journal of } \\
\text { Research in } \\
\text { Science } \\
\text { Teaching }\end{array}$ & 2004 \\
\hline 27 & $\begin{array}{l}\text { Sibel Erduran; Shirley } \\
\text { Simon; Jonathan } \\
\text { Osborne }\end{array}$ & $\begin{array}{l}\text { TAPping into Argumentation: Developments in the } \\
\text { Application of Toulmin's Argument Pattern for } \\
\text { Studying Science Discourse }\end{array}$ & $\begin{array}{c}\text { Science } \\
\text { Education }\end{array}$ & 2004 \\
\hline 28 & $\begin{array}{l}\text { J. Rod Watson; Julian } \\
\text { R. L. Swain; Cam } \\
\text { McRobbie }\end{array}$ & $\begin{array}{l}\text { Students' Discussions in Practical Scientific } \\
\text { Inquiries. Research Report }\end{array}$ & $\begin{array}{l}\text { International } \\
\text { Journal of } \\
\text { Science } \\
\text { Education }\end{array}$ & 2004 \\
\hline 29 & Troy D. Sadler & $\begin{array}{l}\text { Informal reasoning regarding socioscientific issues: } \\
\text { A critical review of research }\end{array}$ & $\begin{array}{l}\text { Journal of } \\
\text { Research in } \\
\text { Science } \\
\text { Teaching }\end{array}$ & 2004 \\
\hline 30 & Anton E. Lawson & $\begin{array}{l}\text { The Nature and Development of Hypothetico- } \\
\text { Predictive Argumentation with Implications for } \\
\text { Science Teaching }\end{array}$ & $\begin{array}{l}\text { International } \\
\text { Journal of } \\
\text { Science } \\
\text { Education }\end{array}$ & 2003 \\
\hline 31 & $\begin{array}{l}\text { Anat Zohar; Flora } \\
\text { Nemet }\end{array}$ & $\begin{array}{l}\text { Fostering Students' Knowledge and Argumentation } \\
\text { Skills through Dilemmas in Human Genetics. }\end{array}$ & $\begin{array}{l}\text { Journal of } \\
\text { Research in } \\
\text { Science } \\
\text { Teaching }\end{array}$ & 2002 \\
\hline 32 & $\begin{array}{l}\text { María-Pilar Jiménez- } \\
\text { Aleixandre; Cristina } \\
\text { Pereiro-Muñoz }\end{array}$ & $\begin{array}{l}\text { Knowledge Producers or Knowledge Consumers? } \\
\text { Argumentation and Decision Making about } \\
\text { Environmental Management }\end{array}$ & $\begin{array}{l}\text { International } \\
\text { Journal of } \\
\text { Science } \\
\text { Education }\end{array}$ & 2002 \\
\hline 33 & Laurence Simonneaux & $\begin{array}{l}\text { Analysis of Classroom Debating Strategies in the } \\
\text { Field of Biotechnology. }\end{array}$ & $\begin{array}{l}\text { Journal of } \\
\text { Biological } \\
\text { Education } \\
\end{array}$ & 2002 \\
\hline 34 & $\begin{array}{l}\text { Yehudit J. Dori; Revital } \\
\text { T. Tal; Masha Tsaushu }\end{array}$ & $\begin{array}{l}\text { Teaching biotechnology through case studies: Can } \\
\text { we improve higher order thinking skills of } \\
\text { nonscience majors? }\end{array}$ & $\begin{array}{l}\text { Science } \\
\text { Education }\end{array}$ & 2002 \\
\hline 35 & Mansoor Niaz; & Arguments, $\quad$ contradictions, & Science & 2002 \\
\hline
\end{tabular}




\begin{tabular}{|c|c|c|c|c|}
\hline & $\begin{array}{l}\text { Damarys Aguilera; } \\
\text { Arelys Maza; Gustavo } \\
\text { Liendo }\end{array}$ & $\begin{array}{l}\text { conceptual change in students' understanding of } \\
\text { atomic structure }\end{array}$ & Education & \\
\hline 36 & $\begin{array}{l}\text { Carla Zembal-Saul; } \\
\text { Danusa Munford; } \\
\text { Barbara Crawford; } \\
\text { Patricia Friedrichsen; } \\
\text { Susan Land }\end{array}$ & $\begin{array}{l}\text { Scaffolding preservice science teachers' evidence- } \\
\text { based arguments during an investigation of natural } \\
\text { selection }\end{array}$ & $\begin{array}{l}\text { Research in } \\
\text { Science } \\
\text { Education }\end{array}$ & 2002 \\
\hline 37 & Laurence Simonneaux & $\begin{array}{l}\text { Role-Play or Debate To Promote Students' } \\
\text { Argumentation and Justification on an Issue in } \\
\text { Animal Transgenesis. }\end{array}$ & $\begin{array}{l}\text { International } \\
\text { Journal of } \\
\text { Science } \\
\text { Education } \\
\end{array}$ & 2002 \\
\hline 38 & Anton E. Lawson & $\begin{array}{l}\text { Sound and faulty arguments generated by preservice } \\
\text { biology teachers when testing hypotheses involving } \\
\text { unobservable entities }\end{array}$ & $\begin{array}{l}\text { Journal of } \\
\text { Research in } \\
\text { Science } \\
\text { Teaching }\end{array}$ & 2001 \\
\hline 39 & $\begin{array}{l}\text { Gregory J. Kelly, } \\
\text { Allison Takao }\end{array}$ & $\begin{array}{l}\text { Epistemic levels in argument: an analysis of } \\
\text { university oceanography students' use of evidence in } \\
\text { writing }\end{array}$ & $\begin{array}{l}\text { Science } \\
\text { Education }\end{array}$ & 2001 \\
\hline 40 & $\begin{array}{l}\text { Kathleen Hogan, Mark } \\
\text { Maglienti }\end{array}$ & $\begin{array}{l}\text { Comparing the epistemological underpinnings of } \\
\text { students' and scientists' reasoning about conclusions }\end{array}$ & $\begin{array}{l}\text { Journal of } \\
\text { Research in } \\
\text { Science } \\
\text { Teaching }\end{array}$ & 2001 \\
\hline 41 & $\begin{array}{l}\text { Russell Tytler; Sandra } \\
\text { Duggan; Richard Gott }\end{array}$ & $\begin{array}{l}\text { Dimensions of evidence, the public understanding of } \\
\text { science and science education }\end{array}$ & $\begin{array}{l}\text { International } \\
\text { Journal of } \\
\text { Science } \\
\text { Education } \\
\end{array}$ & 2001 \\
\hline 42 & Randy K. Yerrick & $\begin{array}{l}\text { Lower Track Science Students' Argumentation and } \\
\text { Open Inquiry Instruction. }\end{array}$ & $\begin{array}{l}\text { Journal of } \\
\text { Research in } \\
\text { Science } \\
\text { Teaching }\end{array}$ & 2000 \\
\hline 43 & $\begin{array}{l}\text { Maria Pilar Jiménez- } \\
\text { Aleixandre, Anaxela } \\
\text { Bugallo Rodrígues, } \\
\text { Richard A. Richard A. } \\
\text { Duscghl }\end{array}$ & $\begin{array}{l}\text { "Doing the Lesson" or "Doing Science": Argument } \\
\text { in High School Genetics }\end{array}$ & $\begin{array}{l}\text { Science } \\
\text { Education }\end{array}$ & 2000 \\
\hline 44 & $\begin{array}{l}\text { Rosalind Driver, Paul } \\
\text { Newton, Jonathan } \\
\text { Osborne }\end{array}$ & Establishing the Norms of Scientific Argument & $\begin{array}{l}\text { Science } \\
\text { Education }\end{array}$ & 2000 \\
\hline 45 & Philip Bell & $\begin{array}{l}\text { Scientific arguments as learning artifacts : designing } \\
\text { for learning from the web with KIE. The knowledge } \\
\text { integration environment }\end{array}$ & $\begin{array}{l}\text { International } \\
\text { Journal of } \\
\text { Science } \\
\text { Education }\end{array}$ & 2000 \\
\hline 46 & $\begin{array}{l}\text { Paul Newton; Rosalind } \\
\text { Driver; Jonathan } \\
\text { Osborne }\end{array}$ & $\begin{array}{l}\text { The place of argumentation in the pedagogy of } \\
\text { school science }\end{array}$ & $\begin{array}{l}\text { International } \\
\text { Journal of } \\
\text { Science } \\
\text { Education } \\
\end{array}$ & 1999 \\
\hline 47 & $\begin{array}{l}\text { Tasos Patronis; Despina } \\
\text { Potari; Vassiliki } \\
\text { Spiliotopoulou }\end{array}$ & $\begin{array}{l}\text { Students' Argumentation in Decision-Making on a } \\
\text { Socio-Scientific Issue: Implications for Teaching. }\end{array}$ & $\begin{array}{l}\text { International } \\
\text { Journal of } \\
\text { Science } \\
\text { Education } \\
\end{array}$ & 1999 \\
\hline 48 & Derrick R. Lavoie & $\begin{array}{l}\text { Effects of Emphasizing Hypothetico-Predictive } \\
\text { Reasoning within the Science Learning Cycle on } \\
\text { High School Student's Process Skills and } \\
\text { Conceptual Understandings in Biologyl }\end{array}$ & $\begin{array}{c}\text { Journal of } \\
\text { Research in } \\
\text { Science } \\
\text { Teaching } \\
\end{array}$ & 1999 \\
\hline
\end{tabular}




\begin{tabular}{|c|l|l|c|c|}
\hline 49 & $\begin{array}{l}\text { Gregory J. Kelly; } \\
\text { Stephen Druker; } \\
\text { Catherine Chen }\end{array}$ & $\begin{array}{l}\text { Students' Reasoning about Electricity: Combining } \\
\text { Performance Assessments with Argumentation } \\
\text { Analysis. }\end{array}$ & $\begin{array}{c}\text { International } \\
\text { Journal of } \\
\text { Science } \\
\text { Education }\end{array}$ & 1998 \\
\hline 50 & Dana Zeidler & $\begin{array}{l}\text { The Central Role of Fallacious Thinking in Science } \\
\text { Education. }\end{array}$ & $\begin{array}{c}\text { Science } \\
\text { Education }\end{array}$ & 1997 \\
\hline 51 & Dana Zeidler & $\begin{array}{l}\text { Fallacies and Student Discourse: Conceptualizing } \\
\text { the Role of Critical Thinking in Science Education. }\end{array}$ & $\begin{array}{c}\text { Science } \\
\text { Education }\end{array}$ & 1992 \\
\hline
\end{tabular}


Esses 51 artigos foram os documentos que compuseram a amostra da presente pesquisa. Após a obtenção dos artigos, os dados foram analisados sob dois focos: análise dos perfis de pesquisa e análise do uso da obra de Toulmin (1958) como referencial teórico.

Procedimentos de coleta de dados para a análise dos perfis de pesquisa

O termo perfil foi definido como sendo as características do artigo científico que indicam seu foco de estudo. Para análise dos perfis de pesquisa, foram utilizados os seguintes descritores para coleta de dados: dos elementos textuais, pergunta de pesquisa, foco, objetivo - elemento textual; e dos elementos pré-textuais, objetivo - resumo. O quadro 9 (apêndice I) traz a relação completa de artigos e os dados obtidos a partir dos descritores citados.

Abaixo seguem os procedimentos para a seleção dos dados, utilizados na construção do quadro 9. Para tanto, foram realizadas análises preliminares que fundamentaram a definição das etapas de busca.

Para a coleta de dados do descritor objetivo - elemento textual, foram realizadas as seguintes etapas:

1. Procura do subitem da parte textual do artigo relativo ao objetivo;

2. Leitura do subitem à procura do objetivo;

3. Nas situações em que não foi possível identificar o objetivo com clareza a partir das etapas 1 e 2, utilizou-se a ferramenta de busca do software leitor de arquivos com extensão $p d f$, na procura dos seguintes termos: "aim", "goal”, "purpose”;

4. Transcrição do objetivo;

5. Nas situações em que não foi possível identificar o objetivo com clareza a partir das etapas 3 e 4, o campo relativo ao descritor objetivo - elemento textual do quadro 9 foi preenchido com a seguinte sentença "NÃO FOI POSSÍVEL LOCALIZAR O OBJETIVO EM UM FORMATO CLARO”

Para a coleta de dados do descritor pergunta de pesquisa, foram realizadas as seguintes etapas:

1. Procura do subitem da parte textual do artigo relativo ao objetivo; 
2. Leitura de 2 a 3 parágrafos que o antecedem e/ou o sucedem na procura da pergunta de pesquisa;

3. Nas situações em que não foi possível identificar a pergunta de pesquisa com clareza a partir das etapas 1 e 2, utilizou-se a ferramenta de busca do software leitor de arquivos com extensão $p d f$, na procura dos seguintes termos: "how", "what", "why", "whether"

4. Leitura das sentenças que rodeavam cada termo em busca da pergunta de pesquisa;

5. Transcrição da pergunta de pesquisa;

6. Nas situações em que não foi possível identificar a pergunta de pesquisa com clareza a partir das etapas 3 e 4, o campo relativo ao descritor pergunta de pesquisa foi preenchido com a seguinte sentença "NÃO FOI POSSÍVEL LOCALIZAR A PERGUNTA DE PESQUISA EM UM FORMATO CLARO”

Para a coleta de dados do descritor foco, foram realizadas as seguintes etapas:

1. Procura do subitem da parte textual do artigo relativo à pergunta de pesquisa;

2. Leitura do subitem em que se encontrou a pergunta de pesquisa à procura do foco;

3. Nas situações em que não foi possível identificar o foco de pesquisa com clareza a partir das etapas 1 e 2, procedeu-se à procura do subitem da parte textual do artigo relativo ao objetivo;

4. Leitura do subitem em que se encontrou o objetivo, à procura do foco;

5. Transcrição do foco de pesquisa $^{8}$;

7. Nas situações em que não foi possível identificar o foco de pergunta com clareza a partir das etapas 3 e 4, o campo relativo ao descritor foco foi preenchido com a seguinte sentença "NÃO FOI POSSÍVEL LOCALIZAR O FOCO DE PESQUISA EM UM FORMATO CLARO”

Para a coleta de dados do descritor objetivo - Parte pré-textual (Resumo), foram realizadas as seguintes etapas:

\footnotetext{
${ }^{8}$ Apesar de apresentar etapas de busca parecidas com as de busca do objetivo, o foco não se confunde com o objetivo, pois: 1. não é o período que sucede imediatamente os termos "aim", "goal" e "purpose"; e 2. não tem a mesma especificidade que o objetivo.
} 
1. Identificação das partes do resumo, a saber: referencial teórico elou justificativa; objetivo - Parte pré-textual (Resumo); método; resultados e discussão; e, conclusão;

2. Transcrição dos dados obtidos a partir do descritor objetivo - Parte pré-textual (Resumo);

3. Nas situações em que não foi possível identificar o objetivo de pesquisa a partir das etapas 1 e 2, o campo relativo ao descritor objetivo - Parte pré-textual (Resumo) foi preenchido com a seguinte sentença "NÃO FOI POSSÍVEL LOCALIZAR O OBJETIVO DE PESQUISA", no parágrafo que se inicia com "Para a coleta de dados do descritor objetivo" e termina com "[...]propósitos do artigo.

Durante a leitura dos resumos, foi possível verificar que alguns deles, ou apresentavam só o foco do artigo, ou não apresentavam o objetivo de forma clara. Por isso, foi necessário criar o descritor foco elou objetivo, ao invés de somente 'objetivo', para a coleta de dados sobre os propósitos do artigo.

Procedimentos de coleta de dados para a análise do uso da obra de Toulmin (1958) como referencial teórico

Nessa análise, foi utilizado o descritor trecho sobre o uso de Toulmin (1958) como referencial teórico, presente nos elementos textuais. O quadro 10 (apêndice II) traz a relação completa de artigos e os dados obtidos a partir desse descritor.

Para a coleta de dados do descritor trecho sobre o uso de Toulmin (1958) como referencial teórico, foram realizadas as seguintes etapas:

1. Utilizando a ferramenta de busca do software leitor de arquivos com extensão $p d f$, buscou-se o termo "Toulmin";

2. Verificação, no referencial bibliográfico, se se tratava da obra The uses of argument, do autor Stephen Toulmin, publicado pela editora Cambridge University Press em 1958;

3. Na situação em que a obra citada de Toulmin não correspondia à descrita na etapa 2 , ou em que não havia nenhuma citação do mesmo autor no artigo analisado, o campo relativo ao descritor trecho sobre o uso de Toulmin (1958) como referencial teórico do quadro 10 foi 
preenchido com a seguinte sentença "A OBRA DE TOULMIN NÃO FOI CITADA NO REFERENCIAL TEÓRICO OU METODOLÓGICO"

4. Na situação em que a obra citada de Toulmin correspondia à descrita na etapa 2 , foi feita a leitura, seguida de transcrição, do trecho que trazia informações sobre seu uso no referencial teórico do artigo analisado. ${ }^{9}$

\footnotetext{
${ }^{9}$ Não foram coletados dados referentes a trechos localizados nas partes de desenvolvimento e conclusão do artigo; e sim, naqueles localizados na introdução. Entende-se por introdução a parte do relatório científico que compreende a revisão bibliográfica, apresentação do problema de pesquisa e métodos utilizados.
} 


\section{RESULTADOS E DISCUSSÃO}

\subsection{Descrição das categorias de análise}

Baseado na classificação utilizada por Tsai e Wen (2005), os artigos foram classificados em três tipos: (1) artigo empírico, como a pesquisa quantitativa e qualitativa (ex.: artigo 21, em que 22 estudantes de quatro classes de Ciências na Noruega foram entrevistados sobre a construção de novos cabos elétricos e o possível aumento do risco de leucemia infantil); (2) artigo de posição, que sustenta uma posição específica sobre determinada questão do ensino das Ciências (ex.: artigo 44, que defende a inclusão e o papel central do argumento no ensino de Ciências); e, por último, (3) artigo de revisão, que resume literaturas da área sem propôr enfaticamente uma posição (ex.: artigo 29, que apresenta uma revisão crítica da pesquisa sobre o raciocício informal relativo a questões sociocientíficas). Essas categorias foram semelhantes às utilizadas por Smith et. al. (1998 apud TSAI e WEN, 2005) no levantamento da produção científica no campo da psicologia educacional.

A classificação dos artigos em foco no professor e foco no aluno resultou da análise dos dados, não sendo, portanto, uma categoria a priori. Ao contrário, ela surgiu no momento da organização dos dados, assim como as demais apresentadas abaixo. Consideraram-se artigos com foco no aluno aqueles cuja pergunta de pesquisa envolvia a avaliação e/ou compreensão de uma habilidade e/ou estratégia utilizada por um aluno e/ou grupo de alunos em uma situação de ensino-aprendizagem em Ciências (ex.: artigo 32, em que o objetivo foi estudar os componentes de conhecimento e habilidades necessárias para a tomada de decisão em contextos sociocientíficos, com alunos entre 16 e 17 anos de idade). Por sua vez, consideraram-se artigos com foco no professor, aqueles cuja pergunta de pesquisa envolvia a avaliação e/ou compreensão de uma habilidade e/ou estratégia utilizada por um professor e/ou grupo de professores em uma situação de ensino-aprendizagem em Ciências (ex.: artigo 20, em que se investigou o desenvolvimento das habilidades de ensino de argumentação ao longo de um curso de formação, com um grupo de 12 professores de Ciências de escolas de Londres). 
Além da classificação quanto ao tipo do artigo e quanto ao sujeito que foi o foco da análise, os artigos também foram classificados quanto ao seu perfil e ao uso da obra de Toulmin (1958) como referencial teórico.

No presente estudo, foi possível identificar três supraperfis da pesquisa em AEC (quadro 3) que agrupam nove perfis (quadro 4). Além disso, também foi possível identificar tipos de uso da obra de Toulmin (1958) como referencial teórico dos artigos (quadro 5), organizados em seis categorias. Portanto, esses dois focos de análise (perfis e supraperfis de pesquisa; e uso da obra de Toulmin (1958) como referencial teórico) foram utilizados neste estudo para identificar as tendências de pesquisa em AEC. Abaixo seguem as descrições de cada categoria, sob cada foco de análise.

Primeiramente foram descritos os supraperfis, para, em seguida, descrever os perfis. No entanto, a análise dos dados seguiu a ordem inversa. Após terem sido classificados em perfis, os artigos foram reunidos em grupos mais abrangentes (supraperfis), de acordo com suas características.

Sob o foco de análise por perfis e supraperfis, identificaram-se os supraperfis SP1, SP2 e SP3.

O supraperfil SP1 é composto por artigos que realizam estudos sobre a natureza da Ciência ou sobre o ensino de Ciências. Eles correspondem um grupo específico de estudos apontado nos trabalhos de von Aufschnaiter et. al. (2008) e Jiménez-Aleixandre e Erduran (2007). Von Aufschnaiter et. al. (2008), enfatizam a investigação sobre argumentação das comunidades científicas nesses estudos. Jiménez-Aleixandre e Erduram (2007) referem-se a esses trabalhos como estudos de Ciência, que ressaltaram a importância do discurso na construção do conhecimento científico e suas consequências para a educação.

O supraperfil SP2 contém estudos com foco na estrutura do argumento e/ou na construção da argumentação. Os artigos de SP2 correspondem a outro grupo de estudos, conforme apontado por von Aufschnaiter et. al. (2008). Para os autores, esse conjunto de pesquisas focalizou na argumentação dentro da sala de aula de Ciências, ao invés de focalizarem nas comunidades científicas. A pesquisa AEC emergiu de estudos com foco no discurso em sala de aula durante o ensino-aprendizagem de Ciências. Nesse contexto, a argumentação surgiu como meio de facilitar o discurso entre estudante-estudante e entre estudante-professor. Além disso, 
esses estudos conduziram ao desenvolvimento de modelos de análise do argumento, predominantemente baseados no trabalho de Toulmin (1958).

Por fim, o supraperfil SP3 possui estudos com foco no ensino e aprendizagem. Os artigos de SP3 correspondem ao período mais recente da pesquisa em AEC, conforme apontado por von Aufschnaiter et. al. (2008) e Jiménez-Aleixandre e Erduran et. al., (2007). Para von Aufschnaiter et. al. (2008), pesquisas atuais na área realizam a análise descritiva do conteúdo que os estudantes mobilizam durante a argumentação, ou utilizam um delineamento pré/pós-teste para analisar os avanços no conhecimento dos estudantes. O quadro apontado por Jiménez-Aleixandre e Erduran (2007) sobre pesquisas correntes na área, também dá destaque para estudos sobre aprendizagem.

\begin{tabular}{|l|l|}
\hline Supraperfil $1(\mathrm{SP} 1)$ & $\begin{array}{l}\text { Estudos sobre a natureza da Ciência ou sobre o ensino de Ciências (P1, } \\
\mathrm{P} 2, \mathrm{P} 3)\end{array}$ \\
\hline Supraperfil 2 (SP2) & $\begin{array}{l}\text { Estudos com foco na estrutura do argumento e/ou na construção da } \\
\text { argumentação (P4, P5, P7) }\end{array}$ \\
\hline Supraperfil 3 (SP3) & Estudos com foco no ensino e aprendizagem (P6, P8, P9) \\
\hline
\end{tabular}

Quadro 3. Descrição dos supraperfis e indicação dos perfis que os compõem.

Ainda sob o foco de análise por perfis e supraperfis, identificaram-se os perfis P1, P2,

\section{P3, P4, P5, P6, P7, P8 e P9.}

O perfil P1 contém artigos que procuram justificar a importância da argumentação para o ensino de Ciências. O único artigo contido neste perfil é o artigo 44 (Driver et. al., 2000).

O perfil P2 contém artigos que discutem as práticas discursivas da Ciência e suas implicações para o ensino de Ciências. $\mathrm{O}$ artigo 30 que exemplifica o foco de pesquisa dos artigos que compõem esse perfil. O propósito desse artigo é explicar a natureza da argumentação hipotético-preditiva, seu desenvolvimento e seu potencial uso nas aulas de Ciências.

O perfil P3 possui artigos que discutem teoricamente instrumentos metodológicos utilizados na pesquisa em argumentação no ensino de Ciências. O objetivo do artigo 7 ilustra bem esse perfil. Nele, os autores investigaram inúmeras estruturas analíticas que pesquisadores do ensino de Ciências vêm utilizando para avaliar a natureza e qualidade dos argumentos dos estudantes. 
O perfil P4 tem sua descrição parecida com a do perfil P3. Os artigos de P4 avaliam ou propõem instrumentos metodológicos utilizados na pesquisa em argumentação. Porém, são duas as diferenças entre perfil P3 e P4: neste, estão inseridos artigos empíricos e que realizam a avaliação ou proposição de instrumentos metodológicos; enquanto, naquele, estão inseridos artigos que realizam discussões e reflexões com caráter de revisão. $\mathrm{O}$ artigo 27 de $\mathrm{P} 4$ pode ser tomado como modelo desse perfil. Seu foco principal foi no desenvolvimento e uso do TAP (Toumin's Argument Pattern) como uma ferramenta para traçar a quantidade e a qualidade da argumentação no discurso científico.

O perfil P5 é composto por artigos que analisam a argumentação e/ou o argumento dos alunos em estratégias de ensino baseadas em temas sociocientíficos e/ou científicos. O foco dos artigos desse perfil é exemplificado no objetivo do artigo 6, em que os autores relatam que o propósito da pesquisa foi documentar os padrões de argumentação dos estudantes, em pequenos grupos de discussão, sobre uma questão sociocientífica controversa.

O perfil P6 constitui-se de artigos que analisam o processo de aprendizado dos conteúdos conceituais de Ciências dos alunos nas aulas de Ciências em estratégias de ensino baseadas em temas sociocientíficos e/ou científicos. Esse perfil se diferencia de P5 por investigar o aprendizado, e não a argumentação e/ou argumento. $\mathrm{O}$ artigo 2 serve de modelo daqueles que estão inseridos em P6. Um dos interesses dessa pesquisa foi estudar como estudantes incorporam seus conhecimentos do conteúdo específico em lições baseadas na argumentação. Além disso, essa pesquisa investigou como estudantes desenvolvem e melhoram sua compreensão da Ciência nessas lições e como a quantidade e qualidade dos argumentos dos estudantes são influenciados por seu conhecimento dos conteúdos específicos.

O perfil P7 contém artigos que avaliam a eficácia de uma estratégia de ensino na promoção ou não da argumentação dos alunos nas aulas de Ciências. Esse perfil não se confunde com P6, pois avalia a eficácia de estratégias quanto à argumentação dos estudantes, e não quanto ao seu aprendizado. $\mathrm{O}$ artigo 26 exemplifica o foco de pesquisa dos artigos que compõem o perfil P7. Nesses artigos os autores procuraram identificar algumas estratégias pedagógicas necessárias para promover habilidades relacionadas à argumentação de jovens em lições de Ciências. Os autores também buscaram determinar em que medida as lições que seguiam essas estratégias pedagógicas levavam a melhorias na qualidade dos argumentos dos estudantes. 
O perfil $\mathbf{P 8}$ possui artigos que investigam o desenvolvimento de habilidades argumentativas de professores de Ciências. Diferente dos perfis P5, P6, e P7, o P8 e o perfil P9, focalizam sua pesquisa no professor, e não no aluno. $\mathrm{O}$ objetivo do artigo 4 ilustra bem o perfil P8. Nele, os autores investigaram a eficácia do uso de portfólios por professores, a fim de demonstrar o desenvolvimento de habilidades no ensino de argumentação, e sua análise reflexiva sobre a prática.

Por fim, no perfil P9, estão artigos que avaliaram o uso da argumentação para ensinar conteúdos específicos a professores de Ciências. O foco dos artigos desse perfil é exemplificado no objetivo do artigo 15 , em que os autores relatam, como propósito da pesquisa, determinar os efeitos do PAC (Pratical Argumentation Course) na percepção dos professores sobre a natureza da Ciência e sobre um assunto específico (grupos indígenas no currículo sul-africano para o ensino de Ciências).

\begin{tabular}{|l|l|}
\hline Perfil 1 (P1) & Justificativa da importância da argumentação para o ensino de Ciências \\
\hline Perfil 2 (P2) & Discussões de práticas discursivas da Ciência e suas implicações para o ensino de Ciências \\
\hline Perfil 3 (P3) & $\begin{array}{l}\text { Discussão teórica sobre instrumentos metodológicos utilizados na pesquisa em } \\
\text { argumentação no ensino de Ciências }\end{array}$ \\
\hline Perfil 4 (P4) & $\begin{array}{l}\text { Avaliação e/ou proposição de instrumentos metodológicos utilizados na pesquisa em } \\
\text { argumentação no ensino de Ciências }\end{array}$ \\
\hline Perfil 5 (P5) & $\begin{array}{l}\text { Análise da argumentação e/ou do argumento dos alunos em estratégias de ensino baseadas } \\
\text { em temas sociocientíficos e/ou científicos }\end{array}$ \\
\hline Perfil 6 (P6) & $\begin{array}{l}\text { Análise do processo de aprendizado dos conteúdos conceituais de Ciências dos alunos nas } \\
\text { aulas de Ciências em estratégias de ensino baseadas em temas sociocientíficos e/ou } \\
\text { científicos. }\end{array}$ \\
\hline Perfil 7 (P7) & $\begin{array}{l}\text { Avaliação da eficácia de uma estratégia de ensino na promoção ou não da argumentação dos } \\
\text { alunos nas aulas de Ciências }\end{array}$ \\
\hline Perfil 8 (P8) & $\begin{array}{l}\text { Desenvolvimento de habilidades para o ensino de argumentação em Ciências e/ou avaliação } \\
\text { das condições para esse ensino }\end{array}$ \\
\hline Perfil 9 (P9) & \begin{tabular}{l} 
Uso da argumentação para ensinar conteúdos específicos a professores de Ciências \\
\hline Quadro 4.Desciço
\end{tabular} \\
\hline
\end{tabular}

Quadro 4. Descrição dos perfis

Finalmente, sob o foco de análise por tipo de uso da obra de Toulmin (1958) como referencial teórico, identificaram-se seis tipos, organizados nas categorias T1, T2, T3, T4, T5 e T6. 
A categoria T1 contém artigos que utilizaram os conceitos de argumento e argumentação de Toulmin, para defini-los ou justificar sua centralidade no ensino de Ciências. $\mathrm{O}$ artigo 3 exemplifica o foco de pesquisa dos artigos que compõem essa categoria. O propósito desse artigo é revisar uma gama de concepções teóricas de argumentação e discutir possíveis implicações no ensino de Ciências. Uma das concepções tanto de argumento, quanto de argumentação considerada no estudo é a da obra de Toulmin (1958).

A categoria T2 contém artigos que fazem uso não restrito do TAP como ferramenta de análise do argumento. O TAP, Toulmin's Argument Pattern, da tradução literal Padrão de Argumento de Toulmin, foi, e ainda é, utilizado por pesquisadores em ensino de Ciências para analisar o argumento produzido por alunos, principalmente. Os artigos da categoria T2 utilizam esse padrão sem nenhuma, ou com poucas, ressalvas, no que se refere à sua adequação para analisar os argumentos elaborados nos respectivos contextos de pesquisa. O foco dos artigos dessa categoria é exemplificado pelo artigo 11, em que foram analisadas transcrições de lições utilizando TAP. Os autores desse estudo justificam a escolha desse padrão, pois afirmam que ele é comumente aceito por outros pesquisadores da área como uma ferramenta conclusiva de análise do argumento. Nesse caso, como em todos os outros artigos inseridos na categoria T2, os autores utilizaram o TAP para analisar seus dados, sem realizarem modificações no modelo para adequação ao contexto ou objetivo de pesquisa. Por isso que, na descrição dessa categoria, consta 'uso não restrito do TAP'.

Ao contrário da categoria T2, a categoria T3 contém artigos que fazem uso restrito do TAP como ferramenta de análise do argumento. Um trecho da metodologia do artigo 1 ajuda na compreensão da categoria T3. Nele, os autores citam o valor que a obra de Toulmin tem na análise do argumento, mas ressaltam que, a partir dessa ferramenta, seria esperado identificar mais afirmações do que justificativas e garantias, em grande parte dos argumentos analisados. No intuito de utilizar uma ferramenta de análise que mais atendesse seus objetivos de pesquisa, os autores adotaram um esquema de avaliação elaborado por Erduran et. al. (2004), no qual o sistema de classificação das habilidades argumentativas proposto por Toulmin foi estendido, para, não só conseguir avaliar a qualidade e quantidade da argumentação dos estudantes nas aulas de Ciências, mas também para analisar a argumentação de toda a instrução pedagógica (lição) ao invés de fazê-lo somente em trechos isolados do discurso em sala de aula. 
A categoria T4 é composta por artigos que avaliam o TAP como ferramenta de análise do discurso. $\mathrm{O}$ objetivo do artigo 27 ilustra bem esse perfil. Nele, os autores avaliam em que medida o TAP é aplicável na análise de dados do discurso em sala de aula.

A categoria T5 constitui-se de artigos que criticam o TAP ou fazem uso de outro modelo de análise do argumento. Os artigos 14 e 9 exemplificam o foco de pesquisa dos artigos que compõem a categoria T5. No primeiro, os autores destacam a forma acrítica que o modelo de Toulmin tem sido aplicado em vários campos, criticando muitos pesquisadores que o veem (nas palavras de Toulmin) como campo independente ou universalmente aplicáveis a todas as formas de argumento. No segundo artigo, seus autores relatam que, apesar do modelo de Toulmin ser aplicado por muitos pesquisadores no ensino de Ciências para analisar argumentos que ocorrem no discurso em grupos de alunos ou na sala de aula, foi adotado um modelo alternativo para superar problemas particulares encontrados no TAP.

Por fim, a categoria T6 reuniu artigos que não utilizaram Toulmin (1958) como referência bibliográfica. Dito de outra forma, a obra de Toulmin de 1958 não consta na lista de referências bibliográficas dos artigos de T6.

\begin{tabular}{|l|l|}
\hline Categoria T1 & $\begin{array}{l}\text { Uso dos conceitos de argumento e argumentação de Toulmin no artigo, para } \\
\text { defini-los ou justificar sua centralidade no ensino de Ciências }\end{array}$ \\
\hline Categoria T2 & Uso não restrito do TAP* como ferramenta de análise do argumento \\
\hline Categoria T3 & Uso restrito do TAP como ferramenta de análise do argumento \\
\hline Categoria T4 & Avaliação do TAP como ferramenta de análise do argumento \\
\hline Categoria T5 & Crítica ao TAP ou uso de outro modelo de análise do argumento \\
\hline Categoria T6 & Não uso do modelo \\
\hline \\
Quadro 5. Descrição das categorias do tipo de uso da obra de Toulmin (1958) como referencial teórico \\
Toulmin's Argument Pattern, da tradução Padrão de Argumento de Toulmin, presente em Toulmin (2001).
\end{tabular}

5.2 Análise dos perfis e supraperfis de pesquisa

Análise dos perfis 
O quadro 6 apresenta um esquema da classificação dos perfis, constando o número de artigos em cada perfil e seus respectivos anos de publicação. 


\begin{tabular}{|c|c|c|c|c|}
\hline \multicolumn{3}{|c|}{ Classificação dos artigos segundo categorização por perfis } & IDE & APU \\
\hline \multirow{6}{*}{$\begin{array}{l}\text { Artigos de } \\
\text { revisão e de } \\
\text { posição } \\
\text { [6] }\end{array}$} & $\begin{array}{l}\text { (P1) Justificativa da importância da } \\
\text { argumentação para o ensino de Ciências [1] }\end{array}$ & & 44 & 2000 \\
\hline & \multirow{3}{*}{$\begin{array}{l}\text { (P2) Discussões de práticas discursivas da } \\
\text { Ciência e suas implicações para o ensino de } \\
\text { Ciências [3] }\end{array}$} & & 3 & 2008 \\
\hline & & & 30 & 2003 \\
\hline & & & 51 & 1992 \\
\hline & \multirow{2}{*}{$\begin{array}{l}\text { (P3) Discussão teórica sobre instrumentos } \\
\text { metodológicos utilizados na pesquisa em } \\
\text { argumentação no ensino de Ciências [2] }\end{array}$} & & 7 & 2008 \\
\hline & & & 29 & 2004 \\
\hline \multirow{45}{*}{$\begin{array}{l}\text { Artigos } \\
\text { Empíricos } \\
\text { [45] }\end{array}$} & \multirow{40}{*}{$\begin{array}{c}\text { Foco nos alunos } \\
{[\mathbf{4 0}]}\end{array}$} & \multirow{5}{*}{$\begin{array}{l}\text { (P4) Avaliação e/ou proposição de } \\
\text { instrumentos metodológicos utilizados na } \\
\text { pesquisa em argumentação no ensino de } \\
\text { Ciências [5] }\end{array}$} & 9 & 2008 \\
\hline & & & 10 & 2008 \\
\hline & & & 27 & 2004 \\
\hline & & & 39 & 2001 \\
\hline & & & 49 & 1998 \\
\hline & & \multirow{17}{*}{$\begin{array}{l}\text { (P5) Análise da argumentação e/ou do } \\
\text { argumento dos alunos em estratégias de } \\
\text { ensino baseadas em temas sociocientíficos } \\
\text { e/ou científicos [17] }\end{array}$} & 6 & 2008 \\
\hline & & & 11 & 2007 \\
\hline & & & 17 & 2007 \\
\hline & & & 18 & 2007 \\
\hline & & & 19 & 2006 \\
\hline & & & 21 & 2006 \\
\hline & & & 22 & 2006 \\
\hline & & & 23 & 2006 \\
\hline & & & 24 & 2006 \\
\hline & & & 25 & 2006 \\
\hline & & & 34 & 2004 \\
\hline & & & 32 & 2002 \\
\hline & & & 36 & 2002 \\
\hline & & & 40 & 2001 \\
\hline & & & 41 & 2001 \\
\hline & & & 43 & 2000 \\
\hline & & & 47 & 1999 \\
\hline & & \multirow{7}{*}{$\begin{array}{l}\text { (P6) Análise do processo de aprendizado } \\
\text { dos conteúdos conceituais de Ciências dos } \\
\text { alunos nas aulas de Ciências em estratégias } \\
\text { de ensino baseadas em temas } \\
\text { sociocientíficos e/ou científicos. [7] }\end{array}$} & 2 & 2008 \\
\hline & & & 5 & 2008 \\
\hline & & & 8 & 2008 \\
\hline & & & 31 & 2002 \\
\hline & & & 35 & 2002 \\
\hline & & & 45 & 2000 \\
\hline & & & 50 & 1997 \\
\hline & & \multirow{11}{*}{$\begin{array}{l}\text { (P7) Avaliação da eficácia de uma } \\
\text { estratégia de ensino na promoção ou não da } \\
\text { argumentação dos alunos nas aulas de } \\
\text { Ciências [11] }\end{array}$} & 1 & 2008 \\
\hline & & & 12 & 2007 \\
\hline & & & 13 & 2007 \\
\hline & & & 16 & 2007 \\
\hline & & & 26 & 2004 \\
\hline & & & 28 & 2004 \\
\hline & & & 33 & 2002 \\
\hline & & & 37 & 2001 \\
\hline & & & 38 & 2001 \\
\hline & & & 42 & 2000 \\
\hline & & & 48 & 1999 \\
\hline & \multirow[t]{5}{*}{ Foco nos professores [5] } & \multirow{3}{*}{$\begin{array}{l}\text { (P8) Desenvolvimento de habilidades para } \\
\text { o ensino de argumentaçã̃o em Ciências e/ou } \\
\text { avaliação das condições para esse ensino } \\
\text { [3] }\end{array}$} & 4 & 2008 \\
\hline & & & 20 & 2006 \\
\hline & & & 46 & 1999 \\
\hline & & \multirow{2}{*}{$\begin{array}{l}\text { (P9) Uso da argumentação para ensinar } \\
\text { conteúdos específicos a professores de } \\
\text { Ciências [2] }\end{array}$} & 14 & 2007 \\
\hline & & & 15 & 2007 \\
\hline
\end{tabular}

Quadro 6. Perfis da pesquisa em argumentação no ensino de Ciências, onde $P=P e r f i l$, IDE= Número de identificação do artigo, $\mathrm{APU}=\mathrm{Ano}$ de publicação do artigo 
A figura 1 traz as porcentagens de números de artigos por perfil. O perfil P5 possui o maior número de artigos, 32\%, seguido do perfil $\mathrm{P} 7$ com $22 \%$. A porcentagem de artigos nos perfis P6, P4, P2, P8, P9 e P3 foram de 14\%, 10\%, 6\%, 6\%, 4\% e 4\%, respectivamente. O perfil que apresentou menos artigos foi P1, com $2 \%$.

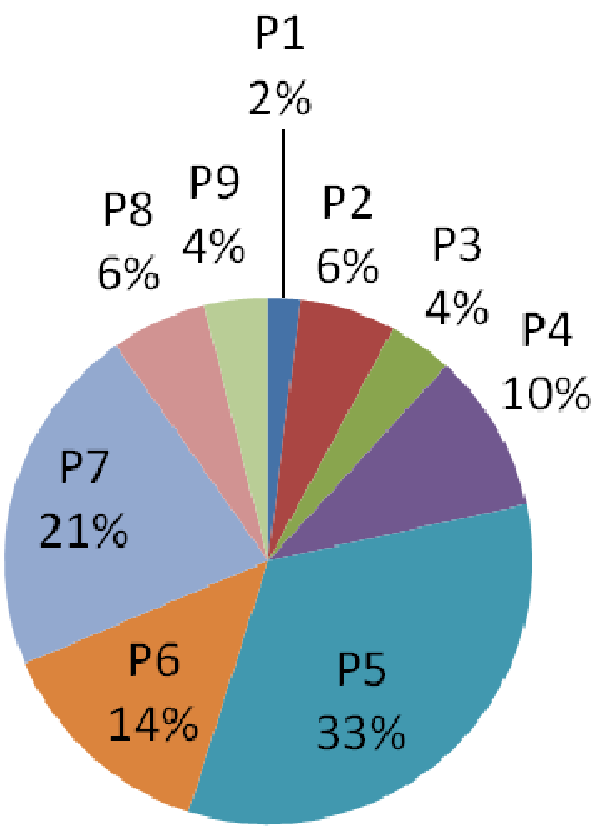

Figura 1. Porcentagem de publicações entre 1988 a 2008 por perfil

Os perfis de pesquisa P5 (análise da argumentação e/ou do argumento dos alunos em estratégias de ensino baseadas em temas sóciocientíficos e/ou científicos) e P7 (avaliação da eficácia de uma estratégia de ensino na promoção ou não da argumentação dos alunos nas aulas de Ciências) predominaram na pesquisa em AEC no período analisado.

Esses perfis de pesquisa vão ao encontro do que von Aufschnaiter et. al. (2008) descrevem como tentativas de elaborar um esquema para avaliar a qualidade da argumentação. Os autores ainda lembram que a maioria desses estudos baseou-se no layout do argumento desenvolvido por Toulmin (1958). O artigo 27, incluso em P5, é um desses estudos. Nele, o foco de análise foi a natureza da argumentação e sua avaliação, ao invés da análise do conteúdo do próprio argumento. Os autores desse estudo publicaram, no mesmo ano (2004), outro artigo, 26 (incluso em P7), divulgando resultados da pesquisa cujo objetivo foi avaliar o progresso nas habilidades argumentativas dos estudantes analisados. Nesse artigo, também fica evidenciado o 
foco na avaliação da argumentação dos sujeitos, e não de seu conteúdo. Portanto, verificou-se que pesquisas com perfil de análise do argumento ou da argumentação predominaram em comparação a outros perfis no período de 1988-2008.

O perfil P6 (análise do processo de aprendizado dos conteúdos conceituais de Ciências dos alunos nas aulas de Ciências em estratégias de ensino baseadas em temas sociocientíficos e/ou científicos) ficou em terceiro lugar, em relação às demais linhas de pesquisa na área.

Ao contrário dos artigos dos perfis P5 e P7, aqueles de P6 focalizam na análise do aprendizado em detrimento da análise do argumento ou da argumentação. Yore et. al. (2003) afirmam que a pesquisa em EC, nas últimas décadas, vem reconhecendo o valor do uso da discussão e argumentação para auxiliar os estudantes a construir conhecimentos da Ciência, porém pouco tem se discutido sobre suas implicações em sala de aula. Von Aufschnaiter et. al. (2008) reafirmam essa lacuna de pesquisa com foco na aprendizagem. Os autores, ao levantarem o histórico de produção científica em AEC, lembram que uma minoria de trabalhos debruçou-se sobre a aprendizagem. Os dados da presente pesquisa contrastam com esse quadro, na medida em que apresentam o foco de pesquisa acima citado em terceiro lugar em comparação aos nove perfis analisados, compondo $14 \%$ dos artigos da amostra, perdendo em quantidade somente para aqueles com foco no argumento ou na argumentação.

O perfil P4 (avaliação e/ou proposição de instrumentos metodológicos utilizados na pesquisa em argumentação no ensino de Ciências) correspondeu a 10\% de todos os artigos analisados. Os artigos inseridos nesse perfil estão intimamente ligados ao perfil P5, já que retroalimenta sua produção. Logo, parece natural que a pesquisa relacionada ao perfil P4 seja alvo de maior interesse (10 \%) do que as demais linhas (P8, P9 e P3 e P1, com 6\%, 4\%, 4\% e 1\%, respectivamente), estas, não diretamente relacionadas aos perfis que predominam na área (P5, P7 e P6).

Os artigos inseridos no perfil P2 (discussões de práticas discursivas da Ciência e suas implicações para o ensino de Ciências), por sua vez, fazem parte da pesquisa em AEC que Jiménez-Aleixandre e Erduran (2007) denominam como estudos da Ciência. Esses estudos destacam a importância do discurso na construção do conhecimento científico e suas consequências para a educação. Os dados da presente pesquisa convergem com aqueles de Yore et. al. (2003), em que os autores constatam ser limitada a pesquisa em LEC sobre como a natureza da Ciência influencia as características e o conteúdo do discurso oral e escrito na 
Ciência e como esses processos podem ser aplicados nas aulas de Ciências. A tendência na pesquisa em LEC citada pelos autores reflete na pesquisa em AEC, na medida em que o número de artigos de P2 (3) é duas vezes menor do que a média do número total de artigos por perfil (6).

Os perfis P8 (desenvolvimento de habilidades para o ensino de argumentação em Ciências e/ou avaliação das condições para esse ensino), P9 (uso da argumentação para ensinar conteúdos específicos a professores de Ciências) e P3 (discussão teórica sobre instrumentos metodológicos utilizados na pesquisa em argumentação no ensino de Ciências) estão numericamente em penúltimo lugar na pesquisa em AEC. Os perfis P8, P9 e P3, junto com P1 e P2, possuem poucos artigos se comparados aos demais perfis. Sobre P8 e P9, sugere-se que a baixa porcentagem de artigos reflete o caráter recente dos respectivos temas de investigação, ambos com foco no professor, ao invés de ter o foco no aluno. As revisões de literatura na área não dão conta de estudos com foco em professores, como é o caso de P8 e P9.

Dessa forma, sugere-se que a maioria dos artigos nessas linhas de pesquisa seja recente na área, e, por isso, esses artigos ainda não tenham sido considerados nas referências utilizadas (von AUFSCHNAITER et. al. 2008; JIMÉNEZ-ALEIXANDRE e ERDURAN, 2007). Dados sobre o padrão de distribuição dos artigos nesses dois perfis - discussão feita mais adiante neste trabalho permitem inferir acerca das tendências de pesquisa na área com foco nos professores. Quanto aos artigos de P3, sugere-se outro tipo de discussão. Esses, junto com os pertencentes a P2 e a P1, compõem estudos de revisão e de posição. Sugere-se, dessa forma, que estudos desse tipo são minoria em comparação aos empíricos.

O número de artigos do perfil P1 (justificativa da importância da argumentação para o ensino de Ciências) endossa essa afirmação. Esse perfil foi o que menos recebeu atenção da comunidade científica. Trata-se de um perfil com somente um artigo (44). Contudo, os dados da presente pesquisa apresentados até o momento não permitem avaliar seu impacto na pesquisa em AEC.

Os resultados na tabela 1 mostram um aumento da produção científica em AEC, iniciado ao final da década de 1990. Para fins de análise, serão considerados dois períodos nas discussões que se seguem: o primeiro sendo entre 1998-1999; e o segundo, 2000-2008. Foram considerados os período de 1988 a 1999 e 2000 a 2008, ao invés de 1988 a 1998 e 1999 a 2008, pois, para a presente pesquisa, considera-se o ano de 2000 como ponto chave na pesquisa em AEC. Por esse 
motivo, os períodos não tiveram o mesmo número de anos. Assim, de um total de 21 anos, o primeiro período possui 12 anos, e o segundo 9. 
Tabela 1. Número de publicações por perfil no período de 1988- 2008

\begin{tabular}{|c|c|c|c|c|c|c|c|c|}
\hline \multirow{2}{*}{ Perfil } & $1998-2008(n=51)$ & $1988(\mathrm{n}=0)$ & $1989(\mathrm{n}=0)$ & $1990(n=0)$ & $1991(\mathrm{n}=0)$ & $1992(n=1)$ & $1993(n=0)$ & $1994(\mathrm{n}=0)$ \\
\hline & Num. art (\%) & Num. $\operatorname{art}(\%)$ & Num. $\operatorname{art}(\%)$ & Num. $\operatorname{art}(\%)$ & Num. $\operatorname{art}(\%)$ & Num. $\operatorname{art}(\%)$ & Num. $\operatorname{art}(\%)$ & Num. $\operatorname{art}(\%)$ \\
\hline 1 & $1(2,0 \%)$ & $0(0,0 \%)$ & $0(0,0 \%)$ & $0(0,0 \%)$ & $0(0,0 \%)$ & $0(0,0 \%)$ & $0(0,0 \%)$ & $0(0,0 \%)$ \\
\hline 2 & $3(5,9 \%)$ & $0(0,0 \%)$ & $0(0,0 \%)$ & $0(0,0 \%)$ & $0(0,0 \%)$ & $1(100,0 \%)$ & $0(0,0 \%)$ & $0(0,0 \%)$ \\
\hline 3 & $2(3,9 \%)$ & $0(0,0 \%)$ & $0(0,0 \%)$ & $0(0,0 \%)$ & $0(0,0 \%)$ & $0(0,0 \%)$ & $0(0,0 \%)$ & $0(0,0 \%)$ \\
\hline 4 & $5(9,8 \%)$ & $0(0,0 \%)$ & $0(0,0 \%)$ & $0(0,0 \%)$ & $0(0,0 \%)$ & $0(0,0 \%)$ & $0(0,0 \%)$ & $0(0,0 \%)$ \\
\hline 5 & $17(33,3 \%)$ & $0(0,0 \%)$ & $0(0,0 \%)$ & $0(0,0 \%)$ & $0(0,0 \%)$ & $0(0,0 \%)$ & $0(0,0 \%)$ & $0(0,0 \%)$ \\
\hline 6 & $7(13,7 \%)$ & $0(0,0 \%)$ & $0(0,0 \%)$ & $0(0,0 \%)$ & $0(0,0 \%)$ & $0(0,0 \%)$ & $0(0,0 \%)$ & $0(0,0 \%)$ \\
\hline 7 & $11(21,6 \%)$ & $0(0,0 \%)$ & $0(0,0 \%)$ & $0(0,0 \%)$ & $0(0,0 \%)$ & $0(0,0 \%)$ & $0(0,0 \%)$ & $0(0,0 \%)$ \\
\hline 8 & $3(5,9 \%)$ & $0(0,0 \%)$ & $0(0,0 \%)$ & $0(0,0 \%)$ & $0(0,0 \%)$ & $0(0,0 \%)$ & $0(0,0 \%)$ & $0(0,0 \%)$ \\
\hline 9 & $2(3,9 \%)$ & $0(0,0 \%)$ & $0(0,0 \%)$ & $0(0,0 \%)$ & $0(0,0 \%)$ & $0(0,0 \%)$ & $0(0,0 \%)$ & $0(0,0 \%)$ \\
\hline \multirow{2}{*}{ Perfil } & $1995(\mathrm{n}=0)$ & $1996(\mathrm{n}=0)$ & $1997(n=1)$ & $1998(n=1)$ & $1999(n=3)$ & $2000(n=4)$ & $2001(\mathrm{n}=5)$ & $2002(\mathrm{n}=5)$ \\
\hline & Num. art (\%) & Num. art (\%) & Num. art (\%) & Num. art (\%) & Num. art (\%) & Num. art (\%) & Num. art (\%) & Num. art (\%) \\
\hline 1 & $0(0,0 \%)$ & $0(0,0 \%)$ & $0(0,0 \%)$ & $0(0,0 \%)$ & $0(0,0 \%)$ & $1(25,0 \%)$ & $0(0,0 \%)$ & $0(0,0 \%)$ \\
\hline 2 & $0(0,0 \%)$ & $0(0,0 \%)$ & $0(0,0 \%)$ & $0(0,0 \%)$ & $0(0,0 \%)$ & $0(0,0 \%)$ & $0(0,0 \%)$ & $0(0,0 \%)$ \\
\hline 3 & $0(0,0 \%)$ & $0(0,0 \%)$ & $0(0,0 \%)$ & $0(0,0 \%)$ & $0(0,0 \%)$ & $0(0,0 \%)$ & $0(0,0 \%)$ & $0(0,0 \%)$ \\
\hline 4 & $0(0,0 \%)$ & $0(0,0 \%)$ & $0(0,0 \%)$ & $1(100,0 \%)$ & $0(0,0 \%)$ & $0(0,0 \%)$ & $1(20,0 \%)$ & $0(0,0 \%)$ \\
\hline 5 & $0(0,0 \%)$ & $0(0,0 \%)$ & $0(0,0 \%)$ & $0(0,0 \%)$ & $1(33,3 \%)$ & $1(25,0 \%)$ & $2(40,0 \%)$ & $2(40,0 \%)$ \\
\hline 6 & $0(0,0 \%)$ & $0(0,0 \%)$ & $1(100,0 \%)$ & $0(0,0 \%)$ & $0(0,0 \%)$ & $1(25,0 \%)$ & $0(0,0 \%)$ & $2(40,0 \%)$ \\
\hline 7 & $0(0,0 \%)$ & $0(0,0 \%)$ & $0(0,0 \%)$ & $0(0,0 \%)$ & $1(33,3 \%)$ & $1(25,0 \%)$ & $2(40,0 \%)$ & $1(20,0 \%)$ \\
\hline 8 & $0(0,0 \%)$ & $0(0,0 \%)$ & $0(0,0 \%)$ & $0(0,0 \%)$ & $1(33,3 \%)$ & $0(0,0 \%)$ & $0(0,0 \%)$ & $0(0,0 \%)$ \\
\hline 9 & $0(0,0 \%)$ & $0(0,0 \%)$ & $0(0,0 \%)$ & $0(0,0 \%)$ & $0(0,0 \%)$ & $0(0,0 \%)$ & $0(0,0 \%)$ & $0(0,0 \%)$ \\
\hline \multirow{2}{*}{ Perfil } & $2003(n=1)$ & $2004(n=5)$ & $2005(n=0)$ & $2006(n=7)$ & $2007(\mathrm{n}=8)$ & $2008(\mathrm{n}=10)$ & & \\
\hline & Num. art (\%) & Num. $\operatorname{art}(\%)$ & Num. art (\%) & Num. $\operatorname{art}(\%)$ & Num. $\operatorname{art}(\%)$ & Num. $\operatorname{art}(\%)$ & & \\
\hline 1 & $0(0,0 \%)$ & $0(0,0 \%)$ & $0(0,0 \%)$ & $0(0,0 \%)$ & $0(0,0 \%)$ & $0(0,0 \%)$ & & \\
\hline 2 & $1(100,0 \%)$ & $0(0,0 \%)$ & $0(0,0 \%)$ & $0(0,0 \%)$ & $0(0,0 \%)$ & $1(10,0 \%)$ & & \\
\hline 3 & $0(0,0 \%)$ & $1(20,0 \%)$ & $0(0,0 \%)$ & $0(0,0 \%)$ & $0(0,0 \%)$ & $1(10,0 \%)$ & & \\
\hline 4 & $0(0,0 \%)$ & $1(20,0 \%)$ & $0(0,0 \%)$ & $0(0,0 \%)$ & $0(0,0 \%)$ & $2(20,0 \%)$ & & \\
\hline 5 & $0(0,0 \%)$ & $1(20,0 \%)$ & $0(0,0 \%)$ & $6(0,0 \%)$ & $3(37,5 \%)$ & $1(10,0 \%)$ & & \\
\hline 6 & $0(0,0 \%)$ & $0(0,0 \%)$ & $0(0,0 \%)$ & $0(0,0 \%)$ & $0(0,0 \%)$ & $3(30,0 \%)$ & & \\
\hline 7 & $0(0,0 \%)$ & $2(40,0 \%)$ & $0(0,0 \%)$ & $0(0,0 \%)$ & $3(37,5 \%)$ & $1(10,0 \%)$ & & \\
\hline 8 & $0(0,0 \%)$ & $0(0,0 \%)$ & $0(0,0 \%)$ & $1(0,0 \%)$ & $0(0,0 \%)$ & $1(10,0 \%)$ & & \\
\hline 9 & $0(0,0 \%)$ & $0(0,0 \%)$ & $0(0,0 \%)$ & $0(0,0 \%)$ & $2(25,0 \%)$ & $0(0,0 \%)$ & & \\
\hline
\end{tabular}


No início da década de 2000, observou-se um período de crescente aumento do número de publicações até o ano de 2008. Ao longo desse período, no entanto, puderam-se observar quedas significativas das publicações nos anos de 2003 e 2005. Essas quedas contrastam parcialmente com os resultados de pesquisa de Lee et. al. (2009). Os autores desse estudo selecionaram 869 artigos de ensino de Ciências publicados entre 2003-2007, dos três principais periódicos da área (Journal of Research in Science Teaching, Science Education e International Journal of Science Education), analisando-os segundo a nacionalidade dos autores, o tipo de pesquisa, o tema de pesquisa e a frequência de citações por outros pesquisadores. Nesse universo, verificou-se que em 2003 e 2006 houve menor número de publicações na área.

Os dados da presente pesquisa convergem com os resultados de Lee et. al. (2009) no que se refere a 2003, porém divergem quanto a 2006. Como pode ser observado na tabela 1 , houve menor número de artigos no ano de 2003 e 2005, e não em 2003 e 2006. Esses resultados sugerem que, pelo menos em 2006, a pesquisa em AEC não acompanhou numericamente a pesquisa $\mathrm{EC}$, na medida em que não houve correspondência na diminuição do número de publicações em ambas as áreas.

Seguindo a ordem da porcentagem de artigos por perfil (figura 1), da maior para a menor, abaixo serão discutidas as tendências observadas em cada um dos nove perfis, ao longo dos 21 anos considerados nesta pesquisa (1998-2008).

Os artigos do perfil P5 (análise da argumentação e/ou do argumento dos alunos em estratégias de ensino baseadas em temas sociocientíficos e/ou científicos) estão dispostos num intervalo de 10 anos (1999 a 2008), ou seja, em um significativo intervalo de tempo, considerados os 21 anos analisados na presente pesquisa. Esse fato contrasta com a tendência apresentada por von Aufschnaiter et. al. (2008) e Jiménez-Aleixandre e Erduran (2007). Os autores classificam como inicias na pesquisa em AEC, aqueles trabalhos que fazem análise de discurso durante o ensino e a aprendizagem de Ciências apontando para a importância e o papel da AEC.

Sugere-se que o fato dos artigos de P5 estarem dispostos em um grande intervalo do período estudado, e não só no período inicial da pesquisa, é devido à diversificação dos tipos de análise do argumento ao longo do tempo. A diversificação dos artigos nesse perfil é tal, que foi possível identificar três tipos de pesquisa no interior de P5: 1. análise da argumentação e/ou do argumento dos alunos em estratégias de ensino baseadas em temas sociocientíficos (artigos 11, 
22, 24, 36 e 43); 2. análise da argumentação e/ou do argumento dos alunos em estratégias de ensino baseadas em temas científicos (artigos 6, 17, 34, 41 e 47); e 3. influência do conteúdo específico das Ciências Naturais e/ou do conteúdo relativo à moral na elaboração de argumentos pelos alunos $(18,21,23,25,19,35$ e 40$)$.

O número total de artigos em P5 e sua diversidade dentro do perfil apoiam a ideia de que, na pesquisa em AEC, predominam artigos cujo foco é na avaliação do argumento dos alunos e sugerem o perfil P5 como foco consagrado na área.

O número de publicações nos tipos 1, 2 e 3, respectivamente, 5, 5 e 7, sugere que estudos do terceiro tipo foram relativamente mais explorados ao longo do período analisado em comparação com os demais. No entanto, não foi possível identificar qualquer concentração de publicações nos três tipos de pesquisa, em determinado período. Isso pode ser constatado observando o período em que foram publicados artigos de cada tipo. Artigos do tipo 3 possuem artigos no período de 2001-2007, enquanto os do tipo 1 e 2 possuem no período de 1999-2008 e 2000-2007, respectivamente. Esses dados sugerem que, dentro do perfil de pesquisa em que se analisa o argumento/ou a argumentação de estudantes em estratégias de ensino baseadas em temas sociocientíficos e/ou científicos (P5), há uma discreta valorização de estudos sobre a influência da natureza da evidência utilizada pelos estudantes ao argumentarem.

O perfil P7 (avaliação da eficácia de uma estratégia de ensino na promoção ou não da argumentação dos alunos nas aulas de Ciências) ocupa a segunda posição na porcentagem de números de artigos publicados por perfil (figura 1).

Em recente estudo, Lee et. al. (2009) constataram que no período entre 1998 a 2007 aumentou o número de pesquisas em EC que investigaram os contextos de aprendizagem e características dos alunos, em detrimento de investigar assuntos como as concepções prévias dos estudantes e a mudança conceitual. Os resultados na presente pesquisa vão ao encontro dessa constatação. Isso pode ser verificado ao analisar dois resultados desta pesquisa. Primeiro, a porcentagem de artigos de P7 publicados por ano (tabela 1), onde é possível observar que os anos de 2007 e 2008 concentram quase metade dos artigos desse perfil (47,5\%) em comparação com o período anterior. Em segundo lugar, a expressiva atenção que esse tipo de pesquisa recebeu ao longo dos 21 anos analisados pode ser verificada, na mesma tabela, ao observar a porcentagem total de artigos em P7 (21\%), em comparação com as demais. Logo, no que se refere ao aumento 
de estudos sobre os contextos de aprendizagem, a pesquisa em AEC parece ter acompanhado a pesquisa em EC.

A análise dos dados (quadro 9 e quadro 6) ainda permite discutir outro aspecto dos artigos de P7. Do cruzamento dos dados de ambos os quadros, observam-se dois tipos de artigos: aqueles que avaliam a influência de contextos de aprendizagem na habilidade argumentativa dos estudantes $(1,12,13,16,26,28,33$ e 37$)$; e aqueles que avaliam a influência de contextos de aprendizagem em outras habilidades, cuja identificação foi feita analisando os argumentos e seus tipos (38, 42 e 48). Esses últimos artigos foram publicados no período de 1999-2001, enquanto aqueles, no período de 2001-2008. A partir desses resultados, é possível verificar que artigos do primeiro tipo são mais recentes do que aqueles do segundo tipo. Assim, sugere-se que o foco de pesquisa no interior do perfil P7 variou entre o uso da argumentação como indicador de habilidades centrais de aprendizado em Ciências, para a avaliação da influência do contexto de aprendizagem sobre a própria argumentação como habilidade central nesse aprendizado.

Os artigos dos perfis P5 e P7 estão distribuídos de forma mais uniforme ao longo do período analisado. Com os artigos dos perfis restantes, P1, P2, P3, P4, P6, P8 e P9, no entanto, a situação é inversa. Nesse último caso, as publicações aparecem de forma pontual e não uniforme.

Os resultados da presente pesquisa sugerem correlação entre o número de artigos por perfil e a uniformidade de distribuição das publicações ao longo do período analisado: quanto maior o número de artigos no perfil, maior a uniformidade dessas publicações. A distribuição dos artigos dos perfis P5 e P7 ilustram essa correlação. O número de artigos em P5 e P7 é o maior em comparação aos outros, e sua distribuição é a mais uniforme comparada a dos demais perfis. Isso pode ser verificado observando a relação entre o número de anos em que houve, pelo menos, uma (1) publicação em cada perfil e o número total de artigos de cada perfil (tabela 2). Assim, temos, para o perfil P5, a relação de 8/17, e para P7, 6/8. A relação dos perfis da P1, P2, P3, P4, P6, P8 e P9 são, respectivamente, $1 / 1,3 / 3,2 / 2,4 / 5,4 / 7,3 / 3$ e 1/2. Essas relações refletem a correspondência em que, quanto maior o valor do denominador, maior o número do numerador. Por isso, os resultados sugerem a existência de correlação entre o número de artigos por perfil e a uniformidade de publicações ao longo do período analisado.

Tabela 2. Número de anos em que houve, pelo menos, uma (1) publicação em cada perfil e número total de artigos por perfil, entre 1988 e 2008 


\begin{tabular}{|c|c|c|c|c|c|c|c|c|c|}
\hline & $\overline{P 1}$ & $\mathbf{P 2}$ & $\overline{\text { P3 }}$ & P4 & P5 & P6 & P7 & P8 & $\overline{P 9}$ \\
\hline 1988 & 0 & 0 & 0 & 0 & 0 & 0 & 0 & 0 & 0 \\
\hline 1989 & 0 & 0 & 0 & 0 & 0 & 0 & 0 & 0 & 0 \\
\hline 1990 & 0 & 0 & 0 & 0 & 0 & 0 & 0 & 0 & 0 \\
\hline 1991 & 0 & 0 & 0 & 0 & 0 & 0 & 0 & 0 & 0 \\
\hline 1992 & 0 & 1 & 0 & 0 & 0 & 0 & 0 & 0 & 0 \\
\hline 1993 & 0 & 0 & 0 & 0 & 0 & 0 & 0 & 0 & 0 \\
\hline 1994 & 0 & 0 & 0 & 0 & 0 & 0 & 0 & 0 & 0 \\
\hline 1995 & 0 & 0 & 0 & 0 & 0 & 0 & 0 & 0 & 0 \\
\hline 1996 & 0 & 0 & 0 & 0 & 0 & 0 & 0 & 0 & 0 \\
\hline 1997 & 0 & 0 & 0 & 0 & 0 & 1 & 0 & 0 & 0 \\
\hline 1998 & 0 & 0 & 0 & 1 & 0 & 0 & 0 & 0 & 0 \\
\hline 1999 & 0 & 0 & 0 & 0 & 1 & 0 & 1 & 1 & 0 \\
\hline 2000 & 1 & 0 & 0 & 0 & 1 & 1 & 1 & 0 & 0 \\
\hline 2001 & 0 & 0 & 0 & 1 & 2 & 0 & 2 & 0 & 0 \\
\hline 2002 & 0 & 0 & 0 & 0 & 2 & 2 & 1 & 0 & 0 \\
\hline 2003 & 0 & 1 & 0 & 0 & 0 & 0 & 0 & 0 & 0 \\
\hline 2004 & 0 & 0 & 1 & 1 & 1 & 0 & 2 & 0 & 0 \\
\hline 2005 & 0 & 0 & 0 & 0 & 0 & 0 & 0 & 0 & 0 \\
\hline 2006 & 0 & 0 & 0 & 0 & 6 & 0 & 0 & 1 & 0 \\
\hline 2007 & 0 & 0 & 0 & 0 & 3 & 0 & 3 & 0 & 2 \\
\hline 2008 & 0 & 1 & 1 & 2 & 1 & 3 & 1 & 1 & 0 \\
\hline $\begin{array}{l}\text { Num. de anos em que houve, } \\
\text { pelo menos, uma (1) publicação }\end{array}$ & 1 & 3 & 2 & 4 & 8 & 4 & 7 & 3 & 1 \\
\hline Num. total de artigos & 1 & 3 & 2 & 5 & 17 & 7 & 11 & 3 & 2 \\
\hline
\end{tabular}

Os artigos do perfil P6 (análise do processo de aprendizado dos conteúdos conceituais de Ciências dos alunos nas aulas de Ciências em estratégias de ensino baseadas em temas sociocientíficos e/ou científicos) foram publicados entre os anos de 1997 e 2008, observando-se uma concentração de artigos no ano de 2008.

Esses dados de pesquisa corroboram para o que aponta von Aufschnaiter et al. (2008). Esses autores afirmam que nas últimas três décadas, um grande corpo de pesquisa se concentrou no desenvolvimento de conhecimentos científicos por parte dos estudantes. Para a pesquisa em AEC, em específico, investigações que focalizam a aprendizagem, ao invés de ter como foco as habilidades argumentativas dos estudantes, são em menor número. Isso pode ser observado 
comparando a porcentagem de artigos de P6 (14\%), com média das porcentagens dos demais perfis que focalizam exclusivamente na análise das habilidades argumentativas dos estudantes, P4, P5, P7 e P8 (17,6 \%).

Apesar do número de artigos em P6 não superar o de perfis como de P5 e P7, é evidente a concentração de publicações desse tipo em um período mais recente. Isso pode ser observado comparando o número de artigos publicados entre 1997-2002 (3) e aqueles publicados somente no ano de 2008 (3). Assim, os resultados sugerem que a pesquisa em AEC apresenta tendência recente para a investigação de questões ligadas à aprendizagem. Em outras palavras, em AEC, a pesquisa com foco na aprendizagem é recente, mas ainda não supera as pesquisas com foco na habilidade argumentativa dos alunos.

Outro dado interessante é a lacuna entre 2003-2007, em que não foram publicados artigos do perfil P6. Esses resultados apontam para um investimento dos pesquisadores em AEC em estudos que não focam na aprendizagem, ao longo desse período.

A análise do quadro 9 permite levantar outras discussões para P6, agora quanto à natureza dos artigos. É possível identificar, dos seis artigos inclusos no perfil P6, dois (artigos 5 e 31) cujos dados dos descritores analisados nesta pesquisa permitem classificá-los como pesquisas enfatizando o produto, e um (artigo 2) como pesquisa enfatizando o processo de aprendizagem. Não foi possível identificar o enfoque metodológico dos artigos 8, 35, 45 e 50, pois os dados colhidos não contêm informação suficiente.

O trabalho de von Aufschnaiter et al. (2008) auxilia da discussão desses resultados. Nele, os autores ressaltam o número de publicações em EC investigando a aprendizagem de conteúdos específicos da área. Basicamente, estes estudos assentam-se numa epistemologia construtivista e tem como objetivo determinar a mudança conceitual dos alunos, bem como identificar estratégias de ensino que promovam essa mudança. Na maioria desses estudos, os procedimentos empíricos investigam os produtos, em vez dos processos de aprendizagem do estudante. "Normalmente, essa pesquisa utiliza delineamento pré / pós-teste para investigar os conceitos dos alunos antes e depois da instrução, mas a natureza do processo de mudança conceitual não é geralmente explorada". (p. 103, tradução nossa). Os autores concluem salientando que as principais questões dos processos pelos quais o desenvolvimento conceitual ocorre ainda são teórica e empiricamente vagas. 
Nesse sentido, observa-se que existem algumas informações da pesquisa importantes para sua caracterização que não estão dispostas nos dados colhidos a partir dos descritores da presente pesquisa. Em especial, informações sobre a metodologia da pesquisa estudada poderiam detalhar mais as características da pesquisa, permitindo melhor classificar e identificar os artigos. Isso permitiria, por exemplo, identificar se os artigos 8, 65, 45 e 50 têm foco no processo de aprendizagem ou no produto e, consequentemente, permitiria levantar outros aspectos das tendências de pesquisa em AEC.

Os artigos de $\mathbf{P 4}$ (avaliação e/ou proposição de instrumentos metodológicos utilizados na pesquisa em argumentação no ensino de Ciências) estão distribuídos no período entre 1988-2008 (tabela 1). Não é possível identificar uma concentração expressiva no número de publicações desse perfil, uma vez que estão distribuídos de forma mais uniforme do que os artigos de outros perfis, como, por exemplo, os de P6, concentrados em 2008.

Os estudos inseridos em P4, dessa forma, acompanham todo o período analisado sem apresentar períodos de intenso crescimento ou diminuição no número de publicações. Esses resultados sugerem correlação desse perfil com P5 e P7. Nestes perfis, o foco principal reside na análise do argumento ou da argumentação dos estudantes. Como afirmam von Aufschnaiter et al. (2008), predominaram estudos de exploração da ferramenta metodológica para a análise do argumento, no período inicial da pesquisa em AEC. Dessa forma, é razoável pensar que estudos com o perfil P4 subsidiaram aqueles dos perfis P5 e P7 e, dessa forma, estivessem concentrados no período inicial analisado. No entanto, o padrão de distribuição de artigos em P4 sugere que esse tipo de investigação não esteve presente somente no início da pesquisa, mas em todo período. Logo, sugere-se que pesquisas empíricas sobre ferramentas teórico-metodológicas de análise do argumento acompanharam a produção científica sobre a análise do argumentação dos estudantes, não se restringindo, dessa forma, ao período inicial da pesquisa em AEC.

Quanto à natureza dos artigos de $\mathrm{P} 4$, a análise do quadro 9 permite identificar certa homogeneidade entre os artigos. Dados sobre o tipo de uso da obra de Toulmin (1958) como referencial teórico nesses estudos, no entanto, podem revelar tendências impossíveis de serem detectadas com os dados apresentados até o momento.

O perfil P2 (discussões de práticas discursivas da Ciência e suas implicações para o ensino de Ciências) possui artigos que se distribuem no período de 1992-2008. Não foi possível 
identificar nenhum período de concentração de artigos desse perfil. Foram publicados três artigos de P2; um em 1992, e os dois restantes em 2003 e 2008.

Verificou-se também um grande período em que não houve nenhuma publicação de P2 (1993-2002, 9 anos). Porém, os demais perfis também apresentaram essa lacuna de tempo em que não houve nenhuma, ou quase nenhuma, publicação. Isso pode ser observado ao se comparar, na tabela 1, a quantidade total de artigos publicados nos períodos de 1988-1999 e de 2000-2008, 6 e 45 , respectivamente. Dessa forma, não se identificou qualquer tendência de pesquisa para o perfil P2, dado que, somado ao fato de não ser possível levantar um padrão de distribuição das publicações ao longo dos 21 anos analisados, o reduzido número de artigos nesse perfil dificulta uma análise de tendência de pesquisa.

Esses resultados corroboram a existência de correlação entre o número de artigos por perfil e a uniformidade de publicações ao longo do período analisado, assunto já tratado ao discutir o padrão de distribuição de artigos de P5 e P7. No caso de P2, assim como é esperado para P8, P8, P3 e P1, o reduzido número de artigos nesses perfis corresponde a uma distribuição não uniforme, heterogênea, ao longo dos 21 anos analisados.

O perfil P8 (desenvolvimento de habilidades para o ensino de argumentação em Ciências e/ou avaliação das condições para esse ensino) possui artigos publicados no período de 19982008. Verificou-se que, dos três artigos que compõem o perfil, dois são recentes, sendo um de 2006 e outro de 2008. De modo geral, apesar do reduzido número de artigos neste perfil (3), os resultados sugerem que esse é um perfil jovem dentro da pesquisa em AEC. Jiménez-Aleixandre e Erduran (2007) apresentam como focos recentes e promissores na área, aqueles envolvendo estudos culturais e sociológicos e sua relação com a argumentação. Além desse foco, os autores apostam nos estudos da relação de poder e de gênero como uma nova e rica perspectiva de investigação para a pesquisa em AEC. Entretanto, os resultados sobre os artigos de P8 divergem para o que apontam esses autores. O quadro da pesquisa em EC levantado por Lee et al. (2009) aproxima-se mais dos resultados do presente estudo, na medida em que indicam, na pesquisa em EC, um aumento do número de estudos sobre ensino, nos últimos 10 anos de pesquisa na área. Nesse sentido, a pesquisa em AEC, referente a estudos sobre ao desenvolvimento de habilidades de ensino de argumentação, parece acompanhar a tendência da pesquisa em EC.

A análise dos três artigos que compõem P8 (quadro 9) permite observar diferenças entre eles. O artigo 46 (de 1999) investiga se professores do ensino básico dão oportunidades aos 
estudantes para desenvolverem habilidades argumentativas. Os artigos 4 e 20, mais recentes (2006 e 2008, respectivamente), possuem outro foco. Nesses estudos, pesquisadores, ou avaliam a influência de um programa de formação de professores na promoção de habilidades argumentativas dos estudantes, ou realizam uma triagem visando encontrar a melhor estratégia de ensino dessas habilidades. Nesse sentido, da mesma forma que a pesquisa com foco na análise do argumento (perfis P5 e P7) subsidiou aquela com foco na aprendizagem (P6), a pesquisa de caráter mais propositivo sobre pedagogias para o ensino de argumentação (artigos 4 e 20) só surgiram respaldadas em estudos anteriores sobre as condições para esse ensino (artigo 46). Logo, os resultados sugerem que, passado um período em que a pesquisa em AEC investigava as condições para o ensino de argumentação nas aulas de ciências, iniciaram-se estudos na tentativa de propor e avaliar situações para esse de argumentação.

Os artigos do perfil P9 (uso da argumentação para ensinar conteúdos específicos a professores de Ciências) foram publicados em um único ano: 2007. A presença de estudos P9 somente nesse ano sugere seu caráter recente na pesquisa em AEC. A discussão de P9 assemelhase em grande parte à de $\mathrm{P} 8$. Em ambos os casos, o corpo de pesquisa que precedeu os perfis $\mathrm{P} 9 \mathrm{e}$ P8 parecem ter subsidiado esse novo foco de estudo, na medida em que pesquisas sobre as condições para o ensino de argumentação precederam aquelas cujo foco era propor e avaliar situações desse ensino. No entanto, há uma significativa diferença entre os artigos de P8 e de P9. Naqueles, o foco era no desenvolvimento de habilidades para o ensino de argumentação. Nesses, no entanto, as pesquisas utilizaram a argumentação como estratégia de ensino para tratar de assuntos concernentes a determinados aspectos do currículo de Ciências da África do Sul, em um programa de formação de professores já em exercício. É interessante observar que esse é o primeiro momento no período analisado que a argumentação é tem esse papel na área de pesquisa.

Dessa forma, mais uma vez os resultados da presente pesquisa convergem com o quadro da pesquisa em EC desenhado por Lee et al. (2009). Nesse estudo, os autores indicam um aumento do número de pesquisas sobre ensino, nos últimos 10 anos de pesquisa em EC. Assim, a pesquisa em AEC, referente a estudos sobre o uso da argumentação para ensinar conteúdos específicos a professores de Ciências, parece acompanhar a tendência da pesquisa em EC. E ainda. A natureza dos artigos do perfil P9 dá indícios de que existe considerável leque de 
possibilidades de usos da argumentação na pesquisa com foco no professor, ainda não explorados.

O perfil P3 (discussão teórica sobre instrumentos metodológicos utilizados na pesquisa em argumentação no ensino de Ciências) compreende dois artigos. Um publicado em 2004 (29) e outro em 2008 (7), tornando-os relativamente recentes na pesquisa em AEC. A literatura da área (von AUFSCHNAITER, 2008) reconhece a consagração da linha de pesquisa com foco na avaliação ou proposição de instrumentos de análise do argumento, porém não faz a diferenciação entre pesquisa de revisão e empírica. Na presente pesquisa, esta é representada pelos estudos em P4, e a aquela, em P3. Os artigos de P4 estão distribuídos no período de 1988-2008, enquanto os de P3, 2004-2008. A comparação desses dados sugere que a pesquisa de revisão sobre avaliação ou proposição de instrumentos metodológicos na área sucedeu a pesquisa empírica sobre o mesmo assunto.

A partir de uma análise mais detalhada da natureza dos artigos de P3 (quadro 9), é possível observar que se trata de estudos de revisão sobre o tema. Partindo do pressuposto de que trabalhos acadêmicos de revisão necessariamente avaliam um corpus representativo de produção anterior, deduz-se que não seria possível sua elaboração caso não houvesse um conjunto de artigos que o antecedessem. Levaram quatro anos entre o início formal da pesquisa na área ${ }^{10} \mathrm{e} a$ publicação do artigo 26. Em convergência com os resultados da presente pesquisa, Lee et al. (2009), comparando publicações em EC de 1998-2002 com as de 2003-2007, verificaram aumento no número de pesquisas de revisão. Esses autores ainda lembram que esse tipo de estudo foi fundamental para o desenvolvimento da área. Esses dados sugerem que o volume de produção científica foi suficiente para subsidiar um estudo de revisão após quatro anos de pesquisa empírica na área.

Por fim, o perfil P1 (justificativa da importância da argumentação para o ensino de Ciências) é composto por apenas um artigo (artigo 44). Verificou-se grande aumento no número de artigos após sua data de publicação. Esse aumento pode ser observado na tabela 3. Nela, é apresentado o número de artigos em cada perfil em dois períodos consecutivos: o primeiro referente ao intervalo de tempo entre 1988-1999; e o segundo, entre 2000-2008.

\footnotetext{
${ }^{10}$ Como já citado anteriormente, nesta pesquisa considera-se o ano de 2000 como início formal da pesquisa em AEC.
} 
Tabela 3. Número de publicações por perfil nos períodos de 1988- 1999 e de 2000-2008

\begin{tabular}{cccc}
\hline \multirow{2}{*}{ Perfil } & $1998-2008(\mathrm{n}=51)$ & & 2000-2008 $(\mathrm{n}=45)$ \\
\cline { 2 - 3 } & Num. art $(\%)$ & Num. art $(\%)$ & Num. art $(\%)$ \\
\hline 1 & $1(2,0 \%)$ & $0(0,0 \%)$ & $1(2,2 \%)$ \\
2 & $3(5,9 \%)$ & $1(16,7 \%)$ & $2(4,4 \%)$ \\
3 & $2(3,9 \%)$ & $0(0,0 \%)$ & $2(4,4 \%)$ \\
4 & $5(9,8 \%)$ & $1(16,7 \%)$ & $4(8,9 \%)$ \\
5 & $17(33,3 \%)$ & $2(33,3 \%)$ & $16(35,6 \%)$ \\
6 & $7(13,7 \%)$ & $1(16,7 \%)$ & $6(13,3 \%)$ \\
7 & $11(21,6 \%)$ & $1(16,7 \%)$ & $10(22,2 \%)$ \\
8 & $3(5,9 \%)$ & $0(0,0 \%)$ & $2(4,4 \%)$ \\
9 & $2(3,9 \%)$ & $0(0,0 \%)$ & $2(4,4 \%)$ \\
\hline
\end{tabular}

A tabela 3 apresenta dois dados interessantes sobre o padrão de publicação na área. $\mathrm{O}$ primeiro refere-se ao número de artigos por período: 6 no primeiro; e 45 no segundo. $O$ segundo, ao aumento na diversificação da pesquisa em AEC, indicado pelo aumenta no número de perfis de pesquisa: 5, no primeiro período e; 9 no segundo.

Ambos os resultados corroboram a ideia de que a publicação do artigo de Driver et al. (2000) ajudou a impulsionar a pesquisa em AEC. Pesquisas anteriores constataram esse mesmo aumento substancial na quantidade de artigos na área a partir do ano de 2000 (BOZZO e MOTOKANE, 2009a, 2009b).

A análise dos resultados da tabela 3 também permite identificar um padrão de distribuição dos artigos nos demais perfis (P2, P3, P4, P5, P6, P7, P8, P9). Em todos os casos, houve um aumento no número de artigos, comparando o primeiro (1988-1999) e o segundo (2000-2008) períodos.

$\mathrm{O}$ aumento mais acentudado ocorreu nos perfis P5 e P7, nos quais também houve maior número de artigos em todo período analisado (17 e 11, respectivamente). Os perfis P1, P2, P3, P8 e P9, ao contrário, apresentaram um discreto aumento no número total de artigos publicados $(1,1$, 2, 2 e 2, respectivamente). Nesses casos, também se observou menor número total de artigos ao longo dos 21 anos considerados na presente pesquisa (1, 2, 3, 2 e 2, respectivamente). Ocuparam um lugar intermediário no aumento de artigos, os perfis P4 (3) e P6 (5). Mais uma vez, o acréscimo na quantidade de artigos entre um período e outro acompanha o número total de artigos publicados nesses perfis (5 e 7, respectivamente). Dado que em todos os perfis, a maior parte das publicações encontra-se no segundo período, constatou-se que a produção científica na pesquisa em AEC concentra-se no período entre de 2000 e 2008. 
O conjunto de perfis foi discutido de acordo com o aumento do número de artigos do primeiro para o segundo períodos, na seguinte ordem: daqueles em que houve maior aumento para aqueles com menor aumento.

Os anos de 2006 e 2007 concentraram maior número de artigos de P5 e P7. Diferentemente do que ocorreu em 2008, em que houve relativa diminuição no número de artigos desses dois perfis. Ainda em 2006 e 2007, destacaram-se, em P5, pesquisas sobre a influência da natureza do conteúdo utilizado nas justifictivas dos argumentos produzidos por alunos. Em P7, os estudos focalizaram na influência de contextos de aprendizagem na habilidade argumentativa dos estudantes.

Esses resultados convergem com o apontado por Jiménez-Aleixandre e Erduran (2007) e Lee et al. (2009). Os primeiros afirmam que a maioria da pesquisa internacional em Ciências começou a enfatizar o papel da evidência e justificativias desde o fim da década de 1990. Assim, a pesquisa em AEC explora o tema de forma anacrônica com a pesquisa em EC, porém seguindo as mesmas tendências. Já Lee et al. (2008), ressaltam o aumento de publicações sobre contextos de aprendizagens no período de 2003-2007. Por isso, consideravelmente em consonância com a pesquisa em EC, a área de AEC apresenta semelhanças nos focos de estudo que se referem à valorização do papel da evidência durante a construção do argumento, e à também valorização dos contextos de aprendizagem, nos anos de 2006 e 2007. A consonância não é total, pois existe algum anacronismo em relação à pesquisa em AEC com aquela em EC.

Ao contrário do aumento no número de artigos ocorrido em P5 e P7, o aumento nos perfis P1, P2, P3, P8 e P9 deu-se de forma muito menos acentuada. Apesar de ter sido identificado um padrão heterogêneo de publicações dos artigos desses perfis, observou-se relativa concentração de publicações nos anos 2007 e 2008, excetuando-se o artigo de P1, cuja publicação data de 2000.

Nesses anos, para esses perfis, observou-se uma produção científica do tipo de revisão, ou de posição, ou com focos até então não estudados. Devido ao caráter recente de estudos de revisão - os quais necessitam de um corpo consistente de pesquisas para serem realizados, e à exploração de novos focos de investigação - que se originam de perguntas surgidas nas pesquisas anteriores, explica-se o aumento pouco acentuado do númerro de artigos dos perfis P1, P2, P3, P8 e P9, pois são jovens dentro da pesquisa em AEC. 
Por fim, verifica-se um padrão mais uniforme de $\mathbf{P 4}$ e P6, comparado aos perfis P1, P2, P3, P8 e P9. Novamente, houve concentração de artigos no ano de 2008. Os artigos de P4 e P6 são estudos que retroalimentam a pesquisa de P5, avaliando os intrumentos metodológicos, e estudos com foco na aprendizagem.

Análise entre artigos com foco nos alunos e com foco nos professores

Como pode se observar no quadro 6, os artigos com foco nos alunos compreendem quatro perfis, P4, P5, P6 e P7. Como já foi discutido, verifica-se que os artigos do perfil P6 aparecem somente da segunda metade do período estudado em diante. Já os artigos dos perfis P5 e P7 estão distribuídos de forma mais uniforme, estando presente nas duas metades do período considerado na presente pesquisa. $\mathrm{O}$ foco dos artigos de P6 referem-se à aprendizagem, em detrimento da análise do argumento ou da argumentação e da eficácia de estratégias na promoção de habilidade argumentativas, no caso dos perfis P5 e P7, respectivamente. Dado isso, verifica-se o caráter recente do foco dos artigos em AEC no aprendizado, alinhando-se, mais uma vez, ao apresentado em Aufschnaider et al. (2008) e -Aleixandre e Erduran (2007) quando ressaltam o gradual aumento na afiliação da pesquisa na área aos referenciais sócio-culturais e, consequentemente aumento da atenção ao aspecto multidirecional do processo de ensino-aprendizagem.

Como visto anteriormente, os artigos do perfil P4, aproximam-se do momento inicial da pesquisa em AEC (von Aufschnaiter et al., 2008; Jiménez-Aleixandre e Erduran, 2007), por realizarem estudos de exploração da ferramenta metodológica para a análise do argumento.

No entanto, pela análise de ferramentas não ser publicada em período posterior a 2004, sugere-se que essa área não vem sendo tão pesquisada quanto anteriormente. Parece claro que estudos metodológicos não cessarão, pois são essenciais a qualquer área de pesquisa. Contudo, dado o período em que foram publicados os artigos do perfil P4, e dado o foco dos artigos dos perfis P5, P6 e P7, discutidos acima, sugere-se o deslocamento da atenção da pesquisa na área para aspectos da aprendizagem, em detrimento de estudos com enfoque metodológico, visando à elaboração de ferramentas de análise do argumento.

A análise dos perfis que compõem os artigos com focos nos alunos, permite verificar que: esses artigos estão inseridos em um amplo intervalo de tempo (de 1997 a 2008); possuem o maior número de perfis, comparado, tanto aos artigos com foco no professor, quanto aos artigos de 
revisão e de posição (quadro 6). Sugere-se que os artigos que constituem os perfis com foco no aluno são a amostra mais significativa de artigos, já que refletem, em seus distintos focos, as mudanças ocorridas na pesquisa em AEC ao longo do tempo, devido ao elevado número de perfis e artigos que possui.

Apesar de considerar os artigos com foco no aluno como a amostra mais significativa deste estudo, a análise daqueles com foco nos professores, também permitiu a visualização de mudanças da pesquisa.

Dois autores contribuem para essa a discussão. Teixeira (2009) aponta que, inicialmente, os estudos da área "se concentraram na fala do professor (RUSSEL \& MORROW, 1986), para irem se ampliando entre alunos e professores e a participação de aprendizes (CANDELA, 1999; DRIVER et. al., 1999; SANDOVAL e REISER, 2004)” (p. 22). Sobre esse período inicial da pesquisa, Jiménez-Aleixandre e Erduran (2007) estudos que exploraram o papel da autoridade. Em ambas as perspectivas, tanto a de Teixeira (2009), quanto a de Jiménez-Aleixandre e Erduran (2007), é possível verificar que: os primeiros artigos da pesquisa em AEC tinham foco na fala do professor; e que esses artigos investigavam dimensões sociais do argumento segundo a assimetria de poder criada nas aulas de Ciências. Assim, segundo a literatura é possível identificar a diferença entre os enfoques dos artigos no início da pesquisa em AEC e nos mais recentes: aqueles tinham enfoque nas dimensões sociais do argumento, e estes tem na formação de professores de Ciências.

Os resultados da presente pesquisa aproximam-se do quadro recente da pesquisa em AEC apresentada por Jiménez-Aleixandre e Erduran (2007) e Teixeira (2009), quando investigam o papel do professor. Isso, pois os artigos com foco no professor têm foco, ou no desenvolvimento de habilidades argumentativas dos professores, ou na aprendizagem de conteúdos específicos para os professores de Ciências; ambos inseridos em um contexto de formação de professores, ao invés de investigarem dimensões sociais do argumento.

Outra discussão refere-se à relação entre o grau de compreensão de determinado assunto e a proposição de novos temas de pesquisa. Para os fins da presente pesquisa, isso se relaciona com o fato de que não seria possível promover situações de formação de professores de Ciências em AEC sem, antes, construir um corpo teórico mínimo sobre o assunto. Dessa forma, é esperado que a pesquisa com foco no professor, especialmente aquela referente a contextos de formação de professores, seja recente e escassa na área. 
Análise entre artigos empíricos, de revisão e de posição

São seis artigos de revisão e de posição (quadro 6), distribuídos em 3 perfis. A data de publicação dos artigos desses perfis vai de 1992 a 2008. No entanto, por razões já apresentadas anteriormente na presente pesquisa, ressalta-se que a produção nessa área concentra-se da segunda metade do período analisado em diante. Isso pode ser verificado comparando o número de artigos publicados a partir de 2000 e o número de artigos anteriores, 5 e 1, respectivamente.

Já os artigos empíricos correpondem a 45 artigos, distribuídos em seis perfis. A data de publicação dos artigos desses perfis vai de 1997 a 2008. Da mesma forma que os artigos de revisão e de posição, os empíricos estão concentrados na segunda metade do período analisado. Isso pode ser verificado comparando o número de artigos publicados de 2000 em diante e o número de artigos anteriores, 45 e 6 , respectivamente.

A comparação da distribuição dos artigos de revisão e de posição e empíricos ao longo do tempo sugere a ideia de que, a publicação de ambos os tipos de artigo está concentrada na segunda metade do período estudado. É possível, então, identificar uma concentração da pesquisa em AEC no período entre 2000 e 2008.

No entanto, os dados sobre o número de artigos de revisão e de posição e empíricos permitem a visualização de diferenças da tendência de produção em um e outro tipo de artigo. Uma dessas diferenças refere-se ao número total de artigos em cada um dos tipos de publicação. Apesar dos artigos de revisão e de posição e empíricos guardarem semelhança quanto à concentração temporal de publicações para a segunda metade do período estudado, o número de artigos empíricos é maior do que o de revisão e de posição. Esses resultados remetem a uma discussão já realizada, quando se analisou os dados sobre o perfil P3. Nessa discussão, foi possível identificar a natureza de revisão dos dois artigos do perfil, ressaltando-se a necessidade de se avaliar um corpus representativo de produção científica antes da produção de um trabalho de revisão.

Os resultados e a análise sobre o perfil P3, somados aos recém-analisados sobre publicações desse tipo, permitem sugerir que o tipo de pesquisa de revisão e de posição que vem sendo publicada na pesquisa em AEC: 1.tem caráter predominante de estudos de revisão, quer sejam revisões da produção de outros campos do saber, quer sejam revisões da própria área de 
AEC; e, 2.é mais recente do que a empírica, devido ao fato dessa ter fornecido subsídios para a produção daquela.

Os dados sobre o número de perfis, somados àqueles sobre o número de artigos, permitem ainda outra discussão. Observa-se uma relação em que, quanto maior o número de artigos - quer sejam eles empíricos, de revisão ou de posição, maior o número de perfis, e vice-versa. Dessa forma, verifica-se que os artigos empíricos possuem maior número de artigos em relação aos de revisão e de posição e, consequentemente, maior número de perfis. Isso sugere maior diversidade de pesquisas empíricas em comparação às do tipo de revisão e de posição.

\section{Análise dos supraperfis}

O quadro 7 apresenta um esquema da classificação dos supraperfis (SP1, SP2 e SP3), constando o número de artigos em cada supraperfil e seus respectivos anos de publicação. 


\begin{tabular}{|c|c|c|}
\hline $\begin{array}{c}\text { Classificação dos artigos segundo categorização por } \\
\text { supraperfis }\end{array}$ & IDE & APU \\
\hline \multirow{6}{*}{$\begin{array}{l}\text { (SP1) Estudos sobre a natureza da ciência ou } \\
\text { sobre o ensino de Ciências [6] }\end{array}$} & 3 & 2008 \\
\hline & 7 & 2008 \\
\hline & 29 & 2004 \\
\hline & 30 & 2003 \\
\hline & 44 & 2000 \\
\hline & 51 & 1992 \\
\hline \multirow{33}{*}{$\begin{array}{l}\text { (SP2) Estudos com foco na estrutura do } \\
\text { argumento e/ou na construção da } \\
\text { [33] }\end{array}$} & 1 & 2008 \\
\hline & 6 & 2008 \\
\hline & 9 & 2008 \\
\hline & 10 & 2008 \\
\hline & 11 & 2007 \\
\hline & 12 & 2007 \\
\hline & 13 & 2007 \\
\hline & 16 & 2007 \\
\hline & 17 & 2007 \\
\hline & 18 & 2007 \\
\hline & 19 & 2006 \\
\hline & 21 & 2006 \\
\hline & 22 & 2006 \\
\hline & 23 & 2006 \\
\hline & 24 & 2006 \\
\hline & 25 & 2006 \\
\hline & 26 & 2004 \\
\hline & 27 & 2004 \\
\hline & 28 & 2004 \\
\hline & 34 & 2004 \\
\hline & 32 & 2002 \\
\hline & 33 & 2002 \\
\hline & 36 & 2002 \\
\hline & 37 & 2001 \\
\hline & 38 & 2001 \\
\hline & 39 & 2001 \\
\hline & 40 & 2001 \\
\hline & 41 & 2001 \\
\hline & 42 & 2000 \\
\hline & 43 & 2000 \\
\hline & 47 & 1999 \\
\hline & 48 & 1999 \\
\hline & 49 & $\begin{array}{l}1998 \\
\end{array}$ \\
\hline \multirow[t]{12}{*}{ (SP3) Es tudos com foco no ensino e apren dizagem [12] } & 4 & 2008 \\
\hline & 2 & 2008 \\
\hline & 5 & 2008 \\
\hline & 8 & 2008 \\
\hline & 14 & 2007 \\
\hline & 15 & 2007 \\
\hline & 20 & 2006 \\
\hline & 31 & 2002 \\
\hline & 35 & 2002 \\
\hline & 45 & 2000 \\
\hline & 46 & 1999 \\
\hline & 50 & 1997 \\
\hline
\end{tabular}

Quadro 7. Supraperfis da pesquisa em argumentação no ensino de Ciências, onde $\mathrm{SP}=$ Supraperfil, IDE= Número de identificação do artigo, APU=ano de publicação do artigo 
A figura 2 traz as porcentagens dos números de artigos por supraperfil. O supraperfil SP2 possui o maior número de artigos, $65 \%$, seguido do supraperfil SP3 com $23 \%$. O perfil que apresentou menos artigos foi SP1, com $12 \%$.

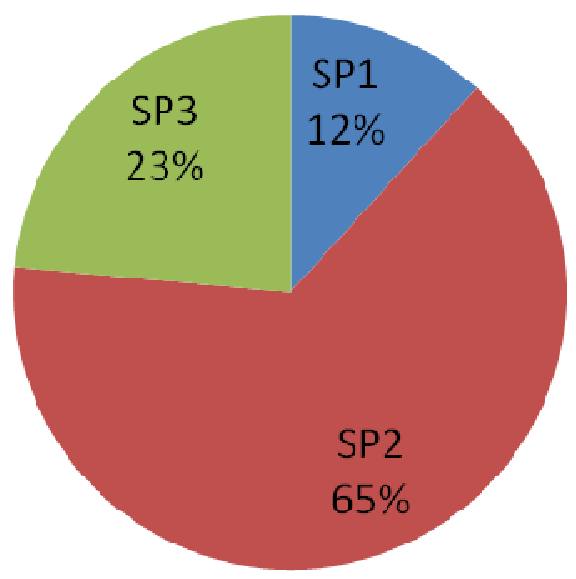

Figura 2. Porcentagem de publicações entre 1988 a 2008 por supraperfil

O supraperfil de SP2 (estudos com foco na estrutura do argumento e/ou na construção da argumentação) predominou na pesquisa em AEC no período analisado. Os artigos desse seuperfil vão ao encontro do que von Aufschnaiter et al. (2008) descrevem como tentativas de elaborar um esquema para avaliar a qualidade da argumentação.

Yore et al. (2003) enfatizam que, no período de 1978-2003, a pesquisa em EC valorizou o uso da discussão, argumentação, leitura, e escrita para ajudar estudantes a construírem conhecimento de e sobre Ciências. Dito de outra forma, os autores destacam a importância do discurso nas aulas de Ciências.

A assunção da comunidade científica sobre centralidade da argumentação no ensino de Ciências, por meio de estudos sobre a Ciência e sobre o próprio ensino de Ciências (metaciência), resultou na elaboração de instrumentos metodológicos que pudessem de forma cada vez mais precisa, avaliar, tanto a qualidade, quanto a quantidade dos argumentos produzidos por estudantes em aulas de ciências. Os dados da presente pesquisa apontam exatamente para esse quadro, na medida em que o superperperfil SP2 apresentou o maior número de artigos.

O supraperfil SP3 (estudos com foco no ensino e aprendizagem) ficou em segundo lugar, em relação aos demais supraperfis. 
Ao contrário dos artigos de SP2, aqueles de SP6 focalizam na análise do aprendizado em detrimento da análise do argumento ou da argumentação. Yore et al. (2003) afirmam que a pesquisa em EC, nas últimas décadas, vem reconhecendo o valor do uso da discussão e argumentação para auxiliar os estudantes a construir conhecimentos da Ciência, porém pouco tem se discutido sobre suas implicações em sala de aula. Os autores, ao levantarem o histórico de produção científica em AEC, citam que uma minoria de trabalhos debruçou-se sobre a aprendizagem. Os dados da presente pesquisa contrastam com esse quadro, na medida em que apresentam o foco de pesquisa acima citado em segundo lugar, representado pelos artigos de SP3 (23\%), perdendo em quantidade somente para aqueles de SP2 (65\%).

A diferença entre as porcentagens também chama a atenção. Entre o supraperfil SP3 e SP2, existem 42 pontos porcentuais, uma diferença menor do que a existente entre o SP3 e SP1, 11 pontos porcentuais. Quando se compara SP3 com SP1, a diferença é mais acentuada, 53 pontos porcentuais. Esses dados além reforçarem o predomínio de artigos com supraperfil SP2, sugerem outra discussão. Em curto espaço de tempo, parece ser improvável uma mudança no quadro na pesquisa em AEC, em que SP3 predomine sobre SP2, e consequentemente sobre SP1, dado que seu volume de pesquisa nos 21 anos analisados é quase três vezes menor do que de SP2.

A pesquisa com foco da aprendizagem, incluindo aí, investigações acerca da formação inicial e continuada de professores de Ciências, não superam aqueles que estudam a estrutura do argumento ou os processos para usa elaboração (SP2). Porém, ganhou mais destaque ao longo dos 21 anos em comparação àquelas cujo foco estiveram nos estudos sob re Ciências e sobre o próprio ensino de Ciências. Prova disso são os estudos sobre formação inicial ou continuada de professores de Ciências. Como já discutido anteriormente, parece razoável que pesquisas que focalizam na instrução de professores não inaugurem a determinada linha de pesquisa. Antes, demandam um considerável corpo de pesquisa para que seus resultados culminem na avaliação e testes de estratégias de ensino diretamente relacionadas aos novos referenciais.

O número de artigos do supraperfil SP1 (Estudos sobre a natureza da ciência ou sobre o ensino de Ciências) foi o menor, em comparação com SP2 e SP3. Uma análise imediata conduziria a conclusão de que é uma área de menor interesse. No entanto, avaliando a natureza dos artigos desse supraperfil, a avaliação é diferente. Trata-se de um supraperfil que possui, essencialmente, artigos de revisão e de posição. De um lado, possui relevância por constituir-se, em sua maioria, de estudos de revisão, que apoiam os avanços da pesquisa em AEC. De outro, 
avaliam ferramentas utilizadas nessa pesquisa, subsidiando determinadas linhas da produção científica na área. Assim, apesar de apresentar menor número de artigos (6) do que os demais supraperfis (33 e 12, quadro 7), essa área pode ser considerada essencial para o desenvolvimento da pesquisa na área, justificando-a, fundamentando-a e avaliando-a; quase como uma metaciência.

Nesse sentido, o reduzido número de artigos em SP1 jutifica-se pela sua natureza. Na pesquisa em EC, a produção de artigos empíricos é maior do que a de artigos teóricos, de revisão e de posição juntos (LEE et al., 2009). Disso decorre que não é possível afirmar sobre a atenção que a comunidade científica dedica a determinada linha de pesquisa somente pelo número absoluto de artigos publicados. O padrão de distribuição dessas publicações e sua natureza auxiliam no entendimento dessas relações.

Os resultados na tabela 4 apresentam o mesmo cenário da pesquisa em AEC que a tabela 1, discutida anteriormente: aumento da produção científica na área ao final da década de 1990; e quedas significativas das publicações nos anos de 2003 e 2005. Entretanto, na tabela 4 é possível detalhar as tendências de pesquisa nos três supraperfis identificados. 
Tabela 4. Número de publicações por supraperfil no período de 1988- 2008

\begin{tabular}{|c|c|c|c|c|c|c|c|c|}
\hline Sunranerfi1 & $1998-2008(\mathrm{n}=51)$ & $1988(\mathrm{n}=0)$ & $1989(\mathrm{n}=0)$ & $1990(\mathrm{n}=0)$ & $1991(\mathrm{n}=0)$ & $1992(\mathrm{n}=1)$ & $1993(\mathrm{n}=0)$ & $1994(\mathrm{n}=0)$ \\
\hline Suprapertil & Num. art (\%) & Num. art (\%) & Num. art (\%) & Num. art (\%) & Num. art (\%) & Num. art (\%) & Num. art (\%) & Num. art (\%) \\
\hline 1 & $6(11,0 \%)$ & $0(0,0 \%)$ & $0(0,0 \%)$ & $0(0,0 \%)$ & $0(0,0 \%)$ & $1(100,0 \%)$ & $0(0,0 \%)$ & $0(0,0 \%)$ \\
\hline 2 & $33(64,7 \%)$ & $0(0,0 \%)$ & $0(0,0 \%)$ & $0(0,0 \%)$ & $0(0,0 \%)$ & $0(0,0 \%)$ & $0(0,0 \%)$ & $0(0,0 \%)$ \\
\hline 3 & $12(23,5 \%)$ & $0(0,0 \%)$ & $0(0,0 \%)$ & $0(0,0 \%)$ & $0(0,0 \%)$ & $0(0,0 \%)$ & $0(0,0 \%)$ & $0(0,0 \%)$ \\
\hline
\end{tabular}

\begin{tabular}{|c|c|c|c|c|c|c|c|c|}
\hline \multirow{2}{*}{ Supraperfil } & $1995(\mathrm{n}=0)$ & $1996(n=0)$ & $1997(\mathrm{n}=1)$ & $1998(n=1)$ & $1999(n=3)$ & $2000(n=4)$ & $2001(n=5)$ & $2002(n=5)$ \\
\hline & Num. art (\%) & Num. art (\%) & Num. art (\%) & Num. art (\%) & Num. art (\%) & Num. art (\%) & Num. art (\%) & Num. art (\%) \\
\hline 1 & $0(0,0 \%)$ & $0(0,0 \%)$ & $0(0,0 \%)$ & $0(0,0 \%)$ & $0(0,0 \%)$ & $1(25,0 \%)$ & $0(0,0 \%)$ & $0(0,0 \%)$ \\
\hline 2 & $0(0,0 \%)$ & $0(0,0 \%)$ & $0(0,0 \%)$ & $1(100,0 \%)$ & $2(66,7 \%)$ & $2(50,0 \%)$ & $5(100,0 \%)$ & $3(60,0 \%)$ \\
\hline 3 & $0(0,0 \%)$ & $0(0,0 \%)$ & $1(100,0 \%)$ & $0(0,0 \%)$ & $1(33,3 \%)$ & $1(25,0 \%)$ & $0(0,0 \%)$ & $2(40,0 \%)$ \\
\hline
\end{tabular}

\begin{tabular}{|c|c|c|c|c|c|c|}
\hline \multirow{2}{*}{ Supraperfil } & $2003(\mathrm{n}=1)$ & $2004(n=5)$ & $2005(\mathrm{n}=0)$ & $2006(\mathrm{n}=7)$ & $2007(\mathrm{n}=8)$ & $2008(\mathrm{n}=10)$ \\
\hline & Num. art (\%) & Num. art (\%) & Num. art (\%) & Num. art (\%) & Num. art (\%) & Num. art (\%) \\
\hline 1 & $1(100,0 \%)$ & $1(20,0 \%)$ & $0(0,0 \%)$ & $0(0,0 \%)$ & $0(0,0 \%)$ & $2(20,0 \%)$ \\
\hline 2 & $0(0,0 \%)$ & $4(80,0 \%)$ & $0(0,0 \%)$ & $6(85,7 \%)$ & $6(75,0 \%)$ & $4(40,0 \%)$ \\
\hline 3 & $0(0,0 \%)$ & $0(0,0 \%)$ & $0(0,0 \%)$ & $1(14,3 \%)$ & $2(25,0 \%)$ & $4(40,0 \%)$ \\
\hline
\end{tabular}


Seguindo a ordem da porcentagem de artigos por supraperfil (figura 2), da maior para a menor, abaixo serão discutidas as tendências observadas em cada um dos três supraperfis, ao longo dos 21 anos considerados nesta pesquisa (1998-2008).

O caráter relativamente recente da pesquisa em AEC, em comparação a outras linhas, já consagradas na pesquisa em EC, auxilia a discutir os resultados do supraperfil SP2 (estudos com foco na estrutura do argumento e/ou na construção da argumentação). A necessidade de entender qual a natureza dos argumentos, os detalhes no processor de construção da argumentação, a natureza das explicações dos estudantes, as condições que mais favorecem a produção de argumentos ou a argumentação em sala de aula, todos, são temas de pesquisa que necessariamente antecedem sua aplicação consciente e crítica em sala de aula.

Outras linhas de pesquisa, com é o da História e Filosofia de Ciências no ensino de Ciências, não fogem a essa regra. Martins (2007) aponta para a relevância da História e da Filosofia da Ciência para a pesquisa em ensino de ciências. "Sob diversos aspectos, [História e da Filosofia da Ciência] tem sido apontada com bastante freqüência na literatura especializada da área. A necessidade de incorporação de elementos históricos e filosóficos no ensino médio chega a ser praticamente consensual [...]” (MARTINS, 2007, p. 112).

No entanto, apesar do reconhecimento da relevância do assunto para o EC, aspectos sobre ensino-aprendizagem ainda vem sendo pesquisados e debatidos na comunidade científica. Da mesma forma, é esperado o maior volume de pesquisa em AEC que concentrou esforços buscando entender a estrutura do argumento e o processo de construção da argumentação, antes do surgimento da pesquisa em ensino-aprendizado em argumentação. Apesar da recente diversificação que a área vem sofrendo, não seria um excesso dedutivo imaginar que, no período que sucede o recorte de tempo da presente pesquisa, estudos do supraperfil SP2 ainda predominem no cenário mundial de pesquisa em AEC.

Outro resultado interessante refere-se à relação do número de artigos de pubicados por ano de SP2 e o número de artigos dos demais supraperfis. Ao longo de todo o período analisado, SP2 sempre se manteve na liderança em relação ao número de artigos em SP1 e SP3. Assim, foi possível constatar que, além do predomínio geral de artigos com foco na análise da estrutura do argumento e/ou da construção da argumentação sobre os outros tipos, esse supraperfil de produção também liderou em todos os anos do recorte temporal escolhido na presente pesquisa, exceto em 2008, em que o número de artigos em SP2, foi igual ao de SP3. Isso sugere uma 
recente diversificação de abordagens na pesquisa. A diminuição gradativa da liderança da pesquisa com supraperfil SP2 nos anos de 2006, 2007 e 2008 reafirma esse quadro. Nesses anos, os artigos de SP2 representaram 85,7\%, 75,0\% e 40\% das publicações, enquanto os dois outros superfis, somados, representaram $14,3 \%, 25,0 \%$ e $60,0 \%$ das publicações, respectivamente, para os mesmos anos.

Nos resultados sobre o supraperfil SP3 (estudos com foco no ensino e aprendizagem), dois aspectos chamam a atenção. O primeiro refere-se às lacunas de tempo em que não foram publicados artigos desse supraperfil. Essas lacunas correspondem às apresentadas nos demais supraperfis, 2003 e 2005. Nesses anos, há somente 1 artigo publicado, pertecente ao supraperfil SP1. Logo, a ausência de artigos de SP3 nesses dois anos é esperada, na medida em que acompanha o padrão de distribuição dos demais supraperfis. Contudo, o mesmo não acontece para os anos de 2001 e 2004, em que, enquanto foram publicados 5 em 2001 e 4 artigos em 2004, de SP2, nota-se a ausência de artigos de SP3. A análise dos perfis dos artigos de SP2 e SP3 nesses dois anos, não revela nenhuma relação que explicaria a ausência de artigos de SP3 nos dois anos acima citados. A partir dos resultados do presente estudo, constatou-se, então, que nos anos de 2001 e 2004 não foram publicadas investigações com foco na aprendizagem. E ainda, que predominaram estudos com foco na estrutura do argumento e/ou na construção da argumentação.

O segundo aspecto que chama a atenção em SP3 refere-se a um gradativo aumento no número de artigos entre 2006 e 2008. Enquanto o número de artigos de SP2 diminui gradativamente nos anos de 2006, 2007 e 2008, os de SP3 aumentaram, representando 14,3\%, $25 \%$ e $40 \%$ das publicações dos respectivos anos. Nesse sentido, os dados da presente pesquisa reforçam a ideia de outros autores que realizarm um levantamento da pesquisa na área de EC (LEE et al., 2009) e de LEC (YORE et al., 2003), de que vem ganhando destaque a produção científica que enfatiza o contexto8 de aprendizagem, na pesquisa em EC e a própria aprendizagem, em LEC. O momento da pesquisa em AEC, portanto, parece acompanhar esse caminho da pesquisa em EC, em que o destaque está sobre como promover a aprendizagem por meio da argumentação.

A figura 3 representa, de forma geral, a tendência atual da pesquisa no ensino de Ciências, referente ao ganho de destaque na pesquisa sobre a aprendizagem acima citado. 


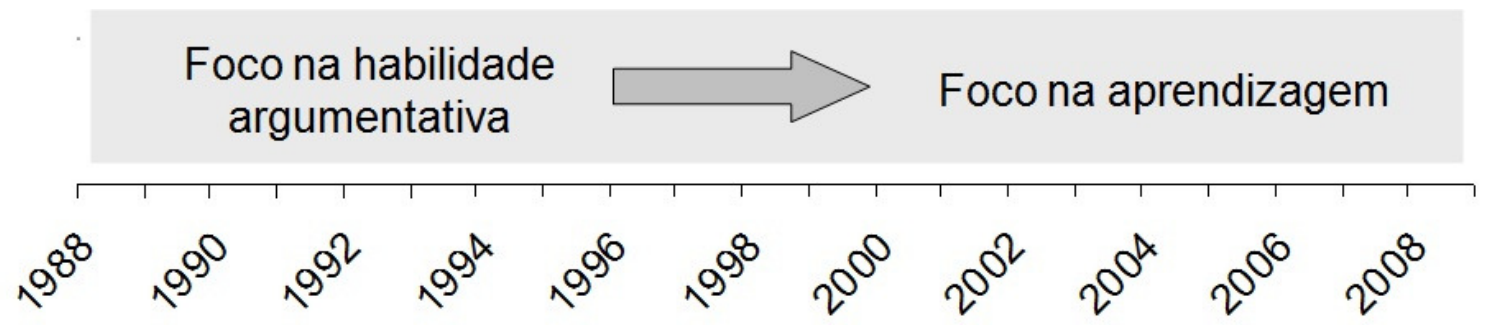

Figura 3. Eixo de mudança da pesquisa em AEC sobre o foco da pesquisa

Os artigos do supraperfil SP1 (estudos sobre a natureza da ciência ou sobre o ensino de Ciências) estão distribuídos de forma heterogênea ao longo do período considerado na presente pesquisa. Poucas vezes (2) predominou sobre os demais supraperfis, sendo que, nesses episódios (1992 e 2003), os artigos de SP1 publicados foram os únicos no ano. Observou-se uma ligeira concetração de artigos em 2008. Os 2 artigos de SP1 publicados em 2008 são do tipo de revisão, os quais baseiam-se corpo de pesquisa já existente. Caso se leve em conta o ano 2000 como início formal da pesquisa em AEC, por motivos já expostos no presente trabalho, oito anos de pesquisa na área demandaram estudos de revisão, tanto sobre a avaliação de instrumentos metodógicos, quanto de instrumentos teóricos utilizados na investigação em AEC

Ainda sobre a natureza dos artigos de SP1, outro aspecto parece conveniente de ser discutido. É esperado que esse tipo de pesquisa esteja, por um lado, no início do período analisado, e por outro presente ao longo dos últimos 21 anos, ao mesmo tempo em que os demais supraperfis de pesquisa vinham sendo explorados. Espera-se esse padrão de distribuição, uma vez que artigos desse seuperperfil revisam e criticam os resultados até então obtidos. Logo, a distribuição de artigos de SP1 ao longo dos 21 anos analisados justifica-se por três motivos: 1 . pela necessidade de fundamentação teórica para validá-la como área de pesquisa (representada pela publicação do artigo de Driver et al., 2000) e; 2 pela necessidade de momentos de avaliação dos instrumentos teóricos e metodológicos até então utilizados na pesquisa e; 3. em terceiro lugar, pela apresentação de novos rumos da pesquisa, devido à tomada de consciencia da comunidade científica do que se produziu até determinado o momento e qual a natureza dessa produção.

A tabela 5 mostra o número de publicações por supraperfil nos períodos de 1988-1999 e 2000-2008. A maioria das discussões a respeito do padrão de distribuição dos artigos e de sua natureza já foram realizadas no presente trabalho ao analisar, perfil a perfil, as tabelas 1 e 3 . No 
entanto, os resultados da tabela 5 permitem enxergar outro aspecto relevante da tendência da produção na área.

Tabela 5. Número de publicações por supraperfil nos períodos de 1988- 1999 e de 2000-2008

\begin{tabular}{|c|c|c|c|}
\hline \multirow{2}{*}{ Supraperfil } & $1998-2008(n=51)$ & $1988-1999(n=6)$ & $2000-2008(n=45)$ \\
\hline & Num. art (\%) & Num. art (\%) & Num. art (\%) \\
\hline 1 & $6(11,0 \%)$ & $1(16,7 \%)$ & $5(11,1 \%)$ \\
\hline 2 & $33(64,7 \%)$ & $3(50,0 \%)$ & $30(66,7 \%)$ \\
\hline 3 & $12(23,5 \%)$ & $2(34,3 \%)$ & $10(22,2 \%)$ \\
\hline
\end{tabular}

Esse aspecto refere-se à velocidade de aumento do número de artigos em cada supraperfil. O número de artigos de SP2 aumentou 10 vezes (de 3 para 30), enquanto os de SP1 e SP3 aumentaram, ambos, 5 vezes (de 1 para 5, e de 2 para 10, respectivamente). Destaca-se aqui o supraperfil SP2, que, ao mesmo tempo em que predomina sobre os demais quanto à velocidade de crescimento na área, também apresentou maior número de artigos em comparação dos demais supraperfis (33, em comparação a 6 e 12). Disso decorre que artigos com foco na estrutura do argumento e/ou na construção da argumentação, além de serem mais numerosos, cresceram em número de publicações mais rápido do que artigos com foco, ou no estudo sobre a natureza da ciência ou sobre o ensino de Ciências, ou ensino e aprendizagem.

Os resultados apontam para uma relação entre o número de artigos e a diversidade da pesquisa na área; relação esta relevante para a análise das tendências de pesquisa na área. No primeiro período considerado (1988-1999), as pesquisas focavam: em SP1, na discussão de práticas discursivas da Ciência e suas implicações para o ensino de Ciências (P2); em SP2, na análise do argumento em estratégias de ensino nas aulas de ciências (P5) e na avaliação, tanto dos instrumentos metodológicos utilizados na pesquisa, quanto de estratégias de ensino na promoção da argumentação (P4 e P5); e, por último, em SP3, os artigos focalizavam no desenvolvimento de habilidades para o ensino de argumentação em Ciências (P6) e no uso da argumentação para ensinar conteúdos específicos a professores de Ciências (P9).

Já no segundo período (2000-2008), o leque de temas e abordagens de investigação aumentou. SP1 passou a tratar de estudos de P1 e P3, além de artigos de P2 que permanceram de um período para outro. O supraperfil SP2 continuou com investigações de P4, P5 e P7. Por fim, artigos de SP3 estenderam seu perfil de pesquisa, incluindo estudos de P8. 
Como é possível observar, o supraperfil que sofreu maior incremento no número de perfis de um período para o outro foi SP1 (de 1, P2, para 3 perfis, P1, P2, P3). Por outro lado, o superprefil SP2 não apresentou incremento no número de perfis de um período para outro (P4, P5 e P7em ambos os períodos). Finalmente, o supraperfil SP3 apresentou incremento intermediário entre SP1 e SP2 no número de perfis de um período para outro (de 2, P6 e P8, para 3, P6, P8 e P9).

Desses resultados, sugere-se que: 1. no segundo período houve maior diversidade de estudos sobre a natureza da Ciência ou sobre o ensino de Ciências comparado ao primeiro; 2. a diversidade de estudos que focalizam na análise do argumento ou na construção da argumentação manteve-se semelhante em ambos os períodos; 3. a pesquisa sobre ensino e aprendizagem apresentou discreto aumento em sua diversidade de um período para outro; 4. quanto maior o número de artigos no supraperfil, menos aumentou sua diversidade de um período para outro, sendo o contrário, também verdadeiro e; 5. quanto maior o número de artigos no supraperfil, maior a velocidade com que aumentou o número de publicações do primeiro para o segundo períodos. 


\subsection{Análise do uso da obra de Toulmin (1958) como referencial teórico}

O quadro 8 apresenta o esquema de classificação dos tipos de uso da obra de Toulmin como referencial teórico nos artigos analisados. No quadro constam o número de artigos em cada categoria (T1, T2, T3, T4, T5 e T6), seus números de identificação e os respectivos anos de publicação. 


\begin{tabular}{|c|c|c|}
\hline $\begin{array}{l}\text { Classificação dos artigos segundo o tipo de uso } \\
\text { de Toulmin (1958) como referencial teórico }\end{array}$ & Art & Ano \\
\hline \multirow{8}{*}{$\begin{array}{l}\text { (T1) Uso dos conceitos de argumento e } \\
\text { argumentação de Toulmin no artigo, para defini-los } \\
\text { ou justificar sua centralidade no ensino de Ciências } \\
\text { [8] }\end{array}$} & 3 & 2008 \\
\hline & 30 & 2003 \\
\hline & 31 & 2002 \\
\hline & 35 & 2002 \\
\hline & 44 & 2000 \\
\hline & 46 & 1999 \\
\hline & 50 & 1997 \\
\hline & 51 & 1992 \\
\hline \multirow{15}{*}{$\begin{array}{l}\text { (T2) Uso não restrito do TAP como ferramenta de } \\
\text { análise do argumento [15] }\end{array}$} & 4 & 2008 \\
\hline & 5 & 2008 \\
\hline & 11 & 2007 \\
\hline & 16 & 2007 \\
\hline & 17 & 2007 \\
\hline & 21 & 2006 \\
\hline & 22 & 2006 \\
\hline & 26 & 2004 \\
\hline & 28 & 2004 \\
\hline & 32 & 2002 \\
\hline & 37 & 2001 \\
\hline & 42 & 2000 \\
\hline & 43 & 2000 \\
\hline & 45 & 2000 \\
\hline & 47 & 1999 \\
\hline \multirow{7}{*}{$\begin{array}{l}\text { (T3) Uso restrito do TAP como ferramenta de } \\
\text { análise do argumento [7] }\end{array}$} & 1 & 2008 \\
\hline & 2 & 2008 \\
\hline & 10 & 2008 \\
\hline & 12 & 2007 \\
\hline & 19 & 2006 \\
\hline & 20 & 2006 \\
\hline & 49 & 1998 \\
\hline \multirow{3}{*}{$\begin{array}{l}\text { (T4) Avaliação do TAP como ferramenta de } \\
\text { análise do argumento [3] }\end{array}$} & 7 & 2008 \\
\hline & 27 & 2004 \\
\hline & 29 & 2004 \\
\hline \multirow{5}{*}{$\begin{array}{l}\text { (T5) Crítica ao TAP ou uso de outro modelo de } \\
\text { análise do argumento [5] }\end{array}$} & 6 & 2008 \\
\hline & 9 & 2008 \\
\hline & 14 & 2007 \\
\hline & 23 & 2006 \\
\hline & 39 & 2001 \\
\hline \multirow[t]{13}{*}{ (T6) Não uso do modelo [13] } & 8 & 2008 \\
\hline & 13 & 2007 \\
\hline & 15 & 2007 \\
\hline & 18 & 2007 \\
\hline & 24 & 2006 \\
\hline & 25 & 2006 \\
\hline & 34 & 2004 \\
\hline & 33 & 2002 \\
\hline & 36 & 2002 \\
\hline & 38 & 2001 \\
\hline & 40 & 2001 \\
\hline & 41 & 2001 \\
\hline & 48 & 1999 \\
\hline
\end{tabular}

Quadro 8. Categorias do tipo de uso da obra de Toulmin (1958) como referencial teórico da pesquisa em argumentação no ensino de Ciências, onde T= Categoria do tipo de uso de Toulmin, IDE= Número de identificação do artigo, APU=ano de publicação do artigo 
A figura 4 traz as porcentagens de números de artigos por categoria (T1, T2, T3, T4, T5 e T6). Cada categoria refere-se a um tipo de uso da obra de Toulmin (1958) como referencial teórico. A categoria T2 possui o maior número de artigos, 29\%, seguido da categoria T6 com $25 \%$. A porcentagem de artigos nas categorias $\mathrm{T} 1$ e $\mathrm{T} 3$ foram de $16 \%$ e $14 \%$, respectivamente. As categorias que apresentaram menos artigos foram T5 e T4, com 10\% e 6\% respectivamente.

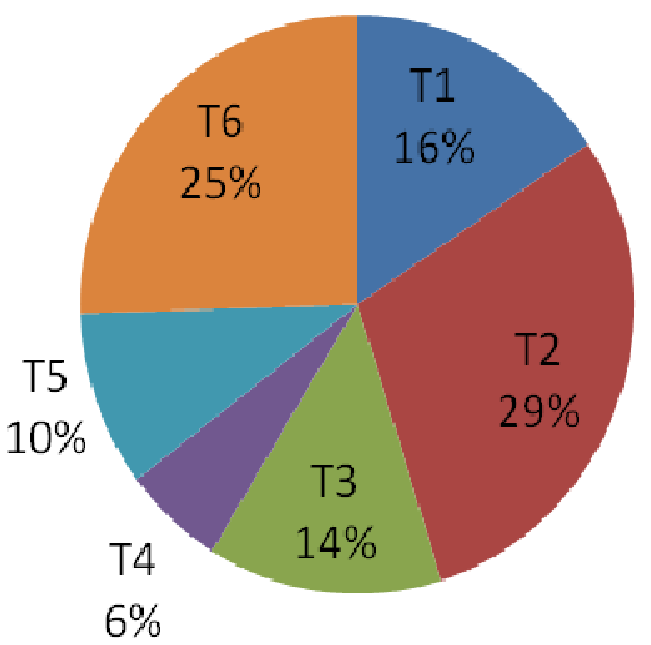

Figura 4. Porcentagem de publicações entre 1988 a 2008 por categoria do tipo de uso da obra de Toulmin (1958) como referencial teórico

Os artigos da categoria T2 (uso não restrito do TAP como ferramenta de análise do argumento) predominaram na pesquisa em AEC no período analisado. A pequena diferença (4\%) entre a porcentagem do número de artigos da categoria T2 e da categoria T6 (não uso do modelo), no entanto, apontam para prevalência de ambas as categorias, T2 e T6. Logo, autores que utilizaram a obra de Toulmin em seu referencial teórico, com vistas a se utilizarem do TAP para a análise de argumentos de forma não restrita (T2), e autores que não utilizaram esse referencial teórico, predominaram na pesquisa em AEC.

Esses resultados soam paradoxais. Como artigos com características tão distintas ocupam, ambos, lugar de destaque na pesquisa em AEC? Alguns pesquisadores afirmam que a utilização de Toulmin (1958) tem sido largamente utilizada na pesquisa em AEC como instrumento metodológico de análise do argumento (SAMPSON e CLARK, 2008; von AUFSCHNAITER et $a l ., 2008$ ). Essa tendência de pesquisa explica a alta porcentagem de artigos em T2 (mais de 1/4 de 
toda a amostra), porém não auxilia a entender o porquê de tantos estudos na categoria T6 (também próximo de $1 / 4$ da amostra). Parece que o cruzamento de dados das análises com foco nos perfis e com aqueles das análises com foco no tipo de uso de Toulmin pode lançar luz sobre essa questão. Essa discussão foi feita neste estudo e encontra-se na parte que discute a triangulação dos dados (subtítulo 5.4) no presente trabalho. A maioria dos trechos de artigos da categoria T1, utilizados como indicadores do tipo de uso da obra de Toulmin, foi encontrada na parte relativa à revisão de literatura, ao invés da parte relativa à metodologia. Além disso, artigos de T1 são, em sua maioria, do tipo de revisão ou de posição. Há menos publicações na pesquisa desses tipos em comparação com a pesquisa empírica (LEE et al., 2009). Dessa forma, os resultados do presente estudo vão parcialmente ao encontro dessa tendência da pesquisa no EC, na medida em que T1 faz parte do grupo de categorias em que se observaram as menores porcentagens de números de artigos (T1, T4 e T5). Parcialmente, pois, apesar disso, T1 lidera com $12 \%$ dos artigos, em comparação com 10\%, tanto para T4, como para T5.

A categoria T3 (uso restrito do TAP como ferramenta de análise do argumento) é a quarta colocada entre as demais categorias em porcentagem de artigos. A diferença entre os artigos de T2 e de T3 é que, naqueles, aplica-se o TAP sem modificações ou adições no instrumento de análise. Enquanto nesses, o TAP fundamentou, ou seja, deu origem a outro instrumento de análise do argumento, na tentativa de superar algumas de suas limitações.

A esse respeito, é possível citar duas principais complicações que pesquisadores da área enfrentaram na utilização desse referencial metodológico: 1. falta de confiabilidade na distinção entre conclusão, dado, justificativa e conhecimento básico, uma vez que os comentários feitos pelos estudantes frequentemente podem ser identificados em múltiplas categorias (JIMÉNEZALEIXANDRE et al., 2000; KELLY et al., 1998); e 2. apesar de Toulmin (1958) ressaltar a importância da campo-dependência em sua obra, o TAP fornece pouca informação sobre componentes campo-dependentes. Esses motivos impeliram parte dos pesquisadores da área a aperfeiçoar a ferramenta, porém, sem abandoná-la, pois, como afirmam Sampon e Clark (1998), o TAP foi e ainda é fundamental para a pesquisa na área por possibilitar a identificação dos componentes do argumento.

Disso decorre que a partir do momento em que se constataram as limitações da ferramenta para análise de argumentos nas aulas de Ciências, a pesquisa com uso restrito do TAP começou a se avolumar, ganhando espaço na área. 
A categoria T5 (crítica ao TAP ou uso de outro modelo de análise do argumento) e a categoria T4 (avaliação do TAP como ferramenta de análise do argumento) correspondem, respectivamente, a 10\% e 6\% dos artigos analisados. Os artigos inseridos em T4 e em T5 estão ligados aos da categoria T3, já que são estudos que avaliam a adequação do TAP na análise do argumento produzidos nas aulas de Ciências ou utilizam outras ferramentas de análise do argumento. Levando em consideração que a pesquisa com uso não restrito de TAP (T2) predomina na área (29\%), e que surgiu, em algum momento da história da pesquisa em AEC, modelos aperfeiçoados do TAP, que procuravam superar algumas das limitações identificadas (T3, 14\%), é natural pensar que o número de publicações avaliando o TAP (T4, 6\%) e utilizando outros instrumentos de análise do argumento (T5, 10\%) seja próxima à de T3, sem, com isso, superar o número de publicações de T2. Dessa forma, artigos em T4 estariam ligados aos de T3, pois permitem identificar quais seriam pontos de melhoria na ferramenta, e artigos de T5, pois representariam uma linha alternativa de análise, depois de constatada a ineficácia do TAP para analisar argumentos produzidos em contextos de sala de aula.

A figura 4 auxilia a ter um panorama geral do tipo de uso de Toulmin no referencial teórico de artigos de AEC, porém não permite identificar tendências ao longo dos 21 anos estudados. Essa idenficação é possível a partir da análise da tabela 6. Essa tabela apresenta o número de artigos em cada categoria, referentes ao uso de Toulmin no referencial teórico, entre o período de 1988-2008. 
Tabela 6. Número de publicações por tipo de uso de Toulmin (1958) como referencial teórico, no período de 1988- 2008

\begin{tabular}{|c|c|c|c|c|c|c|c|c|}
\hline \multirow{2}{*}{ Categ. } & $1998-2008(n=51)$ & $1988(n=0)$ & $1989(n=0)$ & $1990(n=0)$ & $1991(\mathrm{n}=0)$ & $1992(n=1)$ & $1993(n=0)$ & $1994(n=0)$ \\
\hline & Num. art (\%) & Num. $\operatorname{art}(\%)$ & Num. art (\%) & Num. art (\%) & Num. art (\%) & Num. art (\%) & Num. art (\%) & Num. art (\%) \\
\hline T1 & $8(15,7 \%)$ & $0(0,0 \%)$ & $0(0,0 \%)$ & $0(0,0 \%)$ & $0(0,0 \%)$ & $1(100,0 \%)$ & $0(0,0 \%)$ & $0(0,0 \%)$ \\
\hline $\mathrm{T} 2$ & $15(29,4 \%)$ & $0(0,0 \%)$ & $0(0,0 \%)$ & $0(0,0 \%)$ & $0(0,0 \%)$ & $0(0,0 \%)$ & $0(0,0 \%)$ & $0(0,0 \%)$ \\
\hline $\mathrm{T} 3$ & $7(13,7 \%)$ & $0(0,0 \%)$ & $0(0,0 \%)$ & $0(0,0 \%)$ & $0(0,0 \%)$ & $0(0,0 \%)$ & $0(0,0 \%)$ & $0(0,0 \%)$ \\
\hline $\mathrm{T} 4$ & $3(5,9 \%)$ & $0(0,0 \%)$ & $0(0,0 \%)$ & $0(0,0 \%)$ & $0(0,0 \%)$ & $0(0,0 \%)$ & $0(0,0 \%)$ & $0(0,0 \%)$ \\
\hline T5 & $5(9,8 \%)$ & $0(0,0 \%)$ & $0(0,0 \%)$ & $0(0,0 \%)$ & $0(0,0 \%)$ & $0(0,0 \%)$ & $0(0,0 \%)$ & $0(0,0 \%)$ \\
\hline T6 & $13(25,5 \%)$ & $0(0,0 \%)$ & $0(0,0 \%)$ & $0(0,0 \%)$ & $0(0,0 \%)$ & $0(0,0 \%)$ & $0(0,0 \%)$ & $0(0,0 \%)$ \\
\hline
\end{tabular}

\begin{tabular}{|c|c|c|c|c|c|c|c|c|}
\hline \multirow{2}{*}{ Categ. } & $1995(\mathrm{n}=0)$ & $1996(\mathrm{n}=0)$ & $1997(n=1)$ & $1998(n=1)$ & $1999(n=3)$ & $2000(n=4)$ & $2001(n=5)$ & $2002(n=5)$ \\
\hline & Num. art (\%) & Num. art (\%) & Num. art (\%) & Num. art (\%) & Num. art (\%) & Num. art (\%) & Num. art (\%) & Num. art (\%) \\
\hline T1 & $0(0,0 \%)$ & $0(0,0 \%)$ & $1(100,0 \%)$ & $0(0,0 \%)$ & $1(33,3 \%)$ & $1(25,0 \%)$ & $0(0,0 \%)$ & $2(40,0 \%)$ \\
\hline $\mathrm{T} 2$ & $0(0,0 \%)$ & $0(0,0 \%)$ & $0(0,0 \%)$ & $0(0,0 \%)$ & $1(33,3 \%)$ & $3(75,0 \%)$ & $1(20,0 \%)$ & $1(20,0 \%)$ \\
\hline $\mathrm{T} 3$ & $0(0,0 \%)$ & $0(0,0 \%)$ & $0(0,0 \%)$ & $1(100,0 \%)$ & $0(0,0 \%)$ & $0(0,0 \%)$ & $0(0,0 \%)$ & $0(0,0 \%)$ \\
\hline $\mathrm{T} 4$ & $0(0,0 \%)$ & $0(0,0 \%)$ & $0(0,0 \%)$ & $0(0,0 \%)$ & $0(0,0 \%)$ & $0(0,0 \%)$ & $0(0,0 \%)$ & $0(20,0 \%)$ \\
\hline T5 & $0(0,0 \%)$ & $0(0,0 \%)$ & $0(0,0 \%)$ & $0(0,0 \%)$ & $0(0,0 \%)$ & $0(0,0 \%)$ & $1(20,0 \%)$ & $0(00,0 \%)$ \\
\hline T6 & $0(0,0 \%)$ & $0(0,0 \%)$ & $0(0,0 \%)$ & $0(0,0 \%)$ & $1(33,3 \%)$ & $0(0,0 \%))$ & $3(60,0 \%)$ & $2(40,0 \%)$ \\
\hline
\end{tabular}

\begin{tabular}{|c|c|c|c|c|c|c|}
\hline \multirow{2}{*}{ Categ. } & $2003(n=1)$ & $2004(n=5)$ & $2005(\mathrm{n}=0)$ & $2006(n=7)$ & $2007(n=8)$ & $2008(n=10)$ \\
\hline & Num. art (\%) & Num. art (\%) & Num. art (\%) & Num. art (\%) & Num. art (\%) & Num. art (\%) \\
\hline $\mathrm{T} 1$ & $1(100,0 \%)$ & $0(0,0 \%)$ & $0(0,0 \%)$ & $0(0,0 \%)$ & $0(0,0 \%)$ & $1(10,0 \%)$ \\
\hline T2 & $0(0,0 \%)$ & $2(40,0 \%)$ & $0(0,0 \%)$ & $2(28,6 \%)$ & $3(37,5 \%)$ & $2(20,0 \%)$ \\
\hline $\mathrm{T} 3$ & $0(0,0 \%)$ & $0(00,0 \%)$ & $0(0,0 \%)$ & $2(28,6 \%)$ & $1(12,5 \%)$ & $3(30,0 \%)$ \\
\hline $\mathrm{T} 4$ & $0(0,0 \%)$ & $2(40,0 \%)$ & $0(0,0 \%)$ & $0(0,0 \%)$ & $0(0,0 \%)$ & $1(10,0 \%)$ \\
\hline T5 & $0(0,0 \%)$ & $0(0,0 \%)$ & $0(0,0 \%)$ & $1(14,3 \%)$ & $1(12,5 \%)$ & $2(20,0 \%)$ \\
\hline T6 & $0(0,0 \%)$ & $1(20,0 \%)$ & $0(0,0 \%)$ & $2(28,6 \%)$ & $3(37,5 \%)$ & $1(10,0 \%)$ \\
\hline
\end{tabular}


A partir da análise dos resultados apresentados na tabela 6 é possível observar um aumento da diversidade de categorias, ao mesmo tempo em que aumenta o número de artigos. Isso pode ser verificado comparando número de categorias nos anos de 2007 e 2008 (com 5 e 6 categorias, respectivamente) e os demais anos (todos com, no máximo, quatro categorias). Esses dados apontam para um aumento acentuado na diversidade dos tipos de uso da obra de Toulmin ao final do período estudado.

Ao analisar os tipos de uso de Toulmin que foram feitos nos artigos, é possível notar a utilização quase exclusiva do TAP (T2) como ferramenta de análise do argumento durante todo período. No entanto, ao final desse recorte temporal, expandiram-se os usos, na medida em que a pesquisadores reconheceram as limitações e possibilidades do modelo de Toulmin na análise do argumento. Logo, a diversificação do tipo de usos da obra desse autor explica-se pelo surgimento da necessidade de exploração de outros referenciais teórico-medológicos que permitissem um olhar mais aprofundado sobre os argumentos produzidos nas aulas de Ciências.

Os resultados da presente pesquisa também sugerem correlação entre o número de artigos por categoria e a uniformidade de publicações ao longo do período analisado. Uma correlação parecida foi discutida neste trabalho, quando se analisou a relação entre o número de artigos por perfil e uniformidade das publicações. Para o caso da correlação entre o tipo de uso da obra de Toulmin e a uniformidade das publicações, obsevou-se a mesma tendência: quanto maior o número de artigos na categoria, maior a uniformidade dessas publicações. A distribuição dos artigos das categorias T2 e T6 ilustram essa correlação. O número de artigos em T2 e T5 é o maior em comparação aos outros, e sua distribuição é a mais uniforme comparada às demais categorias. Isso pode ser verificado observando a relação entre o número de anos em que houve, pelo menos, uma (1) publicação em cada categoria e o número total de artigos de cada categoria (tabela 7). Assim, temos, para a categoria T2, a relação de 8/15, e para T6, 7/13. A relação das categorias T1, T3, T4 e T5 são, respectivamente, 7/8, 4/7, 2/3 e 4/5. Essas relações refletem a correspondência em que, quanto maior o valor do denominador, maior o número do numerador. Por isso, os resultados sugerem a existência de correlação entre o número de artigos por categoria e a uniformidade de publicações ao longo do período analisado. 
Tabela 7. Número de anos em que houve, pelo menos, uma (1) publicação em cada categoria e número total de artigos por categoria, entre 1988 e 2008

\begin{tabular}{|c|c|c|c|c|c|c|}
\hline & T1 & $\mathbf{T 2}$ & T3 & T4 & T5 & T6 \\
\hline 1988 & 0 & 0 & 0 & 0 & 0 & 0 \\
\hline 1989 & 0 & 0 & 0 & 0 & 0 & 0 \\
\hline 1990 & 0 & 0 & 0 & 0 & 0 & 0 \\
\hline 1991 & 0 & 0 & 0 & 0 & 0 & 0 \\
\hline 1992 & 1 & 0 & 0 & 0 & 0 & 0 \\
\hline 1993 & 0 & 0 & 0 & 0 & 0 & 0 \\
\hline 1994 & 0 & 0 & 0 & 0 & 0 & 0 \\
\hline 1995 & 0 & 0 & 0 & 0 & 0 & 0 \\
\hline 1996 & 0 & 0 & 0 & 0 & 0 & 0 \\
\hline 1997 & 1 & 0 & 0 & 0 & 0 & 0 \\
\hline 1998 & 0 & 0 & 1 & 0 & 0 & 0 \\
\hline 1999 & 1 & 1 & 0 & 0 & 0 & 1 \\
\hline 2000 & 1 & 3 & 0 & 0 & 0 & 0 \\
\hline 2001 & 0 & 1 & 0 & 0 & 1 & 3 \\
\hline 2002 & 2 & 1 & 0 & 0 & 0 & 2 \\
\hline 2003 & 1 & 0 & 0 & 0 & 0 & 0 \\
\hline 2004 & 0 & 2 & 0 & 2 & 0 & 1 \\
\hline 2005 & 0 & 0 & 0 & 0 & 0 & 0 \\
\hline 2006 & 0 & 2 & 2 & 0 & 1 & 2 \\
\hline 2007 & 0 & 3 & 1 & 0 & 1 & 3 \\
\hline 2008 & 1 & 2 & 3 & 1 & 2 & 1 \\
\hline $\begin{array}{l}\text { Num. de anos em que houve, } \\
\text { pelo menos, uma (1) publicação }\end{array}$ & 7 & 8 & 4 & 2 & 4 & 7 \\
\hline Num. total de artigos & 8 & 15 & 7 & 3 & 5 & 13 \\
\hline
\end{tabular}

Seguindo a ordem da porcentagem de artigos por categoria (figura 4), da maior para a menor, abaixo serão discutidas as tendências observadas em cada uma das seis categorias (T1, T2, T3, T4, T5 e T6), ao longo dos 21 anos considerados nesta pesquisa (1998-2008).

Os artigos da categoria T2 (uso não restrito do TAP como ferramenta de análise do argumento) começam a ser publicados em 1999. Desde então, não houve interrupções na publicação de artigos de T2, exceto nos anos de 2003 e 2005, em que não houve publicações em nenhuma categoria. Esses resultados apontam para presença desse tipo de artigo durante todo período analisado, já que o período de produção científica em AEC encontra-se concentrado após do ano de 2000. Logo, estudos queutilizaram fielmente o modelo de 
argumento de Toulmin para analisar os argumentos produzidos nas aulas de Ciências tiveram papel relevante para área.

Quanto à natureza dos artigos na categoria T2, destacam-se estudos mais recentes. Nesses, existem dois tipos de uso da obra de Toulmin que se diferenciam dos demais artigos. Há pesquisas que, além do TAP, utilizam outros componentes e referenciais teóricometodológicos para analisar o argumento produzido pelos estudantes (artigos 16 e 5, dos anos de 2007 e 2008, respectivamente). Outras, utilizam modelos simplificados do TAP, fazendo uso de somente três das seis categorias propostas por Toulmin. Esses artigos utilizam somente o dado, a justificativa e a conclusão, não identificando o conhecimento básico, o qualificador modal e a refutação (artigo 22 e 21, ambos de 2006). O destaque desses dois tipos de pesquisa refere-se ao período de publicação, 2006 a 2008.

Esses dados sugerem uma modificação em estudos em que não houve restrição para o uso do TAP como ferramenta de análise do argumento. Alguns artigos mais recentes, além de se utilizarem do TAP, também usaram ferramentas complementares para análise do argumento. Esse movimento na pesquisa em AEC deveu-se, segundo Sampson e Clark (2008), às limitações da ferramenta de Toulmin, como já citado anteriormente no presente trabalho.

O curioso é que, mesmo na categoria $\mathrm{T} 2$, em que pesquisadores se utilizaram de TAP sem nenhuma restrição, já existem artigos cuja análise do argumento requereu ferramentas complementares. Isso, de um lado, reforça a importância que o TAP teve na pesquisa em AEC. De outro lado, porém, apontam para a necessidade de criação de outras ferramentos de análise do argumento, assim como a utilização de outros referenciais teórico-metodológicos.

Até o ano de 1998, o número de artigos da categoria T6 acompanhou a tendência daqueles nas demais categorias, ou seja, pouquísimas publicações. A situação mudou, no entanto no ano de 2001. Deste momento até 2008, observaram dois picos no número de artigos de T6, 2001 e 2002, e 2006 e 2007. Esses picos coincidiram com os anos em que houve maior número de publicações, 5 e 5, e 7 e 8 , respectivamente. Além disso, nos anos de 2001 e 2002, artigos de T6 superaram os de T2, diferentemente do que ocorreu em 2006 e 2007, em que o número de artigos para essa e aquela categoria foi o mesmo. Apesar do esforço de interpretação, não foi possível identificar nenhuma associação entre esse padrão de distribuição e dos artigos das demais categorias.

Como a obra de Toulmin estava ausente em todos os artigos de T6, não é possível identificar somente com base nos dados da figura 4 e da tabela 6 , qual a natureza desses 
estudos. Mais uma vez, o cruzamento de dados das análises com foco nos perfis e com foco no tipo de uso de Toulmin carrega possibilidades interessantes de análise.

Os artigos da categoria T1 (uso dos conceitos de argumento e argumentação de Toulmin no artigo, para defini-los ou justificar sua centralidade no ensino de Ciências) distribuem-se ao longo de todo período considerado no presente estudo. Desde o ano de 1992, até 2008, os artigos com esse tipo de uso da obra de Toulmin estiveram sempre presentes no cenário da pesquisa. Em dois períodos, no entanto, houve uma lacuna na publicação de artigos de T1: 1988 e 1991 e 2004 a 2007.

A ausência de estudos na categoria T1 entre 1988 e 1991 explica-se, pois, nesse período, não houve publicação de nenhum artigo. No segundo período, no entanto, houve publicações de artigos de todas as categorias em todos os anos, exceto no caso de 2005, em que não foi publicado nenhum artigo.

Sobre esse segundo período de publicação, a relação entre esses resultados de pesquisa e aqueles a respeito do tipo de artigo (classificados como de revisão, de posição ou empírico), sugere duas discussões sobre a distribuição de estudos de T1. Em primeiro lugar, artigos de T1 (total de 6 artigos) são compostos, em sua maioria (4 artigos), por estudos de revisão e de posição, ao invés de empíricos (2 artigos). Explica-se, portanto, porque o número de artigos em cada ano nunca é superior a 1, uma vez que pesquisas de revisão e de posição são mais escassaz e demandam certo volume de pesquisa para serem realizadas. Aliado a esse fato, a segunda discussão diz respeito ao período sem publicações, entre 2004 e 2007. Como a produção de estudos de revisão e de posição demandam um corpus maior de pesquisa, diminuindo, assim, a frequência de publicação desse tipo de artigo, a lacuna de quatro anos entre uma publicação de T1 (2003) e outra (2008) não se distancia do padrão de distribuição esperado.

A análise dos tipos de uso da obra de Toulmin nos artigos da categoria T1 possibilitou levantar tendências sobre a natureza da pesquisa. Todos os artigos de T1 se utilizaram do conceito de argumento de Toulmin a fim de apresentar suas escolhas teóricas. Houve somente um artigo que distoou dos demais quanto ao tipo de uso de Toulmin no referencial teórico, o artigo 51. Este relaciona o argumento ao pensamento crítico de forma explícita no trecho coletado. Os demais artigos, entretanro, utilizaram a obra de Toulmin para definir o argumento ou justificar sua centralidade no EC, porém de formas diferentes. Alguns artigos veem o argumento do ponto de vista de sua prática de uso, e não sob o ponto de vista exclusivo da lógica formal (ex. artigos 3 e 35). Outros remetem à centralidade da argumentação no EC (ex. artigo 50 e 46). Devida à relativa diversidade de temas dentro de 
T1, é possível afirmar que nenhum tipo de estudo predominou. Logo, sugere-se a pesquisa em AEC que utilizou a obra de Toulmin em seu referencial teórico para definir argumentação ou justificar sua centralidade no ensino de Ciências não se concentrou em uma questão de específica ao longo dos últimos 21 anos de pesquisa.

Os artigos da categoria T3 (uso restrito do TAP como ferramenta de análise do argumento) possuem um padrão de distribuição diferente das categorias até então analisadas, T2 T6 e T1. Para essa discussão, no entanto, o foco se voltou para a comparação entre os artigos de T3 e de T2. Comparados aos de T2, aqueles são mais recentes. Isso pode ser verificado observando a data de publicação de estudos em T3. Desde o início do período analisado (1988), até ano de 2006, houve somente uma publicação (1998) em T3. Esta, inclusive, distoa do restante das publicações que fizeram uso da obra de Toulmin à época, na medida em que utilizam o TAP, porém com certa restrição.

Para este assunto, Sampson e Clark (2008) apresentam alguns motivos que impulsionaram a pesquisa em AEC a desenvolver outras ferramentas de análise baseadas no modelo de argumento proposto por Toulmin. Entre eles, os autores citam a subjetividade na classificação dos trechos nas categorias que compõe o TAP, e a ênfase na estrutura campoinvariável (TOULMIN, 1958), em detrimento da estrutura campo-depedente. Nesse caso, a predominância do TAP dificultou a avaliação da qualidade dos argumentos quanto ao conteúdo específico das Ciências mobilizado durante sua produção pelos estudantes.

O caráter recente dos artigos da categoria T3, portanto, vem ao encontro desse cenário de pesquisa em $\mathrm{AEC}$, em que a consciência das limitações dessa ferramenta de análise resultou no seu aperçoamento. A análise da natureza dos estudos nessa categoria endossa e aprofunda a discussão sobre esse aperfeiçoamento. Na maioria dos artigos de T3 (5 de um total de 7 artigos) é possível identificar qual o referencial teórico-metodológico utilizado na elaboração da ferramenta complementar ou derivada do TAP. Desses cinco estudos, dois (artigos 1 e 19) declaram ter usado a ferramenta de análise do argumento desenvolvido por Erduran et al. (2004), dois declaram terem utilizado a desenvolvida por Osborne et al. (2004) (artigos 10 e 12), e uma por Resnick et. al. (1993) (artigo 49). Os dois estudos publicados em 2004 fazem parte de um mesmo projeto desenvolvido entre 1999 e 2001, em Londres, com estudantes que estariam no nível de ensino equivalente ao ensino médio no Brasil. Nesse projeto, intitulado "Enhancing the Quality of Argument in School Science", pesquisadores colaboraram com professores de Ciências para desenvolver atividades pedagógicas em um esforço para inserir a argumentação como componente curricular. 
Os autores dessa ferramenta de análise do argumento simplificam as categorias do TAP, reunindo os dados, justificativas e conhecimento básico em uma única categoria chamada grounds, literalmente traduzível por fundamentos. Sampson e Clark (2008) explicam a ferramenta.

Ao invés de simplesmente identificar a presença ou ausência de fundamentos, a ferramenta de análise classifica os trechos como não tendo fundamento (fundamentos qualidade nível 0), incluindo somente uma explicação sem evidência [...] (fundamentos de qualidade nível 1), usando evidência [...] (fundamentos de qualidade nível 2), e incluindo evidência e uma explicação ou coordenando múltiplas evidências [...] (fundamentos de qualidade nível 3). (SAMPSON e CLARK, 2008, p. 298, tradução nossa).

Sampson e Clark (2008) remetem-se a esse tipo de derivação ao TAP, como modelos 'minimalistas', cuja criação foi motivada, como já citado, pela subjetividade da classificação a partir do modelo de Toulmin, ou pela crescente preocupação na pesquisa em AEC com a natureza da justficativa, em detrimento da identificação de sua ausência ou presença.

Dessa forma, os resultados apontam para considerável a influência que os artigos de Erduran et al., e Osborne et al.tiveram na pesquisa em AEC, no sentido de oferecer alternativas de ferramentas de análise do argumento, que não distoam do TAP, mas aperfeiçoam devido ao movimento de valorização da análise das justificativas e conteúdos dos argumentos produzidos pelos estudantes nas aulas de Ciências. Além disso, outra consideração, agora do campo metodológicos, ressalta nessa análise. Nem todos os trechos coletados dos artigos que continham o tipo de uso da obra de Toulmin (1958), traziam informações suficientes a fim de identificar qual outro referencial teórico-metodológico o autor utilizou para suprir as limitações do TAP.

Os artigos categoria T5 (crítica ao TAP ou uso de outro modelo de análise do argumento) e da categoria T4 (avaliação do TAP como ferramenta de análise do argumento) estão dispostos de forma relativamente uniforme a partir de 1999. Houve uma ligeira concentração de artigos nos anos de 2004 e 2008. Naquele, houve duas publicações, artigos 27 e 29, ambas de T4. E no ano de 2008, três: um de T4 (artigo 7) e dois de T5 (artigos 6 e 9). Esses resultados sugerem que a produção que focaliza tanto a avaliação, quanto a crítica do TAP e uso de modelos alternativos é relativamente recente.

No interior dessas categorias é possível identificar um conjunto de artigos que avaliam ou criticam o TAP sem especificar quais são os pontos de avaliação ou crítica (artigos 7, 9, 23 
e 27), e outro conjunto que apresenta explicitamente esses pontos. Os artigos, 6, 29 e 39, por exemplo, afirmam que o modelo de Toulmin não permite avaliar operações epistêmicas mobilizadas pelos sujeitos da pesquisa. O artigo 14, por sua vez, cita como limitação oriunda do uso do modelo de Toulmin, a dificuldade na análise de aspectos campo-dependentes. $\mathrm{O}$ artigo 6 vai ao encontro da posição desses últimos três artigos, na medida em que enfatiza o conteúdo, ao invés da estrutura do argumento, apontando, também, para a limitação do TAP na compreesão da dimensão social do argumento.

Os resultados da pesquisa realizada por Sampson e Clark (2008) convergem com os resultados do presente estudo. A dupla de autores afirma que, apesar da maioria dos estudos ressaltar a importância do conteúdo, somente algumas ferramentas utilizadas na pesquisa em AEC exploram-no de forma satisfatória (SANDOVAL, 2003; SANDOVAL e MILLWOOD, 2005; ZOHAR e NEMET, 2002). Os pesquisadores ainda asseguram que o TAP não possibita avaliar o conteúdo. O caráter recente dos artigos cujo uso da obra de Toulmin (1958) referiuse a sua avaliação ou crítica adequa-se à nova demanda da pesquisa de buscar outras ferramentas de análise do argumento. Sugere-se, então, que os estudos com foco na avaliação do TAP, em sua crítica e no uso de modelos alternativos para análise do argumento passaram a crescer em 2004 e seus desdobramentos ainda parecem pouco explorados na pesquisa em AEC.

Além na tabela 6, que traz, ano a ano (1989-2008), o número de artigos publicados em cada categoria (T1, T2, T3, T4, T5 e T6), um panorama dos tipos de uso da obra de Toulmin (1958) nos artigos podem também ser analisados a partir da tabela 8. Essa tabela apresenta o número de artigos por categoria, nos dois períodos considerados neste estudo, 1988-1999 e 2000-2008.

Tabela 8. Número de publicações por tipo de uso de Toulmin (1958) como referencial teórico, no período de 1988- 1999 e de 2000-2008

\begin{tabular}{|c|c|c|c|}
\hline \multirow{2}{*}{ Categoria } & $1998-2008(n=51)$ & $1988-1999(\mathrm{n}=6)$ & $2000-2008(n=45)$ \\
\hline & Num. art (\%) & Num. art (\%) & Num. art (\%) \\
\hline $\mathrm{T} 1$ & $8(15,7 \%)$ & $3(50,0 \%)$ & $5(11,1 \%)$ \\
\hline $\mathrm{T} 2$ & $15(29,4 \%)$ & $1(16,7 \%)$ & $14(31,1 \%)$ \\
\hline T3 & $7(13,7 \%)$ & $1(16,7 \%)$ & $6(13,3 \%)$ \\
\hline T4 & $3(5,9 \%)$ & $0(0,0 \%)$ & $3(6,7 \%)$ \\
\hline T5 & $5(9,8 \%)$ & $0(0,0 \%)$ & $5(11,1 \%)$ \\
\hline T6 & $13(25,5 \%)$ & $1(16,7 \%)$ & $12(26,7 \%)$ \\
\hline
\end{tabular}

$\mathrm{O}$ primeiro destaque dos dados apresentados na tabela 8 refere-se às categorias T4 (avaliação do TAP como ferramenta de análise do argumento) e T5 (crítica ao TAP ou uso de outro modelo de análise do argumento). Não foi observada nenhuma publicação no período 
que vai de 1989 a 1999. Toda a produção nessas duas categorias está concentrada no segundo período, 2000-2008. Esses dados reforçam a tendência levantada anteriormente de que os estudos com foco na avaliação do TAP, em sua crítica e no uso de modelos alternativos para análise do argumento são recentes e de que ainda parecem pouco explorados na pesquisa em AEC.

Em contraste, a categoria que apresentou distribuição mais uniforme entre os dois períodos analisado foi T1 (uso dos conceitos de argumento e argumentação de Toulmin no artigo, para defini-los ou justificar sua centralidade no ensino de Ciências). Dos oito artigos de T1, três estão no primeiro período, e cinco, no segundo.

Essa uniformidade parece se justificar pela natureza desses artigos. Trabalhos que utilizaram a obra de Toulmin para definir argumento ou mesmo justificar a centralidade da AEC não necessariamente foram desenhados para que sua fonte de dados se originasse da análise do argumento. Dessa forma, a utilização do TAP também não seria necessária. Assim, artigos que versam sobre argumentação e citam a obra de Toulmin (1958) ocupariam um campo de investigação distinto daquele em que a análise do argumento e/ou dos processos de argumentação é a fonte primeira de dados para a pesquisa. Trabalhos documentais e de revisão fazem parte desse tipo de pesquisa. Esses resultados sugerem que estudos de natureza de revisão tiveram importante papel importante na inauguração da área. Destaque para o artigo 44 (Driver et al., 2000) que marcou a produção científica em AEC, uma vez que se observou aumento no volume de publicações no período posterior à sua publicação.

A categoria T2 (uso não restrito do TAP como ferramenta de análise do argumento) aprensentou o maior número de artigos nos 21 anos analisados (15). A quase totalidade desses artigos foi publicada no segundo período. Esses resultados endossam o ano de 2000 como importante na pesquisa em AEC, uma vez que, a categoria numericamente mais expressiva, T2, encontram-se entre 2000-2008. Além disso, os artigos das categorias T3 e T6 apresentaram padrão de distribuição semelhante, em que a maioria dos estudos situa-se no segundo período. De forma geral, então, todos os artigos concentram-se entre 2000-2008.

Desses resultados, sugere-se que: 1. no segundo período houve maior diversidade de estudos sobre o tipo de uso da obra de Toulmin (1958) como referencial teórico dos artigos, comparado ao primeiro; 2. a pesquisa que fez uso de Toulmin para definir o argumento ou jsutificar sua centralidade no EC teve papel importante na inauguração da pesquisa em AEC entre o final da década de 90 e o início da década seguinte; e 3. pelo fato da análise dos usos de Toulmin (1958) nos artigos remeter diretamente às ferramentas de análise utilizadas na pesquisa em AEC, pôde-se observar que as referências sobre as limitações do TAP 
aumentaram gradativamente ao longo dos 21 anos estudados, com especial destaque para o período a partir do ano de 2004. Os dados da presente pesquisa apontam para os mesmos caminhos levantados por Sampson e Clark (2008), quando asseguram que, atualmente, a tendência de análise do argumento visa à discussão e à utilização de ferramentas menos atomizadas e mais holísticas. 
5.3.Triangulação de dados: relação entre o foco de análise 'perfis e supraperfis de pesquisa' e o foco 'uso da obra de Toulmin (1958) como referencial teórico'

Algumas tendências da pesquisa em AEC puderam ser reveladas analisando-se os artigos, primeiro, sobre o foco de análise nos 'perfis e supraperfis de pesquisa' e, segundo, sobre o foco de análise 'uso da obra de Toulmin (1958) como referencial teórico'. As possibilidades, no entanto, não se encerram nessas análises. A triangulação dos dados analisados sobre os dois focos citados permitiu levantar associações igualmente relevantes sobre as tendências da pesquisa na área.

Para essa triangulação foram considerados os dados sobre os supraperfis e sobre o uso da obra de Toulmin (1958) como referencial teórico. Não foram considerados dados sobre os perfis, pois se considerou a classificação e discussão dos artigos por perfis como etapa preliminar para a criação dos supraperfis, categorias mais amplas e consistentes. A tabela 9 a seguir apresenta o número de artigos de cada supraperfil, SP1, SP2 e SP3, classificados por categoria, T1, T2, T3, T4, T5 e T6. Os dados contidos nessa tabela também foram apresentados em um gráfico de colunas (figura 5).

\begin{tabular}{ccccc}
\hline & SP1 & SP2 & SP3 & Total \\
\cline { 2 - 5 } T1 & 4 & 0 & 4 & $\mathbf{8}$ \\
T2 & 0 & 12 & 3 & $\mathbf{1 5}$ \\
T3 & 0 & 5 & 2 & $\mathbf{7}$ \\
T4 & 2 & 1 & 0 & $\mathbf{3}$ \\
T5 & 0 & 4 & 1 & $\mathbf{5}$ \\
T6 & 0 & 11 & 2 & $\mathbf{1 3}$ \\
\hline Total & $\mathbf{6}$ & $\mathbf{3 3}$ & $\mathbf{1 2}$ & $\mathbf{5 1}$
\end{tabular}

Tabela 9. Número de artigos por supraperfil classificados segundo as categorias de tipo de uso da obra de Toulmin (1958) como referencial teórico 


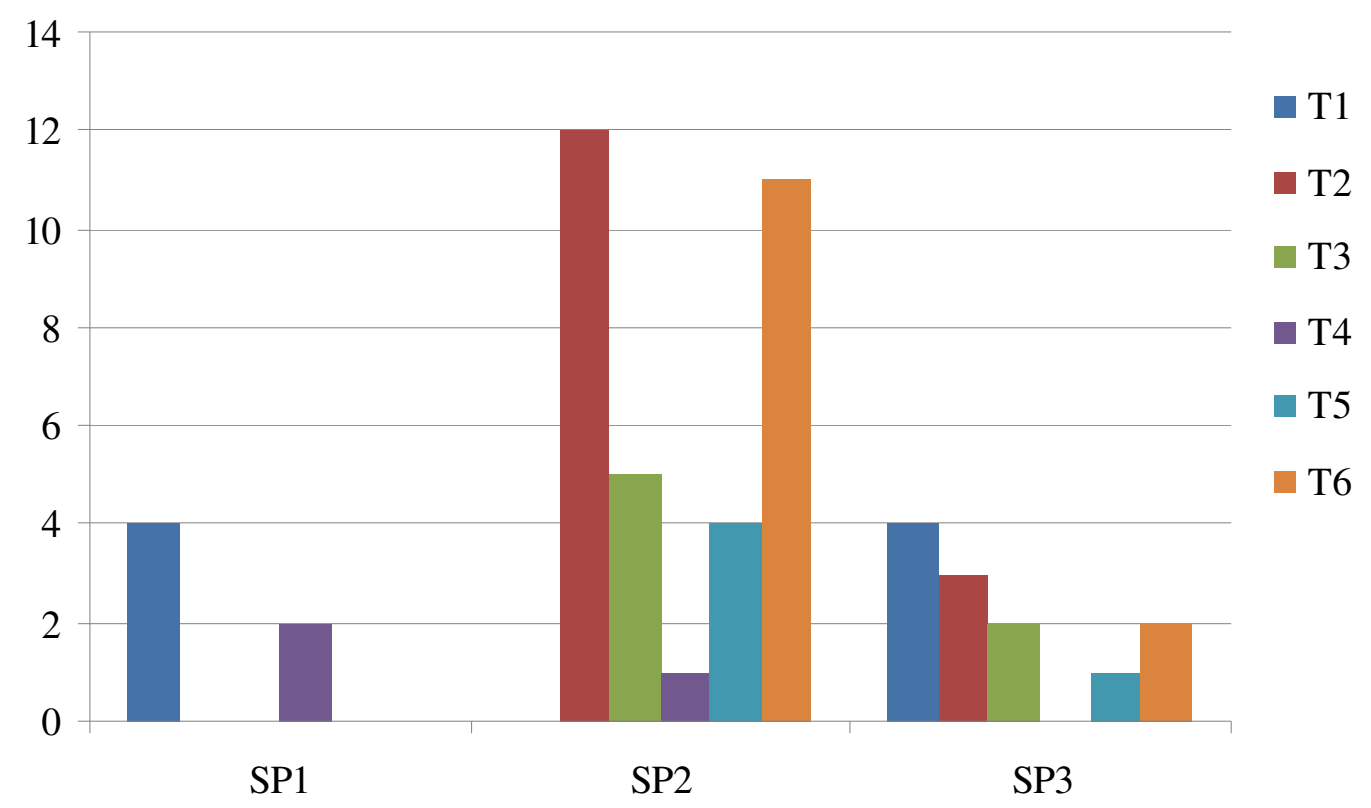

Figura 5. Número de artigos por supraperfil classificados segundo as categorias de tipo de uso da obra de Toulmin (1958) como referencial teórico

A figura 5 permite identificar que dois, dos três supraperfis, apresentaram cinco categorias: SP2 (estudos com foco na estrutura do argumento e/ou na construção da argumentação); e SP3 (estudos com foco no ensino e aprendizagem). O supraperfil SP1 (estudos sobre a natureza da ciência ou sobre o ensino de Ciências) apresentou o menor número de categorias, duas, das seis possíveis.

Ainda analisando a figura 5, observou-se que SP2 reuniu o maior número de artigos nas diferentes categorias. Os supraperfis SP3 e SP1 ocuparam a segunda e terceira colocação, respectivamente. Apesar de mostrar um padrão de distribuição dos dados bem semelhante ao da figura 5, a figura 6 auxilia a aprofundar os resultados de SPT1, na medida em que referencia o número de produção com o total para cada supraperfil.

Seguindo a ordem do número de artigos por supraperfil (figura 5), da maior para a menor, serão discutidos os resultados em cada um dos três supraperfis, segundo as categorias sobre o uso da obra de Toulmin (1958) como referencial teórico.

O primeiro supraperfil discutido é SP2. Esse supraperfil apresentou artigos de todas as categorias, exceto de T1: T2 (uso não restrito do TAP como ferramenta de análise do argumento), T3 (uso restrito do TAP como ferramenta de análise do argumento), T4 (avaliação do TAP como ferramenta de análise do argumento), T5 (crítica ao TAP ou uso de outro modelo de análise do argumento), e T6 (não uso do modelo). 
O supraperfil SP2 contém estudos com foco na estrutura do argumento e/ou na construção da argumentação. O caráter desses estudos é essencialmente empírico, já que seus dados são obtidos, na maioria das vezes, durante situações de ensino de Ciências ou a partir de um produto resultante de tais situações. Portanto, a ausência de artigos de T1 (uso dos conceitos de argumento e argumentação de Toulmin no artigo, para defini-los ou justificar sua centralidade no ensino de Ciências) em SP2 explica-se, pelo menos parcialmente, pela predominância de artigos de revisão e de posição nessa categoria.

Outro dado que chama a atenção em SP2 é o número de artigos em T2 e T6, 12 e 5, respectivamente, superior ao número de artigos nas categorias restantes, T3 (5), T4(1) e T5(4). O caráter contraditório desse resultado já foi supracitado. De um lado, artigos de T2 utilizam o TAP de forma não restrita, ou seja, sem modificações ou adaptações da ferramenta de análise. Do outro lado, naqueles de T6, a obra de Toulmin (1958) em seu referencial teórico sequer consta nos referenciais teóricos.

A respeito dos resultados de T2, a literatura indica uma larga utilização de Toulmin (1958) como instrumento metodológico de análise do argumento na pesquisa em AEC (SAMPSON e CLARK, 2008; von AUFSCHNAITER et al., 2008). Essa tendência de pesquisa explica o elevado número de artigos em T2 (12,), uma vez que estudos de SP2 focalizam na análise do argumento ou do processo de argumentação.

Os resultados de T6, no entanto, exigem maior aprofundamento dos enfoques dados na pesquisa de SP2. Dos 11 artigos inseridos no supraperfil SP2, sete são do perfil P5 (análise da argumentação e/ou do argumento dos alunos em estratégias de ensino baseadas em temas sociocientíficos e/ou científicos), e quatro são de P7 (avaliação da eficácia de uma estratégia de ensino na promoção ou não da argumentação dos alunos nas aulas de Ciências).

Esses resultados auxiliam a detalhar as tendências de pesquisa em AEC, pois ressaltam um ponto não apontado na literatura. Embora, seja consensual reconhecer que a maioria dos pesquisadores da área fez a opção do TAP como ferramenta de análise do argumento, os dados do presente estudo mostram que um terço da produção cujo foco está na estrutura do argumento ou no processo de argumentação não utiliza a obra de Toulmin (1958) como referencial teórico. É interessante pensar nesses resultados como um movimento de busca por outros referenciais teórico-metodológicos que permitam observar os fenômenos educativos e seus produtos com outros olhos. Essa busca pode ser observada desde o final do primeiro período analisado e em quase todo segundo período, uma vez que esses artigos distribuem-se desde 1999 até 2007. 
O supraperfil SP3 (estudos com foco no ensino e aprendizagem), assim como SP2, também apresentou publicações em cinco categorias. No entanto, nesse supraperfil não houve artigos na categoria T4 somente, diferentemente de SP2, em que apareceram artigos de T1.

As questões enfatizadas nos estudos pertencentes a SP3 se afastam da discussão sobre as ferramentas de análise do argumento, já que o foco principal nesse supraperfil é o ensino e aprendizagem, e não a análise da estrutura do argumento. Os resultados da presente pesquisa convergem com esse cenário, dado que nenhum artigo de T4 (avaliação do TAP como ferramenta de análise do argumento) está presente em SP3.

As categorias T1, T2, T3, T5 e T6 contêm 4, 3, 2, 1 e 2 artigos, respectivamente, de um total de 13 artigos em SP3.

Observou-se que, da categoria T1 para a T6, as categorias apresentam números decrescentes de publicações, em que T1 possui valor maior e T5, o menor. O quadro se inverte em T6, situação em que o número de artigos é igual ao de T3.

Artigos de T2 e T3 utilizam a obra de Toulmin recorrendo ao modelo de argumento proposto pelo autor para a análise dos dados. Essas duas categorias têm papel de destaque na pesquisa de SP3, já que a soma dos artigos das duas juntas correpondem a pouco menos do que a metade dos artigos de SP3 (5 artigos de 12 totais). Disso sugere-se que a pesquisa com o uso do TAP foi relevante para os estudos de ensino e aprendizagem.

No entanto, ressalta, ainda mais, o número de artigos de T1 (4 artigos); essa categoria, sozinha, representa um terço de produção em SP3. Em T1, estão os artigos que remetem à obra de Toulmin para definir o argumento ou justificar a centralidade da argumentação no EC. Os artigos pertencentes a essa categoria são 31, 35, 50 e 46, sendo os três primeiros de P6 (análise do processo de aprendizado dos conteúdos conceituais de Ciências dos alunos nas aulas de Ciências em estratégias de ensino baseadas em temas sociocientíficos e/ou científicos) e o último de P8 (desenvolvimento de habilidades para o ensino de argumentação em Ciências e/ou avaliação das condições para esse ensino). Esses dados demonstram que grande parte da pesquisa com foco no ensino e aprendizagem utiliza a obra de Toulmin para fins que não dizem respeito ao TAP. E ainda. Nesses estudos, não há nenhum artigo de revisão ou de posição; todos são empíricos.

Logo, esses resultados também sugerem que, não só a pesquisa de revisão e de posição utiliza o Toulmin para definir o argumento ou justificar a centralidade da argumentação no EC. Aquela com foco no ensino e aprendizagem também o faz.

Diferentemente de T1, T2 e T3, T5 e T6 correspondem à minoria do supraperfil SP3. A respeito de $\mathrm{T} 5$, os dados da presente pesquisa endossam o que apontam Sampson e Clark 
(2008). Esses autores, depois de analisar seis ferramentas utilizadas na pesquisa em AEC, indicaram a necessidade do contínuo aperfeiçoamento das ferramentas de análise do argumento, para passassem a ser mais enfatizados os conteúdos mobilizados pelos estudantes e suas relação epistêmica com as Ciências. Essas considerações convergem com os resultados da presente pesquisa, pois há somente um artigo em SP3 que utiliza um modelo alternativo ao TAP; modelo reconhecidamente limitado na ánalise campo-dependente, e que não permite identificar com a clareza necessária aspectos do conteúdo específico das Ciências. Em outras palavras, observou-se um reduzido número de estudos em SP3 (nesse caso apenas um) que utilizam ferramentas de análise do argumento que buscam superar as limitações do TAP.

Sobre T6, observa-se que SP3 possui mais de $80 \%$ dos artigos classificados nessa categoria, diferentemente de SP2, em que esse número é pouco menor do que metade do total de artigos. Isso pode ser observado verificando o número de artigos que utilizaram a obra de Toulmin (1958) como referencial teórico e o número de artigos que não a utilizaram (T6). Em SP2, houve 22 artigos que utilizaram Toulmin, contra 11 que não utilizaram. Para SP3, essa relação foi de 10 , contra 2 , respectivamente.

Esses dados sugerem, então, que a pesquisa em AEC com foco no ensino de aprendizagem se utiliza mais da obra de Toulmin do que aquela com foco na análise da estrutura e processo de produção do argumento.

Por fim, discutiu-se o supraperfil SP1. Nele, observou-se a presença de duas categorias, T1 (uso dos conceitos de argumento e argumentação de Toulmin no artigo, para defini-los ou justificar sua centralidade no ensino de Ciências) e T4 (avaliação do TAP como ferramenta de análise do argumento). Foram quatro artigos de T1 e dois de T4, de um tota de 6 artigos em SP1. Nesse sentido, pôde-se verificar a predominância de estudos que utilizaram a obra de Toulmin com o objetivo de definir o argumento ou justificar sua centralidade no EC, nos artigos sobre a natureza da ciência ou sobre EC.

O expressivo número de artigos que utilizaram Toulmin para definir o argumento ou justificar sua centralidade no EC também pôde ser observarda no supraperfil SP3, no qual se verificou quatro artigos de T1. Entretanto, a natureza dos estudos de T1 no supraperfil SP1 e SP3 difere. Em SP3, todos os artigos são empíricos e, em sua maioria, analisam o processo de aprendizado dos conteúdos conceituais de Ciências dos alunos nas aulas de Ciências em estratégias de ensino baseadas em temas sociocientíficos e/ou científicos (P6). Já em SP1, todos os artigos são de revisão ou de posição. Desses, três são de P2 (artigos 3, 30 e 51) e um de P1 (artigo 44). Em comparação com os estudos de T1 publicados em SP3, em SP1 predominam artigos que discutem práticas discursivas da Ciência e suas implicações para o 
ensino de Ciências (P1). Quanto ao supraperfil SP2, a análise das figuras 5 e 6 permite identificar a ausência de publicações de T1.

Logo, os resultados da presente pesquisa sugerem que o uso da obra de Toulmin para definir argumento e justificar sua importância compõe parte expressiva, tanto nas investigações com foco na natureza das Ciências, quanto naquelas cujo foco é o ensino e aprendizagem.

Com esse resultado, mais uma vez, o presente estudo aponta para caminhos interessantes da pesquisa em AEC. Nas referenciais bibliográficas desse trabalho (JIMÉNEZALEIXANDRE et al., 2000; KELLY et al., 1998; Sampson e Clark, 2008), a constatação das limitações do modelo de Toulmin para analisar aspectos importantes, como por exemplo, a subjetividade de classificação dos trechos em uma única categoria, é frequentemente levantada. No entanto, os tipos de uso da obra de Toulmin como um todo, e não só relacionado ao seu modelo de argumento como ferramenta de análise, não aparece nas discussões da literatura consultada. Nesse sentido, a contribuição do presente estudo está em desnudar como esse referencial foi utilizado na pesquisa em AEC ao longo de 21 anos.

Nesse caso específico, esse olhar sobre os dados permitiu identificar que, apesar da obra de Toulmin ser frequentemente citada nos artigos analisados a fim de apresentar, avaliar ou criticar o TAP, sua utilização como referencial teórico definindo argumento e justificando sua centralidade no EC foi expressiva na pesquisa em AEC em outras linhas de investigação

Os artigos de $\mathrm{T} 4$, ao contrário de $\mathrm{T} 1$, apresentaram menor número em SP1. No entanto, comparados aos demais supraperfis (1 artigo em SP2 e nenhum em SP3), foi em SP1 que houve maior número de publicações de T4 (2 artigos).

A primeira discussão sobre esses dados refere-se à presença de artigos que fizerem avaliação da ferramenta em SP1, supraperfil em que há somente estudos de revisão e de posição. Da mesma forma que em SP1 concentram-se artigos de revisão, os de T4 também o são. Dessa produção, ressaltam as datas em que foram publicados esses trabalhos: ou a investigação é recente, caso do artigo 7, publicado em 2008; ou foi publicado em 2004, caso do artigo 29. Esta foi a data, conforme se constatou no presente trabalho, a partir da qual estudos com foco na avaliação do TAP, em sua crítica e no uso de modelos alternativos passaram a crescer.

Em umas das discussões anteriores, notou-se que artigos que estão inseridos em SP1 foram importantes na inauguração da área, pois ajudaram na construção do arcabouço teórico, validandando a AEC como área de pesquisa. Além disso, estudos de SP1 contribuíram para a pesquisa na área apresentando novos rumos de investigação, devido à tomada de consciencia 
da comunidade científica do que se produziu até determinado o momento e qual a natureza dessa produção. Nesse sentido, os dados recém discutidos dão relevo ao papel de estudos de revisão de ferramentas de análise para área, os quais fazerm parte do processo de amadurecimento da pesquisa em AEC.

Assim, sufere-se que artigos sobre a natureza da ciência e estudos sobre o EC tenham tido papel fundamental, não só no início da pesquisa, como também ao longo da produção, incluindo estudos de revisão metodológica para a área.

Mesmo após a discussão, supraperfil a supraperfil, dos usos da obra de Toulmin no referencial teórico dos artigos analisados, algumas questões levantandos ao longo deste trabalho ainda não foram respondidas. Uma delas diz respeito à relação entre número de artigos nas categorias (T1, T2, T3, T4, T5e T6) em relação ao aumento do número de artigos nos supraperfis (SP1, SP2 e SP3): o aumento da diversidade no uso de Toulmin corresponde ao aumento do número de supraperfis? Para respondê-la, os dados apresentados nas tabelas 4 e 6 foram comparados, analisando-os sob uma perspectiva cronológica.

Excetuando uma publicação pontual em 1992, observou-se aumento tanto do número de supraperfis, quanto de categorias sobre o uso de Toulmin no referencial teórico. Esse movimento crescente no número de artigos apresentou uma queda brusca nos anos de 2003 e 2005. Tanto nas discussões sobre os supraperfis quanto naquelas sobre as categorias supracitadas, essa diminuição no número de artigos foi discutida. Nos supraperfis, essas quedas contrastam parcialmente com os resultados de pesquisa de Lee et al. (2009), na medida em que, tanto a pesquisa em EC, como a pesquisa em AEC apresentaram queda no número de artigos em 2003. No entanto diverge, pois em 2005, não houve correspondência na diminuição do número publicações em ambas as áreas. Já nas categorias sobre o uso de Toulmin, esses dados foram pouco explorados. A análise das tabelas 10 e 6 permitiu identificar correspondências até então não discutidas. A principal delas foi verificar que, em 2005, não houve publicações em nenhum supraperfil, nem em nenhuma categoria. Esses dados, apesar de esperados, não tinham sido analisados. Esse resultado reforça as considerações sobre correspondência entre a pesquisa em EC e a pesquisa em EC, em que se notou correlação das áreas em 2005, porém não em 2005.

Embora tenha havido uma diminuição substancial de artigos nos anos de 2003 e 2005, o período posterior foi marcado pelo crescimento do número de supraperfis e de categorias sobre o uso de Toulmin. O auge do crescimento foi alcançado em 2008, quando todos supraperfis (SP1, SP2 e SP3) e todas as categorias (T1, T2, T3, T4, T5e T6) foram contempladas na pesquisa da área. 
Munidos desses dados, neste momento é possível responder à questão supracitada. Os resultados da presente pesquisa sugerem que o aumento do número de supraperfis corresponde ao aumento da diversidade no uso de Toulmin.

Além da relação entre aumento do número de supraperfis e aumento da diversidade do uso da obra de Toulmin, a análise dos dados sob uma perspectiva cronológica permitiu analisar a relação entre o número de artigos nos supraperfis e nas categorias e seu padrão de distribuição. Isso pode ser verificado comparando as tabelas 4 e 6 . Na primeira, á possível observar que o supraperfil SP2 possui o maior número de artigos (33) e distribui-se desde 1998 a 2008, apresentando interrupções somente em dois anos, 2003 e 2005. Os dados da tabela 6 vão ao encontro dessa tendência. Os artigos da categoria T2 (15) são os mais numerosos e distribuem-se desde 1999 a 2008, também com duas interrupções nos anos de 2003 e 2005.

Logo, esses resultados sugerem que, embora haja momentos de aumentos e diminuições drásticas no número de artigos, quanto maior esse número em determinada categoria, quer seja o supraperfil, quer seja o tipo de uso da obra de Toulmin, maior será, também, a uniformidade da distribuição desses artigos ao longo do tempo. 


\section{CONCLUSÕES}

As perguntas de pesquisa que o presente trabalho procurou responder foram: é possível identificar perfis nas pesquisas em argumentação no ensino de Ciências publicadas em periódicos especializados, formando conjuntos de artigos com focos parecidos? esse agrupamento auxilia na identificação de tendências de pesquisa em argumentação no ensino de Ciências ao longo dos últimos vinte anos? qual a influência da obra de Toulmin (1958) para a pesquisa na área, nesse período?

A análise dos dados à luz do referencial teórico utilizado permitiu responder as perguntas de pesquisa citadas, como foi apresentado abaixo.

As conclusões deste estudo sobre as tendências da pesquisa em AEC foram feitas abordando os seguintes tópicos: natureza da pesquisa de revisão, de posição e empírica; sujeito que foi o foco da análise; perfis e supraperfis de pesquisa; uso da obra de Toulmin (1958) como referencial teórico; e considerações metodológicas.

As primeiras conclusões tratam da natureza da pesquisa de revisão, de posição e empírica na pesquisa em AEC. A pesquisa de revisão e de posição na área constitui-se predominantemente de estudos do primeiro tipo, quer sejam revisões da produção de outros campos do saber, quer sejam revisões da própria área de AEC. É possível observar também que a pesquisa de revisão é mais recente do que a empírica, devido ao fato desta última fornecer subsídios para a produção da primeira.

Ainda sobre a pesquisa de revisão, notou-se que ela distribui-se ao longo dos 21 anos analisados. Sugerem-se dois motivos pelos quais a pesquisa sobre natureza da Ciência distribui-se ao longo desse período: 1. pela necessidade de momentos de avaliação dos instrumentos teóricos e metodológicos até então utilizados na pesquisa; e 2. pela necessidade de se apresentar novos rumos da pesquisa, devido à tomada de consciência da comunidade científica do que se produziu até determinado momento e qual a natureza dessa produção.

Os resultados permitiram identificar outra característica da pesquisa de revisão e de posição. Ela focaliza mais em estudos sobre epistemologia da Ciência e suas implicações para o EC, do que em estudos de revisão sobre instrumentos metodológicos utilizados na pesquisa em AEC e sobre a justificativa da importância da argumentação para o EC.

Em estudos de AEC, apesar da pesquisa de revisão e de posição apresentar considerável volume de publicações, a pesquisa empírica destaca-se pelo elevado número de 
artigos publicados. Dentro das pesquisas empíricas, ganham destaque aquelas que analisam o argumento ou a argumentação do aluno, em diversos focos de investigação.

Trata-se agora das considerações sobre os sujeitos que foram foco de análise na produção científica em AEC. A análise dos artigos com foco nos alunos permitiu verificar que esses estão inseridos em um amplo intervalo de tempo (de 1997 a 2008). Além disso, relacionam-se a um maior número de perfis, comparado aos artigos com foco no professor. Afora os artigos com foco no aluno serem mais numerosos, também são a amostra mais significativa de artigos, comparando àquela com foco nos professores, já que refletem, em seus distintos focos, as mudanças ocorridas na pesquisa em AEC ao longo do tempo, devido ao elevado número de perfis e artigos que possui.

Apesar de considerar os artigos com foco no aluno como a amostra mais significativa deste estudo, a análise daqueles com foco nos professores, também permitiu a visualização de mudanças da pesquisa.

Os artigos com foco no professor, em sua maioria, têm foco ou no desenvolvimento de habilidades argumentativas dos professores, ou na aprendizagem de conteúdos específicos para os professores de Ciências. Ambos os focos estão inseridos em um contexto de formação de professores, ao invés de investigarem dimensões sociais do argumento; este, tema de investigação no início da pesquisa em AEC, quando o professor era o sujeito da pesquisa

As conclusões neste ponto referem-se às tendências gerais da pesquisa em AEC e, devido aos propósitos e finalidades da presente pesquisa, constituem-se como informaçõeschave para responder ao problema de pesquisa apresentado.

Na pesquisa em AEC, houve deslocamento da atenção da pesquisa para aprendizagem, em razão da maior influência de referenciais sócio-culturais. Essa afirmação apoia-se nas considerações feitas ao longo do presente trabalho, no qual ganha destaque aquela relacionada à análise de artigos com focos sobre a aprendizagem.

No início da pesquisa em AEC, os estudos focalizavam nas habilidades argumentativas, para virem focando-se, com o passar do tempo, na investigação da aprendizagem (figura 3). Nesse sentido, os dados da presente pesquisa reforçam a ideia de outros autores que realizaram um levantamento da pesquisa na área de EC (LEE et. al., 2009) e de LEC (YORE et. al., 2003); vem ganhando destaque a produção científica que enfatiza o contexto de aprendizagem, na pesquisa em EC, e a própria aprendizagem, em LEC. O momento da pesquisa em AEC, portanto, parece acompanhar esse caminho da pesquisa em EC, em que o destaque está sobre como promover a aprendizagem por meio da argumentação. 
A pesquisa sobre análise da argumentação elou do argumento dos alunos em estratégias de ensino baseadas em temas sociocientíficos elou científicos tem se estabelecido cada vez mais na pesquisa em AEC. Dentro desse perfil de pesquisa, há uma discreta valorização de estudos que examinam a natureza da evidência utilizada pelos estudantes ao argumentarem. Além disso, observou-se que passado um período em que a pesquisa em AEC investigava as condições para o ensino de argumentação nas aulas de Ciências, iniciaram-se estudos na tentativa de propor e avaliar situações para esse ensino, o que constitui um importante passo para a pesquisa na área.

De outro lado, há menor número de artigos com foco na análise do processo de aprendizado dos conteúdos conceituais de Ciências dos alunos nas aulas de Ciências em estratégias de ensino baseadas em temas sociocientíficos elou científicos, no entanto este parece ser um foco de pesquisa com alto potencial a ser explorado pela pesquisa em AEC. Essas considerações, portanto, endossam o aumento gradativo do volume de pesquisa em aprendizagem. É importante lembrar, no entanto, que este perfil de pesquisa não supera, ao longo de todo período analisado, a pesquisa com foco na habilidade argumentativa dos alunos.

Também foi possível identificar uma interessante tendência sobre a pesquisa que avalia ferramentas teórico-metodológicas de análise do argumento. Estudos com esse perfil acompanharam a produção científica sobre a análise da argumentação dos estudantes, não se restringindo, dessa forma, ao período inicial da pesquisa em AEC. Dessa forma, a constante avaliação das ferramentas que vêm sendo usadas na pesquisa em AEC teve papel importante para a área ao longo de todo o período analisado.

Sobre o número geral de trabalhos, os resultados permitem discutir sobre a quantidade de artigos sobre AEC e sua relação com a produção na linha de pesquisa em LEC. Entre o início dos anos 80, quando houve aumento do volume de produção em LEC, até o final dos 90, quando houve aumento do volume de produção em AEC, passaram-se aproximadamente 20 anos até o estabelecimento da área de AEC como linha de pesquisa em EC. Sugerimos, dessa forma, que houve um período de mais de duas décadas entre o início da pesquisa em LEC e o início da pesquisa em AEC, o qual figura como interessante tema de investigação futura. Em outras palavras, a pergunta que ressalta a partir da análise dos resultados é: quais motivos levaram a pesquisa em LEC, em algum momento próximo do final da década de 1990, a iniciar estudos sobre argumentação?

Os usos da obra de Toulmin (1958) como referencial teórico dos artigos analisados também dão sinais interessantes do que foi produzido em AEC ao longo dos últimos 21 anos. 
A pesquisa em AEC que se utiliza do TAP predomina na área, e, apesar de existir uma tendência de utilização de modelos alternativos para a análise do argumento, devido às limitações do TAP para avaliar o conteúdo e questões sociais da elaboração do argumento, e para classificar os elementos do argumento nas categorias propostas por Toulmin, seu uso ainda deve perdurar na pesquisa em AEC no curto período de tempo. Essa tendência justificase, pois houve, e ainda há, forte influência desse padrão de análise de argumentos e sua importância na identificação dos componentes do argumento ainda é relevante para os estudos na área. De forma geral também se observou o aperfeiçoamento metodológico, com destaque especial para a criação de ferramentas de análise do argumento alternativas ao TAP.

A esse respeito, sugere-se que estudos com foco na avaliação do TAP, em sua crítica e no uso de modelos alternativos para análise do argumento passaram a crescer em 2004 e seus desdobramentos ainda parecem pouco explorados na pesquisa em AEC.

Finalizando as considerações sobre as tendências gerais da pesquisa em AEC, pode-se dizer que na pesquisa em AEC existiram linhas de investigação que se distribuíram durante praticamente todo o tempo, como foi o caso da análise do argumento em questões sociocientíficas, porém, apresentando contínua modificação em seus focos de estudo. Outras linhas surgiram mais recentemente, como foi o caso de estudos que realizaram avaliação de aspectos de ensino e aprendizagem.

Sobre o uso de Toulmin (1958) como referencial teórico, a tendência foi parecida. Houve algumas linhas de pesquisa que se mantiveram durante quase todo período analisado, ligadas ao uso não restrito do TAP, e outras que surgiram mais recentemente, estas, realizando avaliação do TAP, sua crítica ou uso de modelos alternativos de análise do argumento.

Tanto os dados sobre os supraperfis, quanto aqueles sobre o tipo de uso da obra de Toulmin (1958) como referencial teórico, auxiliaram a desvelar algumas tendências da pesquisa em AEC no período entre 1988-2008. A primeira década do século XXI foi produtiva para a área no que se refere ao número de publicações e à diversidade da pesquisa. Disso decorre que a área promete crescimento e ainda mais diversificação das linhas de pesquisa para os próximos anos. Especial ênfase deve ser dada a aspectos de aprendizagem e ao desenvolvimento de ferramentas de análise do argumento que permitam captar nuanças, tanto de aspectos epistemológicos específicos da Ciência, quanto de aspectos sociais de sua produção.

Estudos posteriores considerando, não só os focos de investigação dos artigos e o tipo de uso da obra de Toulmin no referencial teórico, mas também aspectos metodológicos da produção científica em AEC ajudariam a detalhar as tendências de pesquisa na área. Um 
estudo cuja amostra fosse composta por artigos publicados alguns anos após 2008 revelaria tendências semelhantes às apresentadas nesse estudo? Como estaria distribuída ao redor do mundo a produção científica em AEC? Haveria países predominando na área? Se sim, em que língua? Haveria aumento na diversidade de autores e países publicando na área? Essa diversificação de autores e nacionalidades teria alguma influência na consagração ou no surgimento de novas linhas de pesquisa? Todas são perguntas de pesquisa que podem instigar futuras pesquisas sobre as tendências da produção científica na área.

Por fim, são feitas algumas considerações metodológicas sobre o presente estudo. Os descritores utilizados, a saber: objetivos (da parte pré-textual e da parte textual do artigo), foco e pergunta de pesquisa, auxiliaram na classificação e identificação de perfis de pesquisa em AEC. No entanto, percebemos que informações sobre a metodologia dos trabalhos (informações essas que não foram contempladas nesta pesquisa) têm potencial de fornecerem dados que aprimorem a descrição dos artigos analisados, promovendo, portanto, melhorias na classificação e identificação de artigos na área.

Concluindo, foi possível identificar perfis nas pesquisas em argumentação no ensino de Ciências publicadas em periódicos especializados, formando conjuntos de artigos com focos parecidos, a partir de dados obtidos por meio dos descritores 'pergunta', 'foco' e 'objetivo de pesquisa' e 'uso da obra de Toulmin (1958) como referencial teórico'. Isso foi demonstrado pela reunião dos artigos analisados em nove perfis, esses organizados em três supraperfis, além das seis categorias relacionadas ao tipo de uso de Toulmin (1958) como referencial teórico.

Este estudo analisou os artigos publicados em revistas internacionais de ensino de Ciências, no período entre 1988 e 2008. As tendências de pesquisa sobre os perfis e supraperfis, e usos da obra de Toulmin (1958) como referencial teórico ilustrou o desenvolvimento da investigação no campo do ensino de Ciências nas décadas passadas, e pode também sugerir algumas possíveis direções para o desenvolvimento de novas pesquisas na área. Espera-se que este estudo contribua para pesquisadores e educadores da educação científica na realização de suas pesquisas, e na publicação de seus resultados.

O presente estudo também pode fornecer aos profissionais em educação em Ciências informações sobre quais questões foram amplamente estudadas no campo da pesquisa em AEC. Essa informação pode servir como uma importante base para melhorar a qualidade das decisões de pesquisadores e educadores em torno do assunto. Em particular, este estudo deverá fornecer aos professores e pesquisadores em formação inicial uma visão mais clara da pesquisa realizada na comunidade da educação científica, bem como para estender seu âmbito 
de investigação e suas contribuições acadêmicas. Por exemplo, as análises deste estudo podem ajudar os jovens professores e pesquisadores, não só a identificar perfis e supraperfis de pesquisa, usos da obra de Toulmin nos estudos e tendências nesse campo, mas também a reconhecer questões de pesquisa contemporâneas em destaque

Este estudo também visou proporcionar uma oportunidade para pesquisadores em educação científica reconhecer qual será o próximo passo da pesquisa na área. Sem dúvida, como um campo de investigação internacional e crescente, não faltarão desafios na pesquisa em AEC em um futuro próximo. 


\section{REFERÊNCIAS BIBLIOGRÁFICAS}

BOULTER, C.J. GILBERT, J.K. Argument and science education. In: Costell, P. J. M.; MITCHELL, S. (Org.). Competing and consensual voices: The theory and practice of argumentation. Clevedon, Inglaterra: Multilingual Matters, 1995.

BOZZO, M. V.; MOTOKANE, M. T. Investigação acerca dos focos de interesse da pesquisa sobre argumentação no ensino de ciências. Enseñanza de las Ciências, p. 2475-2479, 2009a. Número extra, VIII Congreso Internacional sobre Investigación en Didáctica de las Ciencias, Barcelona.

Focos de pesquisa em argumentação no ensino de ciências: analisando o referencial teórico. In: ENCONTRO NACIONAL DE PESQUISA EM EDUCAÇÃO EM CIÊNCIAS (ENPEC), 7., Florianópolis, Brasil, 2009. Anais do VII Encontro Nacional de Pesquisa em Educação em Ciências. Florianópolis: ABRAPEC, 2009 b.

CANDELA, A. Praticas discursivas en el aula y calidad educativa. Revista Mexicana de Investigación Educativa, v. 4, n. 8, p. 273-298, 1999.

CERVO, A. L. Metodologia cientifica: para uso dos estudantes universitários. São Paulo: McGraw-Hill do Brasil, 1978.

CERVO, A. L.; BERVIAN, P. A.; SILVA, R da. Metodologia cientifica. 6. ed. São Paulo: Pearson Prentice Hall, 2007.

DE CHIARO, S. e LEITÃO, S. O papel do professor na construção discursiva da argumentação em sala de aula. Psicologia: Reflexão e Crítica, v. 18, n. 3, p. 350-357, set./dez., 2005.

DRIVER, R.; ASOKO, H.; LEACH, J.; MORTIMER, E.; SCOTT, P. Construindo conhecimento científico em sala de aula. Química Nova na Escola, v. 9, p. 31-40, 1999.

DRIVER, R.; NEWTON, P.; OSBORNE, J. Establishing the norms of scientific argumentation in classrooms. Science Education, v. 84, n. 3, p. 287-312, 2000.

DRUKER, S. L.; CHEN, C.; KELLY, G. J. Introducing content to the Toulmin model of argumentation via error analysis. In: Encontro anual da National Association for Research in Science Teaching, Chicago, IL, 1996. 
DUSCHL, R.; OSBORNE, J. Supporting and promoting argumentation discourse. Studies in Science Education, v. 38, p. 39-72, 2002.

ERDURAN, S.; SIMON, S.; OSBORNE, J. TAPping into Argumentation: Developments in the Application of Toulmin's Argument Pattern for Studying Science Discourse. Science Education, v. 88, n. 6, p. 915-933, 2004.

ETKINA, E. Weekly reports: a two-way feedback tool. Science Education, v. 84, n. 5, p. 594-605, 2000.

GIORDAN, M.; POSSO, A. S. O papel de uma ferramenta analítica no planejamento e análise de atividades de ensino mediadas por extratos de vídeo. In: NASCIMENTO, S. S.; PLATIN, C. (Org.). Argumentação e Ensino de Ciências. Curitiba: Editora CRV, 2009.

JIMÉNEZ-ALEIXANDRE, M. P.; BUGALLO, A.; DUSCHL, R. ' Doing the lesson'” or "Doing science": Argument in high school genetics. Science Education, v. 84, n. 6, p. 757$792,2000$.

JIMÉNEZ-ALEIXANDRE, M. P.; ERDURAN, S. Argumentation in Science Education: an Overview. In: ERDURAN, Sibel; JIMÉNEZ-ALEIXANDRE, María Pilar. (Org.).

Argumentation in Science Education: Perspectives from Classroom-Based Research. Dordrecht, Holanda: Springer, 2007. p. 3-28.

JIMÉNEZ-ALEIXANDRE, M. P.; PEREIRO-MUNHOZ, C. Knowledge producers or knowledge consumers? Argumentation and decision making about environmental management. International Journal of Science Education, v. 24, n. 10, p. 1171-1190, 2002.

KELLY, G. J.; DRUCKER, S.; CHEN, C. Students' reasoning about electricity: Combining performance assessments with argumentation analysis. International Journal of Science Education, vol. 20, n. 7, p. 849-871, 1998.

KELLY, G.; DUSCHL, R. Toward a research agenda for epistemological studies in science education. In: Encontro anual da National Association for Research in Science Teaching, New Orleans, LA, 2002.

KEYS, C.W. The development of scientific reasoning skills in conjunction with colaborative writing assignments: an interpretative study of six ninth-grade students. Journal of Research in Science Teaching, v. 31, n. 9, p. 1003-1022, 1994. 
LAKATOS, E. M. Fundamentos de metodologia científica. São Paulo: Atlas, 1985.

LAKATOS, Eva Maria. Metodologia científica. São Paulo: Allas, 1986.

LATOUR, B. W.; WOOLGAR, S. An anthropologist visits the laboratory. In: LATOUR, B. W.; WOOLGAR, W. (Org.). Laboratory life: The construction of scientific facts.

Princeton, NJ: Princeton University Press, 1986.

LEE, M. H.; WU, Y.-T.; TSAI, C.-C. Research trends in science education from 2003 to 2007: a content analysis of publications in selected journals. International Journal of Science Education, v. 31, n. 1, p. 1999-2020, 2009.

LEITÃO, S. The potential of argument in knowledge building. Human Development, v. 43, n. 6, p. 332-368, 2000.

LEMKE, J. L. Talking Science: Language, learning, and values. Norwood, NJ: Ablex, 1990.

MARTINS, A. F. P. História e Filosofia da Ciência no ensino: há muitas pedras nesse caminho.... Caderno Brasileiro de Ensino de Física, v. 24, n. 1, p. 112-131, 2007.

MARTINS, I.; MORTIMER, E.; OSBORNE, J.; TSATSARELIS, C.; JIMÉNEZALEIXANDRE, M. P. Rhetoric and science education. In: BEHRENDT, H.; DAHNCKE, H.; DUIT, R.; GRÄBER, W.; KOMOREK, M.; KROSS, A.; REISKA, P. (Org.). Research in science education - past, present, and future. Dordrecht, Holanda: Kluwer Acadmic, 2001. p. 189-198.

MASON, L. An analysis of children's construction of new knowledge through their use of reasoning and arguing in classroom discussions. International Journal of Qualitative Studies in Education, v. 9, n. 4, p. 411-433, 1996.

MORTIMER, E. F. Sobre chamas e cristais: a linguagem cotidiana, a linguagem científica e o Ensino de Ciências. In: CHASSOT, A.; OLIVEIRA, R. J. Ciência, ética e cultura na educação. São Leopoldo: UNISINOS, 1998.

MORTIMER, E.; SCOTT, P. Meaning making in secondary science classrooms. Maidenhead, England: Open University Press, 2003. 
MUÑOZ-CHÁPULI, R. Escribir para aprender: ensayo de una alternativa en la enseñanza universitaria de las ciencias. Enseñanza de las Ciencias, v. 13, p. 273-278, 1995.

NASCIMENTO, S. S.; PLATIN, C. (Org.). Argumentação e Ensino de Ciências. Curitiba: Editora CRV, 2009.

NASCIMENTO, S. S.; VIEIRA, R. D. A Argumentação em sala de aula de física: limites e possibilidades de aplicação do padrão de Toulmin. In: NASCIMENTO, S. S.; PLATIN, C. (Org.). Argumentação e Ensino de Ciências. Curitiba: Editora CRV, 2009.

NEWTON, P.; DRIVER, R.; OSBORNE, J. The place of argumentation in the pedagogy of school science. International Journal of Science Education, v. 21, n. 5, p. 553-576, 1999.

OSBORNE, J.; ERDURAN, S.; SIMON, S. Enhancing the quality of argument in school science. Journal of Research in Science Teaching, v. 41, n. 10, p. 994-1020, 2004.

OSBORNE, J.; ERDURAN, S.; SIMON, S.; MONK, M. Enhancing the quality of argument in school science. School Science Review, v. 82, n. 301, p. 63-70, 2001

PERELMAN, C.; OLBRECHTS-TYTECA, L. Tratado de argumentação - A Nova Retórica. 2. ed. São Paulo: Editora Martins Fontes, 2005

PONTECORVO, C. Discussing for reasoning: the role of argument in knowledge construction. In: De CORTE, E; LODEWIIJKS, H.; PARMENTIER, R; SPAN, S. (Org.). Learning and instruction: European research in an international context, v. 1, p. 239-250. Oxford: Pergamon Press e Leuven University Press, 1987.

RESNICK, L. B.; SALMON, M.; ZEITZ, C. M.; WATHEN, S. H.; HOLOWCHAK, N. Reasoning in conversation. Cognition and Instruction, v. 11, n. 3, p. 347-364, 1993.

REZENDE, F.; CASTELLS, M. A construção social de significados e argumentação em um fórum de discussão para formação continuada de professores de física. In: NASCIMENTO, S. S.; PLATIN, C (Org.). Argumentação e Ensino de Ciências. Curitiba: Editora CRV, 2009.

RIVARD, L.P. A review of writing to learn in science: implications for practice and research. Journal of Research in Science Teaching, v. 31, n. 1, p. 969-983, 1994. 
RUSSEL, T. E.; MORROW, J. E. Reform in Teacher Education: Perceptions of Secondary Social Studies Teachers. Theory and Research in Social Education, v. 14, n. 4, p. 325-30, 1986.

SAMPSON, V.; CLARK, D. B. Assessment of the Ways Students Generate Arguments in Science Education: Current Perspectives and Recommendations for Future Directions.

Science education, v. 92, n. 3, p. 447-472, 2008.

SANDOVAL, W. A.; MILLWOOD, K. The quality of students' use of evidence in written scientific explanations. Cognition and Instruction, v. 23, n. 1, p. 23-55, 2005.

SANDOVAL, W. A.. Conceptual and epistemic aspects of students' scientific explanations. Journal of the Learning Sciences, v. 12, n. 1, p. 5-51. 2003.

SANDOVAL, W. A.; REISER, B. J. Explanation-driven inquiry: integrating conceptual and epistemic scaffolds of scientific inquiry. Science Education, v. 88, n. 3, p. 345-372, 2004.

SANMARTÍ, N. Enseñar a elaborar textos científicos en las clases de ciencias. Alambique: Didáctica de las Ciencias Experimentales, v. 4, n. 12, p. 51-61, 1997.

SASSERON, L. H.; CARVALHO, A. M. P de. O Ensino de Ciências para a Alfabetização Científica: analisando o processo por meio das argumentações em sala de aula. In:

NASCIMENTO, S. S.; PLATIN, C (Org.). Argumentação e Ensino de Ciências. Curitiba: Editora CRV, 2009.

SEVERINO, A. J. Metodologia do trabalho científico. 23. ed. rev. e atual. São Paulo: Cortez, 2007.

TEIXEIRA, F. M. Argumentação das Aulas de Ciências para as séries iniciais. In: NASCIMENTO, S. S.; PLATIN, C (Org.). Argumentação e Ensino de Ciências. Curitiba: Editora CRV, 2009.

TOULMIN, S. The uses of argument. Cambridge: Cambridge University Press, 1958. Os usos do argumento. São Paulo: Martins Fontes, 2001.

TSAI, C.-C.; WEN, L. M. C. Research and trends in science education from 1998 to 2002: A content analysis of publication in selected journals. International Journal of Science Education, v. 27, n. 1, p. 3-14, 2005. 
von AUFSCHNAITER, C.; ERDURAN, S.; OSBORNE, J; SIMON, S. Arguing to learn and learning to argue: Case studies of how students' argumentation relates to their scientific knowledge. Journal of Research in Science Teaching, v. 45, n. 1, p. 101-131, 2008.

VYGOTSKY, L. S. Pensamento e linguagem. São Paulo: Martins Fontes, 1987.

Mind in society: The development of higher psychological processes. Cambridge: Harvard University Press, 1989.

Formação social da mente. 6. ed. São Paulo (SP): Martins Fontes; 1998.

WERTSCH, J. Voices of the mind: a sociocultural approach to mediated action. Cambridge: Harvard University Press, 1991.

YORE, L; BISANZ, G. L.; BRIAN, H. Examining the literacy component of science literacy: 25 years of language, arts and science research. International Journal of Science Education, v. 25, n. 6, p. 689-725, 2003.

ZOHAR, A.; NEMET, F. Fostering students' knowledge and argumentation skills through dilemmas in human genetics. Journal of Research in Science Teaching, v. 39, n. 1, p. 35$62,2002$. 


\section{APÊNDICES}

\section{Apêndice I}

Quadro 9 - Dados coletados a partir dos descritores: pergunta, foco, e objetivo da pesquisa, em que IDE= número de identificação do artigo, APU=ano de publicação, TIT=título

\begin{tabular}{|c|c|c|c|c|c|c|}
\hline \multirow[t]{2}{*}{ IDE } & \multirow[t]{2}{*}{ APU } & \multirow[t]{2}{*}{ Título } & \multirow[t]{2}{*}{ Pergunta de pesquisa } & \multirow[t]{2}{*}{ Foco } & \multicolumn{2}{|l|}{ Objetivo(s) } \\
\hline & & & & & Parte pré-textual (Resumo) & Parte textual \\
\hline 1 & 2008 & $\begin{array}{l}\mid \text { Disconnections } \\
\text { Between Teacher } \\
\text { Expectations and } \\
\text { Student Confidence } \\
\text { in Bioethics }\end{array}$ & 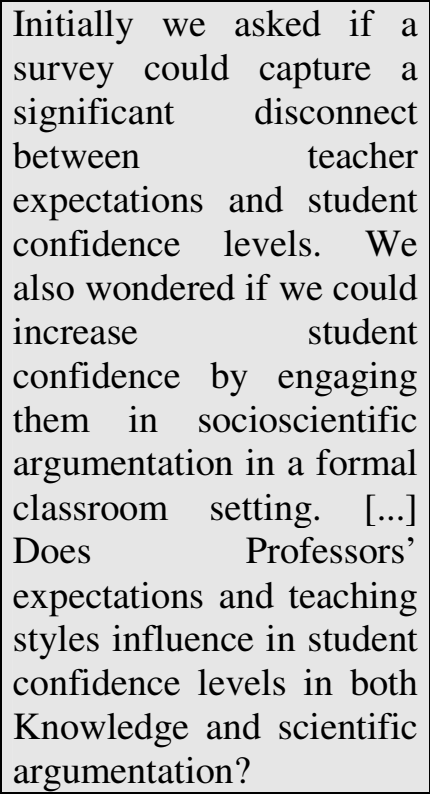 & $\begin{array}{l}\text { Our study compared } \\
\text { college students' } \\
\text { confidence in their } \\
\text { understanding of } \\
\text { specific bioethical } \\
\text { issues to the biology } \\
\text { faculty's expectations } \\
\text { of the students' } \\
\text { confidence }\end{array}$ & $\begin{array}{l}\text { Our study explores observed disconnects } \\
\text { between teacher expectations and student } \\
\text { confidence levels in socioscientific } \\
\text { education, specifically bioethics }\end{array}$ & \begin{tabular}{|lr} 
Our study & explores \\
observed & disconnects \\
between & teacher \\
expectations & and \\
student & confidence \\
levels in socioscientific \\
education, specifically \\
bioethics
\end{tabular} \\
\hline
\end{tabular}




\begin{tabular}{|c|c|c|c|c|c|c|}
\hline \multirow[t]{2}{*}{ IDE } & \multirow[t]{2}{*}{ APU } & \multirow[t]{2}{*}{ Título } & \multirow[t]{2}{*}{ Pergunta de pesquisa } & \multirow[t]{2}{*}{ Foco } & \multicolumn{2}{|l|}{ Objetivo(s) } \\
\hline & & & & & Parte pré-textual (Resumo) & Parte textual \\
\hline 2 & 2008 & $\begin{array}{l}\text { Arguing to Learn } \\
\text { and Learning to } \\
\text { Argue: Case Studies } \\
\text { of How Students' } \\
\text { Argumentation } \\
\text { Relates to Their } \\
\text { Scientific } \\
\text { Knowledge }\end{array}$ & $\begin{array}{l}\text { How is the ability to } \\
\text { engage in argumentation } \\
\text { dependent on scientific } \\
\text { understanding? }\end{array}$ & $\begin{array}{l}\text { NÃO FOI POSSÍVEL } \\
\text { LOCALIZAR O O } \\
\text { FOCO DE PESQUISA } \\
\text { EM UM FORMATO } \\
\text { CLARO. }\end{array}$ & $\begin{array}{l}\text { The objectives of this research, therefore, } \\
\text { were to explore: } \\
\text { (a) How students incorporate their content- } \\
\text { specific knowledge in classroom lessons } \\
\text { based on argumentation. } \\
\text { (b) How students develop and improve } \\
\text { their understanding of science in these } \\
\text { lessons. } \\
\text { (c) How the quantity and quality of } \\
\text { students' arguments are influenced by } \\
\text { students' } \\
\text { content-specific knowledge. }\end{array}$ & 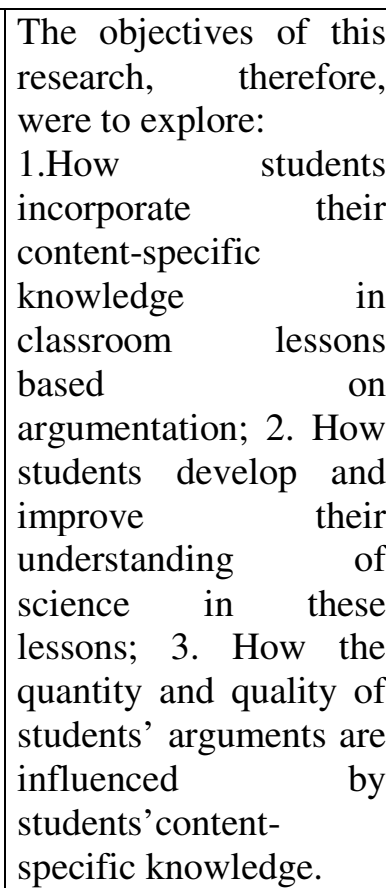 \\
\hline 3 & 2008 & $\begin{array}{l}\text { Conceptualizations } \\
\text { of Argumentation } \\
\text { from r Science } \\
\text { Studies and the } \\
\text { Learning Sciences } \\
\text { and r their } \\
\text { Implications for the } \\
\text { Practices of Science } \\
\text { Education }\end{array}$ & 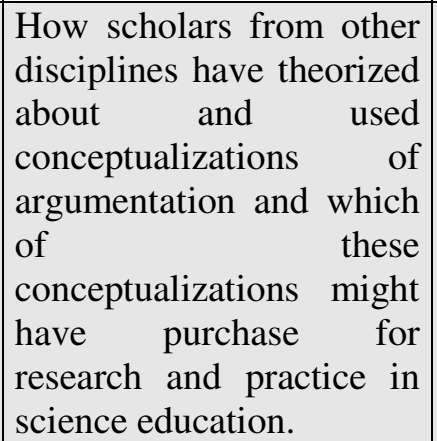 & $\begin{array}{l}\text { What follows is a } \\
\text { review of theoretical } \\
\text { conceptualizations of } \\
\text { argumentation that } \\
\text { stem from formal } \\
\text { logic, argumentation } \\
\text { theory, science studies, } \\
\text { and the learning } \\
\text { sciences. }\end{array}$ & $\begin{array}{l}\text { Provide an example of looking across } \\
\text { disciplines in an effort to gather theoretical } \\
\text { conceptualizations of scientific practices } \\
\text { and discourses to think about the } \\
\text { implications for science education }\end{array}$ & $\begin{array}{l}\text { Gather theoretical } \\
\text { conceptualizations of } \\
\text { scientific practices and } \\
\text { discourses to think } \\
\text { about theimplications } \\
\text { for science education }\end{array}$ \\
\hline
\end{tabular}




\begin{tabular}{|c|c|c|c|c|c|c|}
\hline \multirow[t]{2}{*}{ IDE } & \multirow[t]{2}{*}{ APU } & \multirow[t]{2}{*}{ Título } & \multirow{2}{*}{ Pergunta de pesquisa } & \multirow{2}{*}{ Foco } & \multicolumn{2}{|l|}{ Objetivo(s) } \\
\hline & & & & & Parte pré-textual (Resumo) & Parte textual \\
\hline 4 & 2008 & \begin{tabular}{|lr|}
\multicolumn{2}{|l|}{ Professional Learning } \\
Portfolios & for \\
Argumentation & in \\
School Science &
\end{tabular} & $\begin{array}{l}\text { To see whether teachers } \\
\text { would develop portfolios } \\
\text { of evidence that } \\
\text { demonstrated their growing } \\
\text { accomplishment in the } \\
\text { teaching of argumentation, } \\
\text { and their reflective analysis } \\
\text { of practice }\end{array}$ & $\begin{array}{l}\text { The research reported } \\
\text { here focuses on the use } \\
\text { of portfolios in a } \\
\text { continuous professional } \\
\text { development } \\
\text { programme to enhance } \\
\text { the teaching of } \\
\text { argumentation in } \\
\text { science }\end{array}$ & $\begin{array}{l}\text { The research reported here focuses on the use } \\
\text { of portfolios in a continuous Professional } \\
\text { development (CPD) programme to enhance } \\
\text { the teaching of argumentation in science. The } \\
\text { aim of the research was to see whether } \\
\text { teachers would develop portfólios of evidence } \\
\text { that demonstrated their growing } \\
\text { accomplishment in the teaching of } \\
\text { argumentation, and their reflective analysis of } \\
\text { practice. }\end{array}$ & $\begin{array}{l}\text { NÃO FOI POSSÍVEL } \\
\text { LOCALIZAR } \quad \text { O } \\
\text { OBJETIVO EM UM } \\
\text { FORMATO CLARO }\end{array}$ \\
\hline 5 & 2008 & $\begin{array}{|lr|}\text { Argumentation: } & \mathrm{A} \\
\text { Strategy } & \text { for } \\
\text { Improving } & \\
\text { Achievement } & \text { and } \\
\text { Revealing } & \text { Scientific } \\
\text { Identities } & \end{array}$ & $\begin{array}{lrr}\text { NÃO } & \text { FOI } & \text { POSSÍVEL } \\
\text { LOCALIZAR } & & \text { A } \\
\text { PERGUNTA } & & \text { DE } \\
\text { PESQUISA } & \text { EM } & \text { UM } \\
\text { FORMATO CLARO. } & \end{array}$ & $\begin{array}{lrr}\text { NÃO } & \text { FOI } & \text { POSSÍVEL } \\
\text { LOCALIZAR O FOCO } \\
\text { DE } & \text { PESQUISA EM } \\
\text { UM } & \text { FORMATO } \\
\text { CLARO. } & \end{array}$ & $\begin{array}{l}\text { In this paper we explore the relationship } \\
\text { between learning gains, measured through } \\
\text { pre-assessment and post-assessment, and } \\
\text { engagement in scientific argumentation }\end{array}$ & $\begin{array}{l}\text { This paper examines } \\
\text { group discourse and } \\
\text { individual learning } \\
\text { during the } \\
\text { implementation of the } \\
\text { BioBLAST!fi (BB) } \\
\text { program, which was } \\
\text { designed to engage } \\
\text { middle school and high } \\
\text { school biology students } \\
\text { in the collaborative and } \\
\text { authentic learning of } \\
\text { core biology concepts }\end{array}$ \\
\hline 6 & 2008 & $\begin{array}{l}\text { When Scientific } \\
\text { Knowledge, Daily } \\
\text { Life Experience, } \\
\text { Epistemological and } \\
\text { Social Considerations } \\
\text { Intersect: Students' } \\
\text { Argumentation in } \\
\text { Group Discussions on } \\
\text { a Socio-Scientific } \\
\text { Issue }\end{array}$ & $\begin{array}{lrr}\text { NÃO } & \text { FOI } & \text { POSSÍVEL } \\
\text { LOCALIZAR } & & \text { A } \\
\text { PERGUNTA } & & \text { DE } \\
\text { PESQUISA } & \text { EM } & \text { UM } \\
\text { FORMATO CLARO. } & \end{array}$ & $\begin{array}{l}\text { Of particular interest to } \\
\text { us is the nature of } \\
\text { conversation that occurs } \\
\text { within group discussion } \\
\text { on a socio-scientific } \\
\text { issue. }\end{array}$ & $\begin{array}{l}\text { The purpose of this paper is to document the } \\
\text { argumentation patterns students develop in } \\
\text { small group discussion on a controversial } \\
\text { socioscientific issue. }\end{array}$ & $\begin{array}{l}\text { Document the } \\
\text { argumentation patterns } \\
\text { students develop in } \\
\text { small group discussion } \\
\text { on a controversial } \\
\text { socioscientific issue. }\end{array}$ \\
\hline
\end{tabular}




\begin{tabular}{|c|c|c|c|c|c|c|}
\hline \multirow[t]{2}{*}{ IDE } & \multirow[t]{2}{*}{ APU } & \multirow[t]{2}{*}{ Título } & \multirow[t]{2}{*}{ Pergunta de pesquisa } & \multirow[t]{2}{*}{ Foco } & \multicolumn{2}{|l|}{ Objetivo(s) } \\
\hline & & & & & Parte pré-textual (Resumo) & Parte textual \\
\hline 7 & 2008 & $\begin{array}{l}\text { Assessment of the } \\
\text { Ways Students } \\
\text { Generate Arguments } \\
\text { in Science Education: } \\
\text { Current Perspectives } \\
\text { and } \\
\text { Recommendations } \\
\text { for Future Directions }\end{array}$ & $\begin{array}{lrr}\text { NÃO } & \text { FOI } & \text { POSSÍVEL } \\
\text { LOCALIZAR } & & \text { A } \\
\text { PERGUNTA } & & \text { DE } \\
\text { PESQUISA } & \text { EM } & \text { UM } \\
\text { FORMATO CLARO. } & \end{array}$ & 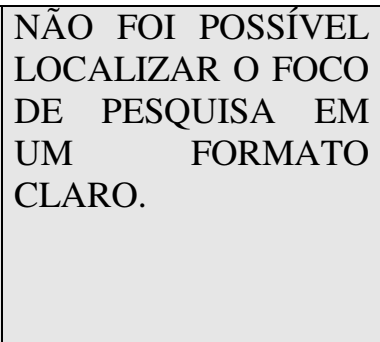 & $\begin{array}{l}\text { Provide an overview of several analytic } \\
\text { frameworks that science educators use to } \\
\text { assess and characterize the nature of or } \\
\text { quality of scientific arguments in terms of } \\
\text { three focal issues: structure, justification, and } \\
\text { content. }\end{array}$ & $\begin{array}{l}\text { We examine several } \\
\text { analytic frameworks that } \\
\text { science education } \\
\text { researchers have } \\
\text { employed to assess the } \\
\text { nature and quality of } \\
\text { students'arguments. }\end{array}$ \\
\hline 8 & 2008 & $\begin{array}{l}\text { Urban Primary-Grade } \\
\text { Children Think and } \\
\text { Talk Science: } \\
\text { Curricular and } \\
\text { Instructional } \\
\text { Practices that Nurture } \\
\text { Participation and } \\
\text { Argumentation }\end{array}$ & $\begin{array}{l}\text { Thus, we are particularly } \\
\text { interested in studying } \\
\text { whether and how young } \\
\text { children theorize in science } \\
\text { in such* a curricular } \\
\text { context. *(para dados } \\
\text { completos a respeito desta } \\
\text { pergunta de pesquisa, ver } \\
\text { anexo I) }\end{array}$ & $\begin{array}{l}\text { In this article, we study } \\
\text { curricular and } \\
\text { instructional practices } \\
\text { that encourage teachers } \\
\text { and children to think } \\
\text { and talk science. }\end{array}$ & $\begin{array}{l}\text { Our goal is to examine how teachers and } \\
\text { children develop understandings around } \\
\text { classifying matter in solids, liquids, and gases } \\
\text { with everyday objects. }\end{array}$ & $\begin{array}{l}\text { Our goal is to examine } \\
\text { how teachers and } \\
\text { children develop } \\
\text { understandings around } \\
\text { classifying matter in } \\
\text { solids, liquids, and gases } \\
\text { with everyday objects }\end{array}$ \\
\hline 9 & 2008 & $\begin{array}{l}\text { Lakatos' Scientific } \\
\text { Research } \\
\text { Programmes as a } \\
\text { Framework } \\
\text { Analysing Informal } \\
\text { Argumentation about } \\
\text { Socio-scientific } \\
\text { Issues }\end{array}$ & $\begin{array}{l}\text { [...] we would like to know } \\
\text { what kind of reasons } \\
\text { undergraduates would } \\
\text { propose when making their } \\
\text { arguments; [...] we wish to } \\
\text { investigate whether } \\
\text { students of science majors } \\
\text { and of non-science majors } \\
\text { perform differently in } \\
\text { informal argumentation; } \\
{[\ldots] \text { we would like to have }} \\
\text { a preliminary investigation } \\
\text { on understanding whether } \\
\text { it is also hard for students } \\
\text { to change their arguments }\end{array}$ & $\begin{array}{l}\text { NÃO FOI POSSÍVEL } \\
\text { LOCALIZAR O FOCO } \\
\text { EM UM FORMATO } \\
\text { CLARO. }\end{array}$ & $\begin{array}{l}\text { The purpose of this study is to explore how } \\
\text { Lakatos' scientific research programmes } \\
\text { might serve as theoretical framework for } \\
\text { representing and evaluating informal } \\
\text { argumentation about socio-scientific issues }\end{array}$ & $\begin{array}{l}\ldots] \text { to investigate } \\
\text { undergraduates' } \\
\text { informal argumentation } \\
\text { regarding SSI (socio- } \\
\text { scientific issues) }\end{array}$ \\
\hline
\end{tabular}




\begin{tabular}{|c|c|c|c|c|c|c|}
\hline \multirow[t]{2}{*}{ IDE } & \multirow[t]{2}{*}{ APU } & \multirow[t]{2}{*}{ Título } & \multirow[t]{2}{*}{ Pergunta de pesquisa } & \multirow[t]{2}{*}{ Foco } & \multicolumn{2}{|c|}{ Objetivo(s) } \\
\hline & & & & & Parte pré-textual (Resumo) & Parte textual \\
\hline 10 & 2008 & $\begin{array}{|lr|}\text { Assessing } & \text { dialogic } \\
\text { argumentation rion } \\
\text { online environments } \\
\text { to relate structure, } \\
\text { grounds, r and } \\
\text { conceptual quality }\end{array}$ & $\begin{array}{l}\text { How can we assess and } \\
\text { characterize the nature of } \\
\text { students argumentation } \\
\text { within online science } \\
\text { learning environments? In } \\
\text { particular, is there a way to } \\
\text { examine the relationships } \\
\text { that exist between levels of } \\
\text { opposition and the types of } \\
\text { comments students make, } \\
\text { their use of grounds, and } \\
\text { the conceptual quality of } \\
\text { their comments? }\end{array}$ & $\begin{array}{l}\text { In this study, we } \\
\text { present an analytic } \\
\text { framework for coding } \\
\text { students' dialogic } \\
\text { scientific argumentation } \\
\text { in the asynchronous } \\
\text { threaded forums of } \\
\text { online science learning } \\
\text { environments. The } \\
\text { framework relates the } \\
\text { level of opposition } \\
\text { found within a } \\
\text { discourse episode and } \\
\text { the types of comments } \\
\text { students make, the } \\
\text { grounds quality } \\
\text { included in those } \\
\text { comments, and the } \\
\text { conceptual quality of } \\
\text { their ideas. }\end{array}$ & $\begin{array}{l}{[\ldots] \text { to investigate the framework's }} \\
\text { potential affordances as well as to } \\
\text { assess issues of reliability and } \\
\text { appropriateness. }\end{array}$ & $\begin{array}{l}\text { (1) presenting the analytic } \\
\text { framework; (2) applying the } \\
\text { analytic framework to } \\
\text { argumentative discussions } \\
\text { occurring within the } \\
\text { asynchronous forums of a } \\
\text { representative online science } \\
\text { learning environment; (3) } \\
\text { considering the implications of } \\
\text { the findings for the } \\
\text { environment; (4) investigating } \\
\text { the reliability, affordances, and } \\
\text { constraints of the proposed } \\
\text { analytic framework through this } \\
\text { process; and,(5) discussing } \\
\text { future directions, including the } \\
\text { adaptation of the framework to } \\
\text { standard classroom contexts } \\
\text { [...] to investigate } \\
\text { undergraduates, informal } \\
\text { argumentation regarding SSI } \\
\text { (socio-scientific issues) }\end{array}$ \\
\hline 11 & 2007 & $\begin{array}{l}\text { Argumentation and } \\
\text { Primary Science }\end{array}$ & $\begin{array}{l}\text { This study seeks to answer } \\
\text { the following research } \\
\text { questions: 1. To what } \\
\text { extent do primary school } \\
\text { pupils engage in purposeful } \\
\text { argument in science, using } \\
\text { concept cartoons as a } \\
\text { stimulus?; } 2 . \text { To what } \\
\text { extent is it possible to } \\
\text { characterize argumentation } \\
\text { in this setting? }\end{array}$ & \begin{tabular}{|lr} 
NÃO FOI POSSÍVEL \\
LOCALIZAR & $\mathrm{O}$ \\
OBJETIVO & DE \\
PESQUISA EM UM \\
FORMATO CLARO.
\end{tabular} & $\begin{array}{l}\text { The research sets out to determine the } \\
\text { extent to which primary school pupils } \\
\text { engage in argumentation and to } \\
\text { characterize their arguments in } \\
\text { primary science lessons }\end{array}$ & 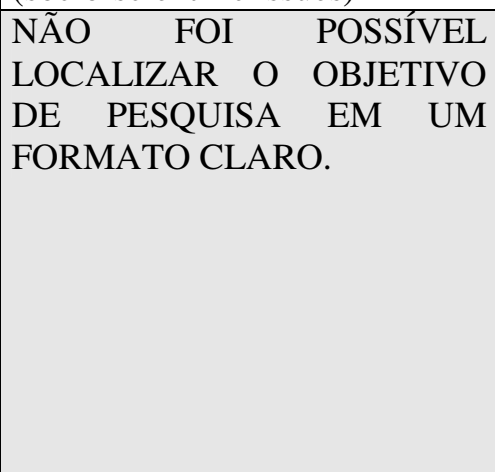 \\
\hline
\end{tabular}




\begin{tabular}{|c|c|c|c|c|c|c|}
\hline \multirow[t]{2}{*}{ IDE } & \multirow[t]{2}{*}{ APU } & \multirow[t]{2}{*}{ Título } & \multirow{2}{*}{ Pergunta de pesquisa } & \multirow[t]{2}{*}{ Foco } & \multicolumn{2}{|l|}{ Objetivo(s) } \\
\hline & & & & & Parte pré-textual (Resumo) & Parte textual \\
\hline 12 & 2007 & \begin{tabular}{|l|}
\multicolumn{2}{|l|}{ Personally-Seeded } \\
Discussions r to \\
Scaffold \\
Argumentation
\end{tabular} & $\begin{array}{lrr}\text { NÃO } & \text { FOI } & \text { POSSÍVEL } \\
\text { LOCALIZAR } & \text { A } \\
\text { PERGUNTA } & \\
\text { PESQUISA } & \text { EM } & \text { UM } \\
\text { FORMATO CLARO. }\end{array}$ & $\begin{array}{l}\text { This study analyzes a } \\
\text { customized online } \\
\text { discourse rystem } \\
\text { designed to integrate } \\
\text { and support scientific } \\
\text { argumentation within } \\
\text { the classroom }\end{array}$ & $\begin{array}{l}\text { The current study asks two questions about } \\
\text { the nature and quality of the argumentation } \\
\text { supported: } \\
\text { 1. What is the structural nature of the } \\
\text { argumentation within personally-seeded } \\
\text { discussions? 2. Can personally-seeded } \\
\text { discussions scaffold high levels of scientific } \\
\text { argumentation as defined by Erduran, } \\
\text { Osborne, and Simon? }\end{array}$ & 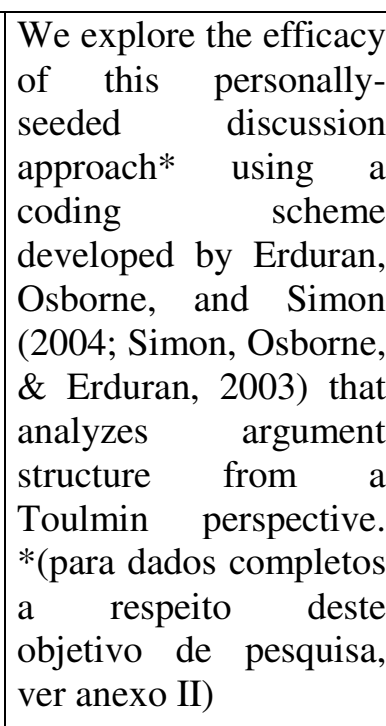 \\
\hline
\end{tabular}




\begin{tabular}{|c|c|c|c|c|c|c|}
\hline \multirow[t]{2}{*}{ IDE } & \multirow[t]{2}{*}{ APU } & \multirow[t]{2}{*}{ Título } & \multirow[t]{2}{*}{ Pergunta de pesquisa } & \multirow[t]{2}{*}{ Foco } & \multicolumn{2}{|l|}{ Objetivo(s) } \\
\hline & & & & & Parte pré-textual (Resumo) & Parte textual \\
\hline 14 & 2007 & $\begin{array}{l}\text { Teachers' Stances and } \\
\text { Practical Arguments } \\
\text { regarding a Science- } \\
\text { Indigenous } \\
\text { Knowledge } \\
\text { Curriculum: Part } 1\end{array}$ & $\begin{array}{|lcr|}\text { NÃO } & \text { FOI } & \text { POSSÍVEL } \\
\text { LOCALIZAR } & & \text { A } \\
\text { PERGUNTA } & & \text { DE } \\
\text { PESQUISA } & \text { EM } & \text { UM } \\
\text { FORMATO CLARO. } & \\
\end{array}$ & $\begin{array}{|lrr|}\text { NÃO FOI } & \text { POSSÍVEL } \\
\text { LOCALIZAR } & \text { O } \\
\text { OBJETIVO } & \text { DE } \\
\text { PESQUISA } & \text { EM } & \text { UM } \\
\text { FORMATO CLARO. }\end{array}$ & $\begin{array}{l}\text { the study attempted to: } \\
\text { 1. provide a detailed account of the } \\
\text { development of the PAC (Practical } \\
\text { Argumentation Course) and related } \\
\text { assessment instruments; 2. determine the } \\
\text { relative effects of the PAC in enhancing the } \\
\text { teachers' understanding of, and awareness } \\
\text { about, a Science-IKS (Indigenous Knowledge } \\
\text { Systems) }\end{array}$ & $\begin{array}{l}\text { 1. provide a detailed } \\
\text { account of the } \\
\text { development of the PAC } \\
\text { and related assessment } \\
\text { instruments; } \\
\text { determine the relative } \\
\text { effects of the PAC in } \\
\text { enhancing the teachers' } \\
\text { understanding of, and } \\
\text { awareness about, a } \\
\text { Science-IKS curriculum }\end{array}$ \\
\hline 15 & 2007 & $\begin{array}{l}\text { Teachers' Stances and } \\
\text { Practical Arguments } \\
\text { regarding a Science- } \\
\text { Indigenous } \\
\text { Knowledge } \\
\text { Curriculum: Part } 2\end{array}$ & $\begin{array}{|lcr|}\text { NÃO } & \text { FOI } & \text { POSSÍVEL } \\
\text { LOCALIZAR } & & \text { A } \\
\text { PERGUNTA } & & \text { DE } \\
\text { PESQUISA } & \text { EM } & \text { UM } \\
\text { FORMATO CLARO. } & \end{array}$ & 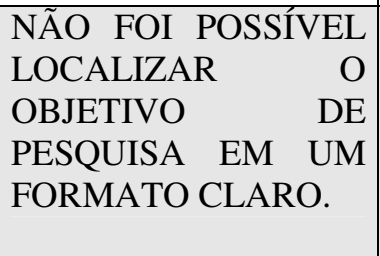 & $\begin{array}{l}\text { the study attempted to: determine effects of } \\
\text { the PAC (Practical Argumentation Course) on } \\
\text { the teachers' perceptions of the NOS (Nature } \\
\text { of Science) and IKS (Indigenous Knowledge } \\
\text { Systems) in the context of a Science-IKS } \\
\text { curriculum }\end{array}$ & $\begin{array}{l}\text { Determine effects of the } \\
\text { PAC on the teachers' } \\
\text { perceptions of the NOS } \\
\text { and IKS in the context of } \\
\text { a Science-IKS } \\
\text { curriculum. }\end{array}$ \\
\hline 16 & 2007 & $\begin{array}{|lr|}\text { Promovendo } & \text { a } \\
\text { argumentação } & \text { no } \\
\text { ensino superior } & \text { de } \\
\text { química } & \end{array}$ & $\begin{array}{|lcr|}\text { NÃO } & \text { FOI } & \text { POSSÍVEL } \\
\text { LOCALIZAR } & & \text { A } \\
\text { PERGUNTA } & & \text { DE } \\
\text { PESQUISA } & \text { EM } & \text { UM } \\
\text { FORMATO CLARO. } & \\
\end{array}$ & $\begin{array}{l}\text { NÃO FOI POSSÍVEL } \\
\text { LOCALIZAR O FOCO } \\
\text { EM UM FORMATO } \\
\text { CLARO. }\end{array}$ & $\begin{array}{llll}\text { NÃO FOI POSSÍVEL LOCALIZAR } & \text { O } \\
\text { OBJETIVO DE PESQUISA } & \end{array}$ & $\begin{array}{l}\text { Neste trabalho temos } \\
\text { como objetivo discutir } \\
\text { em que medida uma } \\
\text { proposta de ensino } \\
\text { pautada na resolução de } \\
\text { casos investigativos } \\
\text { (método de } \\
\text { Caso) foi captudo de } \\
\text { estimular a elaboração } \\
\text { de argumentos por parte } \\
\text { de graduandos } \\
\text { química em } \\
\text { qualidade avaliar a } \\
\text { argumentos por eles } \\
\text { apresentados } \\
\text { resolução dos casos }\end{array}$ \\
\hline
\end{tabular}




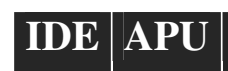

\begin{tabular}{|c|c|c|c|c|c|c|}
\hline 17 & 2007 & 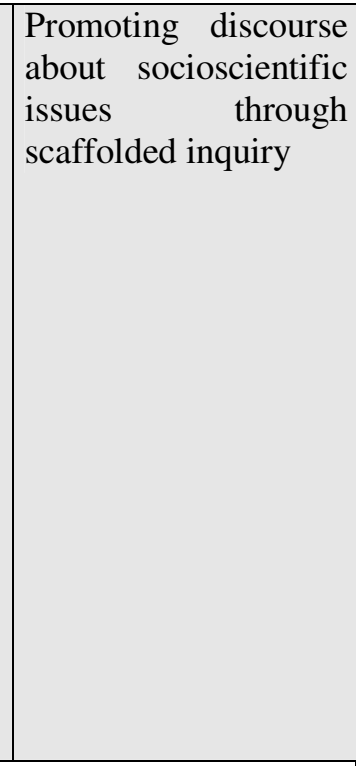 & $\begin{array}{l}\text { Students' epistemological } \\
\text { understandings of issues } \\
\text { related to this web-based } \\
\text { SSI instruction using } \\
\text { controversial material: } \\
\text { Question 1. To what extent } \\
\text { are students able to } \\
\text { recognize and utilize } \\
\text { explicit conceptual NOS } \\
\text { links during a web-based } \\
\text { learning activity embedded } \\
\text { in SSI? Question 2. What } \\
\text { features of argumentation } \\
\text { and discourse are utilized } \\
\text { by students as they engage } \\
\text { in a debate activity using } \\
\text { SSI embedded in NOS } \\
\text { instruction? }\end{array}$ & $\begin{array}{l}{[\ldots] \text { the purpose of this }} \\
\text { case study is to promote } \\
\text { discourse about a SSI } \\
\text { through a scaffolded } \\
\text { inquiry activity. }\end{array}$ & $\begin{array}{l}\text { This case study investigated the } \\
\text { implementation of an inquiry-based } \\
\text { curricular unit that was designed to } \\
\text { promote student discourse and debate on } \\
\text { aspects related to the nature of science, } \\
\text { using a socioscientific issue of genetically } \\
\text { modified foods. }\end{array}$ & $\begin{array}{l}\text { The purpose of this } \\
\text { exploratory case study was } \\
\text { to promote discourse about } \\
\text { SSI through web-based } \\
\text { instruction and examine } \\
\text { the extent to which } \\
\text { students are able to } \\
\text { recognize and utilize } \\
\text { explicit conceptual NOS } \\
\text { links embedded in SSI, and } \\
\text { to examine what features } \\
\text { of argumentation and } \\
\text { discourse are utilized by } \\
\text { students as they engage in } \\
\text { this unit of study }\end{array}$ \\
\hline 18 & 2007 & $\begin{array}{l}\text { High school students' } \\
\text { informal reasoning on } \\
\text { a socio-scientific } \\
\text { issue: Qualitative and } \\
\text { quantitative analyses }\end{array}$ & \begin{tabular}{|lrr} 
NÃO & FOI & POSSÍVEL \\
LOCALIZAR & & A \\
PERGUNTA & & DE \\
PESQUISA & EM & UM \\
FORMATO CLARO. &
\end{tabular} & $\begin{array}{l}\text { The current study was } \\
\text { one of the initial } \\
\text { attempts to develop an } \\
\text { integrated framework } \\
\text { for analyzing students' } \\
\text { argumentation and } \\
\text { decision-making on } \\
\text { socio-scientific issues } \\
\text { with both qualitative } \\
\text { indicators and } \\
\text { quantitative measures. }\end{array}$ & $\begin{array}{l}\text { To gain deeper insights into this important } \\
\text { issue [the significance of learners' informal } \\
\text { reasoning on socio-scientific issues] }\end{array}$ & $\begin{array}{l}\text { With this analytic } \\
\text { framework [framework for } \\
\text { analyzing } \\
\text { argumentation students' } \\
\text { decision-making on socio- } \\
\text { scientific issues], a group } \\
\text { of high school students' } \\
\text { informal reasoning }[\ldots] \\
\text { was explored. The } \\
\text { relationships between } \\
\text { students' } \\
\text { indicators and quantitative } \\
\text { measures for their } \\
\text { reasoning and decision- } \\
\text { making on this issue were } \\
\text { also investigated. }\end{array}$ \\
\hline
\end{tabular}




\begin{tabular}{|c|c|c|c|c|c|c|}
\hline \multirow[t]{2}{*}{ IDE } & \multirow{2}{*}{ APU } & \multirow{2}{*}{ Título } & \multirow{2}{*}{ Pergunta de pesquisa } & \multirow[t]{2}{*}{ Foco } & \multicolumn{2}{|l|}{ Objetivo(s) } \\
\hline & & & & & Parte pré-textual (Resumo) & Parte textual \\
\hline 19 & 2006 & $\begin{array}{|lr|}\text { Socioscientific } \\
\text { Argumentation: The } \\
\text { Effects of Content } \\
\text { Knowledge } \\
\text { Morality }\end{array}$ & $\begin{array}{|llr|}\text { NÃO } & \text { FOI } & \text { POSSÍVEL } \\
\text { LOCALIZAR } & & \text { A } \\
\text { PERGUNTA } & & \text { DE } \\
\text { PESQUISA } & \text { EM } & \text { UM } \\
\text { FORMATO CLARO } & \end{array}$ & $\begin{array}{l}\text { This study explores the } \\
\text { argumentation of high } \\
\text { school students as they } \\
\text { consider and attempt to } \\
\text { resolve socioscientific } \\
\text { issues }\end{array}$ & $\begin{array}{l}\text { Investigate how content knowledge and moral } \\
\text { reasoning contribute to the quality of } \\
\text { argumentation demonstrated in the context of } \\
\text { SSI for high school students }\end{array}$ & $\begin{array}{l}\text { We investigate how } \\
\text { science content } \\
\text { knowledge and moral } \\
\text { reasoning contribute to } \\
\text { argumentation in the } \\
\text { context of genetic } \\
\text { engineering issues }\end{array}$ \\
\hline 20 & 2006 & $\begin{array}{l}\text { Learning to Teach } \\
\text { Argumentation: } \\
\text { Research and } \\
\text { Development in the } \\
\text { Science Classroom }\end{array}$ & $\begin{array}{|llr|}\text { NÃO } & \text { FOI } & \text { POSSÍVEL } \\
\text { LOCALIZAR } & & \text { A } \\
\text { PERGUNTA } & & \text { DE } \\
\text { PESQUISA } & \text { EM } & \text { UM } \\
\text { FORMATO CLARO. } & \end{array}$ & $\begin{array}{l}\text { The research presented } \\
\text { in this paper has } \\
\text { therefore sought to } \\
\text { examine ways in which } \\
\text { teachers can appropriate } \\
\text { the discourse of } \\
\text { argumentation and } \\
\text { whether changes occur } \\
\text { in the nature of } \\
\text { teachers classroom } \\
\text { interactions as they } \\
\text { engage in a Professional } \\
\text { development } \\
\text { programme }\end{array}$ & $\begin{array}{l}\text { Find ways of enhancing young people's skills } \\
\text { by trialling the pedagogical strategies and } \\
\text { determining the extent to which their } \\
\text { implementation enhances teachers' pedagogic } \\
\text { practice with argumentation. }\end{array}$ & $\begin{array}{l}\text { Find ways of enhancing } \\
\text { young people's skills by } \\
\text { trialling the pedagogical } \\
\text { strategies and } \\
\text { determining the extent to } \\
\text { which their } \\
\text { implementation } \\
\text { enhances teachers' } \\
\text { pedagogic practice with } \\
\text { argumentation }\end{array}$ \\
\hline 21 & 2006 & $\begin{array}{l}\text { Patterns in Students' } \\
\text { Argumentation } \\
\text { Confronted with a } \\
\text { Risk-Focused Socio- } \\
\text { Scientific Issue }\end{array}$ & $\begin{array}{l}\text { What were their main } \\
\text { arguments? } \\
\text { knowledge did they regard } \\
\text { as relevant? What would } \\
\text { they like to know more } \\
\text { about? What were their } \\
\text { personal opinions? }\end{array}$ & $\begin{array}{l}\text { The research reported } \\
\text { here was initiated to } \\
\text { meet this need for more } \\
\text { insight into students' } \\
\text { ways of using values } \\
\text { and different types of } \\
\text { knowledge in their } \\
\text { argumentation and } \\
\text { decision-making }\end{array}$ & $\begin{array}{l}\text { This paper reports a qualitative study on } \\
\text { students' informal reasoning } \\
\text { controversial socioscientific issue. }\end{array}$ & $\begin{array}{l}\text { The present study seeks } \\
\text { to identify the } \\
\text { arguments, scientific or } \\
\text { other, that hold a central } \\
\text { position in the students' } \\
\text { reasoning about their } \\
\text { decision on an issue. }\end{array}$ \\
\hline
\end{tabular}




\begin{tabular}{|c|c|c|c|c|c|c|}
\hline \multirow[t]{2}{*}{ IDE } & \multirow[t]{2}{*}{ APU } & \multirow{2}{*}{ Título } & \multirow{2}{*}{ Pergunta de pesquisa } & \multirow{2}{*}{ Foco } & \multicolumn{2}{|l|}{ Objetivo(s) } \\
\hline & & & & & Parte pré-textual (Resumo) & Parte textual \\
\hline 22 & 2006 & \begin{tabular}{lr|} 
Mapping Children's \\
Discussions r of \\
Evidence in Science \\
to \\
Collaboration Assess \\
Argumentation
\end{tabular} & $\begin{array}{l}\text { 1) The analysis will help to } \\
\text { determine the effectiveness } \\
\text { of the activities in } \\
\text { generating reasoning and } \\
\text { argumentation, and also } \\
\text { provide an indication of } \\
\text { how collaboration worked } \\
\text { to achieve these goals. 2) } \\
\text { The research aimed to } \\
\text { clarify how children made } \\
\text { use of evidence in } \\
\text { decision-making activities } \\
\text { and whether they used } \\
\text { evidence to justify } \\
\text { theirdecisions. }\end{array}$ & $\begin{array}{lrr}\text { NÃO } & \text { FOI } & \text { POSSÍVEL } \\
\text { LOCALIZAR O FOCO } \\
\text { DE } & \text { PESQUISA EM } \\
\text { UM } & \text { FORMATO } \\
\text { CLARO. } & \end{array}$ & $\begin{array}{l}\text { The research aimed to clarify how children } \\
\text { made use of evidence in decision-making } \\
\text { activities and whether they used evidence to } \\
\text { justify their decisions }\end{array}$ & $\begin{array}{l}\text { The main aim of this } \\
\text { study was therefore to } \\
\text { examine the ways in } \\
\text { which groups of children } \\
\text { argue and use evidence } \\
\text { in decision-making in } \\
\text { science. }\end{array}$ \\
\hline 23 & 2006 & $\begin{array}{l}\text { A Threshold Model } \\
\text { of } \quad \text { Content } \\
\text { Knowledge } \text { Transfer } \\
\text { for } \quad \text { Socioscientific } \\
\text { Argumentation }\end{array}$ & $\begin{array}{l}\text { How individuals use } \\
\text { scientific content } \\
\text { knowledge as they make } \\
\text { and justify claims relative } \\
\text { to genetic engineering } \\
\text { scenarios? }\end{array}$ & $\begin{array}{l}\text { This study explores } \\
\text { high school and college } \\
\text { student argumentation } \\
\text { in the context of SSI, } \\
\text { i.e., socioscientific } \\
\text { argumentation. }\end{array}$ & $\begin{array}{l}\text { This study explores [..] how individuals use } \\
\text { scientific content knowledge as they make } \\
\text { and justify claims relative to genetic } \\
\text { engineering scenarios. Our work explores } \\
\text { whether and how students transfer genetics } \\
\text { understandings to argumentation contexts } \\
\text { centered on biotechnology and society. }\end{array}$ & $\begin{array}{l}\text { Our work explores } \\
\text { whether and how } \\
\text { students transfer } \\
\text { genetics understandings } \\
\text { to argumentation } \\
\text { contexts centered on } \\
\text { biotechnology and } \\
\text { society. }\end{array}$ \\
\hline 24 & 2006 & $\begin{array}{l}\text { The Features of Peer } \\
\text { Argumentation in } \\
\text { Middle rehool } \\
\text { Students' Scientific } \\
\text { Inquiry }\end{array}$ & $\begin{array}{l}\text { 1. What are the sources of } \\
\text { evidence used in students' } \\
\text { arguments?; 2. Which } \\
\text { strategies are used in } \\
\text { students argumentation?; } \\
\text { 3. How does critical } \\
\text { discussion proceed?; } 4 . \\
\text { Which types of discussion } \\
\text { are found in critical } \\
\text { discussion? }\end{array}$ & $\begin{array}{l}\text { The focus of this paper } \\
\text { is to examine the } \\
\text { features of peer } \\
\text { argumentation among } \\
\text { students during } \\
\text { scientific inquiry) }\end{array}$ & $\begin{array}{l}\text { Hence, the purpose of this study is not to } \\
\text { evaluate but to describe and understand } \\
\text { students' argumentation, and we focused on } \\
\text { the process of argumentation rather than the } \\
\text { form and content of the argument }\end{array}$ & $\begin{array}{lr}\text { NÃO FOI } & \text { POSSÍVEL } \\
\text { LOCALIZAR } & \text { O } \\
\text { OBJETIVO } & \text { DE } \\
\text { PESQUISA } & \text { EM } \\
\text { FORMATO } \\
\text { FOLARO. }\end{array}$ \\
\hline
\end{tabular}




\begin{tabular}{|c|c|c|c|c|c|c|}
\hline \multirow[t]{2}{*}{ IDE } & \multirow[t]{2}{*}{ APU } & \multirow{2}{*}{ Título } & \multirow{2}{*}{ Pergunta de pesquisa } & \multirow[t]{2}{*}{ Foco } & \multicolumn{2}{|l|}{ Objetivo(s) } \\
\hline & & & & & Parte pré-textual (Resumo) & Parte textual \\
\hline 25 & 2006 & $\begin{array}{lr}\text { Science } & \text { students' } \\
\text { critical } & \text { examination } \\
\text { of } & \text { scientific } \\
\text { information related to } \\
\text { socioscientific issues }\end{array}$ & $\begin{array}{l}{[\ldots] \text { we hope to be able to }} \\
\text { shed light on the more } \\
\text { general question of how and } \\
\text { to what extent nonscientists } \\
\text { are epistemically dependent } \\
\text { on different kinds of } \\
\text { experts. }\end{array}$ & $\begin{array}{l}{[\ldots] \text { identifying the }} \\
\text { evaluation criteria used } \\
\text { by the students in this } \\
\text { study. }\end{array}$ & $\begin{array}{l}\text { NÃO FOI POSSÍVEL LOCALIZAR } \mathrm{O} \\
\text { OBJETIVO DE PESQUISA. }\end{array}$ & $\begin{array}{l}{[\ldots] \text { we will focus on }} \\
\text { their [students] use of } \\
\text { different scientific } \\
\text { criteria as well as other } \\
\text { kinds of criteria.[...] we } \\
\text { will discuss the } \\
\text { relevance of different } \\
\text { criteria identified } \\
\text { without using the } \\
\text { division between } \\
\text { scientific and } \\
\text { nonscientific criteria as a } \\
\text { normative distinction. }\end{array}$ \\
\hline 26 & 2004 & $\begin{array}{lr}\text { Enhancing } & \text { the } \\
\text { Quality } & \text { of } \\
\text { Argumentation } & \text { in } \\
\text { School Science } & \end{array}$ & $\begin{array}{l}\text { 1. what can teachers learn } \\
\text { by listening to student } \\
\text { discussion and how can } \\
\text { they foster and improve the } \\
\text { quality of argumentation? } 2 \text {. } \\
\text { Essentially, how can they } \\
\text { respond formatively to } \\
\text { assist their students and } \\
\text { develop their reasoning? } 3 . \\
\text { How, for instance, can they } \\
\text { identify the essential } \\
\text { features of an argument? } \\
\text { How are they to judge that } \\
\text { one argument is better than } \\
\text { another? Also, how should } \\
\text { they model arguments of } \\
\text { quality to their students? }\end{array}$ & $\begin{array}{l}\text { The research presented } \\
\text { herein examines } \\
\text { whether the quality of } \\
\text { "'argument', of young } \\
\text { peoples' argument } \\
\text { about scientific issues } \\
\text { could be enhanced in } \\
\text { science lessons) }\end{array}$ & $\begin{array}{l}\text { 1. Identify some of the pedagogical strategies } \\
\text { necessary to promote "argument" skills in } \\
\text { young people in science lessons. } \\
\text { 2. Trial the pedagogical strategies and } \\
\text { determine the extent to which their } \\
\text { implementation enhances teachers' pedagogic } \\
\text { practice with "argument.", } \\
\text { 3. Determine the extent to which lessons that } \\
\text { follow these pedagogical strategies lead to } \\
\text { enhanced quality in students' arguments. } \\
\text { The focus of the study reported here is, } \\
\text { however, principally on the third area of } \\
\text { interest. }\end{array}$ & $\begin{array}{l}\text { 1. Identify some of the } \\
\text { pedagogical strategies } \\
\text { necessary to promote } \\
\text { "argument" skills in } \\
\text { young people in science } \\
\text { lessons.; 2. Trial the } \\
\text { pedagogical strategies } \\
\text { and determine the extent } \\
\text { to which their } \\
\text { implementation teachers' } \\
\text { enhances } \\
\text { pedagogic practice with } \\
\text { "argument."; } \\
\text { Determine the extent to } \\
\text { which lessons that } \\
\text { follow these pedagogical } \\
\text { strategies lead to } \\
\text { enhanced quality in } \\
\text { students' arguments. }\end{array}$ \\
\hline
\end{tabular}




\begin{tabular}{|c|c|c|c|c|c|c|}
\hline \multirow[t]{2}{*}{ IDE } & \multirow[t]{2}{*}{ APU } & \multirow[t]{2}{*}{ Título } & \multirow[t]{2}{*}{ Pergunta de pesquisa } & \multirow[t]{2}{*}{ Foco } & \multicolumn{2}{|l|}{ Objetivo(s) } \\
\hline & & & & & Parte pré-textual (Resumo) & Parte textual \\
\hline 27 & 2004 & $\begin{array}{l}\text { TAPping into } \\
\text { Argumentation: } \\
\text { Developments in the } \\
\text { Application of } \\
\text { Toulmin's Argument } \\
\text { Pattern for Studying } \\
\text { Science Discourse }\end{array}$ & $\begin{array}{l}\text { 1. How the quality of } \\
\text { argumentation discourse } \\
\text { might progress through } \\
\text { sustained intervention in } \\
\text { the classroom? or indeed; } \\
\text { 2.how TAP could be used } \\
\text { to monitor this change? }\end{array}$ & $\begin{array}{l}\text { The focus of this paper } \\
\text { is to examine the } \\
\text { features of peer } \\
\text { argumentation among } \\
\text { students during scientific } \\
\text { inquiry. }\end{array}$ & $\begin{array}{l}\text { The primary objective of this paper is to } \\
\text { focus on the development and use of TAP } \\
\text { as a tool for tracing the quantity and quality } \\
\text { of argumentation in science discourse. }\end{array}$ & $\begin{array}{l}\text { The primary objective of } \\
\text { this paper is to focus on } \\
\text { the development and use } \\
\text { of TAP (Toulmin's } \\
\text { Argument Pattern) as a } \\
\text { tool for tracing the } \\
\text { quantity and quality of } \\
\text { argumentation in science } \\
\text { discourse [...] Our aim in } \\
\text { this paper is to extend the } \\
\text { applicability of TAP in } \\
\text { data analysis of science } \\
\text { discourse in the classroom } \\
\text { so the choice of TAP is } \\
\text { central to our thesis. }\end{array}$ \\
\hline 28 & 2004 & $\begin{array}{l}\text { Students' Discussions in } \\
\text { Practical } \quad \text { Scientific } \\
\text { Inquiries. }\end{array}$ & $\begin{array}{lcrr}\text { NÃO } & \text { FOI } & \text { POSSÍVEL } \\
\text { LOCALIZAR } & & \text { A } \\
\text { PERGUNTA } & & \text { DE } \\
\text { PESQUISA } & \text { EM } & \text { UM } \\
\text { FORMATO CLARO. } & \end{array}$ & $\begin{array}{l}\text { We were thus looking for } \\
\text { examples of both } \\
\text { monologic and dialogic } \\
\text { argument during student } \\
\text { discussions in the scientific } \\
\text { inquiry reported here. }\end{array}$ & $\begin{array}{l}\text { The present study seeks to identify the } \\
\text { conditions in laboratory-based scientific inquiry } \\
\text { lessons, which promote or hinder argumentation } \\
\text { and discussion }\end{array}$ & $\begin{array}{l}\text { The present study seeks to } \\
\text { identify the conditions in } \\
\text { laboratory-based scientific } \\
\text { inquiry lessons, which } \\
\text { promote or hinder } \\
\text { argumentation and discussion, } \\
\text { by considering the followinag } \\
\text { aspects: 1. the quantity and } \\
\text { quality of argumentation used } \\
\text { during the inquiry process; } \\
\text { and; } 2 \text {.how the socio-cultural } \\
\text { setting in the classroom } \\
\text { influenced the claims made } \\
\text { during the argumentation } \\
\text { processes, both during whole } \\
\text { class discussions and when } \\
\text { students were discussing in } \\
\text { small groups. }\end{array}$ \\
\hline
\end{tabular}




\begin{tabular}{|c|c|c|c|c|c|c|}
\hline \multirow[t]{2}{*}{ IDE } & \multirow[t]{2}{*}{ APU } & \multirow[t]{2}{*}{ Título } & \multirow{2}{*}{ Pergunta de pesquisa } & \multirow{2}{*}{ Foco } & \multicolumn{2}{|l|}{ Objetivo(s) } \\
\hline & & & & & Parte pré-textual (Resumo) & Parte textual \\
\hline 29 & 2004 & $\begin{array}{l}\text { Informal reasoning } \\
\text { regarding } \\
\text { socioscientific } \\
\text { issues: A critical } \\
\text { review of research }\end{array}$ & $\begin{array}{l}\text { Assertions that } \\
\text { socioscientific issues form } \\
\text { an important component of } \\
\text { scientific literacy } \\
\text { (American Association for } \\
\text { the Advancement of } \\
\text { Science, 1990; National } \\
\text { Research Council, 1996; } \\
\text { Siebert \& McIntosh, 2001) } \\
\text { demand the exploration of } \\
\text { how these issues can be } \\
\text { most meaningfully } \\
\text { incorporated in science } \\
\text { curricula and classrooms. } \\
\text { Meeting this challenge } \\
\text { requires (a) an assessment } \\
\text { of what is known and then } \\
\text { (b) an assessment of what } \\
\text { needs to be known. }\end{array}$ & $\begin{array}{l}\text { This article provides a } \\
\text { summary of current } \\
\text { knowledge, identifies } \\
\text { areas which require } \\
\text { additional } \\
\text { concentration, and } \\
\text { makes } \\
\text { recommendations for } \\
\text { classroom } \\
\text { considerations. }\end{array}$ & $\begin{array}{l}\text { This article presents a critical review of } \\
\text { research related to informal reasoning } \\
\text { regarding socioscientific issues. }\end{array}$ & $\begin{array}{l}\text { The purpose of this article } \\
\text { is to review key topics } \\
\text { identified in the empirical } \\
\text { literature concerning } \\
\text { socioscientific issues and } \\
\text { synthesize their findings } \\
\text { as they relate to science } \\
\text { education research and } \\
\text { practice }\end{array}$ \\
\hline 30 & 2003 & $\begin{array}{l}\text { The Nature and } \\
\text { Development of } \\
\text { Hypothetico- } \\
\text { Predictive } \\
\text { Argumentation } \\
\text { with Implications } \\
\text { for Science } \\
\text { Teaching }\end{array}$ & $\begin{array}{l}\text { How do scientists construct } \\
\text { and use arguments? }\end{array}$ & 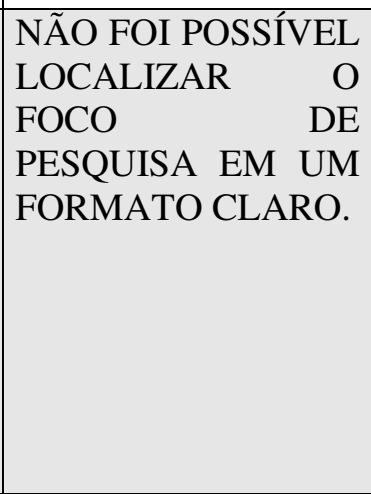 & $\begin{array}{l}\text { The presumption is that engaging students } \\
\text { in argumentation is the best way for them } \\
\text { to not only construct conceptual } \\
\text { knowledge, but also to become skilled in } \\
\text { the use of general forms of argumentation } \\
\text { that are of considerable use in democratic } \\
\text { societies. The purpose of the present paper } \\
\text { is to expand on this theme by explicating } \\
\text { the nature of hypothetico-predictive } \\
\text { argumentation, its development, and its } \\
\text { potential use in the science classroom. }\end{array}$ & $\begin{array}{l}\text { The purpose of the } \\
\text { present paper is } \\
\text { [...]explicating the nature } \\
\text { of hypothetico-predictive } \\
\text { argumentation, its } \\
\text { development, and its } \\
\text { potential use in the } \\
\text { science classroom. }\end{array}$ \\
\hline
\end{tabular}




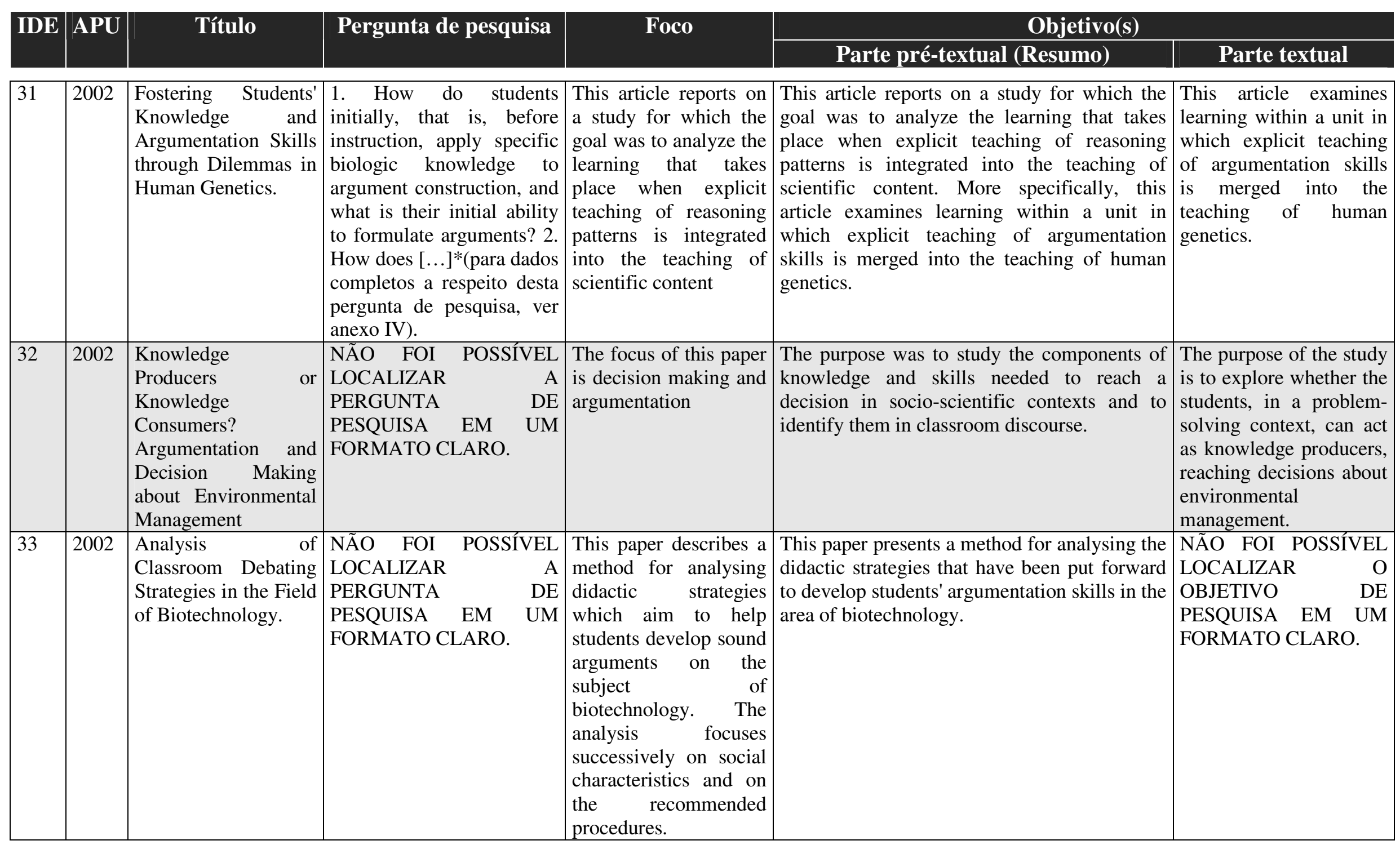




\begin{tabular}{|c|c|c|c|c|c|c|}
\hline \multirow[t]{2}{*}{ IDE } & \multirow[t]{2}{*}{ APU } & \multirow[t]{2}{*}{ Título } & \multirow[t]{2}{*}{ Pergunta de pesquisa } & \multirow[t]{2}{*}{ Foco } & \multicolumn{2}{|c|}{ Objetivo(s) } \\
\hline & & & & & Parte pré-textual (Resumo) & Parte textual \\
\hline 34 & 2002 & $\begin{array}{l}\text { Teaching } \\
\text { biotechnology through } \\
\text { case studies: Can we } \\
\text { improve higher order } \\
\text { thinking skills of } \\
\text { nonscience majors? }\end{array}$ & $\begin{array}{lcrr}\text { NÃO } & \text { FOI } & \text { POSSÍVEL } \\
\text { LOCALIZAR } & & \text { A } \\
\text { PERGUNTA } & & \text { DE } \\
\text { PESQUISA } & \text { EM } & \text { UM } \\
\text { FORMATO CLARO. } & \end{array}$ & $\begin{array}{|lr|}\text { NÃO } & \text { FOI } \\
\text { POSSÍVEL } & \\
\text { LOCALIZAR } & \mathrm{A} \\
\text { PERGUNTA } & \text { DE } \\
\text { PESQUISA } & \text { EM } \\
\text { FORM } \\
\text { FORATO CLARO. }\end{array}$ & $\begin{array}{l}\text { [...] Teaching nonscience majors topics in } \\
\text { biotechnology through case studies is the } \\
\text { focus of this research. [...] The research } \\
\text { goal was to investigate nonscience major } \\
\text { students ability to use various thinking } \\
\text { skills in analyzing environmental and moral } \\
\text { conflicts presented through case studies in } \\
\text { the Biotechnology Module. }\end{array}$ & $\begin{array}{l}\text { The research goal was to } \\
\text { investigate nonscience major } \\
\text { students' ability to use various } \\
\text { thinking skills in analyzing } \\
\text { environmental and moral } \\
\text { conflicts presented through case } \\
\text { studies in the Biotechnology } \\
\text { Module. }\end{array}$ \\
\hline 35 & 2002 & $\begin{array}{l}\text { Arguments, } \\
\text { contradictions, and } \\
\text { resistances, } \\
\text { conceptual change in } \\
\text { students' } \\
\text { understanding of } \\
\text { atomic structure }\end{array}$ & $\begin{array}{l}\text { It is hypothesized that } \\
\text { classroom discussions based } \\
\text { on arguments/counter } \\
\text { arguments the heuristic } \\
\text { principles (Schwab, 1962, } \\
\text { 1974), on which these } \\
\text { scientists based their atom } \\
\text { models, can facilitate } \\
\text { students } \\
\text { understanding of atomic } \\
\text { structure. }\end{array}$ & 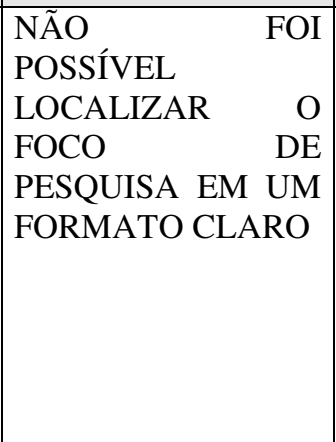 & $\begin{array}{l}\text { The objective of this study is to facilitate } \\
\text { freshman general chemistry students' } \\
\text { understanding of atomic structure based on } \\
\text { the work of Thomson, Rutherford, and } \\
\text { Bohr. }\end{array}$ & $\begin{array}{l}\text { The purpose of this study is to } \\
\text { facilitate freshman general } \\
\text { chemistry } \\
\text { understanding of atudents } \\
\text { structure, based on the work of J. } \\
\text { J. Thomson, E. Rutherford, and } \\
\text { N. Bohr }\end{array}$ \\
\hline 36 & 2002 & $\begin{array}{l}\text { Scaffolding preservice } \\
\text { science teachers' } \\
\text { evidence-based } \\
\text { arguments during an } \\
\text { investigation of natural } \\
\text { selection }\end{array}$ & $\begin{array}{l}\text { The questions that guided } \\
\text { our research were: (1) What } \\
\text { is the nature of the scientific } \\
\text { arguments developed by } \\
\text { preservice teachers? That is, } \\
\text { how do preservice teachers } \\
\text { structure their arguments? In } \\
\text { particular, what evidence do } \\
\text { they use and how do they } \\
\text { use it? In addition [...] } \\
\text { *(para dados completos a } \\
\text { respeito desta pergunta de } \\
\text { pesquisa, ver anexo V). }\end{array}$ & $\begin{array}{|lr|}\text { In this } & \text { study, we } \\
\text { engaged preservice } \\
\text { secondary } r \text { science } \\
\text { teachers enrolled in } \\
\text { their radvanced } \\
\text { methods course in an } \\
\text { extended, complex, } \\
\text { data-rich } \\
\text { investigation. }\end{array}$ & $\begin{array}{l}\text { In this qualitative case study, preservice } \\
\text { science teachers (PSTs) enrolled in their } \\
\text { advanced methods course participated in a } \\
\text { complex, data-rich investigation based on } \\
\text { an adapted version of the Struggle for } \\
\text { Survival curriculum [...]. The questions } \\
\text { that guided the research were: (1) What is } \\
\text { the nature of the scientific arguments } \\
\text { developed by PSTs? (2) How do PSTs go } \\
\text { about constructing scientific arguments } \\
\text { (emphasis on processes and strategies)? (3) } \\
\text { In what ways do the scaffolds embedded in } \\
\text { the Galapagos Finches software influence } \\
\text { the development of PSTs arguments? }\end{array}$ & $\begin{array}{l}\text { Therefore, the purpose of this } \\
\text { study was to investigate the } \\
\text { nature and development of } \\
\text { preservice teachers' arguments } \\
\text { (i.e., structure and use of } \\
\text { evidence; consistency with } \\
\text { scientifically accepted } \\
\text { knowledge) during an } \\
\text { investigation of natural selection, } \\
\text { the processes in which they } \\
\text { engaged to construct those } \\
\text { arguments, and the software } \\
\text { scaffolds that influenced the } \\
\text { development of their arguments. }\end{array}$ \\
\hline
\end{tabular}




\begin{tabular}{|c|c|c|c|c|c|c|}
\hline \multirow[t]{2}{*}{ IDE } & \multirow[t]{2}{*}{ APU } & \multirow[t]{2}{*}{ Título } & \multirow[t]{2}{*}{ Pergunta de pesquisa } & \multirow[t]{2}{*}{ Foco } & \multicolumn{2}{|c|}{ Objetivo(s) } \\
\hline & & & & & Parte pré-textual (Resumo) & Parte textual \\
\hline 37 & 2001 & $\begin{array}{l}\text { Role-Play or Debate } \\
\text { to Promote Students' } \\
\text { Argumentation and } \\
\text { Justification on an } \\
\text { Issue in Animal } \\
\text { Transgenesis. }\end{array}$ & $\begin{array}{|lrr|}\text { NÃO } & \text { FOI } & \text { POSSÍVEL } \\
\text { LOCALIZAR } & \text { A } \\
\text { PERGUNTA } & \text { DE } \\
\text { PESQUISA } & \text { EM } & \text { UM } \\
\text { FORMATO CLARO. }\end{array}$ & 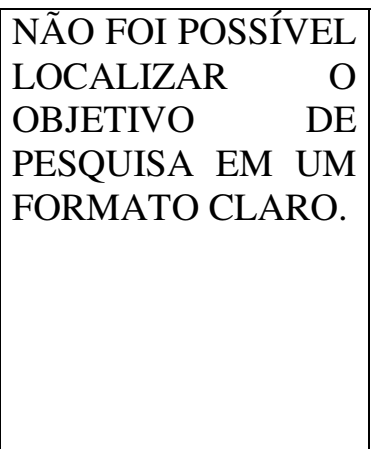 & $\begin{array}{l}\text { This paper compares the impact of a } \\
\text { role-play and a conventional } \\
\text { discussion on students' } \\
\text { argumentation on an issue involving } \\
\text { animal transgenesis. }\end{array}$ & $\begin{array}{l}\text { The aim here was to assess the } \\
\text { impact of an educational } \\
\text { strategy that was unfamiliar to } \\
\text { teachers on the way students } \\
\text { come to decisions: the } \\
\text { performance of a role-play } \\
\text { (variant 1) and comparison } \\
\text { with a conventional debate } \\
\text { (variant 2) on the same topic } \\
\text { (animal transgenesis). }\end{array}$ \\
\hline 38 & 2001 & \begin{tabular}{|lr} 
Sound and faulty \\
arguments generated \\
by r preservice \\
biology rychers \\
when teachesting \\
hypotheses r \\
involving rr \\
unobservable \\
entities
\end{tabular} & $\begin{array}{|lrr|}\text { NÃO } & \text { FOI } & \text { POSSÍVEL } \\
\text { LOCALIZAR } & \text { A } \\
\text { PERGUNTA } & \text { DE } \\
\text { PESQUISA } & \text { EM } & \text { UM } \\
\text { FORMATO CLARO. }\end{array}$ & 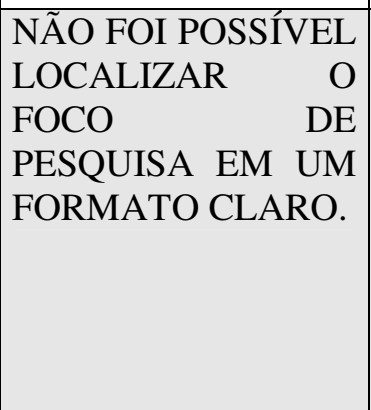 & $\begin{array}{l}\text { NÃO FOI POSSÍVEL LOCALIZAR } \\
\text { O OBJETIVO DE PESQUISA. }\end{array}$ & $\begin{array}{l}\text { Assess student hypothesis- } \\
\text { testing performance when the } \\
\text { abstraceness/ complexity of } \\
\text { the hypotheses being tested } \\
\text { varies within a single context. } \\
\text { [...] a secondary objective in } \\
\text { this study was to identify and } \\
\text { classify types of faulty } \\
\text { arguments. }\end{array}$ \\
\hline 39 & 2001 & $\begin{array}{ll}\text { Epistemic levels } & \text { in } \\
\text { argument: } & \text { an } \\
\text { analysis } & \text { of } \\
\text { university } & \\
\text { oceanography } & \\
\text { students use of } \\
\text { evidence in writing }\end{array}$ & $\begin{array}{|lrr|}\text { NÃO } & \text { FOI } & \text { POSSÍVEL } \\
\text { LOCALIZAR } & \text { A } \\
\text { PERGUNTA } & \text { DE } \\
\text { PESQUISA } & \text { EM } & \text { UM } \\
\text { FORMATO CLARO. }\end{array}$ & $\begin{array}{l}{[\ldots] \text { examination of }} \\
\text { students' writing in } \\
\text { the context of a } \\
\text { university } \\
\text { oceanography course. }\end{array}$ & $\begin{array}{l}\text { The purpose of this paper is to } \\
\text { examine university oceanography } \\
\text { students' use of evidence in writing. }\end{array}$ & $\begin{array}{l}\text { The purpose of this study is } \\
\text { twofold. First, we develop a } \\
\text { research methodology for } \\
\text { analyzing students written } \\
\text { arguments. Second, we apply } \\
\text { this method to assess } \\
\text { university oceanography } \\
\text { students' use of evidence in } \\
\text { writing. }\end{array}$ \\
\hline
\end{tabular}




\begin{tabular}{|c|c|c|c|c|c|c|}
\hline \multirow[t]{2}{*}{ IDE } & \multirow[t]{2}{*}{ APU } & \multirow[t]{2}{*}{ Título } & \multirow[t]{2}{*}{ Pergunta de pesquisa } & \multirow[t]{2}{*}{ Foco } & \multicolumn{2}{|c|}{ Objetivo(s) } \\
\hline & & & & & Parte pré-textual (Resumo) & Parte textual \\
\hline 40 & 2001 & $\begin{array}{l}\text { Comparing the } \\
\text { epistemological } \\
\text { underpinnings of } \\
\text { students'r and } \\
\text { scientists' reasoning } \\
\text { about conclusions }\end{array}$ & $\begin{array}{l}\text { Our central research } \\
\text { questions, then, were: } \\
\text { What epistemic criteria do } \\
\text { adolescents, nonscientist } \\
\text { adults, technicians, and } \\
\text { scientists use when } \\
\text { reasoning about the } \\
\text { validity of conclusions, and } \\
\text { what might account for any } \\
\text { differences in their criteria? }\end{array}$ & $\begin{array}{l}\text { In the study reported } \\
\text { here, we extend this } \\
\text { prior research [Brewer, } \\
\text { Chinn, } \\
\text { Samarapungavan, } \\
\text { 1998; } \\
\text { Samarapungavan, } \\
\text { 1992] by comparing } \\
\text { the actual on-line } \\
\text { reasoning of scientists } \\
\text { and nonscientists to } \\
\text { investigate the role of } \\
\text { epistemological } \\
\text { standards in scientific } \\
\text { thought. }\end{array}$ & $\begin{array}{l}\text { This study examined the criteria that } \\
\text { middle school students, nonscientist } \\
\text { adults, technicians, and scientists used } \\
\text { to rate the validity of conclusions } \\
\text { drawn by hypothetical students from a } \\
\text { set of evidence }\end{array}$ & $\begin{array}{l}\text { We investigated the } \\
\text { epistemological criteria that } \\
\text { underlie how four types of } \\
\text { participants - scientists, } \\
\text { technicians, nonscientist adults, } \\
\text { and middle school students- } \\
\text { judged the validity of } \\
\text { conclusions drawn from a set of } \\
\text { scientific observations. }\end{array}$ \\
\hline 41 & 2001 & $\begin{array}{l}\text { Dimensions } \\
\text { evidence, the public } \\
\text { understanding of } \\
\text { science and science } \\
\text { education }\end{array}$ & $\begin{array}{l}\text { 1. What are the } \\
\text { relationships between } \\
\text { theory and evidence } \\
\text { represented in this issue?2. } \\
\text { What evidence was } \\
\text { proffered by various } \\
\text { participants and in different } \\
\text { forums, and how can it be } \\
\text { characterized? 3. What } \\
\text { 'concepts of evidence' } \\
\text { were important in making } \\
\text { judgements about the } \\
\text { issues? 4. What are the } \\
\text { implications of the case } \\
\text { study for school science } \\
\text { curricula? }\end{array}$ & $\begin{array}{l}\text { In the research } \\
\text { reported below, we are } \\
\text { less concerned with the } \\
\text { substantive } \\
\text { explanatory ideas of } \\
\text { science } \\
\text { 'chemistry' of the } \\
\text { problem) than with the } \\
\text { issue of evidence: what } \\
\text { sorts of evidence were } \\
\text { used by the } \\
\text { participants? }\end{array}$ & $\begin{array}{l}\text { This paper explores the nature and type } \\
\text { of evidence employed by participants } \\
\text { in an issue of public concern. }\end{array}$ & $\begin{array}{l}\text { We examine how the different } \\
\text { types of evidence were brought } \\
\text { to bear on a socio-scientific } \\
\text { issue involving environmental } \\
\text { regulatory policy, and the } \\
\text { implications of this for school } \\
\text { science curricula. }\end{array}$ \\
\hline
\end{tabular}




\begin{tabular}{|c|c|c|c|c|c|c|}
\hline 42 & & $\begin{array}{l}\text { Lower Track Science } \\
\text { Students' } \\
\text { Argumentation and } \\
\text { Open Inquiry } \\
\text { Instruction. }\end{array}$ & $\begin{array}{l}\text { 1. How tentative are lower track } \\
\text { students' knowledge claims, and } \\
\text { can instruction shift their ways of } \\
\text { posing questions about the } \\
\text { world?; 2. What constitutes } \\
\text { lower track students' scientific } \\
\text { explanation, and can instruction } \\
\text { change the nature of their } \\
\text { solutions to open-ended } \\
\text { problems?; 3. Do lower track } \\
\text { students believe they can answer } \\
\text { a scientific question, and } 4 \text {. can } \\
\text { instruction impact their efficacy? }\end{array}$ & $\begin{array}{l}\text { This study }[\ldots] \text { is } \\
\text { highly focused on } \\
\text { whether argumentation } \\
\text { can be acquired by } \\
\text { students who have } \\
\text { experienced } \\
\text { widespread rejection, } \\
\text { failure, and alienation } \\
\text { in school and science } \\
\text { and are accustomed to } \\
\text { a fact-based science } \\
\text { classroom discourse }\end{array}$ & $\begin{array}{l}\text { The purpose of this study was to } \\
\text { examine the effects of open inquiry } \\
\text { instruction with low achieving, } \\
\text { marginalized high school students }\end{array}$ & $\begin{array}{lcr}\text { NÃO } & \text { FOI } & \text { POSSÍVEL } \\
\text { LOCALIZAR } & & \text { O } \\
\text { OBJETIVO } & & \text { DE } \\
\text { PESQUISA } & \text { EM } & \text { UM } \\
\text { FORMATO CLARO. } & \end{array}$ \\
\hline 43 & 2000 & $\begin{array}{l}\text { "Doing the Lesson" } \\
\text { or "Doing Science": } \\
\text { Argument in High } \\
\text { School Genetics }\end{array}$ & $\begin{array}{l}\text { 1. We seek to understand how } \\
\text { the mutual design of curriculum, } \\
\text { instruction, and assessment can } \\
\text { leverage whole class, group, and } \\
\text { individual; 2. Another way to } \\
\text { frame the goal of our research is } \\
\text { by asking how to move } \\
\text { classroom discourse away from } \\
\text { what Bloome, Puro, and } \\
\text { Theodorou (1989) call } \\
\text { procedural displayactivities. } \\
\text { Classrooms are complex settings } \\
\text { where any number of interaction } \\
\text { dynamics take place discourse to } \\
\text { reflect argumentation schemes- } \\
\text { scientific and otherwise }\end{array}$ & $\begin{array}{l}\text { The purpose of our } \\
\text { paper is to report on } \\
\text { the conversational } \\
\text { dynamics in the form } \\
\text { of argumentation } \\
\text { patterns and epistemic } \\
\text { operations rstudents } \\
\text { employ while solving a } \\
\text { problem in the science } \\
\text { classroom }[\ldots] \text { this } \\
\text { article focuses on } \\
\text { argument patterns from } \\
\text { high school students } \\
\text { solving genetics } \\
\text { problems }\end{array}$ & $\begin{array}{l}\text { This article focuses on the capacity of } \\
\text { students to develop and assess } \\
\text { arguments during a high school } \\
\text { genetics instructional sequence. The } \\
\text { research focused on the locating } \\
\text { distinction in argumentation discourse } \\
\text { between "doing science" vs. "doing } \\
\text { school" or "doing the lesson" } \\
\text { (Bloome, Puro, \& Theodorou, 1989). }\end{array}$ & $\begin{array}{l}\text { 1. The identification of } \\
\text { instances of "doing } \\
\text { science" vs. instances of } \\
\text { "doing school" or "doing } \\
\text { the lesson." } 2 \text {. In the } \\
\text { instances of "doing } \\
\text { science," which } \\
\text { argumentative operations } \\
\text { (claims, warrants, etc.) } \\
\text { were used by students and } \\
\text { which relations were } \\
\text { established among them; } 3 \text {. } \\
\text { The identification of use } \\
\text { by the students of } \\
\text { epistemic operations [...]; } \\
\text { that is, operations related } \\
\text { to knowledge construction, } \\
\text { specific from the science } \\
\text { domain }\end{array}$ \\
\hline
\end{tabular}




\begin{tabular}{|c|c|c|c|c|c|c|}
\hline 44 & 2000 & $\begin{array}{l}\text { Establishing the } \\
\text { Norms of Scientific } \\
\text { Argumentation in } \\
\text { classrooms }\end{array}$ & \begin{tabular}{lcrr|} 
NÃO & FOI & POSSÍVEL \\
LOCALIZAR & & A \\
PERGUNTA & & DE \\
PESQUISA & EM & UM \\
FORMATO CLARO. &
\end{tabular} & $\begin{array}{l}\text { This study attempts to } \\
\text { advance those* } \\
\text { implications by } \\
\text { presenting a rationale } \\
\text { for science pedagogy } \\
\text { that is coherent and } \\
\text { based on current } \\
\text { scholarship and } \\
\text { research in the field of } \\
\text { science studies and the } \\
\text { philosophy of science } \\
\text { *(para rados } \\
\text { completos a respeito } \\
\text { deste foco de pesquisa, } \\
\text { ver anexo VI) }\end{array}$ & $\begin{array}{l}{[\ldots] \text { this article develops the case for }} \\
\text { the inclusion and central role of } \\
\text { argument in science education }\end{array}$ & $\begin{array}{l}\text { In this study, therefore, we } \\
\text { develop our case for the } \\
\text { centrality of argument in } \\
\text { science on three strands of } \\
\text { literature: (1) current } \\
\text { perspectives on the nature of } \\
\text { the scientific enterprise itself; } \\
\text { (2) an analysis of the role and } \\
\text { function of argument within } \\
\text { science; and (3) emerging } \\
\text { priorities that require science } \\
\text { education to promote a better } \\
\text { understanding of science and } \\
\text { its nature and enhance the } \\
\text { public understanding of } \\
\text { science. }\end{array}$ \\
\hline 45 & 2000 & $\begin{array}{l}\text { Scientific arguments } \\
\text { as learning artifacts : } \\
\text { designing for learning } \\
\text { from the web with } \\
\text { KIE. The knowledge } \\
\text { integration } \\
\text { environment }\end{array}$ & $\begin{array}{lccr}\text { NÃO } & \text { FOI } & \text { POSSÍVEL } \\
\text { LOCALIZAR } & & \text { A } \\
\text { PERGUNTA } & & \text { DE } \\
\text { PESQUISA } & \text { EM } & \text { UM } \\
\text { FORMATO CLARO. } & \end{array}$ & $\begin{array}{l}\text { This research examines } \\
\text { the overall impact of } \\
\text { one KIE curriculum } \\
\text { project as well as } \\
\text { aspects of argument } \\
\text { building software } \\
\text { called SenseMaker and } \\
\text { a guidance component } \\
\text { called Mildred. }\end{array}$ & $\begin{array}{l}\text { We report on design studies that test } \\
\text { and elaborate on our instructional } \\
\text { framework. Our learning studies assess } \\
\text { the arguments students construct using } \\
\text { the Knowledge Integration Environment } \\
\text { debate project about light propagation } \\
\text { and, explore the relationship between } \\
\text { students' views of the nature of science } \\
\text { and argument construction }\end{array}$ & $\begin{array}{l}\text { In this research, we test the } \\
\text { power of principles from the } \\
\text { Scaffolded Knowledge } \\
\text { Integration framework by } \\
\text { design elements of the KIE } \\
\text { following these principles and } \\
\text { then examining students' } \\
\text { knowledge integration when } \\
\text { using the newly-designed } \\
\text { elements. [...] In this research, } \\
\text { we explore the relationship } \\
\text { among: (a) design elements in } \\
\text { the Knowledge Integration } \\
\text { Environment (KIE); (b) } \\
\text { characteristics of student } \\
\text { arguments; and (c) students' } \\
\text { views of the nature of science }\end{array}$ \\
\hline
\end{tabular}




\begin{tabular}{|c|c|c|c|c|c|c|}
\hline \multirow[t]{2}{*}{ IDE } & \multirow[t]{2}{*}{ APU } & \multirow[t]{2}{*}{ Título } & \multirow[t]{2}{*}{ Pergunta de pesquisa } & \multirow[t]{2}{*}{ Foco } & \multicolumn{2}{|c|}{ Objetivo(s) } \\
\hline & & & & & Parte pré-textual (Resumo) & Parte textual \\
\hline 46 & 1998 & $\begin{array}{l}\text { The place of } \\
\text { argumentation in the } \\
\text { pedagogy of school } \\
\text { science }\end{array}$ & $\begin{array}{l}\text { We therefore developed an } \\
\text { instrument that was oriented } \\
\text { to the following concerns. } \\
\text { (i) To focus upon the } \\
\text { activities being conducted } \\
\text { by pupils.(ii) To focus upon } \\
\text { how pupils are grouped for } \\
\text { carrying out their activities. } \\
\text { (iii) To capture the forms of } \\
\text { interaction between teacher } \\
\text { and pupils. }\end{array}$ & 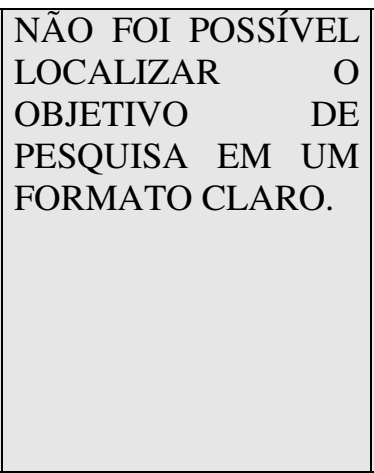 & $\begin{array}{l}\text { Our specific intention was to determine } \\
\text { whether secondary science teachers in } \\
\text { England give pupils opportunities to } \\
\text { develop and rehearse the skills of } \\
\text { argumentation during their lessons }\end{array}$ & 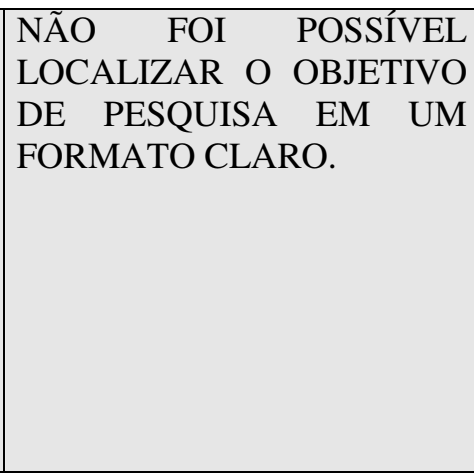 \\
\hline 47 & 1999 & $\begin{array}{l}\text { Students' } \\
\text { Argumentation in } \\
\text { Decision-Making on } \\
\text { a Socio-Scientific } \\
\text { Issue: Implications } \\
\text { for Teaching. }\end{array}$ & $\begin{array}{l}\text { 1. How does the students' } \\
\text { argumentation develop } \\
\text { while they justify their } \\
\text { opinions?; 2. What kind of } \\
\text { arguments do students use } \\
\text { in making decisions? } 3 \text {. } \\
\text { How do students handle } \\
\text { their decision-making and } \\
\text { what values do they bring to } \\
\text { it? }\end{array}$ & 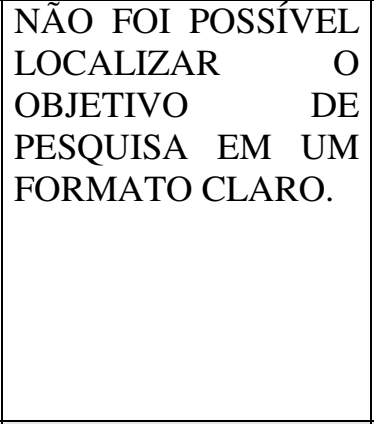 & $\begin{array}{l}\text { This study explores the arguments used } \\
\text { by 14-year-old students in making } \\
\text { decisions about the design of a road in } \\
\text { their area. [...] This paper first } \\
\text { elaborates the general perspective of } \\
\text { such an approach; it then describes the } \\
\text { process of argumentation and analyses } \\
\text { the nature of the students' arguments, } \\
\text { which are discussed on the basis of a } \\
\text { specifically constructed network. }\end{array}$ & $\begin{array}{l}\text { 1. Explore the ways in which } \\
\text { students arrive at a decision } \\
\text { when they work on a real-life } \\
\text { problem.; 2. We also examine } \\
\text { the quality of arguments used } \\
\text { by students as individuals, } \\
\text { while working in groups and } \\
\text { during whole class } \\
\text { interactions. }\end{array}$ \\
\hline 48 & 1999 & $\begin{array}{l}\text { Effects of } \\
\text { Emphasizing } \\
\text { Hypothetico- } \\
\text { Predictive Reasoning } \\
\text { within the Science } \\
\text { Learning Cycle on } \\
\text { High r School } \\
\text { Student's Process } \\
\text { Skills and Conceptual } \\
\text { Understandings in } \\
\text { Biologyl }\end{array}$ & $\begin{array}{lllr}\text { NÃO } & \text { FOI } & \text { POSSÍVEL } \\
\text { LOCALIZAR } & & \text { A } \\
\text { PERGUNTA } & & \text { DE } \\
\text { PESQUISA } & \text { EM } & \text { UM } \\
\text { FORMATO CLARO. } & \end{array}$ & $\begin{array}{l}\text { The purpose of this } \\
\text { research was to } \\
\text { examine the effects of } \\
\text { adding a } \\
\text { prediction/discussion } \\
\text { phase to the learning } \\
\text { cycle prior to the } \\
\text { exploration phase. }\end{array}$ & $\begin{array}{l}\text { This study examined the effects of } \\
\text { adding a prediction/discussion phase at } \\
\text { the beginning of a three-phase learning } \\
\text { cycle involving exploration, term } \\
\text { introduction, and concept application. }\end{array}$ & $\begin{array}{l}\text { The intent was to determine } \\
\text { the power of the added phase } \\
\text { and develop useful guidelines } \\
\text { for effective classroom } \\
\text { instruction with } \\
\text { prediction/discussion-based } \\
\text { learning cycles Specific } \\
\text { objectives sought to compare } \\
{[\ldots]^{*} \text { (para dados completos a }} \\
\text { respeito deste objetivo de } \\
\text { pesquisa, ver anexo VII). }\end{array}$ \\
\hline
\end{tabular}




\begin{tabular}{|c|c|c|c|c|c|c|}
\hline \multirow[t]{2}{*}{ IDE } & \multirow[t]{2}{*}{ APU } & \multirow[t]{2}{*}{ Título } & \multirow{2}{*}{$\begin{array}{l}\text { Pergunta de } \\
\text { pesquisa }\end{array}$} & \multirow[t]{2}{*}{ Foco } & \multicolumn{2}{|c|}{ Objetivo(s) } \\
\hline & & & & & Parte pré-textual (Resumo) & Parte textual \\
\hline 49 & 1998 & $\begin{array}{l}\text { Students' reasoning } \\
\text { about electricity: } \\
\text { combining } \\
\text { performance } \\
\text { assessments with } \\
\text { argumentation } \\
\text { analysis }\end{array}$ & $\begin{array}{l}\text { We focused on how, and } \\
\text { under what conditions, } \\
\text { students justified their } \\
\text { claims concerning } \\
\text { electric circuits while } \\
\text { attempting to solve a } \\
\text { performance assessment } \\
\text { task. }\end{array}$ & \begin{tabular}{|l|} 
In this paper we describe a set \\
of methodological procedures \\
for analyzing students' \\
arguments
\end{tabular} & $\begin{array}{|lll|}\text { In this paper a set } & \text { of } \\
\text { methodological procedures } & \text { to } \\
\text { analyse students' } & \text { arguments } & \text { is } \\
\text { presented } & & \end{array}$ & $\begin{array}{l}\text { We examined the problem- } \\
\text { solving process by focusing on } \\
\text { students' substantive arguments } \\
\text { as they reasoned through a } \\
\text { science task in which they were } \\
\text { required to apply their } \\
\text { knowledge of electricity to } \\
\text { solve a problem }\end{array}$ \\
\hline 50 & 1997 & $\begin{array}{l}\text { The Central Role of } \\
\text { Fallacious Thinking } \\
\text { in Science Education }\end{array}$ & $\begin{array}{l}\text { How the rocial } \\
\text { construction r of } \\
\text { knowledge, in real-life, } \\
\text { nonideal contexts } \\
\text { meshes with the } \\
\text { ideological goals of } \\
\text { AAAS (American } \\
\text { Association for the } \\
\text { Advancement } \\
\text { Science. Project 2061: } \\
\text { Science for all } \\
\text { Americans. Washington, } \\
\text { D, 1989). }\end{array}$ & $\begin{array}{l}\text { This paper will provide a } \\
\text { framework for examining the } \\
\text { role of argumentation and } \\
\text { thinking consistent with the } \\
\text { research on pedagogical and } \\
\text { theoretical } \\
\text { misconceptions.[.. the } \\
\text { present focus is on presenting } \\
\text { a framework to discuss and } \\
\text { illustrate how argumentation } \\
\text { is related to social thinking } \\
\text { (dialogic reasoning) and } \\
\text { conceptual change. }\end{array}$ & $\begin{array}{l}\text { This manuscript presents a model } \\
\text { of conceptual change from a social } \\
\text { constructivism perspective [...] In } \\
\text { this paper a set of methodological } \\
\text { procedures to analyse students' } \\
\text { arguments is presented. }\end{array}$ & $\begin{array}{llrr}\text { NÃO } & \text { FOI } & \text { POSSÍVEL } \\
\text { LOCALIZAR O } & \text { OBJETIVO } \\
\text { DE PESQUISA } & \text { EM } & \text { UM } \\
\text { FORMATO CLARO. }\end{array}$ \\
\hline 51 & 1992 & $\begin{array}{l}\text { Fallacies and Student } \\
\text { Discourse: } \\
\text { Conceptualizing the } \\
\text { Role of Critical } \\
\text { Thinking in Science } \\
\text { Education. }\end{array}$ & $\begin{array}{lr}\text { NÃO FOI POSSÍVEL } \\
\text { LOCALIZAR }\end{array}$ & $\begin{array}{l}\text { Clarify the role of critical } \\
\text { thinking in science education }\end{array}$ & $\begin{array}{llrl}\text { NÃO } & \text { FOI } & \text { POSSÍVEL } \\
\text { LOCALIZAR } & \text { O } & \text { OBJETIVO } \\
\text { PESQUISA. } & & \end{array}$ & $\begin{array}{l}\text { This article will seek to } \\
\text { examine that role [critical } \\
\text { thinking in science education] } \\
\text { by reviewing the following } \\
\text { pertinent areas: Defining and } \\
\text { Conceptualizing Critical } \\
\text { Thinking; Common Fallacies in } \\
\text { Student Argument; Implications } \\
\text { for Science Education }\end{array}$ \\
\hline
\end{tabular}




\section{Apêndice II}

Quadro 10 - Dados coletados a partir do descritor "uso de Toulmin (1958) como referencial teórico", em que IDE= número de identificação do artigo, APU=ano de publicação, TIT=título

\begin{tabular}{|c|c|c|c|}
\hline IDE & APU & Título & Trecho sobre o uso de Toulmin (1958) como referencial teórico \\
\hline 1 & 2008 & $\begin{array}{l}\text { Disconnections Between Teacher Expectations and } \\
\text { Student Confidence in Bioethics }\end{array}$ & $\begin{array}{l}\text { In his landmark book, Toulmin (1958) provided guidelines for evaluating proper } \\
\text { argumentation. [...] The Toulmin model, however, would find claims rather than justifications } \\
\text { or warrants in many of these student arguments. [...] Extending Toulmin's classification of } \\
\text { argumentation skills, Erduran et al. (2004) used the Toulmin Application Pattern (TAP) to } \\
\text { evaluate the quality and quantity of students' argumentation in the science classroom and to } \\
\text { analyze the argumentation of an entire lesson rather than isolated classroom discourse. [...] } \\
\text { Using this adaptation of the Toulmin method, Erduran et al. Could identify how arguments } \\
\text { were distributed throughout the discourse. }\end{array}$ \\
\hline 2 & 2008 & $\begin{array}{l}\text { Arguing to Learn and Learning to Argue: Case Studies } \\
\text { of How Students' Argumentation Relates to Their } \\
\text { Scientific Knowledge }\end{array}$ & $\begin{array}{l}\text { Using video and audio documents of small group and classroom discussions, the quality and } \\
\text { frequency of students' argumentation was analyzed using a schema based on the work of } \\
\text { Toulmin (1958) }\end{array}$ \\
\hline 3 & 2008 & $\begin{array}{l}\text { Conceptualizations of Argumentation from Science } \\
\text { Studies and the Learning Sciences and their } \\
\text { Implications for the Practices of Science Education }\end{array}$ & $\begin{array}{l}\text { Many scholars (e.g., Perelman \& Olbrechts-Tyteca, 1969; Toulmin, 1958/2003; van Eemeren } \\
\text { and Grootendorst, 2004; van Eemeren, Grootendorst, \& Snoeck Henkemans, 2002) argue } \\
\text { against solely applying this syllogistic notion of logic to the study of argumentation because } \\
\text { they believe it does not capture elements of everyday argumentation, which we claim includes } \\
\text { scientific argumentation because of the social nature of scientific practice. [...] Argumentation } \\
\text { is field dependent (Toulmin, 1958/2003; Toulmin et al., 1984; van Eemeren\&Grootendorst, } \\
\text { 2004) [...] Like Pera, Toulmin calls for conceptualizations of argumentation that are } \\
\text { somewhat situated. The context in which argumentation is embedded is important to consider } \\
\text { because it will determine whether arguments put forth are judged as reasonable. }\end{array}$ \\
\hline 4 & 2008 & $\begin{array}{l}\text { Professional Learning Portfolios for Argumentation in } \\
\text { School Science }\end{array}$ & $\begin{array}{l}\text { Toulmin framework was therefore a feature of the way in which we helped teachers to } \\
\text { conceptualise and evaluate argumentation. }\end{array}$ \\
\hline 5 & 2008 & $\begin{array}{l}\text { Argumentation: A Strategy for Improving } \\
\text { Achievement and Revealing Scientific Identities }\end{array}$ & $\begin{array}{l}\text { The researchers agreed that the elements of argumentation as described in Driver et al. (2000), } \\
\text { based on Toulmin (1958), would be used to initially code the transcript [...] The } \\
\text { argumentation review routine for the second unit was transcribed and coded based on Toulmin } \\
\text { (1958) and the four additional categories of argumentation. }\end{array}$ \\
\hline
\end{tabular}




\begin{tabular}{|c|c|c|c|}
\hline 6 & 2008 & $\begin{array}{l}\text { When Scientific Knowledge, Daily Life Experience, } \\
\text { Epistemological and Social Considerations Intersect: } \\
\text { Students' Argumentation in Group Discussions on a } \\
\text { Socio-Scientific Issue }\end{array}$ & $\begin{array}{l}\text { This perspective [deste artigo] is then focused on the content of arguments without separating } \\
\text { knowledge and social aspects. It differed from studies using Toulmin's(1958) argument } \\
\text { pattern which laid more emphasis on argumentation "to determine whether that process can be } \\
\text { facilitated and its quality assessed" (Osborne et al. 2004, p. 1015), to identify the structure of } \\
\text { arguments (Kelly et al. 1998) or to analyse argumentation discourse within different learning } \\
\text { environments (Jimenez-Aleixandre et al. 2000). In the study of Jimenez-Aleixandre et al. } \\
\text { (2000), the authors indicated that Toulmin's argument pattern was not sufficient to interpret } \\
\text { some students interactions in the group discussions. It appears to be limited to explore the } \\
\text { social dimension of argumentation. }\end{array}$ \\
\hline 7 & 2008 & $\begin{array}{l}\text { Assessment of the Ways Students Generate } \\
\text { Arguments in Science Education: Current Perspectives } \\
\text { and Recommendations for Future Directions }\end{array}$ & $\begin{array}{l}\text { Declaração de afiliação do trabalho a uma perspectiva de análise que considere aspectos } \\
\text { sociais e do conhecimento, diferentes das possibilidades de avaliação limitadas do modelo de } \\
\text { Toulmin sobre esses aspectos. }\end{array}$ \\
\hline 8 & 2008 & $\begin{array}{l}\text { Urban Primary-Grade Children Think and Talk } \\
\text { Science: Curricular and Instructional Practices that } \\
\text { Nurture Participation and Argumentation }\end{array}$ & $\begin{array}{l}\text { A OBRA DE TOULMIN NÃO FOI CITADA NO REFERENCIAL TEÓRICO OU } \\
\text { METODOLÓGICO }\end{array}$ \\
\hline 9 & 2008 & $\begin{array}{l}\text { Lakatos' Scientific Research Programmes as a } \\
\text { Framework for Analysing Informal Argumentation } \\
\text { about Socio-scientific Issues }\end{array}$ & $\begin{array}{l}\text { Regarding the model of argumentation, presently Toulmin's model is applied by many science } \\
\text { educators primarily to analyse arguments that occur in group or classroom discourse (Erduran } \\
\text { et al., 2004; Jimenez-Aleixandre, 2002; Kelly \& Chen, 1999; Kelly, Druker, \& Chen, 1998; } \\
\text { Osborne, Erduran, \& Simon, 2004; Russell, 1983; Simonneaux, 2001; Tirri \& Pehkonen, } \\
\text { 2002); however, we have adopted an alternative framework to overcome the particular } \\
\text { problems encountered with Toulmin's model in this study. }\end{array}$ \\
\hline 11 & 2007 & Argumentation and Primary Science & $\begin{array}{l}\text { Analysis of transcripts of the lessons using concept cartoons was carried out using the } \\
\text { framework provided by Toulmin (1958) since this appears to be commonly accepted by other } \\
\text { researchers in this field as the definitive analytical framework. }\end{array}$ \\
\hline
\end{tabular}




\begin{tabular}{|c|c|c|c|}
\hline \begin{tabular}{|l|}
12 \\
\end{tabular} & 2007 & $\begin{array}{l}\text { Personally-Seeded Discussions to Scaffold Online } \\
\text { Argumentation }\end{array}$ & $\begin{array}{l}\text { We explore the efficacy of this personally-seeded discussion approach using a coding scheme } \\
\text { developed by Erduran, Osborne, and Simon (2004; Simon, Osborne, \& Erduran, 2003) that } \\
\text { analyzes argument structure from a Toulmin perspective. }\end{array}$ \\
\hline \begin{tabular}{|l|}
13 \\
\end{tabular} & 2007 & \begin{tabular}{|l} 
Mad City Mystery: Developing Scientific \\
Argumentation Skills with a Place-Based Augmented \\
Reality Game on Handheld Computers
\end{tabular} & $\begin{array}{l}\text { A OBRA DE TOULMIN NÃO FOI CITADA NO REFERENCIAL TEÓRICO OU } \\
\text { METODOLÓGICO }\end{array}$ \\
\hline 14 & 2007 & $\begin{array}{l}\text { Teachers' Stances and Practical Arguments regarding } \\
\text { a Science-Indigenous Knowledge Curriculum: Part } 1\end{array}$ & $\begin{array}{l}\text { Although the TAP has provided a useful insight into the nature of arguments, the uncritical } \\
\text { way in which the model has been applied in various fields has contributed to the barrages of } \\
\text { criticisms levelled against it. For instance, while Toulmin sees his argumentation model as } \\
\text { only provisional and to be "field" or "context" dependent, many researchers and authors of } \\
\text { books see the model as field invariant or universally applicable to all forms of argument. }\end{array}$ \\
\hline \begin{tabular}{|l|}
16 \\
\end{tabular} & 2007 & $\begin{array}{l}\text { Promovendo a argumentação no ensino superior de } \\
\text { química }\end{array}$ & $\begin{array}{l}\text { Para tanto [alcançar o objetivo do trabalho], tomamos como referenciais teóricos o modelo de } \\
\text { Toulmin, apresentado no livro "The Uses of Argument" e o trabalho de JiménezAleixandre et } \\
\text { al., que apresenta um maior detalhamento dos componentes do argumento propostos por } \\
\text { Toulmin. }\end{array}$ \\
\hline 17 & 2007 & $\begin{array}{l}\text { Promoting Discourse about Socioscientific Issues } \\
\text { through Scaffolded Inquiry }\end{array}$ & $\begin{array}{l}\text { In addition to analyzing the content of students' reasoning on the GMF debate, the quality of } \\
\text { their arguments were assessed utilizing Toulmin's (1958) model of argument. }\end{array}$ \\
\hline 19 & 2006 & $\begin{array}{l}\text { Socioscientific Argumentation: The Effects of Content } \\
\text { Knowledge and Morality }\end{array}$ & $\begin{array}{l}\text { Consistent with Toulmin (1958) and more recent efforts to assess argumentation (Erduran, } \\
\text { Simon, \& Osborne, 2004), we were interested in the extent to which participants could support } \\
\text { their positions with grounds (i.e., data, warrants, or backings) }\end{array}$ \\
\hline 20 & 2006 & $\begin{array}{l}\text { Learning to Teach Argumentation: Research and } \\
\text { Development in the Science Classroom }\end{array}$ & $\begin{array}{l}\text { To assess the quality of argumentation, analytical tools derived from Toulmin's argument } \\
\text { pattern were developed and applied to classroom transcripts. [...] The analysis of } \\
\text { argumentation discourse in science lessons was approached from two different perspectives. } \\
\text { First, the analysis focused on ways in which the quality of argument could be determined. We } \\
\text { needed to find an analytical framework to identify and evaluate argumentation, in order to see } \\
\text { whether improvements in pedagogy occurred over time. [...]A suitable analytic framework is } \\
\text { Toulmin's (1958) model (Figure 1), referred to here as Toulmin's argument pattern (TAP) }\end{array}$ \\
\hline
\end{tabular}




\begin{tabular}{|c|c|c|c|}
\hline 21 & 2006 & $\begin{array}{l}\text { Patterns in Students' Argumentation Confronted with a } \\
\text { Risk-Focused Socio-Scientific Issue }\end{array}$ & $\begin{array}{l}\text { In order to identify the students' arguments or reasons, a simplified version of Toulmin's } \\
\text { (1958) layout of argument was employed. Toulmin uses six elements within an argument: } \\
\text { claim, data, warrant, backing, qualifiers, and rebuttals. In this study the focus is on the claim } \\
\text { (what ought to be done), the data, and the warrants proposed by the students. According to } \\
\text { Toulmin (1958), these are the three elements that constitute an argument as such. }\end{array}$ \\
\hline 22 & 2006 & $\begin{array}{l}\text { Mapping Children's Discussions of Evidence in } \\
\text { Science to Assess Collaboration and Argumentation }\end{array}$ & $\begin{array}{l}\text { During the discussions, the children made claims and put forward ideas about their choices. } \\
\text { When the claim was supported by a reference to evidence it was identified as an "argument". } \\
\text { These arguments were analysed using TAP (Toulmin, 1958) in its simplest form (Figure 1), } \\
\text { which included a claim supported by an appeal to data and a warrant that explained the link } \\
\text { between the claim and the data. }\end{array}$ \\
\hline 23 & 2006 & $\begin{array}{l}\text { A Threshold Model of Content Knowledge Transfer } \\
\text { for Socio-scientific Argumentation }\end{array}$ & $\begin{array}{l}\text { Despite its frequent use, TAP presents a number of methodological limitations.[...] Statements } \\
\text { that would have been classified as data, warrants, or backings in Toulmin's scheme were } \\
\text { considered grounds. }\end{array}$ \\
\hline 24 & 2006 & $\begin{array}{l}\text { The Features of Peer Argumentation in Middle School } \\
\text { Students' Scientific Inquiry }\end{array}$ & $\begin{array}{l}\text { A OBRA DE TOULMIN NÃO FOI CITADA NO REFERENCIAL TEÓRICO OU } \\
\text { METODOLÓGICO }\end{array}$ \\
\hline 25 & 2006 & $\begin{array}{l}\text { Science students' critical examination of scientific } \\
\text { information related to socioscientific issues }\end{array}$ & $\begin{array}{l}\text { A OBRA DE TOULMIN NÃO FOI CITADA NO REFERENCIAL TEÓRICO OU } \\
\text { METODOLÓGICO }\end{array}$ \\
\hline 26 & 2004 & $\begin{array}{l}\text { Enhancing the Quality of Argumentation in School } \\
\text { Science }\end{array}$ & $\begin{array}{l}\text { During this phase, analytical tools for evaluating the quality of argumentation were developed } \\
\text { based on Toulmin's argument pattern. [...] An alternative framework for the analysis of } \\
\text { argument is that developed by Walton (1996), which characterizes argument in terms of a } \\
\text { schema of } 25 \text { common forms of reasoning. Our view, however, is that Walton's framework } \\
\text { gives more emphasis to the content of an argument, which was not the essential focus of our } \\
\text { work. Toulmin's model, in contrast, places more emphasis on the generic features of } \\
\text { argument, fitting better with our interest in argumentation in general. In addition, Toulmin's } \\
\text { model has been used as a basis for characterizing argumentation in science lessons, and is } \\
\text { implicit in a coding system of others (Kuhn et al., 1997; Pontecorvo, 1987; Schwarz \& } \\
\text { Lederman, 2002; Zohar \& Nemet, 2002). Following these authors, we therefore used the } \\
\text { Toulmin framework to focus on the epistemic and argumentative operations adopted by } \\
\text { students-that is, their reasoning functions, and strategies. }\end{array}$ \\
\hline 27 & 2004 & $\begin{array}{l}\text { TAPping into Argumentation: Developments in the } \\
\text { Application of Toulmin's Argument Pattern for } \\
\text { Studying Science Discourse }\end{array}$ & $\begin{array}{l}\text { Our aim in this paper is to extend the applicability of tap in data analysis of science discourse } \\
\text { in the classroom so the choice of tap is central to our thesis. }\end{array}$ \\
\hline
\end{tabular}




\section{IDE APU}

\begin{tabular}{|c|c|c|c|}
\hline 28 & 2004 & Students' Discussions in Practical Scientific Inquiries. & $\begin{array}{l}\text { First, it used Toulmin's (1958) procedures for analysing the quality of arguments being made } \\
\text { by students. Second, it took a socio-cultural perspective. }\end{array}$ \\
\hline 29 & 2004 & $\begin{array}{l}\text { Informal reasoning regarding socioscientific issues: A } \\
\text { critical review of research }\end{array}$ & $\begin{array}{l}\text { The investigators were interested in two aspects of the student discussions: "argumentative } \\
\text { operations" and "epistemic operations." Argumentative operations represented the structure } \\
\text { of student argument as defined by Toulmin's (1958) argument pattern. To assess this } \\
\text { component, the researchers dissected student dialogue and categorized statements in terms of } \\
\text { data, claims, warrants, backing, qualifiers, and rebuttals. }\end{array}$ \\
\hline 30 & 2003 & $\begin{array}{l}\text { The Nature and Development of Hypothetico- } \\
\text { Predictive Argumentation with Implications for } \\
\text { Science Teaching }\end{array}$ & $\begin{array}{l}\text { How do scientists construct and use arguments? [...] Toulmin (1958) describes scientific } \\
\text { argumentation primarily as a process of using evidence and warrants and backings to convince } \\
\text { others of the veracity of specific claims. }\end{array}$ \\
\hline 31 & 2002 & $\begin{array}{l}\text { Fostering Students' Knowledge and Argumentation } \\
\text { Skills through Dilemmas in Human Genetics. }\end{array}$ & $\begin{array}{l}\text { The frequent use of the concepts argument and argumentation in this article calls for } \\
\text { definitions. What is an argument? Of the numerous definitions for argument found in the } \\
\text { literature, three are introduced here. Toulmin (1958) defined an argument as an assertion and } \\
\text { its accompanying justification. }\end{array}$ \\
\hline 32 & 2002 & $\begin{array}{l}\text { Knowledge Producers or Knowledge Consumers? } \\
\text { Argumentation and Decision Making about } \\
\text { Environmental Management }\end{array}$ & $\begin{array}{l}\text { Students' conversations were transcribed and analysed using several tools. For the purposes of } \\
\text { this analysis, two are particularly relevant. Toulmin's (1958) argument layout was employed } \\
\text { because it can constitute a powerful tool to analyse classroom discourse. The analysis does not } \\
\text { focus on every sentence, but only on the substantive arguments that require some content } \\
\text { knowledge. }\end{array}$ \\
\hline 33 & 2002 & $\begin{array}{l}\text { Analysis of Classroom Debating Strategies in the } \\
\text { Field of Biotechnology. }\end{array}$ & $\begin{array}{l}\text { A OBRA DE TOULMIN NÃO FOI CITADA NO REFERENCIAL TEÓRICO OU } \\
\text { METODOLÓGICO }\end{array}$ \\
\hline 34 & 2002 & $\begin{array}{l}\text { Teaching biotechnology through case studies: Can we } \\
\text { improve higher order thinking skills of nonscience } \\
\text { majors? }\end{array}$ & $\begin{array}{l}\text { A OBRA DE TOULMIN NÃO FOI CITADA NO REFERENCIAL TEÓRICO OU } \\
\text { METODOLÓGICO }\end{array}$ \\
\hline 35 & 2002 & $\begin{array}{l}\text { Arguments, contradictions, resistances, and conceptual } \\
\text { change in students' understanding of atomic structure }\end{array}$ & $\begin{array}{l}\text { It is important to note that both groups of researchers [pesquisadores em educação e } \\
\text { pesquisadores em ensino de Ciências] have based their research, among other sources, on the } \\
\text { seminal ideas of Toulmin (1958). An important aspect of Toulmin's framework is that } \\
\text { arguments are plausible inferences and not the deductive syllogisms, which "logical } \\
\text { positivism" used to establish the objectivity of scientific explanations. }\end{array}$ \\
\hline 36 & 2003 & $\begin{array}{l}\text { Scaffolding preservice science teachers' evidence- } \\
\text { based arguments during an investigation of natural } \\
\text { selection }\end{array}$ & $\begin{array}{l}\text { A OBRA DE TOULMIN NÃO FOI CITADA NO REFERENCIAL TEÓRICO OU } \\
\text { METODOLÓGICO }\end{array}$ \\
\hline
\end{tabular}




\begin{tabular}{|c|c|c|c|}
\hline 37 & 2001 & $\begin{array}{l}\text { Role-Play or Debate to Promote Students' } \\
\text { Argumentation and Justification on an Issue in Animal } \\
\text { Transgenesis. }\end{array}$ & Their research draws on the method developed by Toulmin (1958) to analyse arguments. \\
\hline 38 & 2001 & $\begin{array}{l}\text { Sound and faulty arguments generated by preservice } \\
\text { biology teachers when testing hypotheses involving } \\
\text { unobservable entities }\end{array}$ & $\begin{array}{l}\text { A OBRA DE TOULMIN NÃO FOI CITADA NO REFERENCIAL TEÓRICO OU } \\
\text { METODOLÓGICO }\end{array}$ \\
\hline 39 & 2001 & $\begin{array}{l}\text { Epistemic levels in argument: an analysis of university } \\
\text { oceanography students' use of evidence in writing }\end{array}$ & $\begin{array}{l}{[\ldots] \text { written discourse offers different challenges and possibilities for analysis }[\ldots] \text { one }} \\
\text { problem identified with Toulmin's layout of arguments is the ambiguity of the categorical } \\
\text { system. [...] furthermore, Toulmin's argumentation approach does not consider the relative } \\
\text { epistemic status (i.e., degree of abstractness of knowledge claims) of the speaker's assertions, } \\
\text { nor the position of embedded claims in larger arguments. These issues are explored in this } \\
\text { study through the examination of students' writing in the context of a university oceanography } \\
\text { course. }\end{array}$ \\
\hline 42 & 2000 & $\begin{array}{l}\text { Lower Track Science Students' Argumentation and } \\
\text { Open Inquiry Instruction. }\end{array}$ & $\begin{array}{l}\ldots] \text { this study's analysis draws upon Toulmin's (1958) description of argumentation as a } \\
\text { useful framework for qualifying working hypotheses. For the purpose of this study Toulmin's } \\
\text { argument framework was interpreted as a possible set of discourse patterns through which to } \\
\text { view students' responses, paying particular attention to my students' use of warrants. Testing } \\
\text { the working hypotheses about the interviews involved @rst examining the shifts that occurred } \\
\text { in all students' usage of hypotheses and predictions and then comparing and contrasting them } \\
\text { to Toulmin's description of warrants argumentation. }\end{array}$ \\
\hline
\end{tabular}




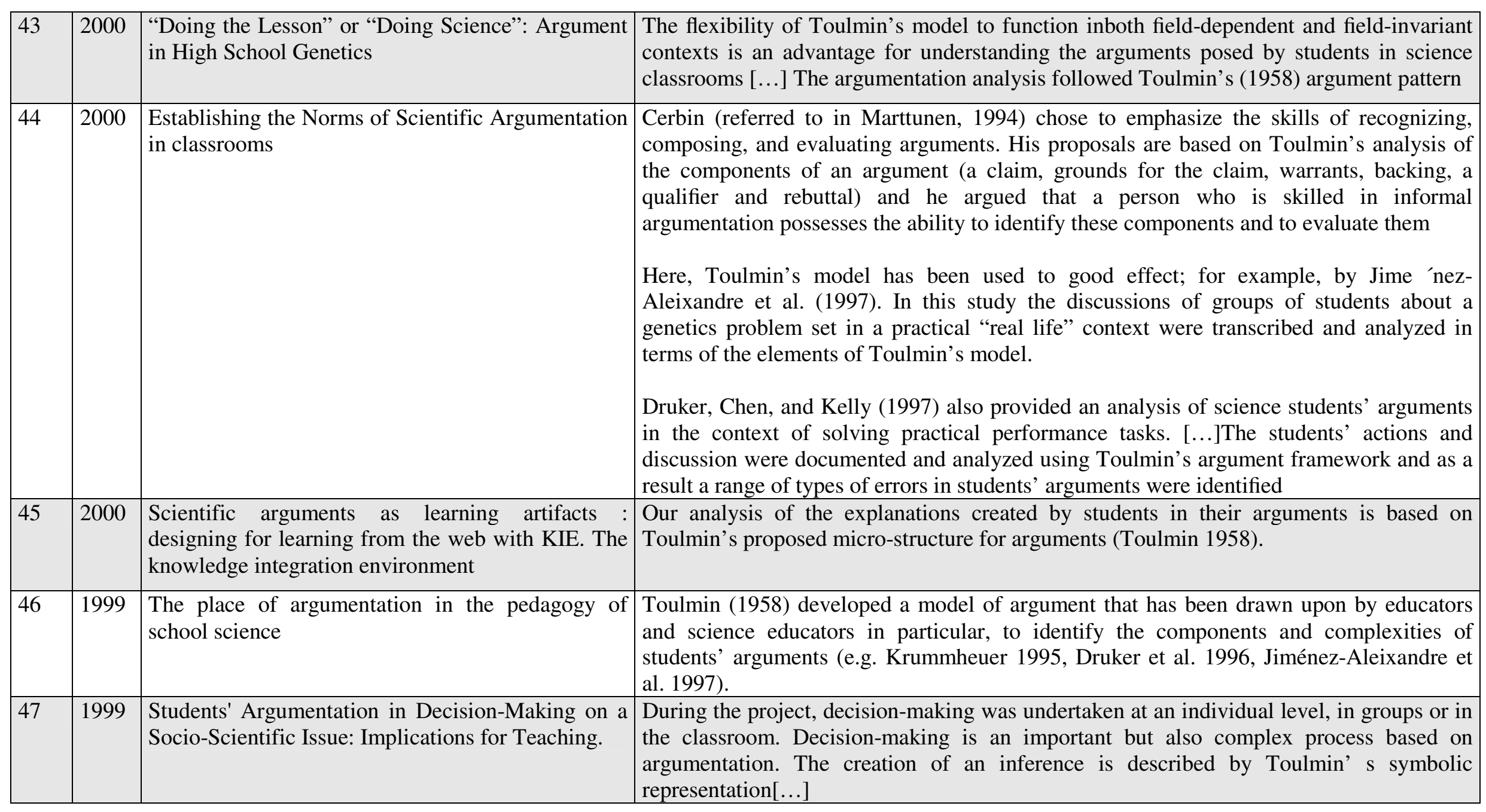




\begin{tabular}{|l|l|l|l|}
\hline 48 & 1999 & $\begin{array}{l}\text { Effects of Emphasizing Hypothetico-Predictive } \\
\text { Reasoning within the Science Learning Cycle on } \\
\text { High School Student's Process Skills and } \\
\text { Conceptual Understandings in Biologyl }\end{array}$ & $\begin{array}{l}\text { A OBRA DE TOULMIN NÃO FOI CITADA NO REFERENCIAL TEÓRICO OU } \\
\text { METODOLÓGICO }\end{array}$ \\
\hline 49 & 1998 & $\begin{array}{l}\text { Students' reasoning about electricity: combining } \\
\text { performance assessments with argumentation } \\
\text { analysis }\end{array}$ & $\begin{array}{l}\text { We began with Toulmin's original set of argument categories (shown in figure 1) and } \\
\text { additions from Resnick et al. (1993) (e.g. challenge), and went through the transcripts of } \\
\text { student discourse. [...]The components of argument as conceived for philosophical } \\
\text { purposes should not be expected, and indeed were not found to be, consistent with actual } \\
\text { talk. Nevertheless, the Toulmin method provided a basis from which we could ground our } \\
\text { discourse analysis }\end{array}$ \\
\hline 50 & 1997 & $\begin{array}{l}\text { The Central Role of Fallacious Thinking in Science } \\
\text { Education }\end{array}$ & $\begin{array}{l}\text { [.] if teachers come to view the development of concepts as a construction of shared } \\
\text { social knowledge, then the study of argument becomes central to science teacher } \\
\text { education and a central objective of science literacy (Toulmin, 1958; Kuhn, 1992; Zeidler } \\
\text { et al., 1992). }\end{array}$ \\
\hline 51 & 1992 & $\begin{array}{l}\text { Fallacies and Student Discourse: Conceptualizing } \\
\text { the Role of Critical Thinking in Science Education. }\end{array}$ & $\begin{array}{l}\text { The most comprehensive use of critical thinking operations is perhaps best exemplified in } \\
\text { the area of argumentation (Toulmin, Rieke, and Janik, 1984; Toulmin, 1958). When } \\
\text { students are engaged in making assertions, supporting and defending those claims through } \\
\text { a well-developed line of reasoning and judging the efficiency of counter arguments during } \\
\text { discussion of socio-scientific issues, they will be making use of the operations identified } \\
\text { above. Failure to adequately utilize those operations during discourse results in fallacious } \\
\text { reasoning and flawed construction of personal epistemologies related to the issues at hand. }\end{array}$ \\
\hline
\end{tabular}




\section{ANEXOS

\begin{abstract}
textual do artigo
\end{abstract} \\ Anexo I - Dados completos sobre a pergunta de pesquisa do artigo 8, retirado da parte}

Thus, we are particularly interested instudying whether and how young children theorize in science in such a curricular context (The present study draws on a larger program of research we call "Integrated Science- Literacy Enactments" (ISLE). It is a collaborative university-school action research project (Pappas, in press), in which university-based researchers (two faculty members, a science educator and a literacy educator, and several research assistants) work together with six urban-school-based teacher researchers to develop, implement, and study two integrated cience-literacy units (Matter and Forest) to explore and understand young, primarygrade children's learning of both scientific content and discourse genres in classrooms where hese units are enacted.).

\section{Anexo II - Dados completos sobre o objetivo do artigo 12, retirado da parte textual do artigo}

We explore the efficacy of this personally-seeded discussion (This study analyzes a customized online discourse system designed to integrate and support scientific argumentation within the classroom. The context is an online thermal equilibrium inquiry laboratory designed for eighthgrade students. The students use a special interface to build principles to describe the data they collect in the laboratory portion of the project. These principles become the seed comments for the online discussion. The software sorts the students into discussion groups with students who have built different principles so that each discussion group represents multiple perspectives. Students then follow a set of guidelines to critique one another's principles. By having students explain and defend their own principles, students take interest in responding to and critiquing the other ideas in the discussion. This structure allows students to engage in the discourse of scientific argumentation and inquiry in a way that parallels scientific communities) approach using a coding scheme developed by Erduran, Osborne, and Simon (2004; Simon, Osborne, \& Erduran, 2003) that analyzes argument structure from a Toulmin perspective.

\section{Anexo III - Dados completos sobre a pergunta de pesquisa do artigo 13, retirado da parte textual do artigo}

Can we create pedagogies that capitalize on these new literacies (Traditional schools and classrooms may be the only place where such information resources are not fully accessible, in part because schools are based on the historic literacies of print and have not adapted to the literacies of multi-modality and interactive technology (Kress, 2003; Lankshear and Knobel, 2001; New London Group, 2000). As Leander and Lovvorn (in press) argue, even "high tech" schools operate accordingly to an underlying cultural logic of "print-based" literacies and pedagogies in which teachers determine learning goals, sanction resources, and dictate what steps students ought to take to complete assignments (cf. Lemke, 1990). Leander and Lovvorn contrast this constellation of school-based literacy practices with kids' practices on the Internet outside of school, where kids interact with multimodal texts, produce as well as consume texts and resources, and, perhaps most critically, embrace epistemologies radically different from those 
underlying schooling (what is "true" is what works in experience or is the consensus of a community, as opposed to appeals to authority-what the teacher dictates as correct). Ironically perhaps, the modes of learning occurring in popular culture, particularly in video games, align with the culture of the new capitalism more closely than school-based literacies do, creating an implicit critique of schooling (Gee, 2003;2004).) and prepare students for life in the 21 st century?

\section{Anexo IV - Dados completos sobre pergunta de pesquisa do artigo 31, retirado da parte textual do artigo}

1. How do students initially, that is, before instruction, apply specific biologic knowledge to argument construction, and what is their initial ability to formulate arguments? 2. How does instruction of the Genetic Revolution unit affect the extent to which students applied specific biological knowledge in constructing arguments? 3. How does instruction of the Genetic Revolution unit affect students' biological knowledge as compared with traditional instruction that covers the same biological content? 4. To what extent does instruction of the Genetic Revolution unit affect students' argumentation skills? 5. Can students who have acquired argumentation skills in the context of the Genetic Revolution unit transfer these skills to a new context (moral dilemmas taken from everyday life)?

\section{Anexo V - Dados completos sobre a pergunta de pesquisa do artigo 36, retirado da parte textual do artigo}

The questions that guided our research were: (1) What is the nature of the scientific arguments developed by preservice teachers? That is, how do preservice teachers structure their arguments? In particular, what evidence do they use and how do they use it? In addition, to what extent are their arguments consistent with scientifically accepted constructs in the domain? (2) How do preservice teachers go about constructing scientific arguments (emphasis on processes and strategies)? (3) In what ways do the scaffolds embedded in the Galapagos Finches software influence the development of preservice teachers' arguments?

\section{Anexo VI - Dados completos sobre o foco de pesquisa do artigo 44, retirado da parte textual do artigo}

This study attempts to advance those (Fuller (1997), for instance, has argued that "most of what non-scientists need to know in order to make informed public judgements about science fall under the rubric of history, philosophy, and sociology of science, rather than the technical content of scientific subjects.") implications by presenting a rationale for science pedagogy that is coherent and based on current scholarship and research in the field of science studies and the philosophy of science).

\section{Artigo VII - Dados completos sobre o objetivo de pesquisa do artigo 48, retirado da parte textual do artigo}

The intent was to determine the power of the added phase and develop useful guidelines for effective classroom instruction with prediction/discussion-based learning cycles. Specific objectives sought to compare and contrast prediction/discussion-based learning cycle (HPD-LC) 
instruction with traditional learning cycle (LC) instruction in high school biology classrooms relative to (a) teachers' attitudes toward learning-cycle instruction, their students, and themselves; (b) students' attitudes and motivations toward science, learning-cycle instruction, their teacher, and their peers; and (c) students' ability to use process skills, apply logical thinking abilities, and demonstrate conceptual understanding in biology. 